Technical Report July 1995

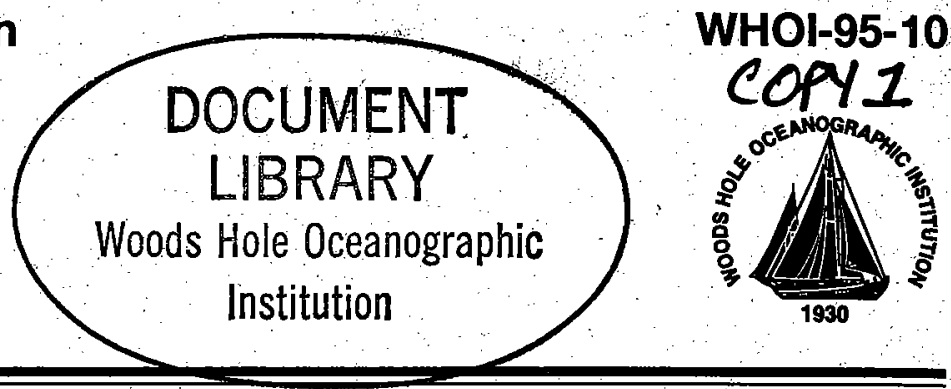

Toward an Effective Protocol on Land-Based Marine Pollution in the Wider Caribbean Region

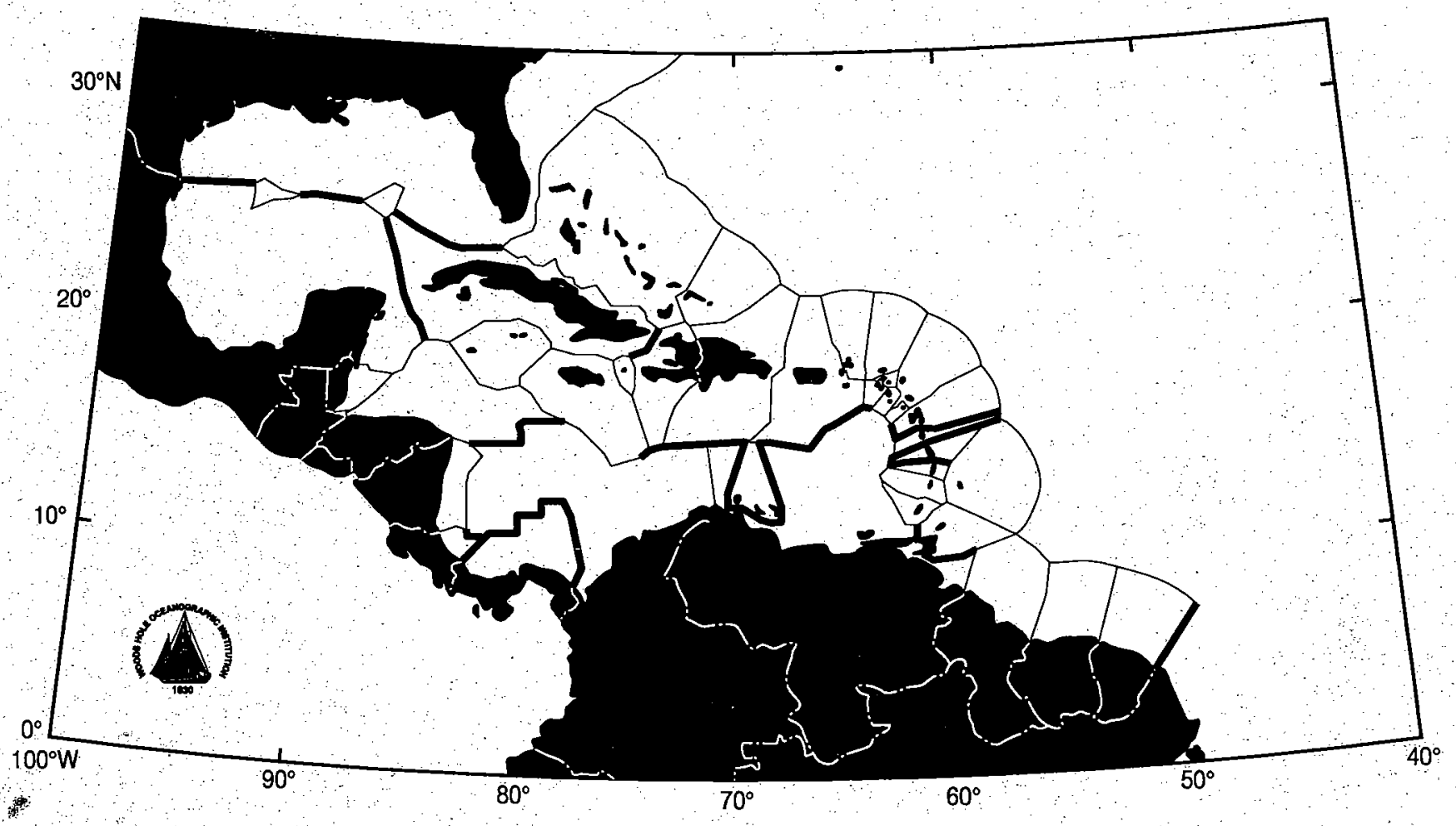

by

Porter Hoagland Mary E. Schumacher Arthur G. Gaines, Jr.

Marine Policy Center

Woods Hole Oceanographic Institution Woods Hole, Massachusetts 02543-1138

Phone 508-548-1400 - Telex 951679 


\section{Toward an Effective Protocol on Land-Based Marine Pollution in the Wider Caribbean Region}

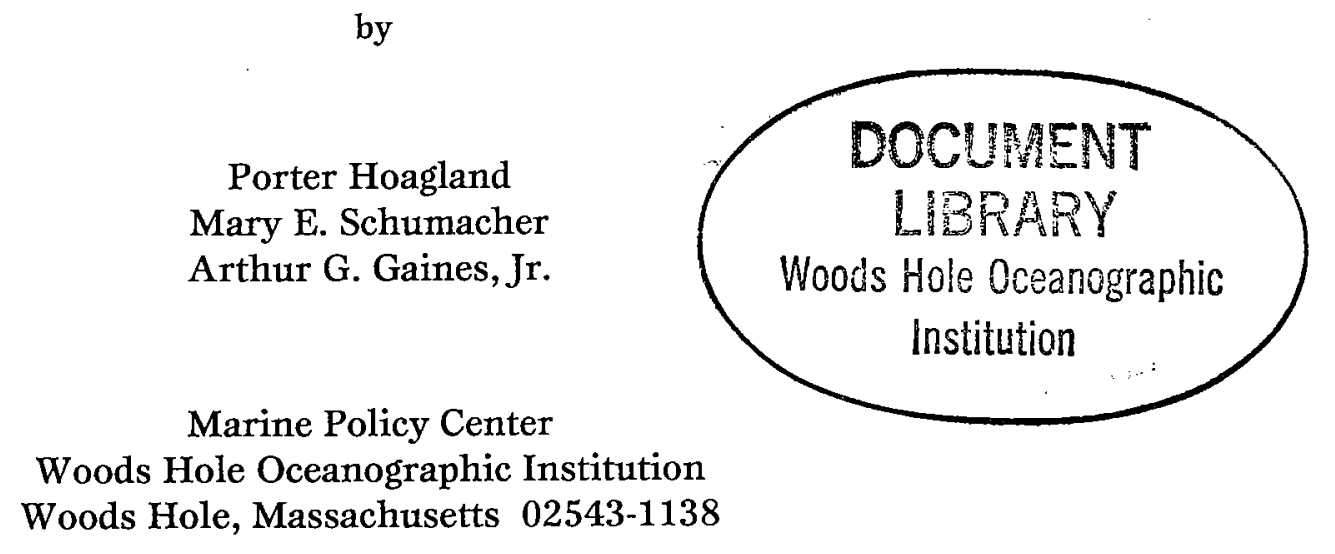

July 1995

Technical Report

Funding provided by the United States Environmental Protection Agency, Office of International Activities under Co-operative Agreement No. CX821540-01-0.

Reproduction in whole or in part is permitted for any purpose of the

United States Government. This report should be cited as:

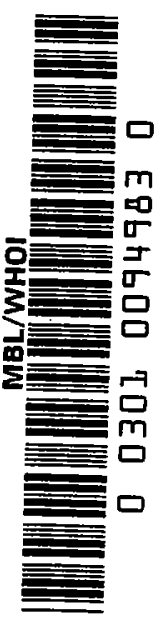

Woods Hole Oceanog. Inst. Tech. Rept., WHOI-95-10.

Approved for publication; distribution unlimited.

Approved for Distribution:

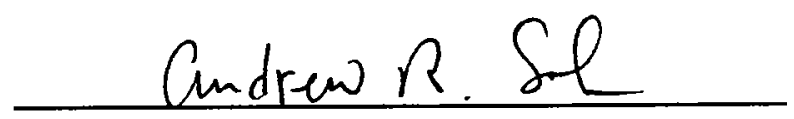

Andrew R. Solow, Director

Marine Policy Center

On the cover: Actual and Hypothetical Maritime Jurisdictions in the Wider Caribbean Region. Adapted from Fenwick (1992).

1995 by the Woods Hole Oceanographic Institution.

Hypothetical boundaries (thin lines) are those identified by the U.S. Department of State in its World Data Bank 2. In most cases, the hypothetical boundaries are approximate equidistant boundaries, and they do not reflect any acceptance by the U.S. government. Some claims may be based upon unilateral assertions; these claims may be subject to change by national legislation or decree or through international boundary negotiations. Boundaries as represented are approximations for general reference only. 



\title{
Toward an Effective Protocol on Land-Based Marine Pollution in the Wider Caribbean Region
}

July 1995

\author{
by \\ Porter Hoagland \\ Mary E. Schumacher \\ Arthur G. Gaines
}

Marine Policy Center

Woods Hole Oceanographic Institution

Woods Hole, Massachusetts 02543 
share a common boundary, such as rivers and their deltas or estuaries. However, the systematic collection and analysis of data on the extent and distribution of localized pollutants has only recently gotten under way. Because inventories are limited to point-source pollutant loads, the results so far are not useful for assessing the extent and distribution of pollutants generated by some of the most significant non-point source activities in the region, including agriculture, forestry, and coastal development projects. In the absence of systematically collected data on non-point pollutant loads for most of the WCR countries and territories, a more complete picture of an individual state or subregion's relative contribution and exposure to LBMP must be inferred from other indicators. We examine a combination of indicators to help assess the inclination and ability of states to undertake independent or joint action to control LBMP problems.

We analyze several issues and arguments that often are assumed to be relevant to the Caribbean and therefore have been used as a basis for pursuing a regionwide approach to LBMP control in the WCR. These issues and arguments include: common-pool pollution effects; scale economies; common pollution problems; and the need for uniform standards (water quality or pollution control standards). Each of these issues must be evaluated carefully with respect to the wide variety of environmental, political, and economic characteristics found in the WCR states. We believe that all of these issues are indeed relevant and valid at some scale in the Caribbean. However, the extent to which they are applicable regionwide is not at all clear.

We believe that strong arguments can be made in favor of a regional protocol containing institutional arrangements that help to resolve pollution problems at the domestic and subregional levels, especially transboundary pollution between adjacent or neighboring states. This kind of an effort can build upon existing bilateral arrangements, if deemed successful, such as those between Venezuela and Trinidad \& Tobago, Mexico and Belize, or the United States and Mexico. We advocate an approach that starts out at a small scale so that valuable, and potentially transferable, experience can be gained at little risk of larger program ineffectiveness. If scientific research demonstrates the need to internalize pollutant effects that are more widespread, then larger subregions might be delineated, building upon the experience gained at the bilateral level. The best approach appears to be an incremental one, building upon successful arrangements among those states that have appropriate incentives for solving real transboundary pollution problems.

We also address the argument for an LBMP protocol in the WCR that gives priority to resolving localized but widely occurring pollution problems-an approach that is clearly more compatible with the environmental realities of the region. We are concerned that the logic of concluding an international protocol to address primarily domestic problems depends upon certain unproven assumptions about clearinghouse efficiencies and other scale economies, and about the likelihood that an international program will be more effective than efforts by 
individual states in attracting funding and other forms of assistance from multilateral and bilateral donor agencies. We believe that these assumptions are valid to a point that stops short of justifying a uniform, regionwide approach to LBMP problems and solutions. We recommend that a protocol focusing on common, nontransboundary LBMP explicitly recognize that some common LBMP problems in the WCR are more common than others, by carefully delineating subregional groupings and approaches on the basis of shared marine environmental problems. We further recommend that in such a case the "umbrella" function of a regional protocol should concentrate on the need to ensure uniform access to all clearinghouse products and on the resolution of issues concerning the internal allocation of financial and technical assistance to individual states and subregions.

We explore three avenues to identifying promising opportunities for mutually beneficial collaborations, or "gains from trade," in pollution control. First, economic commonalities throughout the region are identified, with the states grouped and ranked according to their level of participation in relevant economic sectors. This information is useful in identifying states engaged in a particular polluting activity on a relatively small scale, who could benefit from pollution control approaches and technologies that have already been adopted by another state engaged in the same activity at a much larger scale. At the same time, states operating in the same industries at roughly the same scale of activity may encounter the same LBMP problems and thus might well be interested in cooperating on the development of common solutions. Also considered are the states' existing relations as trade partners, which could serve as an additional basis or support for collaborations and exchanges in LBMP control.

Second, we consider the relative identities of WCR states as polluters and pollutees within geographic subregional groupings, according to an approach developed by Broadus et al. (1993). Specifically, relevant population and economic data are used to estimate the extent to which each state is a source of LBMP; the extent to which it has a stake in controlling the problem; and its relative economic capacity to undertake corrective action. This analysis yields several illustrative examples of key match-ups among source, stakeholder, and facilitator states within and across subregions, in which facilitator states (typically important trading partners or aid providers) influence source states to control their LBMP emissions for the benefit of key stakeholder states. Although this analysis is distinctly geared toward instances of transboundary pollution, we believe that it will be useful even if the negotiating parties concentrate their efforts on collective responses to common, nontransboundary problems. In either case, an understanding of each state's relative standing with respect to source, stake, and capacity should enhance the ability of negotiating parties to identify those specific collaborations and exchanges that are most likely to be successfully implemented.

Third, we develop a qualitative rating system that takes into account not only the size but also the direction of a state's economic incentive with respect to controlling LBMP, and not only 
its economic capacity but also its institutional capacity to undertake corrective action. Like the economic groupings, this approach compares all the WCR states within a single, regionwide context. This rating system helps to predict which states are the most likely to engage in sustained and successful action to control LBMP, and, for the other states, the general types of assistance or special inducements that each is most likely to require in order to participate successfully.

The Cartagena Convention establishes a broad goal with respect to the control of LBMP in the Convention area. As currently articulated, this goal is subject to variable interpretations. In order to improve the potential for protocol effectiveness, this goal must be clarified, its terms should be made more explicit, and objectives should be specified to enable states, collectively or independently, to reach this goal. In particular, the term appropriate measures, found in the Convention's mandate that its Contracting Parties "shall take all appropriate measures to prevent, reduce, or control" LBMP, should be defined explicitly.

One important role for the prospective protocol will be the clarification of rights to a clean marine environment. Broad language in the Cartagena Convention, the United Nations Convention on the Law of the Sea (UNCLOS III), and principles of customary international law lend support to the notion that states affected by pollution originating in another jurisdiction have the right to a clean environment. The emerging "polluter pays" principle is consonant with these sources of law, but appears to apply primarily at the subnational level. However, these sources of law are not unambiguous with respect to the assignment of rights. We develop a stylized model to demonstrate the importance of clearly defined rights and to help elucidate the potential for benefits from agreements, or "gains from trade," in pollution control (Appendix C).

Gains from trade can be facilitated with mechanisms for transfer payments. These mechanisms exist already and have been employed to assist in the resolution of Caribbean LBMP problems to a limited extent. The United States, some European states, Sweden, Canada, and Venezuela already provide foreign aid of various types to many states in the region. These transfer payments can be "tied" specifically to pollution control arrangements in the context of the subregional or bilateral agreements that we have suggested. It is not necessary that transfers be financial; transfers can involve scientific or technological research, expertise, or equipment, or other goods and services.

Another important role for the protocol is the reduction of transactions costs among states involved in pollution control negotiations. Transactions costs can involve costs of information disparities and uncertainty, negotiation, and enforcement. The protocol can also serve the traditional roles of providing a forum to help focus pollution-related scientific research and monitoring and to identify an array of feasible pollution control instruments that might be employed by states in pollution control at the domestic and subregional levels. 
At this juncture, it is not yet possible to evaluate the effectiveness of a protocol on LBMP control for the Caribbean. We can, however, say something about the general features and elements that might be incorporated into a protocol to improve its potential for effectiveness. Notably, the WCR resembles the Mediterranean as a regional sea, suggesting that many lessons, on what to adopt as well as what to avoid, can be drawn from the Mediterranean experience. Experience with the control of LBMP in other regional seas can provide useful lessons as well, particularly in the areas of program financing, political commitment, statements of goals, targets and deadlines, and compliance.

-vii- 


\section{Contents}

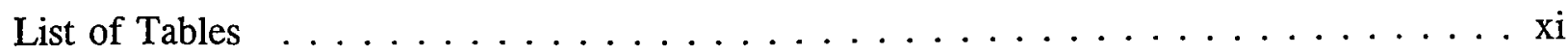

List of Figures $\ldots \ldots \ldots \ldots \ldots \ldots \ldots \ldots \ldots \ldots \ldots \ldots \ldots \ldots \ldots$

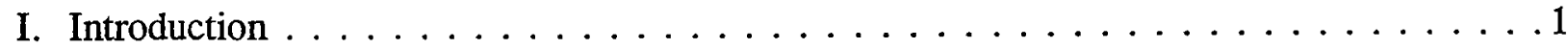

A. Background: Land-Based Marine Pollution and the Wider Caribbean Region .. 1

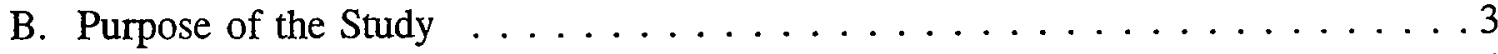

C. Study Approach and Organization of the Report ............. 4

II. Natural Systems, Pollution, and the Interdependency of WCR States . . . . . . . . 9

A. Regional Geography and Freshwater Input . . . . . . . . . . . . . . . . . . .

B. Ocean Circulation . . . . . . . . . . . . . . . . . . 12

C. Weather and Atmospheric Circulation . . . . . . . . . . . . 12

D. Spatial Scales of Pollution in the Wider Caribbean Region . . . . . . . . . 17

E. Subregional Scales of Pollution and the CEPPOL Pollutant Load Inventories 20

F. Summary . . . . . . . . . . . . . . . . . . . 29

III. Commonly Advanced Arguments for Collective Action in the WCR . . . . . . . . 30

A. The Importance of Scale . . . . . . . . . . . . . . . . 30

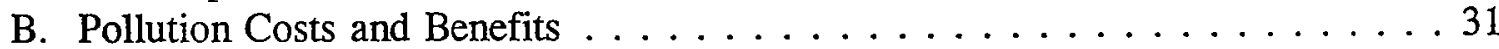

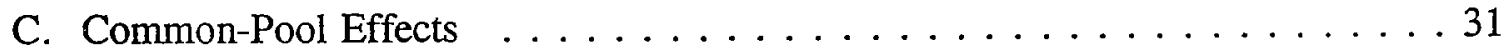

D. Common Environmental Problems . . . . . . . . . . . . . 34

E. Scale Economies and Clearinghouse Efficiencies . . . . . . . . . . 37

F. Uniform Standards . . . . . . . . . . . . . . . . . . . . . . . . . . . . . . . . . . . . . . . . . . . . .

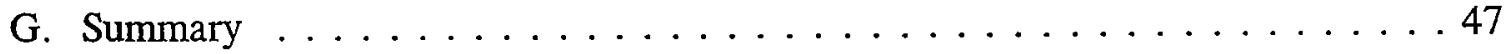

IV. Economic and Institutional Characteristics of the WCR . . . . . . . . . . 49

A. Regional Diversity . . . . . . . . . . . . . . . . . . . . . . . . . . . . . . . . . .

B. The WCR States and the Cartagena Convention . . . . . . . . . . . . . . 49

C. Overview of Demographic and Economic Indicators . . . . . . . . . . . . 54

D. Comparative Overview of the CEPPOL-Designated Subregions . . . . . . . 56

1. Economically heterogeneous subregions . . . . . . . . . . 56

2. Economically homogeneous suubregions ............. 60

3. Marine pollution and resource degradation problems within and across subergions . . . . . . . . . . . . . . . 61

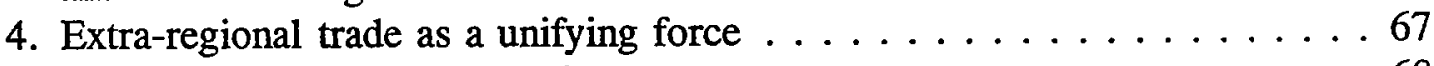

E. Legal and Regulatory Frameworks . . . . . . . . . . . . . 68

F. Measures of Environmental Infrastructure $\ldots \ldots \ldots \ldots$

G. Scientific Capabilities . . . . . . . . . . . . . . . . . 76

H. The Role of NGOs in the WCR . . . . . . . . . . . . . 77

I. Other Regional Organizations $\ldots \ldots \ldots \ldots \ldots \ldots$

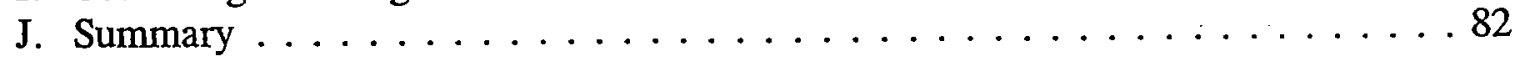




\section{Contents (cont'd.)}

V. Analysis of the Incentives and Prospects for Collective Action . . . . . . . . . 84

A. Analytic Approaches ... . . . . . . . . . . . . . . . . . . . . . . . . . . . . .

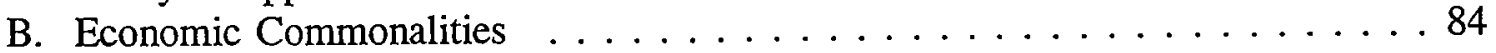

C. Sources and Stakes . . . . . . . . . . . . . . . . . . 92

D. An Alternative Assessment of Capacities and Incentives to Control LBMP - 102

E. Concluding Remarks ... . . . . . . . . . . . . . . . . . 109

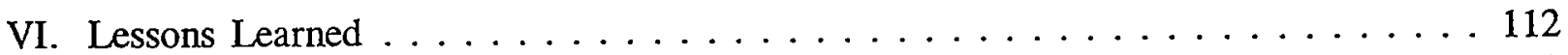

A. Regional Background Characteristics . . . . . . . . . . . . . . 112

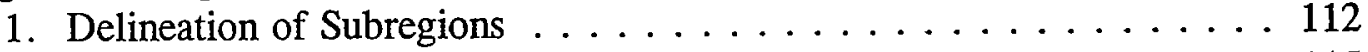

2. Coherence Among Member States . . . . . . . . . . . . . . 115

3. High-Level Political Commitment and Oversight . . . . . . . . . 117

4. Knowledge of Baseline Conditions . . . . . . . . . . . . . 118

B. Elements of Effective Program Design . . . . . . . . . . . . . . 119

1. Clear Goals and Objectives . . . . . . . . . . . . . . 119

2. Obligation to Adopt Measures: Targets and Deadlines . . . . . . . 120

3. Efficiently Designed Program Measures . . . . . . . . . . . . . . . 121

4. Compliance Mechanisms . . . . . . . . . . . . . . . . . 122

5. Mechanisms for Trade ... . . . . . . . . . . . . . 123

6. Adequate Financing Features . . . . . . . . . . . . . . 124

7. Effective Decisionmaking Processes ... . . . . . . . . . . 125

8. Adaptability Over Time ... . . . . . . . . . . . . . . . . 126

C. Dynamic Measures of Effectiveness . . . . . . . . . . . . . . . . 127

1. Level of Compliance . . . . . . . . . . . . . . . . . . . . . . . . . . . . . . . . . . . . . . . . . .

2. Achievement of the Program Goal . . . . . . . . . . . . . . . . . 128

3. Increased Domestic Abatement Efforts . . . . . . . . . . . . . . . . 129

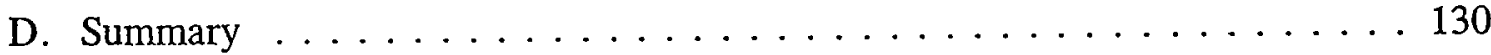

Appendices

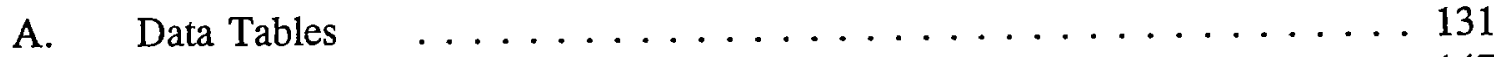

B. Estimation of Drainage Basin and Coastal Populations . . . . . . . . . . 147

C. Opportunities for Gains from Trade: A Stylized Model . . . . . . . . . . 155

D. Consultant Report: E. H. Gladfelter and J. C. Ogden. The status of relevant scientific capabilities and knowledge of land-based marine pollution problems in the Caribbean.

E. Consultant Report: L. A. Kimball. Land-based sources marine pollution: institutions and exchanges.

(unattached)

F. Consultant Report. E. F. Mandelli. Land-based sources of marine pollution, legal instruments, and institutional capabilities in the Spanish-speaking countries of the Wider Caribbean Region. (unattached) 


\section{List of Tables}

1 Lessons Learned from a Comparative Assessment of LBMP in the Baltic, North Sea, and Mediterranean . . . . . . . . . . . . . . . . 5

2 Principal Rivers Draining Into the Wider Caribbean . . . . . . . . . . . 10

3 CEPPOL Results: Waste Loads from Domestic Sources in the

Wider Caribbean Region by Subregion $(\mathrm{t} / \mathrm{y}) \ldots \ldots \ldots \ldots \ldots \ldots$

4 CEPPOL Results: Waste Loads from Industrial Sources in the

Wider Caribbean Region by Subregion $(\mathrm{t} / \mathrm{y}) \ldots \ldots \ldots \ldots \ldots . \ldots 24$

5 Regional Environmental Programs \& Projects in the Caribbean . . . . . . . . 38

6 Pollution Control Instruments: A Qualitative Comparison . . . . . . . . . . . 44

7 Distributional Implications of Instrument Choice . . . . . . . . . . . 46

8 Political Units in the Wider Caribbean Region . . . . . . . . . . . . 50

9 Participation in Law of the Sea, London Dumping, and Cartagena Conventions . . 52

10 Major Net Importers and Net Exporters of Fish and Fish Products in the WCR . 55

11 Observed Resource and Pollution Problems . . . . . . . . . . . . . . 62

12 Authority for Environmental Policy and Enforcement in the WCR States . . . . . 71

13 Measures of Environmental Infrastructure . . . . . . . . . . . . . . 74

14 Regional Environmental Institutions . . . . . . . . . . . . . . . . . . 81

15 Leading Oil and Natural Gas Producers, Oil Refiners, and Producers of

Industrial Chemicals . . . . . . . . . . . . . . . . . 86

16 Leading Agricultural, Sugarcane, and Banana Producers . . . . . . . . . . 87

17 Coastal Development and Leading Fish Producers and Tourist Destinations . . . 89

18 Debt Service Ratios and Leading Recipients of Foreign Aid . . . . . . . . . 90

19 Major Exports and Primary Importing States . . . . . . . . . . . . . . 91

20 Opportunities for Exchange and Cooperation . . . . . . . . . . . . . 93

21 Sources, Stakes, and Capacities within Subregions . . . . . . . . . . . . . 95

22 Key States and Trading Relationships in the Wider Caribbean Region . . . . . . 101

23 Qualitative Ratings of Capacity and Incentive to Undertake LBMP Control . . . 103

24 Overall Prospect of Sustained and Effective Action to Control LBMP . . . . . . 107

25 Checklist: Factors for Regional Program Success . . . . . . . . . . . . . 113

26 Commonality of Specific LBMP Problems as Basis for Subregional Groupings - 116

A.1 Economic and Population Data for WCR States $\ldots \ldots \ldots \ldots \ldots \ldots \ldots$

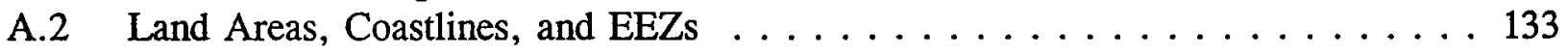

A.3 Selected Indicators of Land-Based Marine Pollution Inputs . . . . . . . . . . 134

A.4 Selected Fisheries Data, 1990 . . . . . . . . . . . . . . . . . 136

A.5 Selected Economic Data on Countries and Territories of the WCR,

Grouped by CEPPOL-Designated Subregions . . . . . . . . . . . . . 137

A.6 Scientific Associations and Member Institutions in the WCR . . . . . . . . 143

A.7 Participation in Global and Regional Organizations . . . . . . . . . . . . . . 144

B.1 Estimated Drainage Basin and Coastal Populations of the WCR States . . . . . 150 


\section{List of Figures}

1 Actual and Hypothetical Maritime Jurisdictions in the Wider Caribbean Region . . . . . . . . . . . . . . . . 2

2 Surface Currents of the Wider Caribbean Region (March) $\ldots \ldots \ldots \ldots \ldots 13$

3 Surface Currents of the Wider Caribbean Region (June) $\ldots \ldots \ldots \ldots \ldots 14$

4 Surface Currents of the Wider Caribbean Region (September) . . . . . . . . . 15

5 Surface Currents of the Wider Caribbean Region (December) . . . . . . . 16

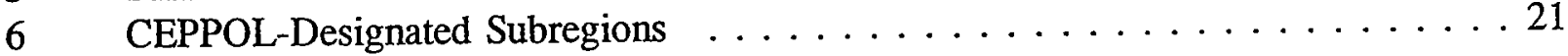

7 Relative Contributions of Combined Pollutants from Domestic and Industrial Sources by Five WCR Subregions $\ldots \ldots \ldots \ldots$

$8 \quad$ Relative Contributions of Individual Pollutants from Domestic and Industrial Sources by Five WCR Subregions . . . . . . . . . 27

9 Relative Contributions of Pollutants from Combined Domestic and Industrial Point Sources by 25 WCR States, Grouped by CEPPOL-Designated Subregions . 28

10 Relationship Between Pollution Emissions and Damages . . . . . . . . . 40

11 Regional Diversity as Measured by GDP Per Capita . . . . . . . . . 51

12 WCR Fish Exports and Per Capita Fish Consumption . . . . . . . . 58

13 Major Regional Areas, Actions, and Actors in Environmental Management and Sustainable Development . . . . . . . . . . . . . . . . . . . 79

14 CEP Contributions (Deficits), $1981-92 \ldots \ldots \ldots \ldots \ldots \ldots$

15 Comparison of Sources, Stakes, and Capacities within CEP Subregions . . . . . . 96

16 Relative Capacities and Incentives to Control LBMP Throughout the WCR . . 105

B.1 Drainage Area of the Wider Caribbean . . . . . . . . . . . . . . . . 149

C.1 A Model of Transboundary Pollution Control . . . . . . . . . . . . 158 


\section{Introduction}

\section{A. Background: Land-Based Marine Pollution and the Wider Caribbean Region}

Land-based marine pollution (LBMP) is the world's most serious marine pollution problem, estimated by the United Nations Joint Group of Experts on the Scientific Aspects of Marine Pollution (GESAMP) to contribute more than 75 percent of the pollutants entering the sea (GESAMP 1990). Negotiations are under way to develop a regional protocol for action to control LBMP in the Wider Caribbean Region (WCR), which is defined by the 1983 Convention for the Protection and Development of the Marine Environment of the Wider Caribbean Region, or Cartagena Convention, to include the Gulf of Mexico, the Caribbean Sea proper, and those parts of the western Atlantic within 200 nautical miles of the Bahamas and Florida, down to the northern border of Brazil.

A map of the Wider Caribbean Region is found in Figure 1, which also depicts the actual (heavy lines) and hypothetical (thin lines) maritime boundaries of the WCR states. ${ }^{1}$ Except for two "doughnut holes" in the Gulf of Mexico, there are no high seas in the region. Several important international boundaries have been agreed upon, but the majority are still undecided. In Section V, we employ this base map as an heuristic tool for displaying certain information about the characteristics of the states of the region.

The Caribbean basin is home to a large and diverse marine ecosystem, including roughly 14 percent of the world's coral reefs; the barrier reef system off Belize is the world's second largest, measuring approximately $220 \mathrm{~km}$ in length. Throughout the region, the reefs receive protection from extensive and productive sea grass beds, which also provide grazing for sea turtles, manatees, fish, and invertebrates. Also characteristic of the region are coastal mangroves that support a grazing food chain and provide nursery grounds for fish and shellfish, while trapping sediments and exporting nutrients (Elder and Pernetta 1991).

The diversity of the region includes not only its natural marine systems but also a tremendously broad range of cultures, languages, political systems, and economies. For example, the WCR is home to the world's largest and most diverse economy (the United States); to countries that are among the world's smallest (St. Kitts \& Nevis, Grenada, St. Vincent \& the Grenadines) and poorest (Haiti, Guyana, Nicaragua); and to one of the world's few remaining

\footnotetext{
${ }^{1}$ We have adapted and updated this map from Fenwick (1992). Hypothetical boundaries are those identified by the U.S. Department of State in its World Data Bank 2. In most cases, the hypothetical boundaries are approximate equidistant boundaries, and they do not reflect any acceptance by the U.S. government. Some claims may be based upon unilateral assertions; these claims may be subject to change by national legislation or decree or through international boundary negotiations. Boundaries as represented are approximations for general reference only.
} 


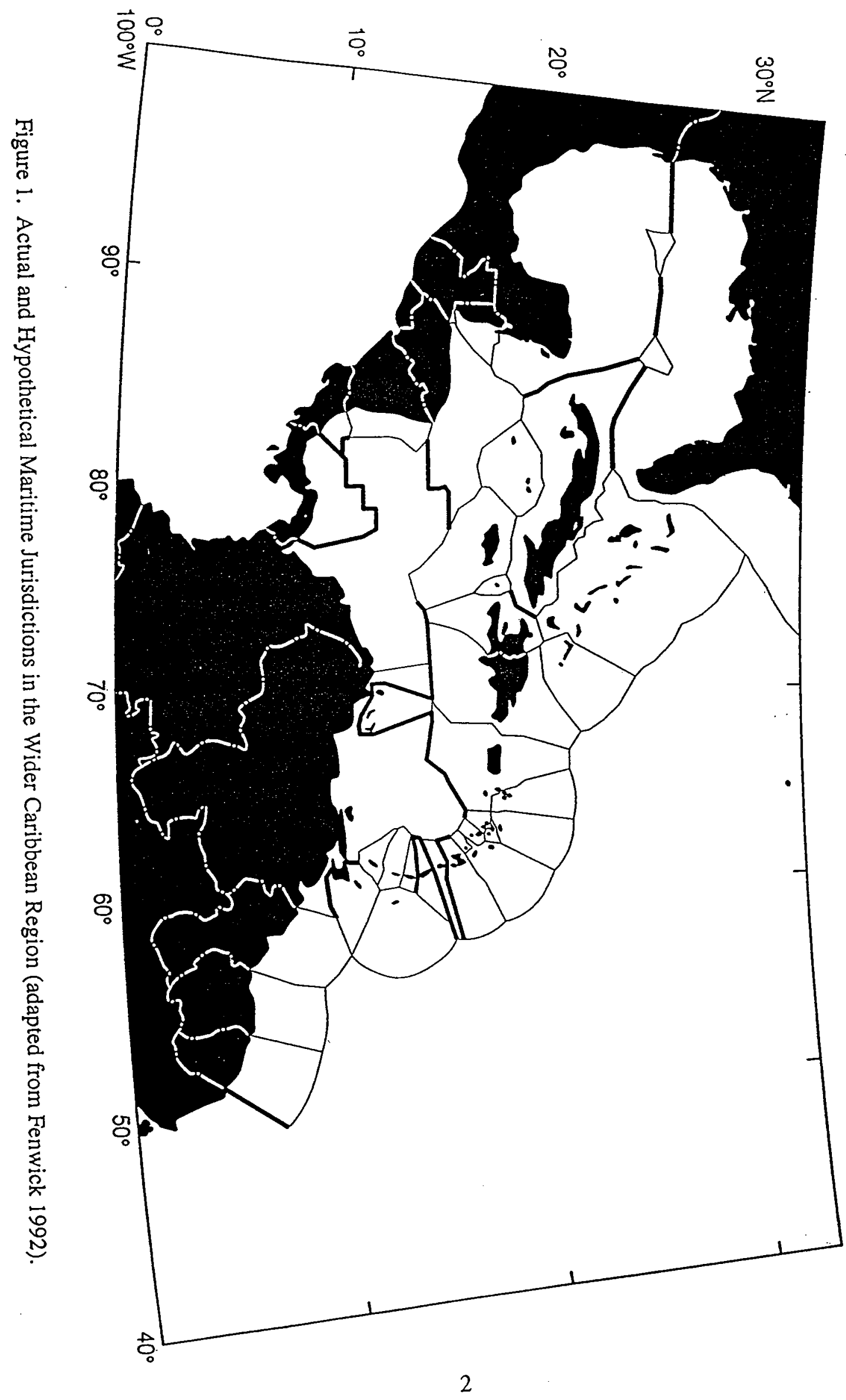


communist states (Cuba).

Despite this diversity, however, and the existence of several distinct subregional identities, there is a relatively high degree of regional interdependence. To a large extent this cohesion is attributable to perceptions by, and patterns of trade with, the United States and other major partners outside the region (United Kingdom, France, Germany, the Netherlands, Canada). For many years these trading patterns emphasized bananas, sugarcane, and other agricultural products. Although these remain important regional exports, in recent decades they have been joined by a variety of manufactured goods. Most significant, however, is the extent to which tourism has come to dominate a large number of WCR economies, with cruise tourism becoming an especially powerful unifying force throughout much of the region.

As in all regions of the globe, local situations and priorities are reflected in the mix of land-based marine pollution problems observed within the region. In addition to agrochemical runoff and discharges of industrial effluents, characteristic conditions include poor sewage treatment facilities; increasing urbanization, especially in coastal areas; upland erosion; and deforestation (UNEP 1989a, 1994a). Even the region's tourist industry, which relies upon perceptions of a pristine environment, itself contributes substantially to degradation of the coastal environment in a variety of ways, including inadequate sewage treatment at tourist facilities, coastal erosion from beach dredging to accommodate accelerated hotel construction, taking of corals, and damage to corals by anchors, spearfishing, and ship waste.

Growing recognition in the 1970s of these and other environmental problems led to the adoption, in 1981, of the Action Plan for the Caribbean Environment Programme (CEP). Initial funding for the CEP came in the form of "seed money" from the United Nations Environment Programme (UNEP), but gradually the governments of the WCR have taken over responsibility for funding and management of the program. Among the signs of the regional governments' "clear commitment" to the CEP, UNEP cites regular contributions to the Caribbean Trust Fund, which supports the CEP, and ratification of the Cartagena Convention, which entered into force in 1986, along with a Protocol concerning Co-operation in Combating Oil Spills in the Wider Caribbean Region (UNEP 1991a). Negotiation of a second protocol, on Specially Protected Areas and Wildlife, followed in January 1990. This report is intended to advance the basis for progress in discussions among the WCR states toward negotiation of a third protocol to the Cartagena Convention, concerning land-based sources of marine pollution in the region.

\section{B. Purpose of the Study}

In May 1993, the US Environmental Protection Agency's Office of International Activities awarded study grant assistance to the Marine Policy Center (MPC) of the Woods Hole Oceanographic Institution to compile information and produce analyses to enhance the 
effectiveness of an international protocol for the control of LBMP in the Wider Caribbean Region. The analyses have been guided by four principal study objectives:

(1) a review and summary of LBMP problems to determine common problems and priority problem areas;

(2) a survey of broadly defined environmental infrastructure to help identify national commitments and national capacities to prevent, reduce, or control LBMP;

(3) a survey and analysis of subregional differences in commitment or interest in regional control of LBMP, to help direct and motivate recommendations for protocol mechanisms; and

(4) a comparison of program approaches from other regions, especially the Baltic, North Sea, and Mediterranean, providing lessons from which an effective program for the Caribbean might be designed.

Special attention to program experiences in the Baltic, North Sea, and Mediterranean regions reflects the fact that these were the first regional environmental programs on LBMP to be evaluated on a comparative basis, in a study also undertaken by the Marine Policy Center (Broadus et al. 1993). That study identified precisely what efforts have been made in these three regions, what has worked best, what has not worked, and why. These lessons are displayed in Table 1 and are referred to throughout this report, directly and indirectly, as we develop our analyses and recommendations concerning an effective LBMP protocol for the Caribbean. We employ the term effective in the sense used by Broadus et al. (1993), where it refers to the degree to which the program's actual effect achieves the program's goals. ${ }^{2}$

\section{Study Approach and Organization of the Report}

Of all the lessons listed in Table 1, perhaps the most fundamental concerns the existence of differences among states in outlook and capability, and the importance of program design to accommodate these differences and thereby serve the real national interests of participating states

\footnotetext{
${ }^{2}$ This definition is consistent with that developed by Bernauer (1995). Bernauer defines effectiveness as the extent to which, holding other factors constant, an institution contributes to "goal attainment." Goal attainment can be measured as the difference between, for example, the quality of the marine environment prior to the implementation of a protocol and its quality when protocol effectiveness is evaluated.
} 
Table 1

Lessons Learned from a Comparative Assessment of LBMP in the Baltic, North Sea and Mediterranean

\begin{tabular}{|c|c|}
\hline clarity & $\begin{array}{l}\text { Costly misunderstandings, false starts and wasted effort can be avoided } \\
\text { by seeking maximum clarity in defining program goals, the relations } \\
\text { among partles, measures and recomendations, and the role of the } \\
\text { secretariat. Particular effort should be made to excise hidden agendas } \\
\text { (eg. If income transfer or lobbling of governments is to be a program } \\
\text { objective, this should be set out clearly and Incorporated explicitiy } \\
\text { into program design). }\end{array}$ \\
\hline $\begin{array}{l}\text { capacity to } \\
\text { avolve }\end{array}$ & $\begin{array}{l}\text { The ability to adjust the program to changed circumstances and improved } \\
\text { knowledge is vital to its effectiveness over time. The method of } \\
\text { keeping the framework convention quite spare and leaving program } \\
\text { elaboration to subsequent protocols, directives, recommendations, or } \\
\text { flexible action plans is useful in this regard. }\end{array}$ \\
\hline $\begin{array}{l}\text { Political } \\
\text { commitment }\end{array}$ & $\begin{array}{l}\text { Program effectiveness will depend inevitably on the political commitment } \\
\text { of the parties, Examples of movement toward enhanced effectiveness were } \\
\text { observed in ali three regions as a result of collective political } \\
\text { intervention by parties at a ministerial. level. The device of an } \\
\text { overarching, high-level political forim above the regionel program, as } \\
\text { in the North sea conferences, appears to have been useful in this } \\
\text { regard. Such a forum also provides a highly-visible focal point for } \\
\text { public pressure, and it contributes to program transparency, which } \\
\text { enhances the reievance and effectiventss of public pressure. }\end{array}$ \\
\hline $\begin{array}{l}\text { opecifleity } \\
\text { of } \\
\text { objectives }\end{array}$ & $\begin{array}{l}\text { Demonstrating effectiveness and clarity in its measures is important } \\
\text { both in sustaining program mupport and in operational program } \\
\text { implementation. For this it is necessary to specify objectives whose } \\
\text { accomplishment can be measured and demonstrated. Targets and timetables } \\
\text { are useful, especially if they are sensitive to differences in the } \\
\text { stakes and economic capabilitles among the parties. Black ilsts and } \\
\text { grey ilsts are useful in specifying the scope of concern, but experience } \\
\text { has pointed to the need to narrow program focus in practice to priority } \\
\text { targets (sometimes called "red ilsts"). }\end{array}$ \\
\hline $\begin{array}{l}\text { scientific } \\
\text { involvement }\end{array}$ & $\begin{array}{l}\text { A mechanism for expert scientifle input and advice is essential, to } \\
\text { clarify the nature and magnitude of problems and to monitor changing } \\
\text { conditions, but it fs lmportant to assure that scientific research } \\
\text { interests do not altogether run away with program resources. The } \\
\text { persuasive establishment of baseline conditions, both in terms of } \\
\text { ambient measures and emissions, must be a priority, as demonstrated by } \\
\text { the hindrances created by shortcomings in doing so in all the cases } \\
\text { examined. It should be recognized that the baseline profiles can be } \\
\text { useful even if somewhat crude, and that assembling credible baselines } \\
\text { vill be expensive and tlme consuming. }\end{array}$ \\
\hline $\begin{array}{l}\text { Belf- } \\
\text { interest } \\
\text { test }\end{array}$ & $\begin{array}{l}\text { States can be expected to serve their own self-1nterests, but program } \\
\text { effectiveness will be improved to the extent that program design takes } \\
\text { account of this and explicitly seeks to accommodate the genuine (rather } \\
\text { than presumed) self-interest of its parties. program structures that } \\
\text { encourage or accommodate agreements and actions by sub-groups of } \\
\text { parties, that allow for flexible financial or technical assistance, or } \\
\text { that provide expllcitly for variable schedules or an "opt out" option on } \\
\text { some measures, may also be helpful in this regard. }\end{array}$ \\
\hline $\begin{array}{l}\text { Mechanisma } \\
\text { for trade }\end{array}$ & $\begin{array}{l}\text { Because the seli-interests of states will differ, and because one of the } \\
\text { principal rationales for collective action ls to facilitate sharing and } \\
\text { exchange. program effectiveness will be enhanced by provision of } \\
\text { mechanisms for explicit trade" (quid pro quos, specialization) among } \\
\text { participants. simliarly, efficiency is served by implementation } \\
\text { measures that take into account differences among states and that } \\
\text { facilitate trading to accomplish mutual objectives (such as tradable } \\
\text { quota schemes). Implicit trades or explicit quid pro quos may be } \\
\text { achieved through program funding schemes. }\end{array}$ \\
\hline $\begin{array}{l}\text { Reporting } \\
\text { and } \\
\text { compliance }\end{array}$ & $\begin{array}{l}\text { Assessing the degree of state compliance with program recommendations } \\
\text { has been obviated in all three cases by the poor performance of state } \\
\text { reporting. Special emphasis in program design should be placed on } \\
\text { specifying expectations for compliance, means for monitoring compliance, } \\
\text { and particularly, procedures that encourage accurate and timely state } \\
\text { reporting. In this regard, keeping the reporting burden simple and at a } \\
\text { minimum is important. It may also be useful to assure that the results } \\
\text { of reporting are useful to ali parties and to suggest a reporting system } \\
\text { that meshes routinely and automaticaliy into the states own practices. } \\
\text { some provision for non-intrusive, third party inspection may also be } \\
\text { useful, though this is only lmplicit in the cases examined through their } \\
\text { lack of success with more conventional, passive means of collecting } \\
\text { state reports. }\end{array}$ \\
\hline Transparency & $\begin{array}{l}\text { Most of the lessons proposed above speak to the value of transparency in } \\
\text { program design and execution, but it warrants explicit inclusion. } \\
\text { program effectiveness is enhanced (both in terms of party state support } \\
\text { over time and of verifiability by other interests) by the maximum } \\
\text { transparency compatible vith the protection of proprietary interests and } \\
\text { the sovereign rights of independent states. }\end{array}$ \\
\hline $\begin{array}{l}\text { Limit } \\
\text { expectations }\end{array}$ & $\begin{array}{l}\text { Regional programs in the real world can at best be catalytic. Measures } \\
\text { to control land-based marine pollution will necessarily occur almost } \\
\text { exclusively through domestic actions. The programs may succeed as a } \\
\text { medium for exchange and consensus among members and as a promoter of } \\
\text { external funding support, which can be used to reinforce internationally } \\
\text { agreed program objectives and revard compliance. The effectiveness of } \\
\text { the reglonal trust fund device is not clear from the cases examined and } \\
\text { must be carefully questioned. Again, clarity of purpose and } \\
\text { transparency cannot be over emphasized. }\end{array}$ \\
\hline
\end{tabular}

Source: Broadus et al. 1993 
(the "self-interest test"). ${ }^{3}$ Without a doubt, WCR States are seriously concerned about environmental quality regionwide, but they are even more concerned about and motivated to act on activities that impinge upon or otherwise threaten the use of ocean resources within their own jurisdictions.

Land-based marine pollution problems typically, and in the first instance, are treated as primarily a domestic issue. Although a state may suffer from marine pollution generated by other states or may benefit from actions taken by another state to improve its own marine environment, the existence of such external effects does not signal automatic agreement on collective actions. Rather, such actions must be perceived as beneficial by individual states if their participation is to be secured.

The data, analyses, and recommendations presented in this report reflect the following basic assumptions about the essential factors that shape a state's perceptions of the likely benefits of participating in collective actions to control LBMP and its prospect of actually realizing benefits:

\begin{abstract}
A state's effective commitment to regional control of land-based marine pollution may be taken approximately to be a function of the potential impacts it most fears from marine pollution, the proportion of its population or economy most exposed to such impacts, its degree of transboundary exposure to inputs from other source states, its own relative contribution as a source, its own endowment of institutional and economic capabilities to tackle the problem, and the additional resources or benefits that might be made available to it through exchange with regional neighbors.
\end{abstract}

(MPC 1993).

These key factors will tend to differ across the region, particularly in a region as diverse as the Wider Caribbean.

Our starting point for analyzing important differences among individual states or subregions of the WCR is a review and summary characterization, in Section II, of the region's natural systems and most significant LBMP problems, including their principal sources and distribution. Special attention is devoted to inventories of selected domestic and industrial pointsource pollutant loads for 25 of the WCR states, as collected and analyzed by the Program for Marine Pollution Assessment and Control (CEPPOL).

The evidence to date indicates that most land-based marine pollutants are not transported far from their sources of discharge, and that transboundary pollution, where it occurs, appears

\footnotetext{
${ }^{3}$ We adopt the perspective in this report that states are naturally "self-interested." The key to an effective landbased marine pollution protocol is to harness the natural self-interest of these states to prevent, reduce, or control marine pollution.
} 
to be confined to border regions. ${ }^{4}$ The potential remains for a generalized "pollution" of the Wider Caribbean to develop or to be detected as more data are systematically collected, which would strengthen the case for a regionwide approach. Nevertheless, an LBMP protocol for the region can be effective if it focuses on transboundary pollution problems at the subregional level or on the numerous incidences of problems of a limited areal extent, whose resolution could benefit from shared experience or attention. The appropriateness of a focus on common, but not necessarily transboundary, LBMP problems is reportedly acknowledged and planned for by the negotiating parties (Wood-Thomas, pers. comm., 1995).

Much of the published literature and written records of WCR discussions have focused on the establishment and implementation of a regionwide approach to the prevention, reduction, or control of LBMP. In Section III, we critique several of the more commonly advanced arguments and proposals and caution against those that are not substantiated by environmental realities or do not reflect a balanced perspective on the costs and benefits of uniform approaches for individual states. We argue that one of the most important challenges facing the Contracting Parties is to correctly characterize the scale of LBMP problems and facilitate identification and implementation of appropriate solutions at the subregional level.

Sections IV and V are concerned with the identification of commonalities and complementarities-environmental, economic, and institutional-that can serve as the basis for subregional collaborations and exchanges. In Section IV, we present a broad range of economic, environmental, and natural resource data for 37 political units, or states, in the WCR, as well as information on their environmental laws, infrastructure, regulation, and enforcement; the extent of their participation in relevant regional and global organizations; and the extent of marine scientific capabilities and NGO involvement and activity. Comparisons are made within the subregional framework established by the CEPPOL program to facilitate its analysis of pointsource pollutant loads and distributions throughout the WCR.

In Section V, we pursue three alternative approaches to identifying promising opportunities for mutually beneficial collaborations, or "gains from trade." First, common export products and economic activities are identified as a potential basis for collaboration on scientific research and pollution control approaches among states at similar scales of activity, or for technology transfer from states operating at larger scales to those operating at smaller scales. Next, we consider the relative identities of WCR states as polluters and pollutees within the CEPPOL subregional groupings, according to the approach developed by Broadus et al. (1993). Specifically, we estimate the extent to which each state is a source of LBMP, has a stake in controlling the problem, and has the economic capacity to take corrective action. Our

\footnotetext{
${ }^{4}$ We employ a broad definition of transboundary pollution to include direct impacts from discharges, impacts on straddling fish stocks (including potential destruction of nursery areas), damage to export goods, impacts on tourism, diminished passive use values. See Broadus and Vartanov (1994) for a description of potential damages from transboundary pollution occurrences.
} 
analysis yields several illustrative examples of key match-ups among source, stakeholder, and facilitator states (i.e., major trading partners or aid providers) within and across subregions. Finally, we develop a rating system that takes into account not only the size but also the direction of a state's economic incentive with respect to controlling LBMP, and not only its economic capacity but also its institutional capacity to undertake corrective action. Although the rating system is rather crude, the results are useful for predicting which states are the most likely to engage in sustained and successful action to control LBMP and, for the other states, the general categories of assistance or special inducements that each is likely to need in order to participate successfully.

In Section VI, we apply to the Wider Caribbean Region the lessons learned about program effectiveness (Table 1) in the earlier, comparative study of programs in the Baltic, North Sea, and Mediterranean regions. We present a checklist of important factors in three main categories-relevant regional background characteristics, program design elements, and indicators of program effectiveness-and compare these factors with expectations about a protocol for the WCR, based upon regional realities and the state of the policy debate over the establishment of an LBMP protocol.

Following the main text of the report are three appendices that provide additional data or further explanation of certain portions of the text. Appendix A contains a number of data tables that support the discussions in Sections IV and V, and Appendix B explains our approach to estimating the proportions of each state's population that live within the drainage area and the coastal zone of the Wider Caribbean Region. (The information in Appendix B is relevant primarily to the discussion of "Sources and Stakes" in Section V, but also to the review of LBMP inputs in Section IV). Appendix C supplements the discussion of "Economic Commonalities" in Section V with a stylized model that examines the effects of property right distributions, burden of proof, and lack of clarity in property rights on the range and extent of possible "gains from trade" to be realized from agreements intended to reduce or control LBMP emissions.

Finally, we note the availability of three additional appendices not included with this report. These are papers prepared by consultants to the Marine Policy Center project to serve as the basis for discussions at a regional workshop of experts held at the University of the West Indies in Barbados in December 1994, and also as expert source materials for the preparation of this report. Gladfelter and Ogden (1994) provides a summary of the relevant scientific capabilities and current knowledge of LBMP problems in the Wider Caribbean. Kimball (1994) presents an overview of the key functions, institutions, and processes involved in the design and implementation of an international protocol on LBMP. Mandelli (1994) surveys the important LBMP problems, legal instruments, and institutional capabilities of the Spanish-speaking countries of the WCR. Copies of each of these papers are available on a limited basis from the Marine Policy Center. 


\section{Natural Systems, Pollution, and the Interdependency of WCR States}

\section{A. Regional Geography and Freshwater Input}

The Caribbean Sea is defined by the margins of Central and South America and the Greater and Lesser Antilles Islands. The Caribbean Sea contains four deep basins separated by prominent undersea ridges. Together with a fifth basin, the Gulf of Mexico, this larger water body comprises the American mediterranean, one of four mediterraneans on earth (the others are the Arctic, the Asiatic, and the European mediterraneans). A still larger entity surrounding the Caribbean is the Wider Caribbean Region (WCR), which adds to the American mediterranean the Bahamas and parts of the sea off the Guianas. The WCR is defined in the Cartagena Convention as comprising "the marine environment of the Gulf of Mexico, the Caribbean Sea, and the areas of the Atlantic Ocean adjacent thereto, south of $30^{\circ}$ north latitude and within 200 nautical miles" of the Atlantic coasts of states from the Bahamas and Florida down to the northern border of Brazil. ${ }^{1}$

The Wider Caribbean Region encompasses an area of 4.31 million $\mathrm{km}^{2}$ and has a mean depth of $2174 \mathrm{~m}$. The drainage basin, from which freshwater is delivered to the coast, has an area of about 5.6 million $\mathrm{km}^{2}$, of which the largest portions are in the United States (62\%), Venezuela (17\%), Colombia (4\%), and Mexico (4\%). While not formally incorporated into the definition of the WCR, the lands draining into the marine area are clearly of importance to management of this area, and particularly so in a discussion of land-based pollution. Of the principal rivers entering this area (Table 2), which collectively deliver about $66,500 \mathrm{~m}^{3} / \mathrm{sec}$ of freshwater, $45 \%$ comes from the Orinoco (Venezuela), $28 \%$ from the Mississippi (U.S.), and $11 \%$ from the Magdalena (Colombia). Fifteen rivers comprise the remaining $16 \%$ of riverine input. An additional, undefined freshwater input enters from the lagoons, mangrove swamps, and bayous that make up a large portion of the coastline, especially along the northern Yucatan Peninsula, eastern Florida, and the north coasts of Colombia and Venezuela.

Also significant is the freshwater input originating from the Amazon River, which is technically outside of the Wider Caribbean Region defined by UNEP. The Amazon discharge approximates $170,000 \mathrm{~m}^{3} / \mathrm{sec}$ of freshwater on average, of which a portion enters the Caribbean along the coast near Trinidad and Tobago. Froelich, Atwood, and Giese (1978) estimate that about half of the freshwater entering the Caribbean Sea, evident as salinity depressions extending to about $100 \mathrm{~m}$ depth, is from this source. This water also contains significant quantities of dissolved silica, an important nutrient for certain phytoplankton.

\footnotetext{
'A still larger area, incorporating parts of the Sargasso Sea and Bermuda and the Gulf of Panama, is referred to as the Intra-Americas Sea by IOCARIBE, the Caribbean and Adjacent Regions Task Force of the Intergovernmental Oceanographic Commission (IOC) of UNESCO.
} 
Table 2

Principal Rivers Draining Into the Wider Caribbean

\begin{tabular}{|c|c|c|c|c|c|}
\hline River & $\begin{array}{c}\text { Drainage } \\
\text { Area }\left(\mathrm{km}^{2}\right)\end{array}$ & $\begin{array}{c}\text { Water } \\
\text { Discharge } \\
\left(\mathrm{m}^{3} \mathrm{sec}^{-1}\right)\end{array}$ & $\begin{array}{c}\text { Sediment } \\
\text { discharge } \\
\left(10^{6} \text { tons/year }\right)\end{array}$ & $\begin{array}{c}\text { Specific } \\
\text { transport } \\
\left(t / \mathrm{km}^{2} / \text { year }\right)\end{array}$ & $\begin{array}{l}\text { Mean turbidity } \\
(\mathrm{mg} / \mathrm{l})\end{array}$ \\
\hline \multicolumn{6}{|l|}{ USA } \\
\hline Mississippi & $3,268,000$ & 18,400 & 222 & 76 & 380 \\
\hline Apalachicola & 44,000 & 620 & 0.16 & 6.8 & 15 \\
\hline Mobile & 97,000 & 1,500 & 4.5 & 42 & 95 \\
\hline Brazos & 114,000 & 160 & 15.9 & 0.14 & 3200 \\
\hline Colorado & 107,000 & 79 & $1.9 *$ & 17.9 & \\
\hline \multicolumn{6}{|l|}{ USA-Mexico } \\
\hline Rio Grande & 467,000 & 23 & very low* & & \\
\hline \multicolumn{6}{|l|}{ Colombia } \\
\hline Magdalena & 235,000 & 7,500 & 234 & 1000 & 1000 \\
\hline \multicolumn{6}{|l|}{ Venezuela } \\
\hline Orinoco & 950,000 & 30,000 & 85.0 & 91 & 90 \\
\hline
\end{tabular}

*Low values due to dams.

Sources: Borgese and Ginsburg, 1982; UNEP, 1994a. 
In addition to freshwater, rivers naturally deliver suspended sediments to the sea. In the case of the Wider Caribbean Region, large amounts of sediment are delivered by the Mississippi (222 million tons/yr), the Magdalena (235 million tons/yr), and the Orinoco ( 85 million tons/yr; UNEP 1989a). The Amazon discharges a large quantity of sediment, of which some portion finds its way into the WCR. For perspective, the dredging required for maintenance of all U.S. navigational waterways and harbors entails about 270 million tons/yr (see Herbich 1992), some of which is disposed of at contained sites on land (see Mangone 1990:189). At the river's mouth, both freshwater and its suspended and dissolved loads become entrained in and dissipated by the prevailing coastal and ocean circulation pattern. In the case of the Mississippi, the Orinoco, and the Amazon, sufficient water volumes are involved that the fate of the river plume can be detected remotely using satellite imagery (Müller-Karger 1993). River discharge directly or indirectly affects surface salinity, concentration and composition of phytoplankton, plant pigments, and suspended sediment concentration. Available satellite imagery shows the Amazon plume moving northward along the Guiana coast from February through May (when the North Equatorial Counter Current is weak), directly entering the Caribbean through passages between Trinidad and Tobago and the mainland, and engulfing these islands and the island of Barbados as well. During this time surface salinity at Barbados may drop from $34 \mathrm{o} / \mathrm{oo}$ to $31 \mathrm{o} / 00$ (Hunte 1994). From June to January, discolored water originating at the mouth of the Amazon veers offshore near French Guiana and curves eastward into the open ocean, in a plume that can be defined on satellite imagery in terms of its pigment concentration. According to Müller-Karger (1993), this period corresponds with the clearest water conditions at Barbados.

The Orinoco River also has a strong impact in the eastern Caribbean Sea, varying seasonally with discharge. During the dry season from February through April, the Orinoco outflow enters the Caribbean between Trinidad and Venezuela moving westward across the southern Caribbean. Eddies in the tropical Atlantic at this time can move Orinoco water offshore to the east of the Antilles, engulfing Barbados in pigment-rich water during JanuaryMarch. During the period of maximum discharge for the Orinoco, the Islands of Trinidad, Tobago, Grenada, and St. Vincent are regularly affected. Imagery taken in October 1979 shows a plume of Orinoco water extending northward nearly to Puerto Rico, along and west of the submerged Aves Ridge.

From other satellite imagery, Müller-Karger (1993) concludes that the Mississippi plume ordinarily moves westward along the Texas shoreline. An October 1982 image of the Western Caribbean shows dispersal of the Magdalena River plume, normally following the coast to the west, extending northwest instead, nearly to the Island of Jamaica. Clearly, much more is to be learned from additional and increasingly sophisticated satellite imagery.

The above demonstrates that the pathway exists for waterborne materials to travel great distances in the WCR, with measurable impacts on phytoplankton chlorophyll concentration, salinity, turbidity, and concentrations of certain chemicals. The extent to which humans affect 
the quantity or composition of river water suggests the extent of transboundary contamination of marine waters in the WCR.

\section{B. Ocean Circulation}

The major ocean surface currents of the Caribbean area have been known in broad brush for many years (e.g., Figures 2-5). These currents in general enter the Wider Caribbean Region from the open ocean to the east and along the northeast coast of Brazil and the Guianas. Water from both the South Atlantic and North Atlantic enter in this way, ultimately feeding into the Gulf Stream in the Straits of Florida in about equal quantities (Richardson, pers. comm., 1994). These surface currents establish a seemingly clear relationship among "upstream" nations to the east and south and "downstream" nations to the west and north. However, as illustrated below, this gross understanding of surface circulation in the Caribbean is clearly incomplete, and important refinements will come from ongoing and future oceanographic research in this area, such as studies under way by IOCARIBE (Maul, pers. comm., 1995).

For example, important departures from the general east-to-west surface circulation pattern exist as a result of gyres along the coasts of Panama, Colombia, and Venezuela, producing west-to-east inshore components of drift. Similarly, eastward-moving back eddies exist along the south coast of the Greater Antilles Islands. These natural patterns of circulation result in transboundary exchange from Belize to Guatemala and Honduras, and from Nicaragua to Costa Rica, Panama, and Colombia.

Deep water in the Caribbean is believed to enter periodically through the deeper passages of the Lesser Antilles. Circulation in the deep water is probably far more quiescent than for surface waters. Thus, the deep water occupying the four basins of the Caribbean Sea, which lies entirely within the exclusive economic zones (EEZs) of adjacent coastal states, is subject to the impacts of human activities in ways that are not well understood.

\section{Weather and Atmospheric Circulation}

Like the surface ocean circulation, prevailing easterly tradewinds result in an upstreamdownstream relationship among nations in the Wider Caribbean Region. Land-based atmospheric pollutants, such as industrial stack effluent and other point source gases and particulates, as well as non-point source pollutants such as chlorinated hydrocarbon pesticides, are relevant to a discussion of transboundary atmospheric contamination.

Between 1886 and 1986, 492 hurricanes (storms of tropical origin with a cyclonic wind circulation of $75 \mathrm{mph}$ or more) have threatened or actually reached the Wider Caribbean Region (see Gray 1992). Damage caused by hurricanes results from direct impacts of wind (and the associated cargo of wind-blown debris), torrential rainfall, and ocean waves and storm 


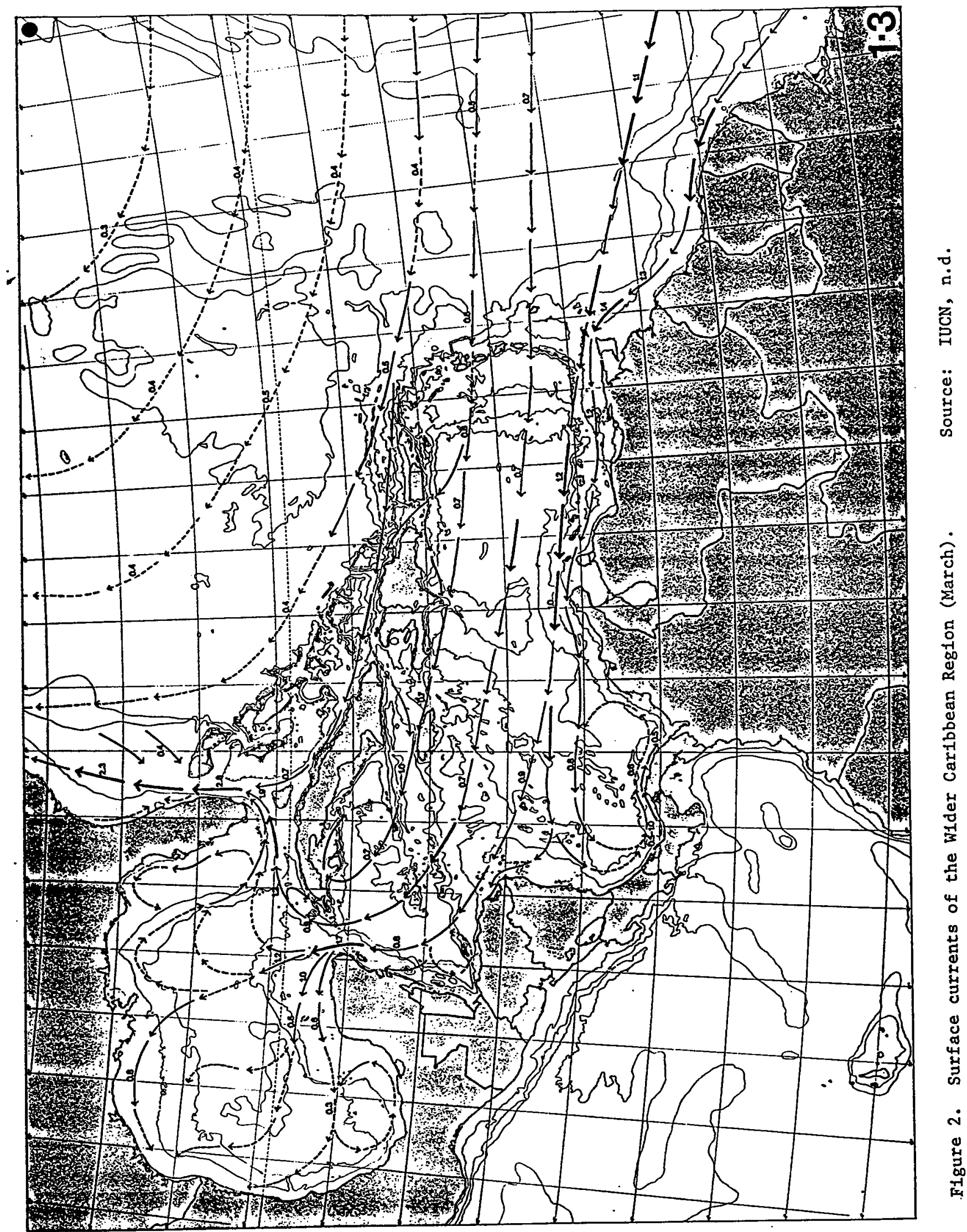




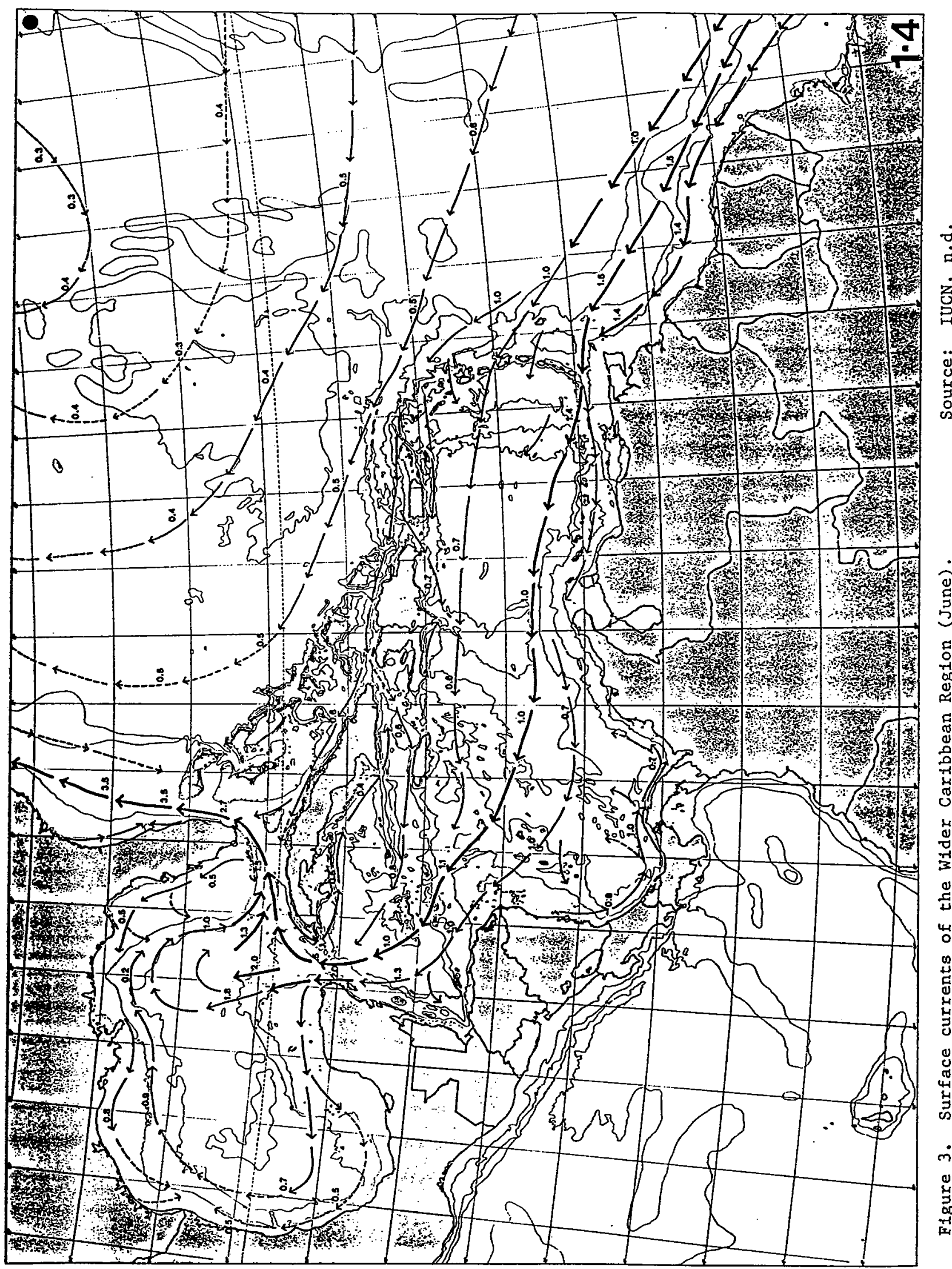




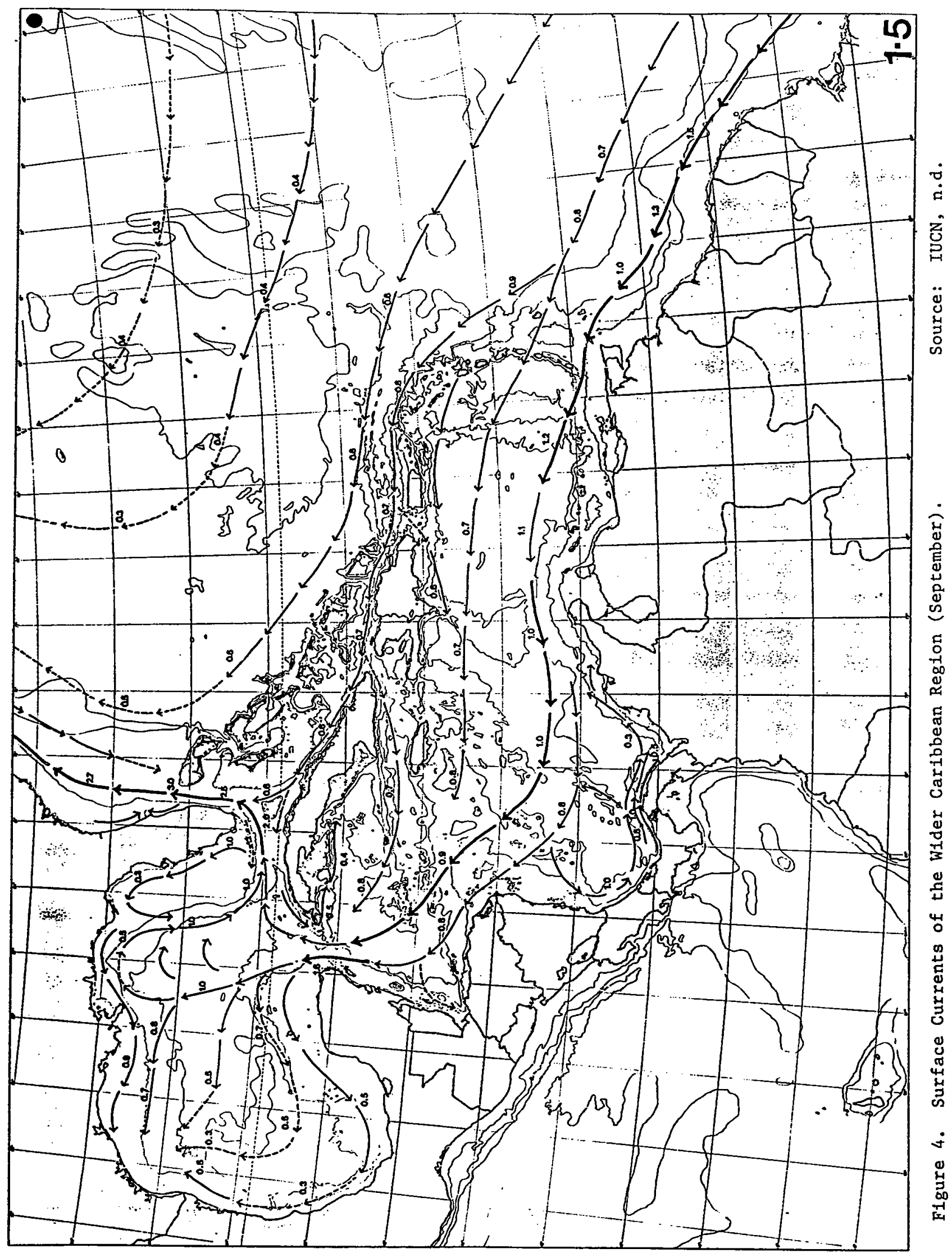




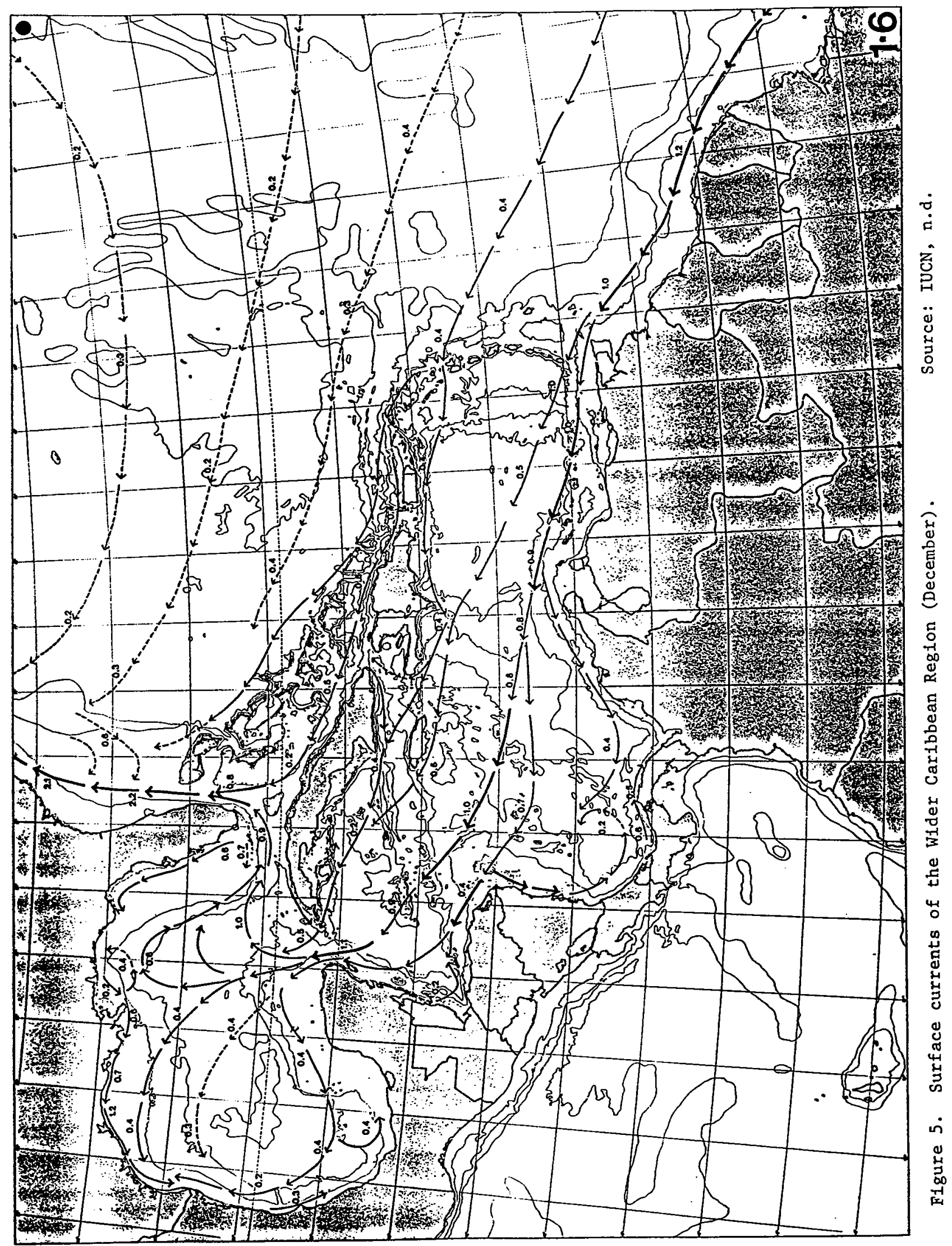


surge-each of which has caused social havoc through devastating loss of crops, housing, civil infrastructure, and human life. The "hurricane season" for this area is June through November, with peak hurricane incidence in August, September, and October. The economic impacts of these storms, and the associated human suffering, have been very severe. The shared natural hazard represented by hurricanes suggests there are regional benefits to be derived from cooperation in hurricane prediction and monitoring, damage relief, and natural hazard standards for industrial siting and construction (especially where use or storage of hazardous materials are involved).

\section{Spatial Scales of Pollution in the Wider Caribbean Region}

In our discussion of regional approaches and opportunities to addressing land-based marine pollution problems, two separate categories of issues are germane:

a) pollution problems of large areal extent, with regional transboundary implications, whose resolution calls for action over a spatial area larger than one or two nations; and

b) pollution problems of limited areal extent, but numerous localized occurrences throughout the region, whose resolution could benefit from shared experience or attention.

In the WCR, by far the most serious damages caused by effluents from land-based sources occur locally, within the territorial sea or exclusive economic zone of the source state. ${ }^{2}$ Most land-based marine pollutants are not transported far from their sources of discharge, and transboundary pollution events, where they occur, appear to be confined to border regions.

Overviews of land-based regional pollution in the Caribbean are given by several recent UNEP papers (see UNEP 1994a and references therein; WWF/ESI 1994 and references therein). The definition of pollution problems in some existing reports is blurred, with a resulting confusion of specific sites, sources, or pathways of pollution. For example, the identification of cholera and infectious hepatitis as important land-based marine pollution problems in the WCR seems to ignore the distinction between contaminated drinking water supplies and contaminated coastal waters, as well as the geographical boundaries of the WCR. References to inadequately treated sewage in some cases are based upon an a priori assumption that secondary wastewater treatment is the sole acceptable option for domestic wastewater disposal in the WCR. Natural processes that link national jurisdictions are sometimes interpreted as

\footnotetext{
${ }^{2}$ For example, in 1992, Jonathan Cannon, the director of the U.S. Gulf of Mexico Program, was quoted as saying: "[ $t$ ]he general judgment, $I$ believe, is that the gulf is not in a crisis state, although there are localized crisis areas" (BNA 1992).
} 
tantamount to a demonstration of transboundary pollution. And naturally occurring phenomena such as red tides, ciguatera poisoning, natural diseases in corals and other marine animals, seagrass die-offs, and certain mass mortalities in the sea (cf., Brongersma-Sanders 1957), are taken as evidence of human impacts. Effectively setting priorities and addressing abatement of existing pollution problems and their prevention in the future requires clear and technically sound definition of the pollution problems or their potential to develop.

Gladfelter and Ogden (1994; see Appendix D) divide pollutants into two categories; a) enrichment of naturally occurring substances, and b) introduction of new contaminants. These authors appropriately include other human-derived stresses, such as over-fishing and mangrove clearing, as sources of pollution. According to the US National Oceanic and Atmospheric Administration (NOAA), the following sources should ultimately be included in a pollutant discharge inventory:

a) Point sources (industry and wastewater treatment facilities)

b) Urban non-point runoff (stormwater runoff and combined overflow discharges)

c) Non-urban non-point sources (agriculture and forest runoff)

d) Upstream sources (pollutants carried to the sea from inland sources)

e) Irrigation return flows (agricultural pollutants carried in irrigation runoff).

To this list should be added pollutants carried in direct groundwater discharge to the sea. According to UNEP (1994a), the major land-based pollutants entering the Caribbean are: sewage, hydrocarbons, sediments, nutrients, pesticides, litter and marine debris, and toxic wastes.

Perhaps the most widespread coastal pollution problem globally is nutrient overenrichment. It is also among the most common marine pollution problems in the Caribbean, where nutrients are added as sewage discharge and runoff of dissolved fertilizer. (Fertilizer use is estimated to have increased $33 \%$ between 1979 and 1989.) Nevertheless, nutrient overenrichment, though widely occurring in the WCR, is believed to be a problem of localized scale at the present time, as is the case in most regions of the globe.

Altered sediment delivery to coastal waters can have negative impacts, if increased, on mangrove, seagrass, and coral habitats; and if decreased, on deltaic wetlands. Clearing of forest lands, mining operations, and ocean disposal of dredged materials are sources of sediments that are known to be increasing at the present time. (See Cortés and Risk 1985 for a discussion of the effects of deforestation on reefs.) Reefs near the Central American coast and areas of the 
eastern Caribbean are believed to be suffering from sediment stress related to agricultural practices and tourism development, but it does not appear that the problem involves transboundary or regional spatial scales. CEPPOL pilot studies initiated in 1992 at four regional laboratories in the region may shed additional light on the impact of various pollutants, including sewage, oil, and particularly sediments, on reefs and other coastal ecosystems (Mandelli, pers. comm., 1995).

Disposal of sewage in coastal waters is a topic of great concern internationally, but also a topic of significant misunderstanding. The two major elements of concern regarding sewage are public health and nutrient overenrichment (in extreme instances, excessive organic loading can be an issue as well). Combining industrial and domestic waste streams can compound the problem by adding chemical toxicity to the above problems, which can frustrate effective wastewater treatment and recycling and add an additional environmental impact. Where tourism and aesthetics are particularly important, sewage disposal can become a charged issue. Moreover, an emphasis in some quarters on deploying standardized or best available technologies has helped promote the idea that low-cost solutions to handling domestic wastes, such as on-site disposal in leaching beds, are ineffective, and that expensive high-technology wastewater treatment plants are always preferable. These perceptions are neither technically correct nor in the public interest. A more balanced and innovative view of wastewater treatment is evident in UNEP (1991b). Salas (1994) points out, appropriately, that standard secondary wastewater treatment facilities do not eliminate nutrients from the effluent stream, often add toxic disinfectants for pathogen control (with undesirable secondary environmental impacts), and leave disposal of solids (sludge) as an unresolved separate problem. Modern wastewater treatment facilities are costly to build, operate, and maintain in monetary terms and in terms of energy and freshwater consumption.

We are not aware of any regional-scale impacts of sewage disposal. Nevertheless, a continuing dialogue on suitable wastewater handling practices and technologies in the WCR is a needed and appropriate element of regional collaboration. A key question is the determination of appropriate water quality standards. For example, certain bacterial standards, such as the fecal coliform water quality indicator, can give a high result that is often falsely attributed to human fecal contamination where it does not exist, rather than to any of a number of other likely sources, such as warm-blooded animals and naturally occurring sediment bacteria.

According to Gladfelter and Ogden (1994), thermal pollution from power plants represents a localized but widely occurring problem in the WCR. ${ }^{3}$

\footnotetext{
${ }^{3}$ Research undertaken for the present study, as reported in Section IV of this report, indicates that thermal pollution is a concern for Barbados, Colombia, the Dominican Republic, the Netherlands Antilles, Puerto Rico, St. Lucia, and the US Virgin Islands.
} 
Oil hydrocarbons represent a pollutant category that one might expect to have regionalscale implications. For example, a 1979 collision of the tank vessels ATLANTIC EMPRESS and AEGEAN CAPTAIN near Trinidad and Tobago spilled an estimated 300,000 tons of oil into the ocean (Famighetti 1995), or approximately eight times the volume of the well-known 1989 EXXON VALDEZ spill in Prince William Sound, Alaska; and oil released in the 1979 Ixtoc wellhead blow-out accident in the Gulf of Mexico was about 16 times the Valdez spill. Neither of these spills has received significant attention in the discussion of pollution or habitat degradation in the WCR, however, including UNEP's (1994a) review of hydrocarbon pollution in the WCR. Of course, the UNEP report focuses on land-based sources of pollution; nonetheless, it does include discussion of natural seeps entering the Caribbean (citing Harvey 1987) at a depth of 150 to $250 \mathrm{~m}$ (amounting to an estimated 1 million tons, or 27 times the Prince William Sound spill).

The distribution of tar and dissolved/dispersed hydrocarbons was the subject of a major six-year study by CARIPOL (Atwood et al. 1987). The study revealed interesting trends in the spatial and time distribution of hydrocarbon residues. Nevertheless, Gladfelter and Ogden (1994) conclude, "While pollution of this sort is unsightly and deadly to some large marine animals, it is not among the highest priority problems affecting the coastal ecosystems: the coral reefs, the mangroves, and the seagrass beds." UNEP (1994a) concludes: ". . . information required to ascertain the ecological and health risks caused by long-term chronic oil discharges into the coastal marine environment of the WCR, is still very limited. . . ."

\section{E. Subregional Scales of Pollution and the CEPPOL Pollutant Load Inventories}

UNEP's 1994 Regional Overview of Land-Based Sources of Pollution in the Wider Caribbean Region (UNEP 1994a) summarizes the results to date of national inventories of landbased marine pollution in the WCR as reported by the Program for Marine Pollution Assessment and Control (CEPPOL), which is administered jointly by UNEP and the Intergovernmental Oceanographic Commission (IOC). For purposes of assessing the geographical distribution of the pollution load and analyzing the results, the CEPPOL program divided the WCR into six geographic subregions (see Figure 6). Within this arrangement, three political units are designated as falling into more than one geographical subregion: Mexico spans Subregions I and II (Gulf of Mexico and Western Caribbean); Cuba spans Subregions I and III (Gulf of Mexico and Northeastern-Central Caribbean); and the Netherlands Antilles spans Subregions IV and V, with the islands of St. Maarten, St. Eustasius, and Saba assigned to the Eastern Caribbean subregion (IV) and the islands of Bonaire and Curacao to the Southern Caribbean (V). ${ }^{4}$

\footnotetext{
${ }^{4}$ Although not listed in Figure 6, Aruba, a member of the Netherlands Antilles Federation until 1986, is included by CEPPOL as a separate political unit within Subregion V.
} 


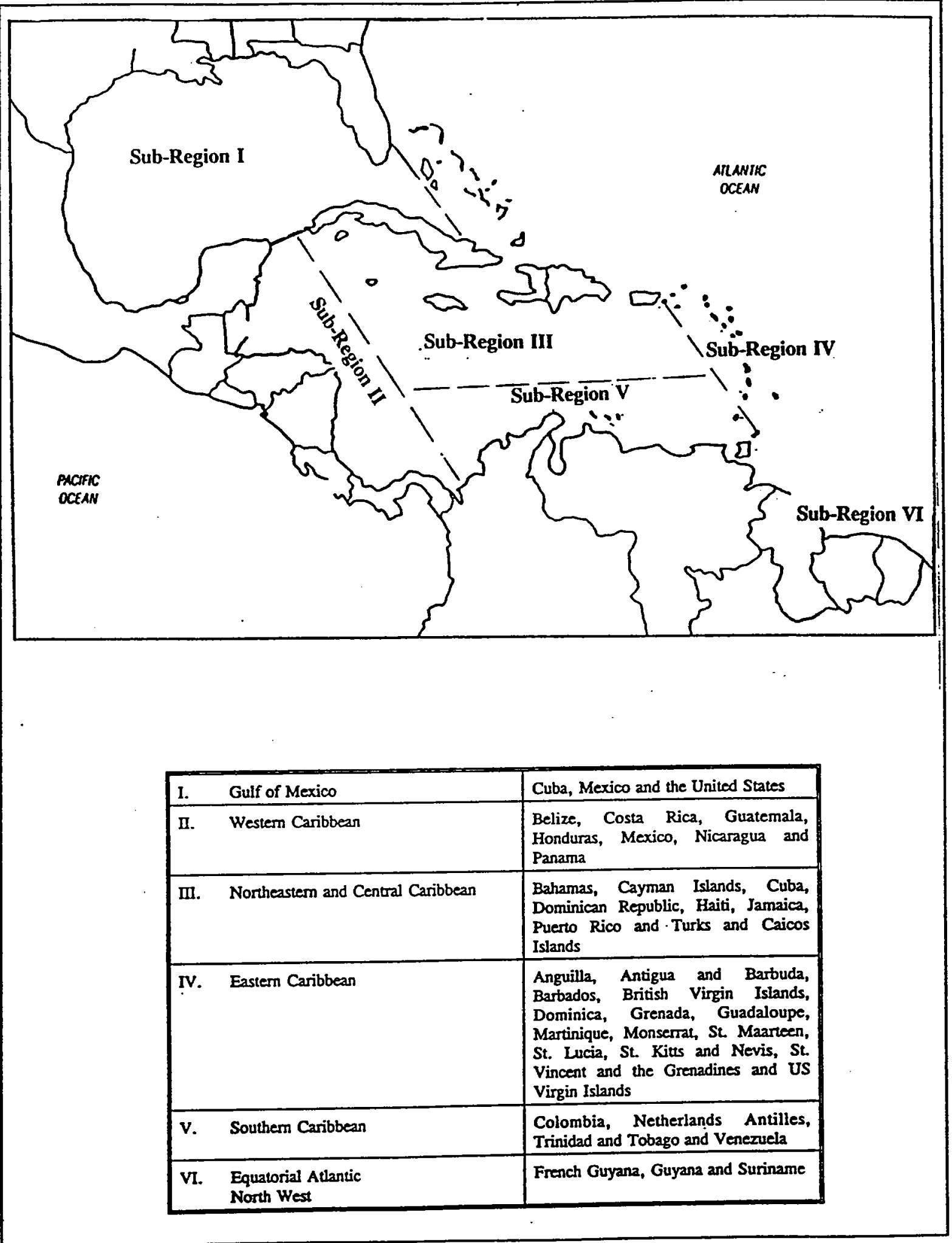

Figure 6. CEPPOL-designated subregions (Source: UNEP 1994) 
As of 1994, the CEPPOL program had compiled data on biological oxygen demand (BOD), total suspended solids (TSS), total nitrogen (TN), total phosphorus (TP), and oil and grease inputs from domestic and industrial point sources in 24 WCR countries, and from point and non-point sources combined in the U.S. Gulf Coast region. Additional information, such as the presence or absence of phenols and various heavy metals, was also recorded though not quantified. The results, as summarized in the 1994 UNEP Regional Overview, are displayed in Tables 3 and 4.

In considering the results, some important limitations of the data should be taken into account, especially: the non-comparability of data for the U.S. Gulf Coast; the absence of certain countries and of an entire subregion from the inventory; and the lack of information as to the basis for normalizing the data. ${ }^{5}$

Attempts by this study to ascertain the point-source share of U.S. Gulf Coast pollutant loads have been unsuccessful, but it is useful to bear in mind that non-point sources have been estimated to contribute between 70 percent and 90 percent of the nutrient loads (i.e., nitrogen and phosphorus) entering the Gulf of Mexico from U.S. land-based sources (Broadus and Vartanov 1994), with industrial-scale agriculture being by far the largest of the non-point source contributors. For certain other countries in the WCR, the proportion of all land-based nutrients from non-point sources can be expected to be substantially greater than in the United States, because of such factors as the generally lower availability of domestic septic and municipal sewage treatment facilities and, in some countries, the more intensive use of fertilizers. Similar factors hold true for non-nutrient pollutants from non-point sources, particularly pesticides, the use of which has been dramatically curtailed in the United States in recent years but remains intensive in Venezuela, Mexico, and the Central American countries (Henao et al. 1993; UNEP 1994a).

The subregion completely missing from the inventory is Subregion VI (the Equatorial Atlantic North West), which includes French Guiana, Guyana, and Suriname. To the extent that transboundary pollution effects do exist, it is unfortunate indeed not to have any data on pollution sources within the subregion that is the furthest upstream of the six subregions in the WCR. Also missing from the inventory are data for Guatemala and Nicaragua (Subregion II); the Bahamas, the Cayman Islands, and Haiti (Subregion III); and Anguilla, Martinique, Guadeloupe, and Montserrat (Subregion IV). ${ }^{6}$ As demonstrated in Section IV of this report,

\footnotetext{
${ }^{5}$ In assessing the value of the Regional Overview (UNEP 1994a), Gladfelter and Ogden (1994) note that the information in the report is of limited value for assessing "pollutant load per year per (a) cubic meter of seawater, (b) acre of benthic community impacted, (c) unit of coastline, (d) unit of human population, etc."

${ }^{6}$ According to Enrique Mandelli (pers. comm., 1995), who participated in the analysis of the CEPPOL data, financial assistance and guidelines for preparation of pollutant inventories were provided by CEPPOL to several of the missing states (i.e., Guyana, Suriname, Guadeloupe, Martinique, and the Cayman Islands).
} 
Table 3

CEPPOL Results: Waste Loads from Domestic Sources

in the Wider Caribbean Region by Subregion ( $t / y)$

\begin{tabular}{|c|c|c|c|c|c|}
\hline Country/Sub-Region & BOD & TSS & $\mathbf{n N}$ & $\mathbf{T P}$ & $\begin{array}{c}\text { Oil and } \\
\text { Grease }\end{array}$ \\
\hline $\begin{array}{l}\text { Sub-Region I } \\
\text { Cuba(NE Coast) } \\
\text { Mexico(Gulf Coast) } \\
\text { USA(Gulf Coast) } \\
\text { Sub-Total }\end{array}$ & $\begin{array}{r}53,734 \\
24,529 \\
37,393 \\
\\
115,656 \\
\end{array}$ & $\begin{array}{r}50,811 \\
20,964 \\
44,552 \\
\\
116,327 \\
\end{array}$ & $\begin{array}{r}4,198 \\
4,184 \\
25,688 \\
\\
34,070 \\
\end{array}$ & $\begin{array}{r}5,915 \\
1,810 \\
11,416 \\
19,141 \\
\end{array}$ & $\begin{array}{r}5,985 \\
8,379 \\
27,006 \\
\\
41,370 \\
\end{array}$ \\
\hline $\begin{array}{l}\text { Sub-Règion II } \\
\text { Belize } \\
\text { Costa Rica } \\
\text { Honduras } \\
\text { Mexico(Car. Coast) } \\
\text { Panama } \\
\text { Sub-Total }\end{array}$ & $\begin{array}{r}1,905 \\
530 \\
9,626 \\
3,756 \\
969 \\
\\
16,785\end{array}$ & $\begin{array}{r}2,100 \\
1,079 \\
8,235 \\
3,232 \\
1,781 \\
16,427\end{array}$ & $\begin{array}{r}650 \\
210 \\
625 \\
607 \\
327 \\
2,419\end{array}$ & $\begin{array}{r}320 \\
25 \\
823 \\
261 \\
38 \\
1,467 \\
\end{array}$ & $\begin{array}{r}240 \\
20 \\
450 \\
1,256 \\
35 \\
\\
2,001\end{array}$ \\
\hline $\begin{array}{l}\text { Sub-Region II } \\
\text { Cuba (Car. Coast) } \\
\text { Dom. Republic } \\
\text { Jamaica } \\
\text { Puerto Rico } \\
\text { Turks \& Caicos Is. } \\
\text { Sub-Total } \\
\end{array}$ & $\begin{array}{r}9,413 \\
40,573 \\
4,227 \\
16,819 \\
47 \\
\\
71,079 \\
\end{array}$ & $\begin{array}{r}3,481 \\
60,000 \\
6,658 \\
20,000 \\
75 \\
\\
90,214 \\
\end{array}$ & $\begin{array}{r}572 \\
3,027 \\
1,097 \\
530 \\
13 \\
5,239 \\
\end{array}$ & $\begin{array}{r}296 \\
4,182 \\
133 \\
890 \\
2 \\
- \\
5,503\end{array}$ & $\begin{array}{r}112 \\
5,125 \\
350 \\
500 \\
2 \\
6,089\end{array}$ \\
\hline $\begin{array}{l}\text { Sub-Region IV } \\
\text { Antigua \& Barbuda } \\
\text { Barbados } \\
\text { Brit. Virgin Is. Dominica } \\
\text { Grenada } \\
\text { St. Lucia } \\
\text { St. Kitts \& Nevis } \\
\text { St. Vin. \& Gren. } \\
\text { US Virgin Islands } \\
\text { Sub-Total }\end{array}$ & $\begin{array}{r}29 \\
3,838 \\
85 \\
51 \\
86 \\
25 \\
250 \\
26 \\
400 \\
4,790 \\
\end{array}$ & $\begin{array}{r}45 \\
3,300 \\
145 \\
81 \\
136 \\
40 \\
390 \\
40 \\
440 \\
4,617 \\
\end{array}$ & $\begin{array}{r}7 \\
290 \\
26 \\
13 \\
22 \\
29 \\
66 \\
7 \\
250 \\
710 \\
\end{array}$ & $\begin{array}{r}1 \\
378 \\
3 \\
2 \\
3 \\
2 \\
9 \\
1 \\
132 \\
531\end{array}$ & $\begin{array}{r}1 \\
290 \\
2 \\
2 \\
2 \\
1 \\
5 \\
1 \\
200 \\
504 \\
\end{array}$ \\
\hline $\begin{array}{l}\text { Sub-Region V } \\
\text { Aruba } \\
\text { Colombia } \\
\text { Netherlands Ant. } \\
\text { Trinidad \& Tobago } \\
\text { Venezuela } \\
\text { Sub-Total }\end{array}$ & $\begin{array}{r}61 \\
26,300 \\
85 \\
1,000 \\
232,725 \\
260,171\end{array}$ & $\begin{array}{r}52 \\
42,120 \\
5 \\
1,567 \\
185,000 \\
\\
228,744\end{array}$ & $\begin{array}{r}20 \\
7,118 \\
40 \\
1,585 \\
77,575 \\
\\
86,338 \\
\end{array}$ & $\begin{array}{r}4 \\
986 \\
1 \\
59 \\
32,425 \\
33,475\end{array}$ & $\begin{array}{r}1 \\
620 \\
1 \\
28 \\
18,325 \\
18,975\end{array}$ \\
\hline GRAND TOTAL & 506,482 & 456,329 & 128,796 & 60,117 & 68,939 \\
\hline
\end{tabular}

Source: UNEP 1994a 


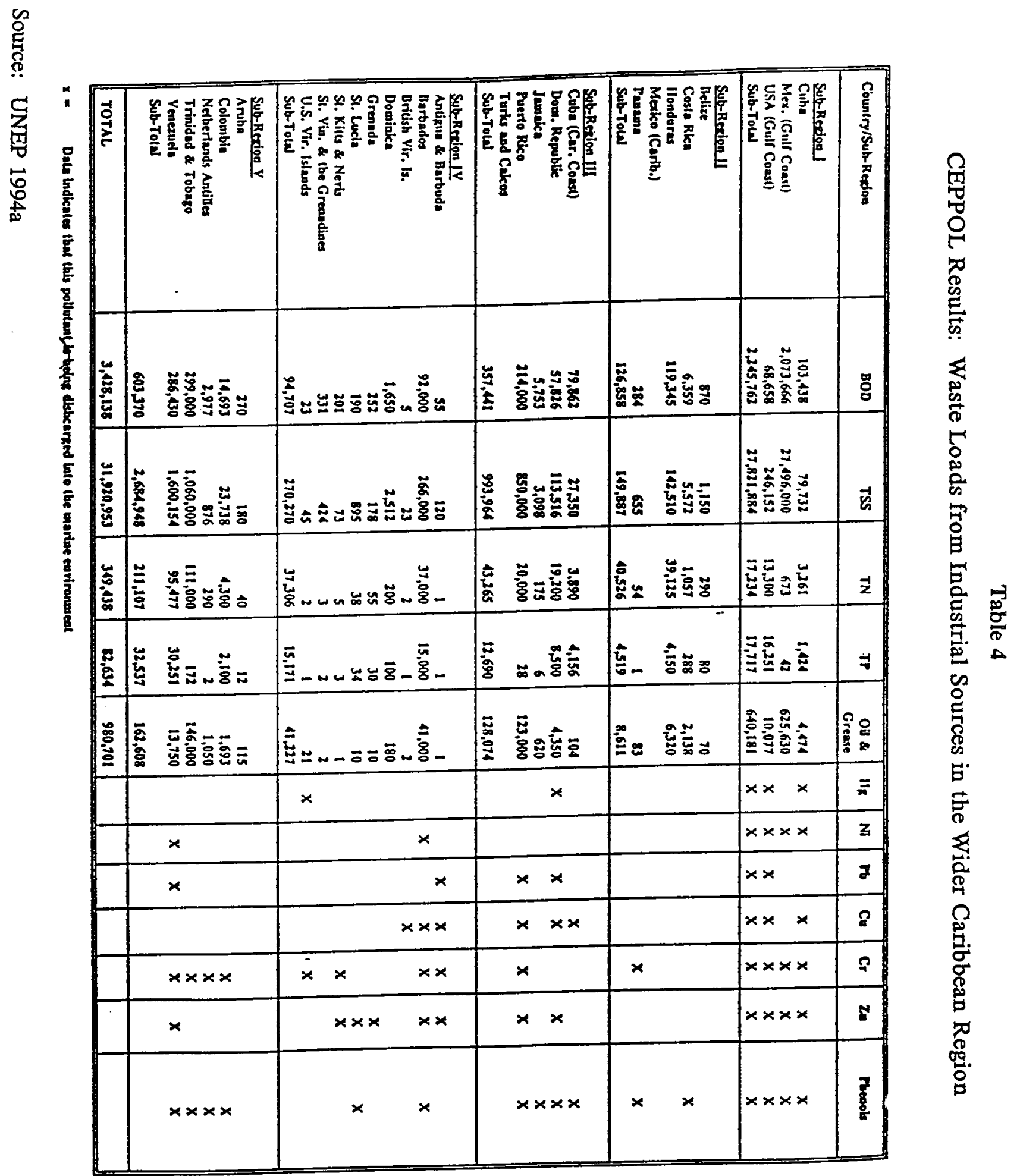


individual country omissions have varying degrees of influence on the picture that emerges from the CEPPOL data on point-source pollutant loads. For example, the lack of data for Guatemala and Nicaragua probably has little effect on the point-source results for Subregion II (or overall), because the population centers and major economic activities of both countries are oriented toward the Pacific coast and largely outside the Caribbean drainage basin (see Appendix B), and because both countries provide quite low access to sewage treatment services in rural areas. Within Subregion III, inclusion of the Bahamas, Cayman Islands, and Haiti all would likely have had some effect on the observed distribution of domestic pollutants, though least so in the case of Haiti, where sewage treatment services are available to a very low percentage of the population. In addition, Haiti would likely have had observed industrial pollutants, although probably at a lower level than Jamaica's. For Subregion IV, the omission of Guadeloupe is likely to have affected the industrial pollutant results, since both Guadeloupe and Barbados process sugar, rum, and other sugar byproducts in amounts that can be inferred from GDP data to be roughly twice as large for Barbados as for Guadeloupe. In the case of Anguilla, Martinique, and Montserrat, it appears unlikely, from what little data are available, that their inclusion would have substantially altered the picture. The same can be said about all three Subregion VI states with respect to industrial pollutants, but it is possible that domestic pollutant results for Subregion VI might have approached those for Subregion II.

Figure 7 depicts the relative contributions of domestic and industrial pollutants by the five subregions for which CEPPOL data were reported. It is readily apparent that substantially more than half the total pollutant load included in the inventory is generated in Subregions I and V. Figure 8, which displays the subregional contributions of individual pollutants, indicates that Subregion I contributes less nutrient loading (TN and TP) from domestic sources than Subregion $\mathrm{V}$, and no more from industrial sources than any of the other subregions, notwithstanding the fact that the Subregion I data include both point and non-point source pollutants for the U.S. Gulf Coast.

The relative contributions of individual states are depicted in Figure 9. Among the more striking results are the indications that Puerto Rico and Barbados each contributes more pollutant loading from industrial point sources than the United States, and that Mexico contributes more than ten times the industrial pollutant loading of any other state in the CEPPOL inventory (accounting for 82 percent of the entire WCR industrial pollutant load). As for domestic point sources, it is noteworthy that Cuba and the Dominican Republic is each responsible for a greater pollutant load than Mexico, and that Venezuela contributes far more in domestic pollutants than Colombia.

To a large extent, some of the more anomalous results of the CEPPOL inventory are explained by its limitation to point sources of pollution. As noted in UNEP's 1994 Regional Overview, for example, this limitation has the effect of reporting the greatest domestic pollution loads for those states that provide sewage treatment services to the greatest number of people, 
Combined Domestic Waste Loads

(tons/year)

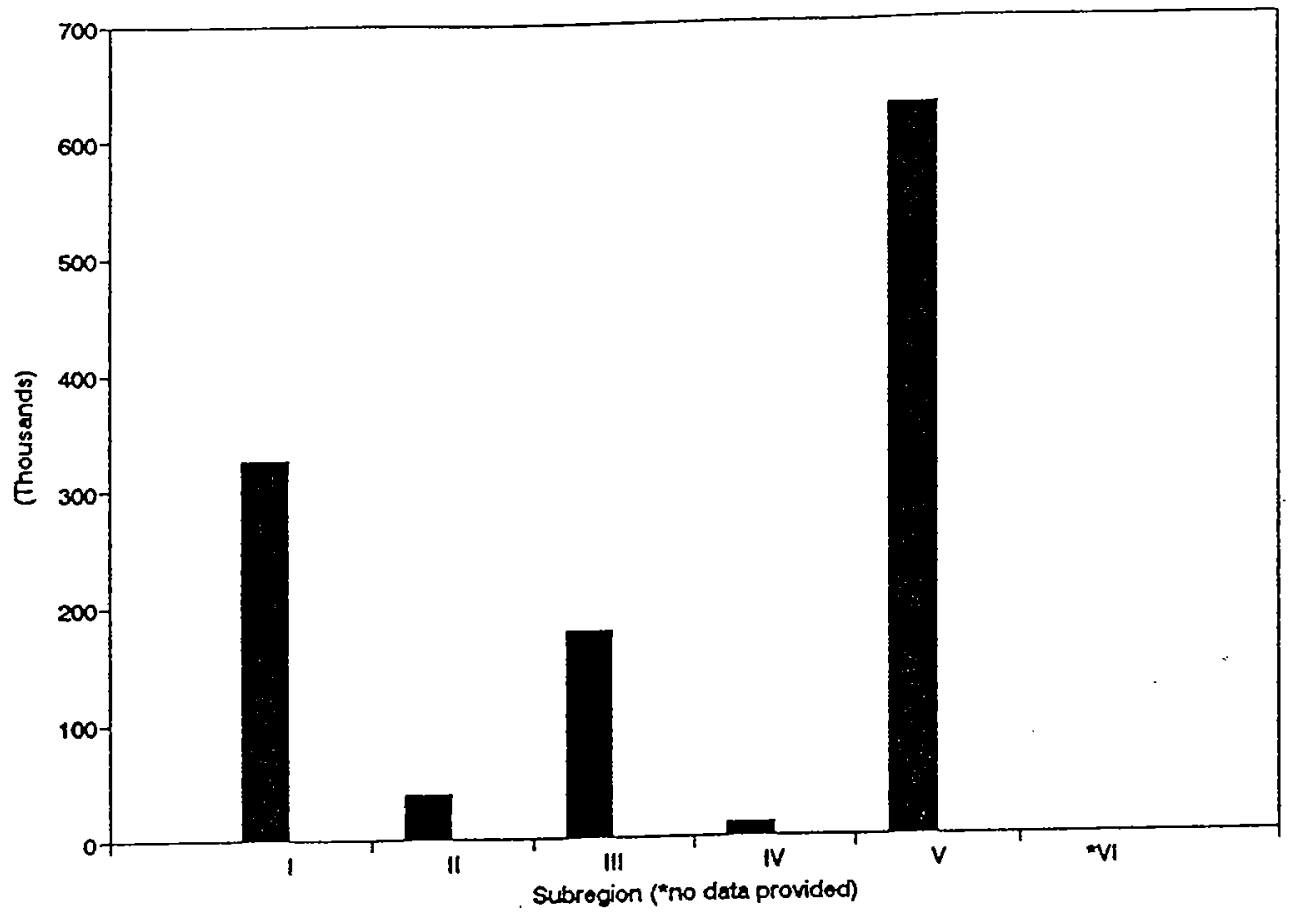

Combined Industrial Waste Loads

(tons/year)

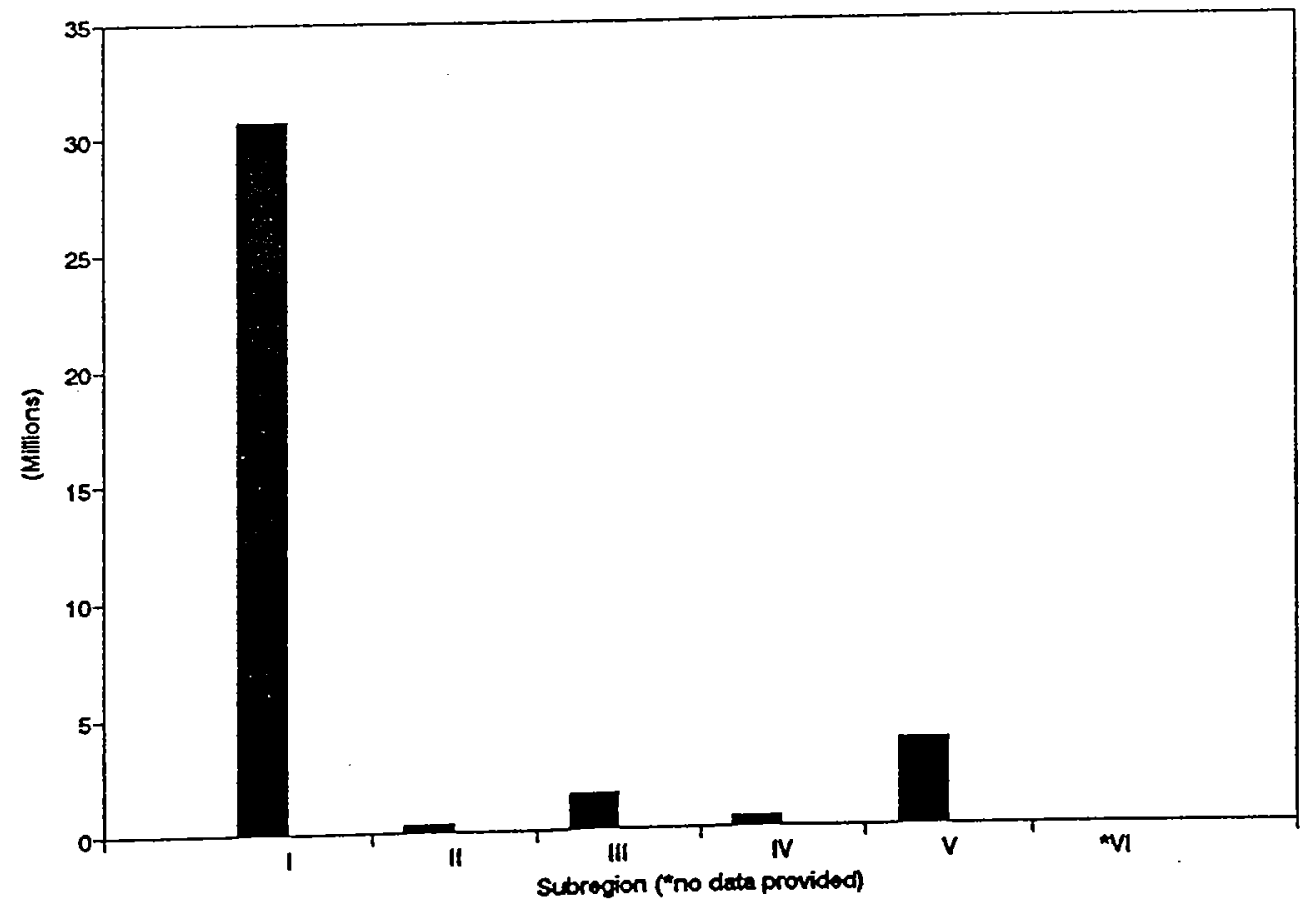

Figure 7. Relative Contributions of Combined Pollutants from Domestic and Industrial Sources by five WCR Subregions (Source: UNEP 1994a) 

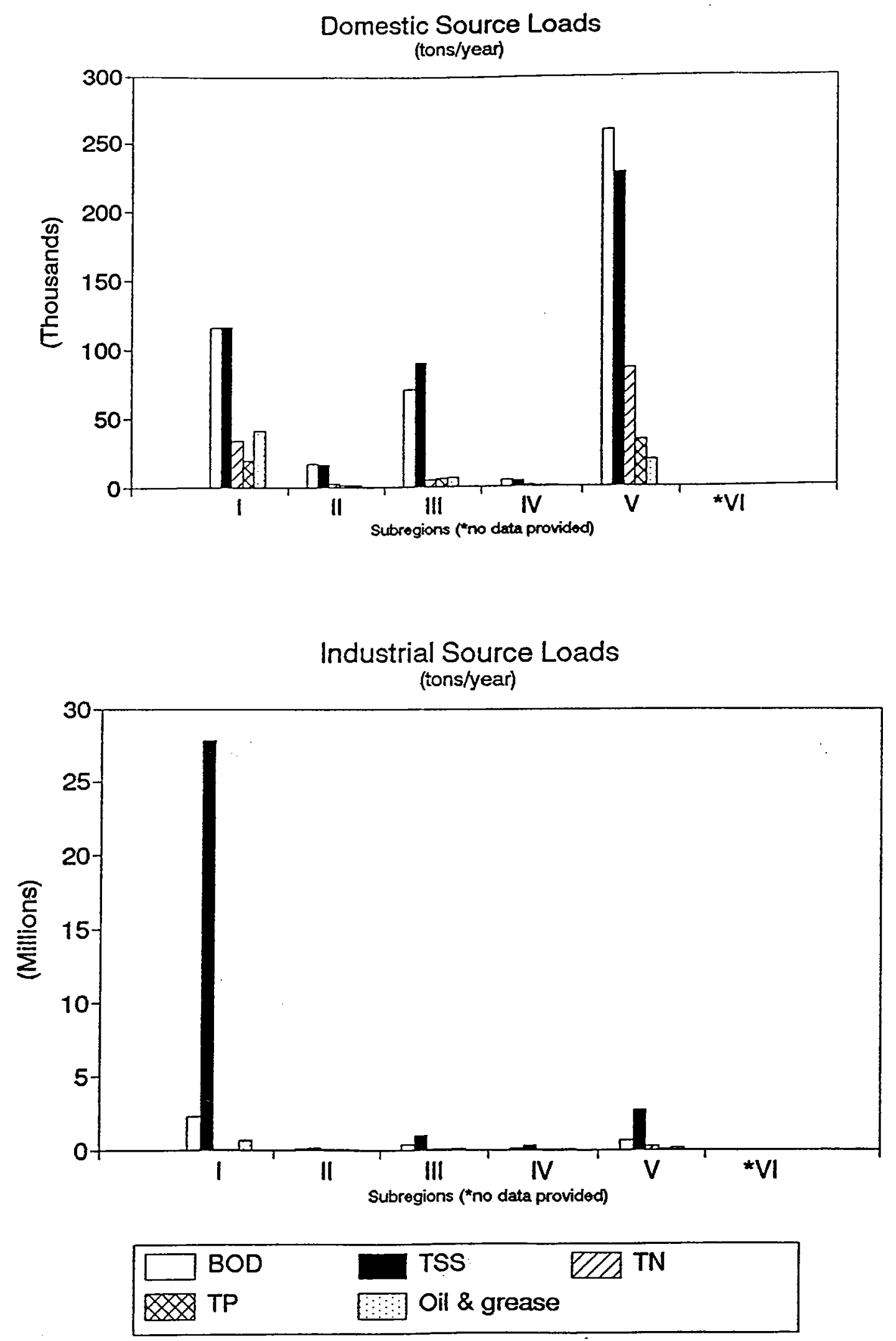

Figure 8. Relative Contributions of Individual Pollutants from Domestic and Industrial Sources by five WCR Subregions (Source: UNEP 1994a) 


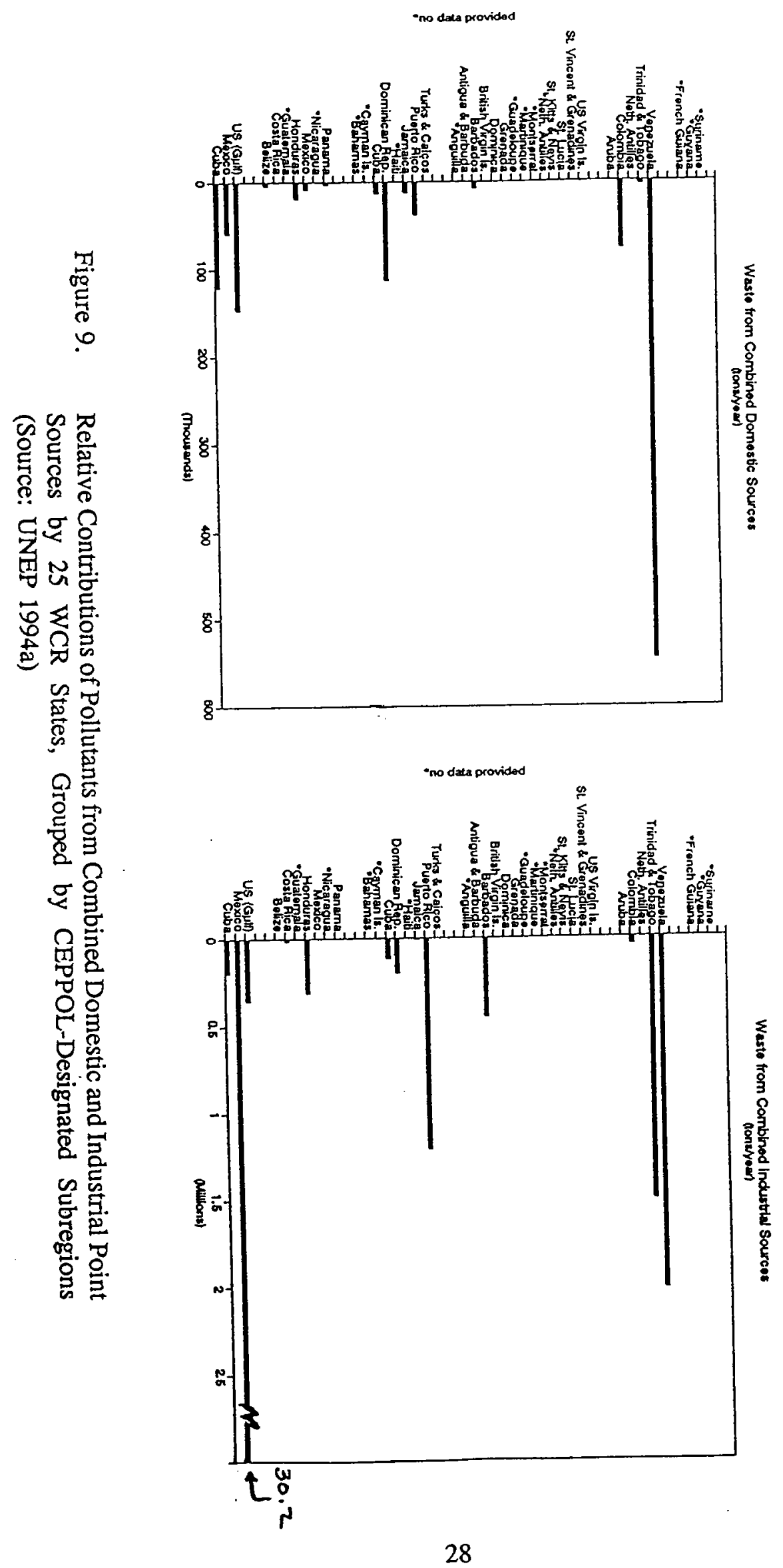


while failing to capture the extent to which a population's domestic waste goes completely unmanaged or inadequately treated. It also does not address (except for the United States, for which non-point source loads were included) pollution from such significant WCR non-point sources as agriculture, forestry, marinas, construction, urban runoff, and automotive emissions.

\section{F. Summary}

All nation-states of the Wider Caribbean Region use the marine environment as a sink for the discharge of pollutants from land-based sources. By far the most serious damages caused by effluents from land-based sources occur locally, within the territorial sea or exclusive economic zone of the source state. Most land-based marine pollutants are not transported far from their sources of discharge, and transboundary pollution events, where they occur, appear to be confined to border regions.

As the WCR is an open system that exchanges massive amounts of water on a continuous basis, it is understandable that there is no clear evidence that discharges from WCR states contribute to a generalized "pollution" of the Caribbean Sea and its associated gulfs. Discharges from the major river systems move considerable distances within and across subregions, and sediment loads and litter are transported long distances across the region. Our state of knowledge regarding the transport of other pollutants is too limited, however, to suggest what movements occur beyond the local and subregional scales.

The systematic collection and analysis of data on the extent and distribution of localized pollutants has only recently gotten under way. As of 1994, the CEPPOL program had prepared inventories and begun an analysis of the distribution of selected land-based marine pollutants generated by domestic and industrial point sources in 24 WCR states, and by domestic and industrial point and non-point sources combined in the United States Gulf Coast region. Because all but one of these CEPPOL inventories are limited to point-source pollutant loads, the results so far cannot be used to assess the extent and distribution of pollutants generated by some of the most significant non-point source activities in the region, including agriculture, forestry, and coastal development projects.

In the absence of systematically collected data on non-point pollutant loads for most of the WCR countries and territories, a more complete picture of an individual state or subregion's relative contribution and exposure to LBMP must be inferred from other indicators. The combination of indicators considered in Section IV is useful as well for assessing the inclination and ability of states to undertake independent or joint action to control LBMP problems. 


\section{Arguments for Collective Action in the WCR}

\section{A. The Importance of Scale}

The published literature and written records of WCR discussions focuses on the establishment and implementation of a regionwide approach to the prevention, reduction, or control of LBMP. In this section, we examine several issues and arguments that are being debated as bases for pursuing a "regionwide" approach to LBMP control in the WCR. These issues and arguments include: common-pool pollution effects; common problems; scale economies; and the need for uniform standards (water quality or pollution control standards).

Some of our discussion is critical of several broad arguments that have been made in favor of an LBMP protocol for the Caribbean. The intent of this criticism is constructive; whether or not an international agreement has the potential to be effective depends upon a careful assessment of the arguments made in favor of collective action. Our analysis cannot be used in place of the international negotiations that must occur to work out the details of a protocol. But we hope to give the negotiators an understanding of the different sides of the issues involved.

All of these issues are indeed relevant and valid at some scale in the Caribbean. However, the extent to which they are applicable regionwide is not at all clear. To a significant extent, protocol effectiveness will depend upon whether or not the Contracting Parties can correctly characterize the scale of LBM pollution problems and tailor appropriate solutions.' These activities are among the most important ones to be addressed by a protocol and implemented through its institutions.

The occurrence of transboundary movements of pollution (or of natural resources affected by pollution) is among the most powerful rationales for an international protocol on pollution reduction. Increasingly, the existence of common, but nontransboundary, pollution problems within the jurisdiction of many states is being advocated as a justification for an international protocol. An understanding of common socio-economic characteristics, as we describe in Sections IV and V, can be useful in identifying potential benefits from agreements and relationships to control pollution. We discuss the potential for these kinds of "gains from trade" in the Caribbean in Section V.

\footnotetext{
' Implicit in this statement is the point that regionwide approaches to LBM pollution problems may be ineffective if the problems themselves are not regionwide.
} 


\section{B. Pollution Costs and Benefits}

As we consider the arguments commonly advanced for collective action with respect to LBMP in the WCR, we should maintain a balanced perspective on the types of benefits and costs involved in pollution control.

Land-based waste discharges should be described as "pollution" only to the extent that other human activities or valued characteristics of the marine environment are affected adversely by the effluents. ${ }^{2}$ Discharges can affect such uses of the WCR coastal and marine environments as coastal tourism and recreation, nursery grounds for fish and wildlife, commercial and recreational fisheries, and biological diversity. Scientists have begun to document the potential, and in some cases actual, impacts of land-based effluents in the WCR (Gladfelter and Ogden 1994; UNEP 1994a and references therein). The social costs of these impacts have not been documented to date, ${ }^{3}$ but they are likely to vary considerably by state and geographic location.

WCR states face a great variety of economic development problems, including issues associated with effluents from human activities. The introduction of nutrients, pesticides, sewage, and industrial effluents into local marine environments is a direct consequence of expanding populations and the siting of industrial facilities in coastal zones or major watersheds. It is very important to recognize that Caribbean coastal and marine environments provide substantial economic benefits as sinks for agricultural runoff, sewage, and industrial effluents. Any measures taken to reduce or control discharges from land-based sources are likely to be costly, but solutions to some of the most significant problems can be achieved with minimal financial investments, e.g., properly sited outfalls. Evaluation of these benefits and costs, and considerations of their distribution among the citizens of a state or across states, are relevant to the problems of LBMP control.

\section{Common-Pool Effects}

Consider a situation in which a set of states share a common-pool resource, such as a regional marine environment. Marine pollutants originating in one or more of the states of the

\footnotetext{
${ }^{2}$ This definition is the anthropocentric one currently accepted and embodied in international environmental law (Hunter, Sommer, and Vaughan 1994). Note that the definition of "pollution" found in Article 1(4) of UNCLOS III appears more broad, in that it also encompasses "harm to living resources and marine life." Kimball (1995) explains that the definition of pollution is being broadened in three ways: the precautionary principle has begun to be adopted as a nonbinding norm; harm to "living resources" now often includes harm to "marine ecosystems"; and coastal zones and related waters are beginning to be considered a part of the marine environment.

${ }^{3}$ Estimates of the benefits of natural marine environments in the Caribbean, such as coral reefs or marshes, are only just emerging. See Pendleton (1994); Spurgeon (1992); van't Hof (1985); or Lynne, Conroy, and Prochaska (1981).
} 
region flow across national boundaries. ${ }^{4}$ Adverse impacts of pollution may occur in all states. Because each of these states could benefit, at no cost, from expensive pollution control undertaken by any other state in the region, incentives for unilateral pollution control are diminished. If this kind of "free-riding" can be curtailed through regional collective action, then it may be possible for pollution emissions to be reduced to a greater extent. Most regional LBMP protocols are in the nature of contracts through which the states of a region attempt to obligate themselves to reduce the tendency to free-ride in the reduction and control of pollution. In fact, mechanisms designed to control or reduce free-riding behavior can be the most important elements of such protocols.

In some regional seas, such as the Baltic, the rationale for an international protocol on land-based sources of marine pollution appears clear (Broadus et al. 1993). There are many sources of potential pollutants and many states affected by transboundary pollutant flows. Furthermore, substantial uncertainty exists about the precise source of any particular pollutant, making it costly to assign liability for pollution impacts. This statement is especially true for historical contributions to stocks of persistent pollutants. Multilateral pollution reduction is needed to reduce impacts felt by all states in the region.

In the WCR, sources and effects are localized, and therefore the need for an international agreement on multilateral pollution reduction is not as clear as in the case of the Baltic. A fundamental question for the WCR is why, within the context of a regional protocol, should a state assume a serious obligation ${ }^{5}$ to other states to clean up discharges of pollution that originate and remain within its own borders. ${ }^{6}$ This is precisely the issue faced by the Mediterranean states in their attempts to regulate LBMP in that region.

Unless voluntarily relinquished, each WCR state has the right to determine its own path of economic development, subject to customary international law (HLR 1991). Any particular state's choice of development path could involve discharges into its local coastal or marine environments. Each state has the right to perform its own evaluation of benefits and costs associated with the release of effluents. Absent transboundary effects and subject to relevant

\footnotetext{
${ }^{4}$ Analogously, natural resource stocks might cross national boundaries. If these stocks are harmed by pollution in one nation's waters, then adverse economic effects may be felt by another nation.

${ }^{5}$ Clearly there is a legal obligation on the part of state-parties to the Cartagena Convention to prevent, reduce and control pollution from land-based sources. Whether states take this obligation seriously depends upon their definition of "appropriate measures" and, if defined, whether such measures are implemented. Protocol "effectiveness" depends critically upon the extent to which states take their obligations seriously.

${ }^{6}$ Charney (1994) explains that UNCLOS III "effectively addresses" the issues related to reconciliation between a nation's obligation to protect and preserve the marine environment and its sovereign right to exploit its natural resources. Yet it would appear that the language of Article 193 and other language in the Convention relating to the use of "best practicable means" to prevent, reduce or control pollution is broad enough to accommodate relaxed interpretations in specific contexts.
} 
international law, it is unclear that other states or the international community in concert have the right to impose environmental standards on any particular state and thereby affect its choice of development path.

According to principles of international law and custom, each state also has the right to voluntarily relinquish its right to economic self-determination. Each WCR state has the right to enter into trades, agreements, or other types of relations with other states in the region, including agreements to adopt policies for pollution control, such as the Cartagena Convention or UNCLOS III. Two-thirds of the WCR states are Contracting Parties to the Cartagena Convention, which calls for the development of a protocol on land-based sources of marine pollution. Article 7 of the Convention provides a good example of the voluntary relinquishment, to an unspecified extent, of each state's right to economic self-determination. As agreed, parties to the Cartagena Convention "shall take all appropriate measures to prevent, reduce and control pollution" from land-based sources (emphasis added). The use of the term "shall" denotes an obligation on the part of each state-party. A difficult debate has now been initiated on what measures might be considered "appropriate" (Wood-Thomas, pers. comm., 1995). ${ }^{7}$

Evolving international law of the marine environment, such as that embodied in UNCLOS III, has enlarged its focus to include pollution impacts both across state boundaries and within a state's exclusive economic zone and territory, including estuaries (see Charney 1994). Historically, however, perceptions of the need for international control of marine pollution at the domestic level have arisen mainly from concerns about the potential for international impacts of insufficient domestic controls. Meng (1987) concludes, therefore, that it "seems inevitable that the notion of transfrontier pollution will remain one of the bases for the development of international law on marine pollution control, simply because to respect and protect state sovereignty has always been a fundamental object of international law." We suggest that the existence of transboundary pollutant flows is one of the strongest reasons for an international LBMP protocol. ${ }^{8}$

The adverse effects of transboundary marine pollution often are uncertain or not immediate. States may wish to avert the risks of any negative impacts of transboundary marine

\footnotetext{
${ }^{7}$ The extent to which a LBMP protocol will be considered effective, ex post, will depend upon the clarity of the definition of "appropriate measures" in this context.

8 To suggest that an international protocol must be negotiated and implemented to control pollution only at the domestic level would appear, at best, to invite ineffectiveness. Can one reasonably expect that states unaffected by another state's domestic pollution will bear the burden of enforcement against the polluting state? Charney (pers. comm. 1985) argues that "third" states can protect a "commons," such as the marine environment, even if no state is directly injured. However, a significant obstacle is the cost of bringing the action.
} 
pollution on their own marine and coastal environments and resources. ${ }^{9}$ In the presence of such risks, it can be sensible for states to be conservative with respect to marine pollution problems. Risk-aversion with regard to the expected impacts of transboundary pollution provides a rationale for collective action similar to that in the presence of actual impacts. However, in the absence 'of demonstrated impacts, the implementation of pollution reduction measures is likely to be more problematic.

In the WCR, adjacent or neighboring states can perceive more clearly the benefits and costs of marine pollution and pollution controls than can states that are separated by great distances. LBMP problems can be observed more easily, benefits from pollution control are more likely to be realized, and monitoring and enforcement costs may be much smaller in a subregional, especially bilateral, context. A central role of an LBMP protocol in the Caribbean should be to encourage states to agree to pollution reduction at bilateral or subregional levels, delineated on the basis of transboundary effects, where they are known to occur, or common environmental problems. We discuss this role in greater detail in Section $\mathrm{V}$.

Several international heritage sites and transboundary fishery resources exist in the Caribbean (Elder and Pernetta 1991). States may have a legal obligation to reduce or to eliminate activities that have an adverse effect on internationally protected sites or species. With respect to the arguments discussed above, these resources and protected areas are analytically identical to the problem of a common-pool resource. For stationary resources, such as marine protected areas, the same arguments we have made already concerning the advantages of subregional approaches can be reiterated. For fugitive resources, such as some species of marine fisheries, similar arguments can likewise be made, although the geographic distribution of cause and effect may differ from the distribution of marine pollution.

\section{Common Environmental Problems}

In the WCR, transboundary pollution problems tend to occur across shared watercourses, in shared estuaries, or across nearshore marine boundaries. Other serious LBMP problems exist, but these tend to be localized, affecting uses or harming resources of the state from which the pollution originates (Section II). Thus one of the strongest reasons for negotiating an international agreement to control LBMP, namely the occurrence of international pollution effects, appears not as strong in the Caribbean as in other regional seas, such as the Baltic or the North Sea.

Because of localized intrastate pollution in the WCR, many observers have recommended

\footnotetext{
${ }^{9}$ Aversion to risks does not necessarily imply avoidance of risks at all costs. In other words, we do not recommend adoption of the extreme version of the "precautionary principle" (see Broadus 1992).
} 
that an LBMP protocol should focus on approaches to the resolution of local, not transboundary, pollution problems. An important issue to raise in this context is whether or not an international agreement is needed to resolve local pollution problems. An alternative course of action would be for each state to make its own decisions and take its own actions with respect to LBMP problems that are clearly not international in effect. These independent decisions and actions might involve seeking or trading for financial or technical assistance from other states, within the region or elsewhere.

What are the kinds of barriers that exist to prevent Caribbean states from acting on their own to resolve localized LBMP problems? Several barriers have been identified, including insufficient financial or physical resources to control LBMP, inadequate institutions, such as laws and policies, and even ignorance or lack of recognition of LBMP as an environmental problem.

In cases in which pollution control resources are insufficient, analysts have suggested that an international protocol may provide a partial solution. For example, Kimball (pers. comm., 1995) has pointed out that ". . a well-functioning agreement may attract international assistance from multilateral and bilateral donor agencies. Thus, the agreement leverages international assistance for domestic problems, creating incentives for the polluter state to join." We expect that states may be able to attract international assistance, even in the absence of an international agreement. However, the conclusion of such an agreement may enhance the significance of LBMP as an international problem relative to other social problems. If this is true, it is possible that financial resources that might have been directed to resolve other problems are more likely to be directed toward LBMP.

Others have suggested that the conclusion of an LBMP protocol resolves a "fairness" problem in which international assistance is directed only toward an elite subset of states, or perhaps to specific groups of states in defined "subregions," on the basis of their perceived capabilities. For example, Wood-Thomas (pers. comm., 1995) states that "[i]f we work exclusively at the subregional level, several sub-regional groups may not be able to take meaningful action because they do not possess adequate human or financial resources. External resources (World Bank, USA, etc.) may not be able to support all of the subregions addressing similar problems, and they will therefore most likely lend support to those sub-regions which are best organized and institutionally capable." The extent to which this statement is true depends upon how international assistance is allocated. Recently, the lion's share of international assistance funds from the United States to the WCR has been flowing to Haiti and Nicaragua, which arguably are not well-organized or institutionally capable. But other organizations, such as the World Bank, may employ different criteria. Even if an LBMP protocol does level the playing field in terms of attracting international assistance, issues persist about allocating this assistance internally among the Contracting Parties. Presumably, these issues can be addressed through fairness rules incorporated into the protocol. 
It is also possible that the Contracting Parties to a protocol can provide for contributions from each party to a central fund. We discuss below in Section IV.I the status of contributions (and unfulfilled pledges) to the CEP fund. Tietenberg (pers. comm., 1995) has suggested that annual fees might be levied on WCR states (or individual pollution sources) to fund monitoring and enforcement activities, as is currently the practice with respect to some forms of air pollution in the United States. The size of the fee might be tied to the level of pollution so that there is an incentive for states to lower discharges. However, unless the fees are small, there may be difficulties in getting states to agree initially to participate in such a program. And if the fees are small, they are unlikely to provide much of a source reduction incentive. In addition, a system for accurate and consistent measurement of point source and nonpoint source pollution must be established, unless fees are based on a fixed level of allowable discharges.

An even more difficult problem concerns the lack of institutional infrastructure in many of the states of the region. We address the status of these institutions in Section IV.E below. The most serious cases are those states in which political power is held by those who benefit from using the marine environment for waste disposal and in which those who suffer from LBMP have little or no political power. It may be difficult, if not impossible, to encourage such states to agree to a protocol, unless their participation is tied specifically to other issues. Linking LBMP to other issues will require an examination of the relevant political conditions for those states that are reluctant to participate, and negotiation on a case-by-case basis.

Some analysts have argued that international collective action, such as that called for in a regional LBMP protocol, can stimulate the development of institutions and domestic programs to implement the provisions of the agreement. If domestic programs are developed, one must be concerned with the extent to which these programs can be determined to be effective at local and national levels.

Education about LBMP problems in the WCR will always be important. Our examination of the region suggests that there is a fairly good awareness in each of the states about the presence of localized marine pollution from land-based sources. More work needs to be accomplished with regard to determining the extent of the problem in each state, including the nature of pollutant flows and the size of actual damages and risks. Some good work along these lines is already being accomplished through the CEP and other research programs. Institutions established under the auspices of an LBMP protocol might usefully draw upon or expand existing programs, such as CEPPOL and others, to enhance the awareness and understanding of marine pollution in the region.

Most WCR states have made some measurable progress toward developing and implementing the capacity to deal with localized LBMP problems. We discuss this progress in greater detail in Section $\mathrm{V}$ below. 


\section{E. Scale Economies and Clearinghouse Efficiencies}

Officials of international organizations, such as UNEP, have argued that a regional protocol can facilitate technology transfer, expedite information exchange, and focus the allocation of financial capital and other resources more effectively to solve LBMP problems (UNEP 1994c, 1992; Nollkaemper 1992). These and other coordinative-type activities are the kind commonly associated with a "clearinghouse."

Clearinghouse efficiencies are a type of "scale economy:" as the amount of a particular service, such as information exchange, is increased, the cost per unit declines. In general, economies of scale are likely to be realized when an activity involves relatively high "fixed" costs, ${ }^{10}$ when specialization in the performance of tasks is possible, or where risks can be pooled, such as through the establishment of emergency-response measures. It is important to note that scale economies may exist over a range of certain levels of activity but disappear, resulting in "diseconomies" of scale, at higher levels. The relevant issue with respect to clearinghouse efficiencies is: what is the optimal size of the clearinghouse?

Economies of scale may exist in scientific research and monitoring of land-based sources of marine pollution, too. Table 13, in the next section, lists the research, coordination, and advocacy organizations that focus on marine science in the Caribbean today. It is likely that at least some, if not all, of the relevant economies of scale in scientific research and monitoring have been realized already through the activities of these organizations.

Officials at some international institutions, such as UNEP and the Caribbean Division of the World Bank, have begun developing synoptic views of the primary Caribbean regional environmental institutions and their mandates. Table 5 lists these institutions and their corresponding mandates. These institutions act in clearinghouse capacities, but, according to World Bank officials, the institutional framework is still too fragmented, suggesting that even more centralization is warranted:

The fundamental problem is that these efforts have often led to the formulation of proposals and implementation of activities that, while responding to a priority issue, do so from a particular institutional or even funding source perspective. There is, in general, a need for coordination on a regional basis in order to increase the effectiveness of the regional efforts. (Elvis and Colbert 1994)

${ }^{10}$ As fixed costs are spread out over greater levels of the activity, their per unit contribution to total costs declines. Fixed costs are by definition "recoverable" so that, for example, expenditures that are made on supplies or infrastructure can be recouped if the activity terminates. If these expenditures cannot be recouped, then the costs are "sunk." Sunk costs do not contribute to economies of scale. 


\begin{tabular}{|c|c|}
\hline Donos & Programa/Profocm \\
\hline \multicolumn{2}{|l|}{ UNTRED NATIONB AGENCIRS! } \\
\hline Uniled Nutions Environment Programme (UNEP) & - Ceribbean Environment Programme \\
\hline Unitad Nations Dovalopment Programme & $\begin{array}{l}\text {-Land Use Planning, Human Sealement and Terestrial Provection } \\
\text { Cepacity } 21 \text { Fund }\end{array}$ \\
\hline United Nations Centre for Humen Settements (UNCHS) & -Lund Use Planning and Human Settlements Development - OECS \\
\hline United acions Food and Agriculture Organization (PAO) & -Tropical Forestry Action Plans (CARICOM) \\
\hline $\begin{array}{l}\text { United artions Bcomomic Commission for Latin America } \\
\text { and the Caribbean (ECAAC) }\end{array}$ & $\begin{array}{l}\text {-Environmental Management Issues in Lourism } \\
\text { - Regional Sewage Disposal and Coastal Conservacion Sudics }\end{array}$ \\
\hline Pan American Health Organization (PAHO) & -Environmental Health in Sustainable Tourism Development \\
\hline \multicolumn{2}{|l|}{ MULTRATERAL DEVELOPMENT INSTITUTIONS: } \\
\hline World Bank & $\begin{array}{l}\text { - National Environmental Action plans (NEAPs) } \\
\text {-OECS Waste Management Project } \\
\text {-Wider Caribbean Initiative for Ship-generated Waste (WCISW) }\end{array}$ \\
\hline Inter-American Development Bank (LDB) & - Management of Coastal/Marine Resources - Wider. Caribbenn \\
\hline Caribbeno Developmeat Bank (CDB) & $\begin{array}{l}\text {-National Environmental Action Plans (NEAPs) (with WB) } \\
\text { OECS Waste management Project (with WB) } \\
\text {-Pesticide Pollution in the Windward Lslands (through CEHI) }\end{array}$ \\
\hline European Community (BC) & -CARIFORUM Regional Eavironment Programme under Lome IV \\
\hline European Invertmont Benk (EIB) & -OECS Waste Management (with WB) \\
\hline Organization of American Stules (OAS) & $\begin{array}{l}\text { - Natural Resources Management - includes parks and protected areas } \\
\text { oystem plans } \\
\text { - Environmental and Tourism Awareness }\end{array}$ \\
\hline BKA TBRAL DEVELOPMENT A GEN CIES: & 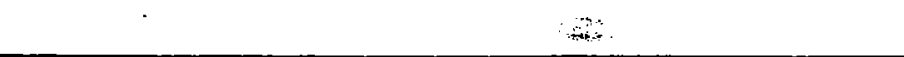 \\
\hline Britih Developon Divinion (BDD) & $\begin{array}{l}\text {-Renewable Natural Resources Programme - Tropical Forestry Action } \\
\text { Plens (with FAO) } \\
\text { - National Environmental Action Plans (with WB) }\end{array}$ \\
\hline Canedien Incerastiond Devalopment Agency (CIDA) & $\begin{array}{l}\text { - Caribbean Basin Management Training (CARICOM) } \\
\text { - Natural Resources Management Dafa Base Project - OECS/Burbadoal } \\
\text { BVI } \\
\text {-Environmental Training programme }\end{array}$ \\
\hline Germen Ageacy for wechnical Cooperation (GTZ) & $\begin{array}{l}\text { - Public Health Education - CARICOM countrios } \\
\text { - Information System Development - CEHI }\end{array}$ \\
\hline $\begin{array}{l}\text { Japanese Policy and Human Resources Development Pund } \\
\text { (PHRD) }\end{array}$ & - National Eavironmental Action Plans (NEAPs) through WB - OECS \\
\hline $\begin{array}{l}\text { Unicad Stules Agency for Intemational Development } \\
\text { (USAID) }\end{array}$ & $\begin{array}{l}\text {-Enviroament and Coasul Resources Management (ENCORE) - OECS } \\
\text { - Eastem Caribbean Policy Project - OECS }\end{array}$ \\
\hline
\end{tabular}


Although there would appear to be the potential for economies of scale, questions persist about how these might be realized through a protocol arrangement and whether a protocol is better than some alternative. To date, clearinghouse roles have been developed and implemented by international organizations with international resources, such as UNEP and the World Bank, with apparently little effect on the commitment, practices, or environmental problems of individual states. The example of UNEP's CEP, which was established in 1982, serves to make the point. Brewster (1994) has identified the following four existing constraints to the successful implementation of CEP: (1) insufficient political commitment; (2) inadequate financial support; (3) organizational weaknesses; and (4) inadequate awareness, expertise, and experience at the domestic level. These constraints are of the same nature as those that may well limit the effectiveness of a regionwide LBMP protocol.

Clearly, there is a role for a clearinghouse on LBMP in the WCR. To a large extent, this role is being performed already by UNEP and the World Bank, as well as by other smaller regional institutions, such as OECS. The fundamental issue is whether additional economies can be achieved by an "umbrella" institution established through the protocol. Although this question cannot be answered until such an institution is established, it is sensible, at least, to question the potential for additional scale economies. We suggest that the best approach is an incremental one. ${ }^{11}$ A clearinghouse established under the LBMP protocol should take advantage of existing institutions and expand step-by-step, testing for the existence of scale economies. ${ }^{12}$

\section{F. Uniform Standards}

The extent to which marine pollution should be controlled depends upon our understanding of both causes and effects, and the extent to which it can be controlled depends upon our ability to influence causes so as to reduce adverse effects. Figure 10, adapted from Fisher and Peterson (1973), describes the relationship between emissions (causes) and the determination of damages (effects). A wide range of pollution control instruments are available, ranging from command-and-control regulations, or standards (Helfand 1991), to market-based approaches (OECD 1994; Tietenberg 1985), or to combinations of the two. The best instrument or combination of instruments may depend upon specific environmental, political, or economic factors. In the WCR, much of the discussion about pollution control instruments has focused on the development of "standards" of two types: ambient water quality standards and technologybased controls.

\footnotetext{
${ }^{11}$ Wood-Thomas (pers. comm. 1995) reports that ". . . we are pushing a reorientation of CEPPOL to serve defined management needs and we will likely pursue a functional linkage of work undertaken through both CEPPOL and IPID," a regional Integrated Planning and Institutional Development Project.

${ }^{12}$ The protocol institution may decide to contract, instead of expand, existing institutions in order to achieve the most efficient level of clearinghouse service.
} 


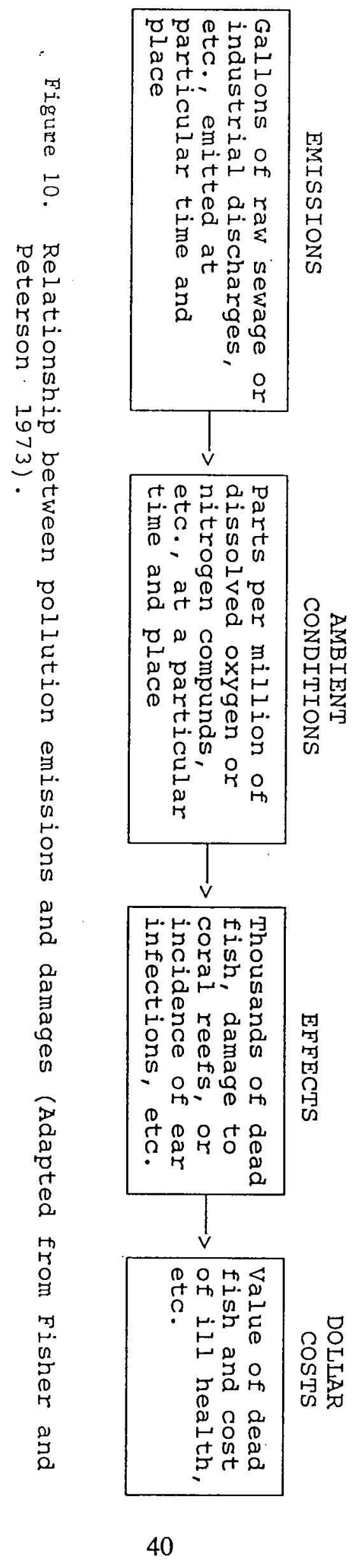


In the Caribbean, concentrations of LBM pollutants, of any type, vary by location; they are "non-uniformly mixed" (Tietenberg 1988). Pollutant levels at each location also may vary over time as a result of environmental events, such as storms; seasonal oceanographic phenomena, such as freshets; or cumulative effects, such as the build-up of pollutant stocks. Pollutant concentrations, of any type, may be attributed to single or multiple sources, such as industrial plant emissions, sewer outflows, or runoff from farms. In general, each pollution source contributes a different amount to the ambient concentration at each location, because of relative proximity, precipitation or mixing, or other reasons. Finally, the distributions of natural resources and human uses of the marine environment also are nonuniform (Elder and Pernetta 1991).

The nonuniform distributions of both ambient pollution concentrations and resources or uses implies that damages from marine pollution are likely to vary by location. Damages can also vary because of differences in the tastes and income levels of the users of resources at particular locations. The differential relative contribution of sources to ambient concentrations at any location implies that costs of pollution control vary by location as well. Costs of pollution control for sources can vary also because of differences in technologies, market conditions, and other factors.

If the causes and effects of marine pollution were uniformly distributed, then uniform regional standards or controls might be appropriate policy instruments. But the existence of nonuniformities in the Caribbean argues strongly for approaches that are capable of dealing effectively with the problem of pollution control at each location. ${ }^{13}$ In other words, regionwide uniform water quality standards and technology-based controls are not necessarily appropriate policy instruments, given the environmental and economic characteristics of the Caribbean.

As a precursor to the selection of a pollution control instrument, we require information about the damages associated with pollution at each Iocation in the Caribbean (see the "dollar costs" box in Figure 10). Ideally, this information would include data on the damages associated with different levels of pollution at each location. Moreover, we need information about the costs of control for sources contributing to pollution at each location. An economically efficient emissions quota or charge could then be set for each location. Preference for either a quota or a charge depends upon the relative levels of knowledge about damages or control costs (Baumol and Oates 1988). ${ }^{14}$

For many pollutants, a surrogate measure of damages, based upon a scientific

\footnotetext{
${ }^{13}$ One might argue that "on average" standards would be appropriate pollution control instruments. Such an argument ignores difficulties of political acceptance of standards (Sand 1991) and the natural tendency to weaken the standards approach through waivers or exceptions (UNEP 1994c).

${ }^{14}$ In general, it can be quite expensive to gather information about either damages or control costs.
} 
understanding of the potential effect of pollutants on human health, often is employed instead (see the "effects" box in Figure 10). A water quality standard can be set to ensure that pollution is kept at some level that has a low probability of health effects (Figure 10). Quotas can be set at levels to ensure that the water quality standard is not exceeded. ${ }^{15}$ Water quality standards are less expensive to administer than the efficient quotas or charges described above, because there is no need to measure damages explicitly. ${ }^{16}$ But because water quality standards consider neither damages nor control costs, their uniform application may require excessively costly pollution control in areas where there are very low levels of marine resource use.

Several analysts have suggested that regional water quality standards should be applied in the Caribbean. In Policy Principles, WWF and ESI (1994: 2) argue for "regional environmental standards and environmental quality commitments. " Their argument is based primarily on the potential benefits of a level regulatory environment across Caribbean states. ${ }^{17}$ Kasten (1994: 17) has argued for establishing a technology-based control program in the short run and supplementing this program with water quality standards in the long run.

The use of the term "regional" in these studies probably implies water quality standards that are "uniform" across the region, but there is no need for this interpretation. For example, in Appropriate Approaches, UNEP (1994c: 27) argues for domestic water quality standards based upon regional standards that can be modified through the use of "exceptions" and "waivers." Exceptions and waivers would be based upon "particular ecological, geographical, and physical characteristics and the level of existing pollution." In this way standards might be made appropriately nonuniform across WCR states. ${ }^{18}$

In order to design technology-based controls that meet established water quality standards, the relationship between pollutant discharges and effects should be known. Often this relationship is not well understood, and pollution controls have been recommended or adopted in many parts of the world without regard to their likely effectiveness in meeting water quality standards or sometimes even prior to the establishment of water quality standards.

Arguments for the adoption of pollution controls without water quality standards arise, in part, from the supposition that control of LBM pollutants must begin before the lengthy processes of establishing water quality standards and understanding cause-and-effect relationships

\footnotetext{
${ }^{15}$ Setting the appropriate quota will require some knowledge of the relationship between emissions and effects, i.e., of the assimilative capacity of the environment.

${ }^{16}$ Water quality standards can also be applied without regard to the costs of control, although it is often the case that policy debates will tend to focus on these costs.

17 This argument is based on the idea of "pollution havens." See below.

${ }^{18}$ Note, however, that if exceptions become widespread, then water quality "standards" may lose their meaning.
} 
are completed. In effect, such an approach is an application of the "precautionary principle," defined, as follows, in the Rio Declaration of the 1992 U.N. Conference on Environment and Development (UNCED):

[w] here there are threats of serious or irreversible damage, lack of full scientific certainty shall not be used as a reason for postponing cost-effective measures to prevent environmental degradation. (emphasis added) ${ }^{19}$

Economic theory, in combination with a substantial body of empirical analysis, indicates that technology-based standards may be one of the most costly ways in which to control pollution (Cropper and Oates 1992; Tietenberg 1985). For example, Lyon and Farrow (1995) have examined the benefits and costs of clean water programs in the United States. Their findings suggest that incremental costs of water pollution control, which are based on estimates of constructing publicly owned treatment works, exceed incremental benefits.

Notwithstanding their relative costliness, there are several reasons why technology-based standards might be promoted as a policy measure. Table 6 presents a comparison of the economic incentives and effects of different types of pollution control instruments. First, from an economic standpoint, the presence of threshold effects in the face of uncertainty about damages or control costs is one of the strongest reasons in favor of establishing technology-based standards. Such effects may exist in the WCR with respect to harmful, persistent pollutants, such as organohalogens.

Many of the WCR states are Contracting Parties to the London Dumping Convention (see Table 9 in Section IV), which has organized pollutants into prohibited (black list) and regulated (grey list) substances. Black list substances tend to be those with threshold effects. One option for the Contracting Parties to the Cartagena Convention is to consider treating LBM pollutants in the same manner as London Dumping Convention pollutants so that, for example, land-based discharges of black list pollutants would be banned and land-based discharges of grey-list pollutants would be regulated by individual states. However, Wood-Thomas (pers. comm., 1995) explains that the negotiations concerning the WCR protocol are leading in a different direction:

We are specifically avoiding a black-list, grey-list approach in the WCR because of lessons learned in the Baltic, North Sea, and Mediterranean. This structure has failed to focus the respective parties on those contaminants that are the priority problems within a region. Changes in the Baltic and North Sea have reflected a recognition of this problem as they have developed "red-lists." We hope to utilize the negotiation of specific annexes to take this concept to a more pragmatic

${ }^{19}$ Adoption of technology-based controls without water quality standards can be considered an application of an extreme version of the precautionary principle (cf., Broadus 1992), one whose adoption might be questioned on economic grounds unless clear threshold effects are suspected. Threshold effects are damages that are severe or irreversible, imposing high levels of social costs if pollution is controlled at too low a level. 

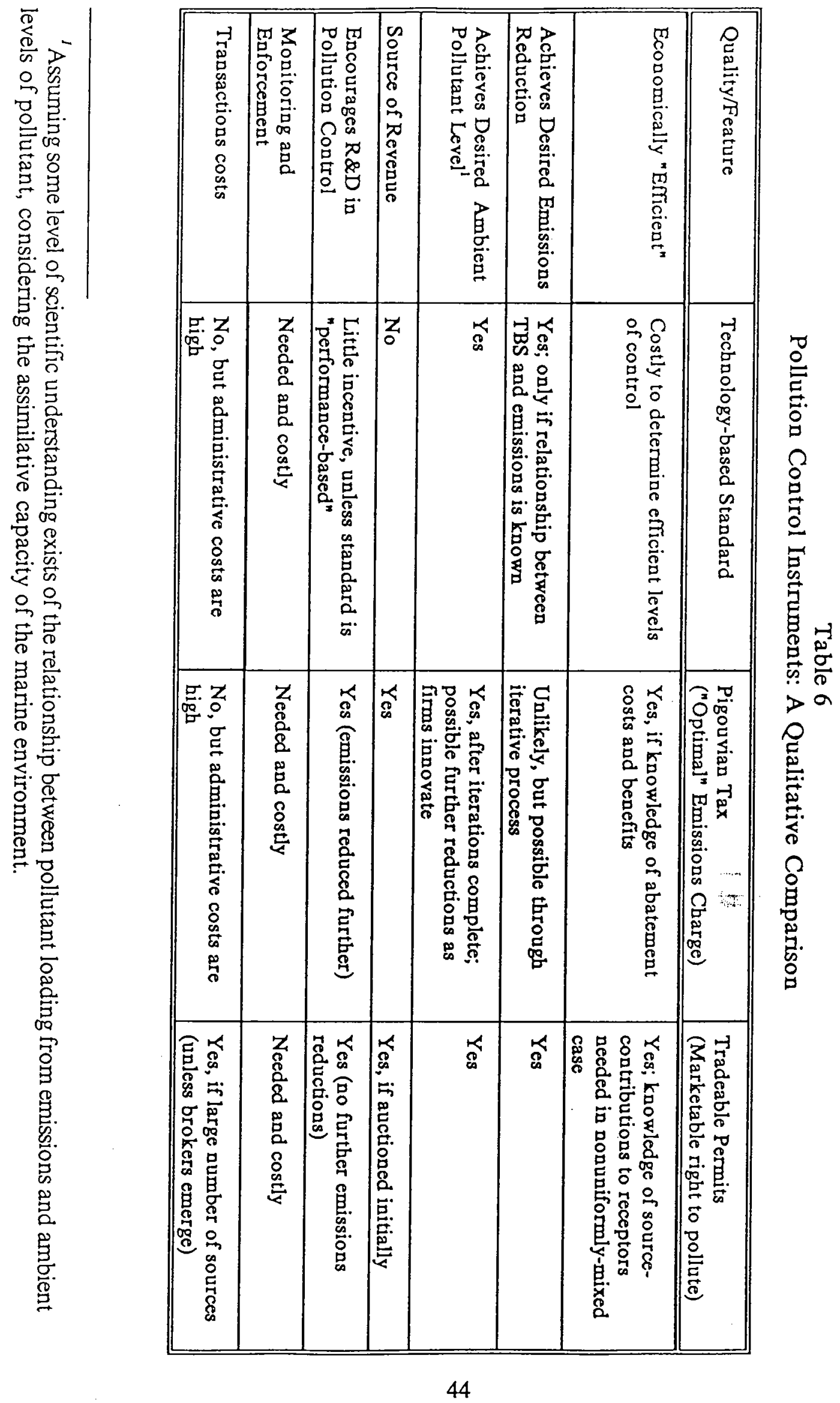
level-focusing effort on the principal source categories that are responsible for the more obvious and gross sources of pollution. Various annexes would then be developed over time as the scientific understanding evolves concerning what pollutants and sources are most important in the Region. As such we use the protocol structure to help rationalize and focus the attention of the parties on those problems that are most significant in the region. The problems vary and are not shared by all, but with adequate flexibility and definition of the annexes, these should provide a useful vehicle to facilitate limited, but pragmatic actions that expand over time (recognizing the scarcity of resources and that scientific understanding will improve and offer new priorities for action).

Second, from a political standpoint, some industries may favor standards because they constitute barriers to entry, and employees of controlled industries may favor standards because of wage-enhancing effects. Table 7, adapted from Dewees (1983), outlines some of these reasons.

Third, from a strategic standpoint, as happened in the case of the negotiations over an LBMP protocol in the Mediterranean, developed states might argue in favor of technology-based standards for at least three reasons: (1) technology-based standards may already be in place; (2) adoption of similar standards removes the incentive, however small, for a developed state's industries to relocate; and (3) establishment of technology-based standards in other states presents market opportunities for existing producers of pollution control technologies.

Technology-based standards are just one of several possible kinds of standards. ${ }^{20}$ Moreover, as shown in Table 6, standards are not the only available pollution control instrument. Given nonuniformities in the distribution of LBMP causes and effects, it is not obvious, ex ante, that technology-based standards will be the most appropriate pollution control instrument in every case. Following the intent of the precautionary principle to encourage the adoption of cost-effective pollution control methods, flexibility in selecting and implementing methods of control seems more appropriate. Further, such flexibility is likely to increase the potential for gains from trade in pollution control and, thereby, to enhance the potential for protocol effectiveness.

Some analysts have argued for uniform standards to "level the environmental playing field." This argument, which is one version of the "pollution haven" hypothesis (Cumberland 1981), states that the implementation of uniform standards removes incentives for industries to relocate to jurisdictions in which standards are low or nonexistent. The pollution haven hypothesis is currently the focus of a number of research efforts in the environmental policy field (Jaffe et al. 1995; Cropper and Oates 1992). Early results from this research are not in full agreement, but basic theory suggests that a policy of "environmental federalism," or the setting of standards at a level which internalizes pollution impacts, is economically efficient (Oates and

\footnotetext{
${ }^{20}$ Helfand (1991) evaluates the economic effects of at least five different kinds of standards.
} 


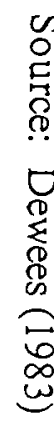

\begin{tabular}{|c|c|c|c|c|c|c|}
\hline 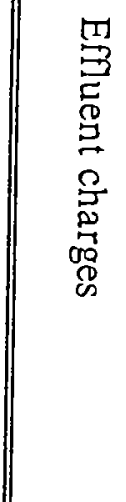 & 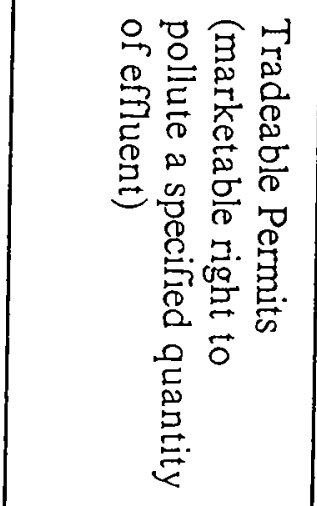 & 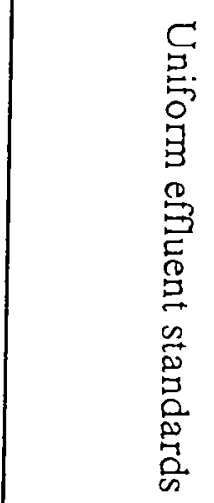 & $\begin{array}{l}z \\
Z \\
0 \\
0 \\
\stackrel{9}{0} \\
\frac{0}{\infty}\end{array}$ & 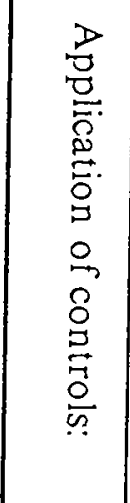 & & \\
\hline 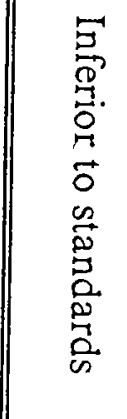 & 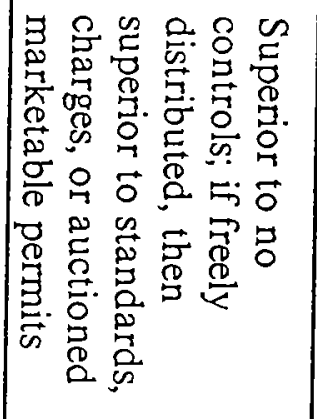 & 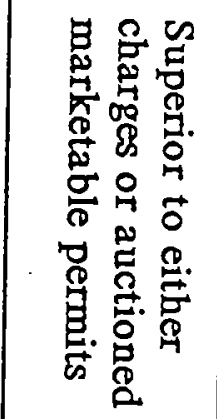 & 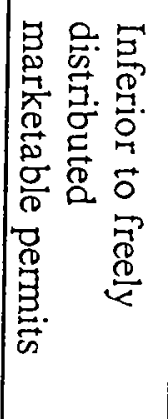 & 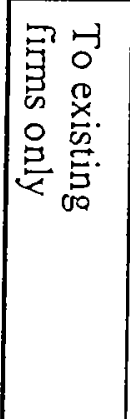 & \multirow[t]{2}{*}{ 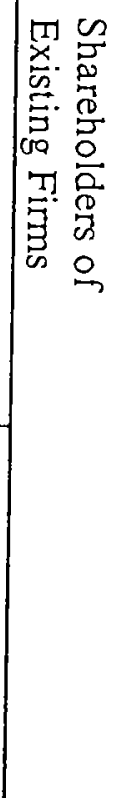 } & \multirow{4}{*}{ 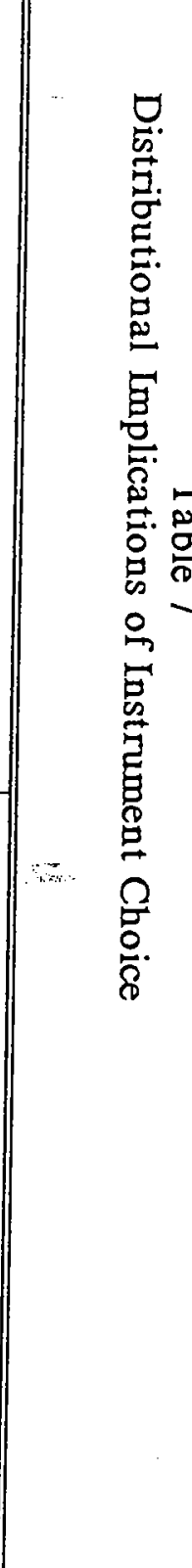 } \\
\hline & 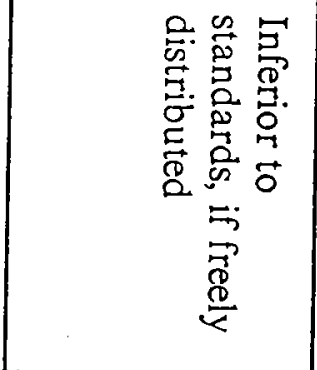 & 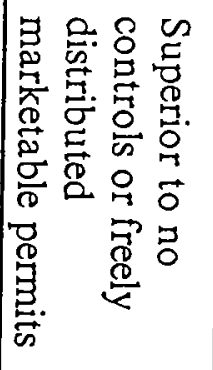 & 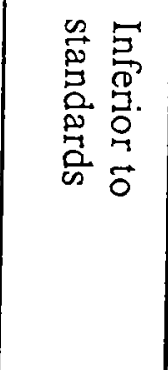 & 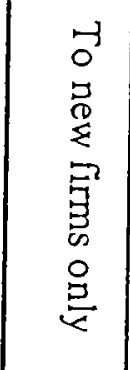 & & \\
\hline 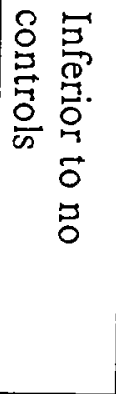 & 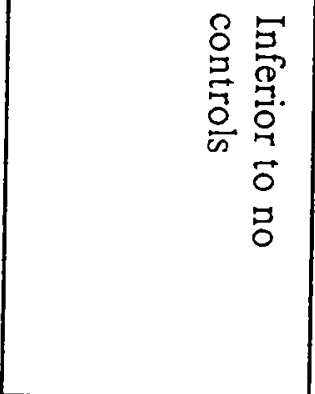 & 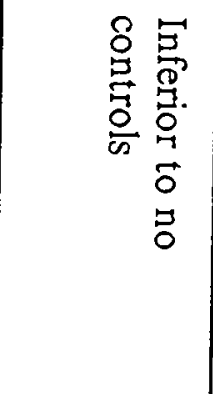 & 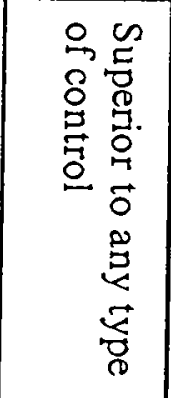 & 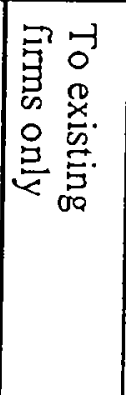 & \multirow[t]{2}{*}{ 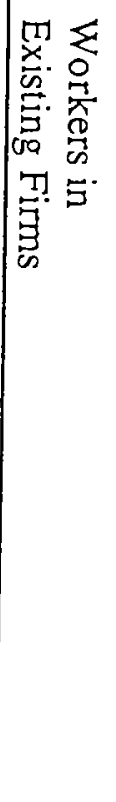 } & \\
\hline 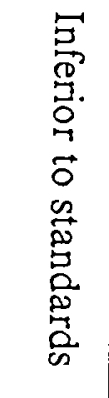 & 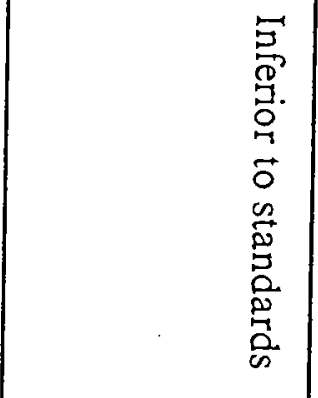 & 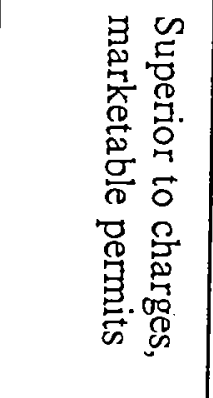 & & 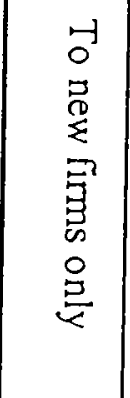 & & \\
\hline
\end{tabular}


Schwab 1988). This result derives its force from the fundamental nonuniformities in cause and effect, described above. ${ }^{21}$ This theoretical result reinforces an argument for the setting of standards at domestic or subregional levels in the Caribbean, although it should be recognized that some states or subregions will need outside assistance in setting standards.

Other considerations suggest that pollution haven arguments are sometimes exaggerated. For example, unlike marine pollution from ships, land-based capital is not completely mobile and cannot be moved costlessly to avoid stringent environmental regulations. Some types of land-based sources, including utilities such as power plants, must be sited in almost every jurisdiction. ${ }^{22}$ For those states that focus on tourism as a major industry, the pollution haven hypothesis would appear to be easily rejected. Also, factors affecting other inputs to an industrial firm's production processes, such as labor costs, may greatly outweigh the estimated costs of environmental regulation in a firm's location decision. For example, Jaffe et al. (1995) find that the costs of industrial compliance with federal pollution control regulations in the United States are a small fraction, averaging only two percent, of the total cost of production.

It is likely that great difficulties will be encountered in attempts to reach agreement on or to implement regionwide uniform water quality standards or technology-based controls, thereby heightening the potential for protocol ineffectiveness. The adoption of regional standards may result in an international consensus on the lowest standards acceptable to all parties (cf., Sand 1991), instead of ones that reflect the size of damages or that adequately protect human health. The nonuniform distribution of causes and effects of LBMP in the WCR strengthens an argument for decisions to be made on water quality standards and pollution control instruments at the subregional, bilateral, or domestic levels. Discussion at regional fora on the benefits of waivers, exemptions, and timetable extensions indicate that the Contracting Parties are aware of the problems of adopting and applying uniform standards. Thus, a critically important role for an LBMP protocol is to help states identify the most appropriate pollution control mechanisms for their individual or shared environmental circumstances.

\section{G. Summary}

Many of the arguments made for concluding an international LBMP protocol in the WCR are valid at some scale. Transboundary pollution occurs along the borders of some states but

\footnotetext{
${ }^{21}$ In their study of the benefits and costs of the U.S. clean water program, Lyon and Farrow (1995) recommend that more attention be given to geographically targeted controls instead of uniform national regulations.

${ }^{22}$ If environmental regulations vary by jurisdiction, then the kinds of technologies employed by utilities may vary as well. But utilities will not be attracted to regions because of nonstringent environmental regulations. In fact, some types of "point" sources, such as sewage treatment facilities, will be attracted to regions because of stringent environmental regulations.
} 
is not a regionwide phenomenon. Nevertheless, it may be one of the strongest reasons for concluding an international agreement. Clearinghouse efficiencies, a type of scale economy, may exist for some categories of pollution problems that are common among the WCR states. Clearinghouse programs exist already in the region, and the issue for protocol negotiators is how to take advantage of these programs through judicious consolidation or expansion in some directions to test for additional scale effects. The nonuniform distribution of causes and effects of marine pollution in the WCR argues for approaches that deal with problems at each location. We argue for flexibility in the adoption of pollution control instruments, such as tradeable permits or emission charges where appropriate. Regionwide requirements for technology controls will be unnecessarily costly and inappropriate unless threshold effects are likely.

Increasingly, observers are arguing for an LBMP protocol in the WCR that gives priority to resolving localized but widely occurring pollution problems. Such an approach is clearly more compatible with the environmental realities of the region than one that seeks only (or primarily) to address transboundary pollution problems. However, the logic of concluding an international protocol to address primarily domestic pollution problems depends upon certain unproven assumptions about clearinghouse efficiencies and other scale economies, and about the likelihood that an international program will be more effective than efforts by individual states in attracting funding and other forms of assistance from multilateral and bilateral donor agencies. We believe that these assumptions are valid to a point that stops well short of justifying a uniform, regionwide approach to LBMP problems and solutions. Rather, recognizing that some common LBMP problems in the WCR are more common than others (see Section IV), we recommend a protocol that carefully delineates subregional groupings and approaches on the basis of common marine environmental problems. We further recommend (in Section VI) that the "umbrella" function of a regional LBMP protocol should concentrate on the need to ensure uniform access to all clearinghouse products and on the internal allocation of financial and technical assistance to individual states and subregions.

In the next two sections, we describe commonalities and differences across WCR states and begin to identify opportunities for mutual benefits in pollution reduction and control, which, if properly elucidated, can be used to encourage subregional pollution control efforts. 


\section{Economic and Institutional Characteristics of the WCR}

\section{A. Regional Diversity}

The limited evidence of transboundary pollution effects noted in the preceding section is an important respect in which the Wider Caribbean Region (WCR) more closely resembles the Mediterranean Sea than either the Baltic or the North Sea. Another striking similarity between the Wider Caribbean and the Mediterranean is the large number of countries bordering the regional sea and the tremendous diversity of cultures, economies, and national priorities that each region embraces.

Four official languages-English, Spanish, French, and Dutch-and dozens of dialects are spoken throughout the Wider Caribbean Region, which encompasses 37 distinct political units: 25 sovereign nations ( 13 island nations and 12 continental), 5 territories of the United Kingdom, 3 overseas departments of France, 2 self-governing units of the Dutch realm (including one island shared by the Netherlands and France), 2 territories of the United States,' and the US-associated commonwealth of Puerto Rico (Table 8). The region's 25 sovereign nations alone range in size from 40,000 persons inhabiting $269 \mathrm{~km}^{2}$ (St. Kitts \& Nevis) to roughly 250 million dispersed over more than 9 million $\mathrm{km}^{2}$ (United States), with economies ranging from the world's largest and most diversified (United States) to one of its most abjectly poor and undeveloped (Haiti) (Figure 11; see also Tables A.1 and A.2 in Appendix A).

\section{B. The WCR States and the Cartagena Convention}

The large number of countries bordering the Gulf of Mexico/Caribbean Sea is reflected in a long list of Contracting Parties to the Convention for the Protection and Development of the Marine Environment of the Wider Caribbean Region, or Cartagena Convention. Participation by the countries and territories of the WCR in the Cartagena Convention and its two existing protocols (on cooperation in combating oil spills and on the establishment of specially protected areas and wildlife) is displayed in Table 9, along with their participation in the Law of the Sea Convention (UNCLOS III) from which the Cartagena Convention takes its definition of pollution, and in the London Dumping Convention, which governs the dumping of wastes from ships into the marine environment. Not listed in Table 9 are the three European states with island territories in the region-France, the Netherlands, and the United Kingdom-that are Parties to the Cartagena Convention. All told, 16 of the 25 sovereign states in the region are Contracting Parties to the Cartagena Convention, and 10 of the 12 foreign dependencies are

\footnotetext{
'Throughout the text, we omit the uninhabited US territory of Navassa Island from counts and discussions of the WCR states. We mention it here only to explain its appearance on the maps in Sections I and V, where individual states are identified in terms of their maritime boundaries; in these maps, Navassa appears as a white area (as do two areas of high seas in the Gulf of Mexico) to the southeast of Cuba.
} 
Table 8

Political Units of the Wider Caribbean Region

\begin{tabular}{|c|c|c|c|c|c|}
\hline \multicolumn{2}{|c|}{ Sovereign States } & \multicolumn{4}{|c|}{ Territories/dependencies } \\
\hline Island & Continental & $\begin{array}{c}\text { France } \\
\text { (overseas } \\
\text { departments) }\end{array}$ & $\begin{array}{c}\text { Netherlands } \\
\text { (self- } \\
\text { governing } \\
\text { units of } \\
\text { Dutch realm) }\end{array}$ & $\begin{array}{c}\text { United } \\
\text { Kingdom } \\
\text { (territories) }\end{array}$ & United States \\
\hline $\begin{array}{l}\text { Antigua \& } \\
\text { Barbuda }\end{array}$ & Belize & $\begin{array}{l}\text { French } \\
\text { Guiana }\end{array}$ & Aruba & Anguilla & $\begin{array}{l}\text { Navassa Is. } \\
\text { (uninhabited } \\
\text { terr.) }\end{array}$ \\
\hline Bahamas & Colombia & Guadeloupe & $\begin{array}{c}\text { Netherlands } \\
\text { Antilles }\end{array}$ & $\begin{array}{l}\text { British } \\
\text { Virgin } \\
\text { Islands } \\
\end{array}$ & $\begin{array}{c}\text { Puerto Rico } \\
\text { (commonwealth) }\end{array}$ \\
\hline Barbados & Costa Rica & Martinique & & $\begin{array}{l}\text { Cayman } \\
\text { Islands }\end{array}$ & $\begin{array}{l}\text { U.S. Virgin } \\
\text { Islands } \\
\text { (territory) }\end{array}$ \\
\hline Cuba & Guatemala & & & Montserrat & \\
\hline Dominica & Guyana & & & $\begin{array}{l}\text { Turks \& } \\
\text { Caicos } \\
\text { Islands }\end{array}$ & \\
\hline $\begin{array}{c}\text { Dominican } \\
\text { Republic }\end{array}$ & Honduras & & & & \\
\hline Grenada & Mexico & & & & \\
\hline Haiti & Nicaragua & & & & \\
\hline Jamaica & Panama & & & & . \\
\hline $\begin{array}{l}\text { St. Kitts \& } \\
\text { Nevis }\end{array}$ & Suriname & & & & \\
\hline St. Lucia & $\begin{array}{l}\text { United } \\
\text { States }\end{array}$ & & & ... & \\
\hline $\begin{array}{l}\text { St. Vincent } \\
\& \\
\text { Grenadines }\end{array}$ & Venezuela & & & & \\
\hline $\begin{array}{c}\text { Trinidad \& } \\
\text { Tobago }\end{array}$ & & & & & \\
\hline
\end{tabular}




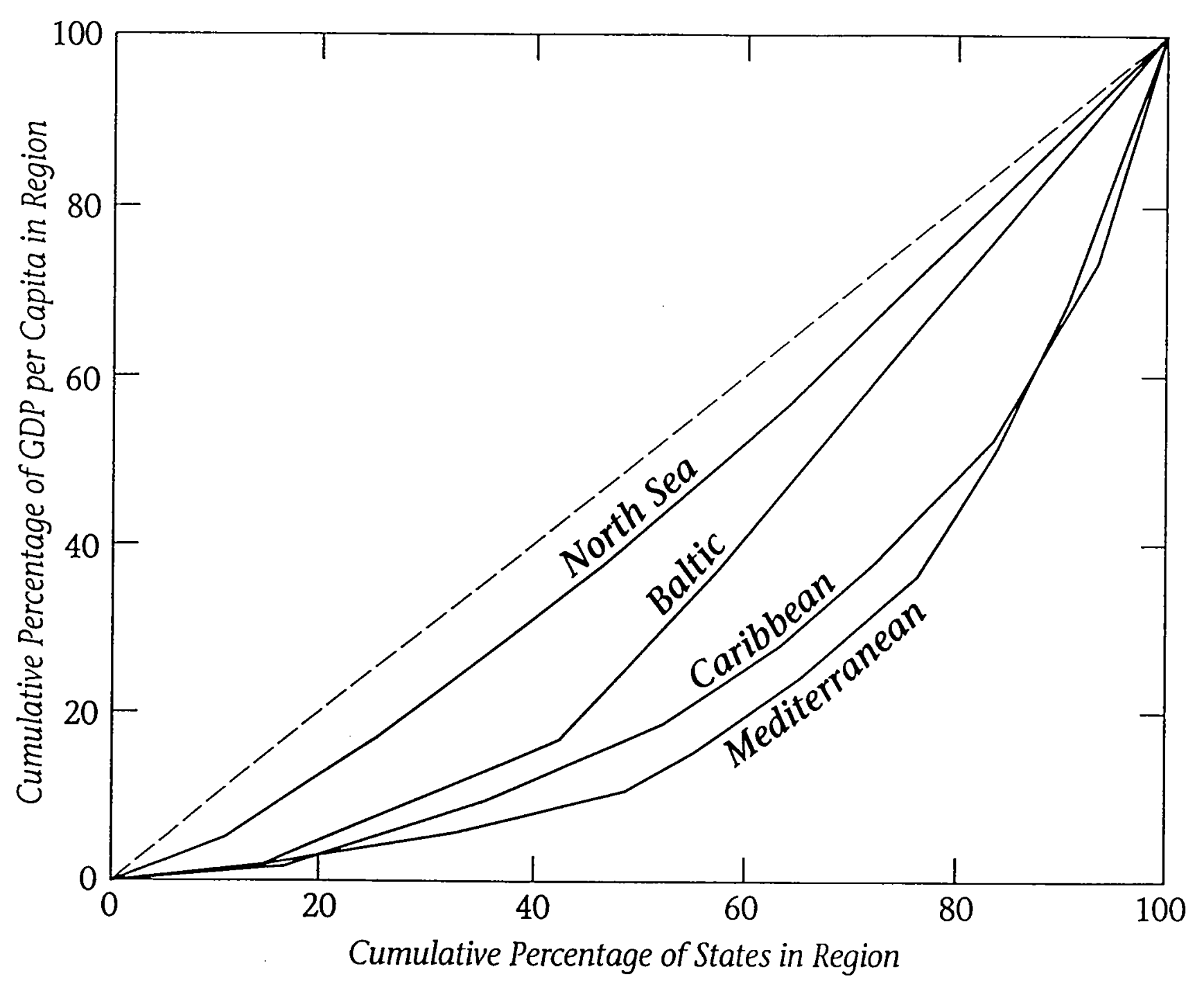

Figure 11. Regional diversity as measured by GDP per capita. Greater diversity is shown as a larger departure from the $45^{\circ}$ dashed line, which depicts a perfectly uniform distribution of GDP per capita. Among the four regions depicted, the Wider Caribbean and the Mediterranean are the most diverse. 
Table 9

Particlpation In Law of the Sea, London Dumplng, and Cartagena Conventions

\begin{tabular}{|c|c|c|c|}
\hline State & $\begin{array}{c}\text { Law of the } \\
\text { Sea }\end{array}$ & $\begin{array}{l}\text { London } \\
\text { Dumping }\end{array}$ & $\begin{array}{l}\text { Cartagena } \\
\text { \& Protocols }\end{array}$ \\
\hline Anguilla" & & - & \\
\hline Antigua \& Barbuda & - & 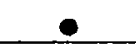 & e \\
\hline Aruba & $\mathrm{O}$ & - & 두. \\
\hline Bahamas & - & & \\
\hline Barbados & 으 & & e \\
\hline Belize & - & . & \\
\hline British Virgin Is. ${ }^{c}$ & & - & 우. \\
\hline Cayman is. & & 은 & 둘. \\
\hline Colombla & 0 & 0 & - 回・ \\
\hline Costa Rica & 는 & - & $\bullet$ \\
\hline Cuba & - & - & - 도. \\
\hline Dominica & - & & - \\
\hline Dominican Republic & $\mathrm{O}$ & $\bullet$ & \\
\hline French Guiana ${ }^{d}$ & $\mathrm{O}$ & $\bullet$ & 무 \\
\hline Grenada & - & & 토 \\
\hline Guadeloupe & 0 & $\bullet$ & e \\
\hline Guatemala & 0 & 으 & 음. \\
\hline Guyana & $\bullet$ & & \\
\hline Haiti & 은 & $\bullet$ & \\
\hline Honduras & $\bullet$ & e & 으믄 \\
\hline Jamaica & - & 은 & 두. \\
\hline Martinique ${ }^{6}$ & 0 & $\bullet$ & e \\
\hline Mexico & - & - & 뭅. \\
\hline Montserrat ${ }^{2}$ & & 울 & \\
\hline Neth. Antilles ${ }^{\circ}$ & 0 & 으 & 우. \\
\hline Nicaragua & 0 & & 음 \\
\hline Panama & 은 & - & - 田・ \\
\hline Puerto Rico & & e & 무. \\
\hline St. Kitts \& Nevis & - & & \\
\hline St. Lucia & e & ㄴ. & 물. \\
\hline St. Vincent \& Grenadines & - & & e \\
\hline Suriname & O & $\bullet$ & \\
\hline Trinidad \& Tobago & 는 & & 으. \\
\hline Turks \& Caicos ${ }^{c}$ & & - & e. \\
\hline United States & & - & e $\mathbf{m}^{*}$ \\
\hline US Virgin Islands & & 으 & 울. \\
\hline Venezuela & & 0 & $\circ \mathbf{0}$ \\
\hline
\end{tabular}

- Convention signed and ratified. O Convention slgned but not ratified.

- Oil spill protocol signed and ratified; $\square$ Oil spill protocol signed but not ratified:

- SPAW protocol signed (only Colombla has ratified)

"Not a Contracting Party to the Cartagena Convention, but participates in the Caribbean Environment Programme.

By Netherlands.

By UK.

'By France (Cartagena Convention signed "with reserve.")

-By US.

Sources: Branes 1991; IMO 1991; Curtis 1993; Broadus and Vartanov 1994: Mandelli 1994: UNEP 1992a; World Bank 1994: WRI 1994. 
bound by its provisions as well. ${ }^{2}$ (Signatories that have not ratified the convention include Honduras, Nicaragua, and the European Economic Community).

The Cartagena Convention was negotiated under the auspices of UNEP, and more specifically of UNEP's Regional Seas Programme, whose charter is to promote "a regional approach to the control of marine pollution and management of marine and coastal resources" (Introduction to Cartagena Convention, UNEP 1983). The Wider Caribbean Region became the fourth designated Regional Seas Programme area in 1981 (the Mediterranean was the first, in 1978), when an intergovernmental meeting at Montego Bay, Jamaica, adopted an Action Plan for the region. As is customary for the UNEP Regional Seas Programme, the Action Plan set forth required program components in the areas of environmental assessment, environmental management, environmental legislation, institutional arrangements, and financial arrangements.

The Cartagena Convention, adopted in March 1983 at Cartagena de Indias, Colombia, satisfies the Action Plan's requirement for environmental legislation. It takes the customary UNEP form of an umbrella convention, elaborated by specific technical protocols, that serves as a legal framework for cooperative regional and national actions. As expressed in the Introduction to the Cartagena Convention, "The legal commitment of Governments clearly expresses their political will to manage individually and jointly their common environmental problems." Article 7 identifies land-based marine pollution (LBMP) as among the environmental problems to be managed.

Joint management of LBMP is likely to be particularly challenging in the case of the WCR, given the large number and broad diversity of the countries involved. As noted in the comparative study of the Baltic, North Sea, and Mediterranean programs, "one may expect cooperation efforts-and particularly the establishment of shared objectives and common approaches-to be the most complicated in regions with relatively heterogeneous member countries" (Broadus et al. 1993). The study goes on to suggest, in the case of the Mediterranean program, that "improvement in managing land-based pollution may be possible by separating and recombining the Mediterranean countries into new subregions, based on environmental considerations."

In the remainder of this section, we consider the prospects for addressing LBMP on a subregional basis, using as our point of departure the six WCR subregions designated by the CEPPOL program. The CEPPOL point-source pollutant inventories and other reports of observed pollutants and associated environmental degradation are reviewed in the context of various economic and institutional factors that shed light on these observations and on the prospects for controlling land-based marine pollution through collective actions and mechanisms.

\footnotetext{
${ }^{2}$ The United Kingdom has ratified the Cartagena Convention on behalf of the British Virgin Islands, the Cayman Islands, and the Turks and Caicos Islands, but not Anguilla or Montserrat.
} 


\section{Overview of Demographic and Economic Indicators}

Selected indicators of LBMP inputs are presented for the 37 countries and island territories of the WCR in Table A.3 (Appendix A). The indicators fall into four general areas of information: on human settlements, agriculture, mining and manufacturing, and deforestation. Information on human settlements includes the estimated concentration of each country's population within the drainage basin and coastal areas of the Wider Caribbean Region (see Appendix B) and the extent to which the population has access to sewage treatment services. This information sheds light, for example, on the CEPPOL finding that a very high proportion of the Subregion V domestic pollutant load is attributable to Venezuela, even though Venezuela's population, at 19 million, is only three-fifths the size of Colombia's: Venezuela's coastal population is approximately 4.5 times greater than Colombia's (Mandelli, pers. comm., 1995; see also Table B.1 in Appendix B). Other information reported in Table A. 3 includes the extent of pesticide and fertilizer use and the distribution of oil refineries, mines, and factories of various types throughout the region.

Subsumed under the statistics on agriculture are those for fisheries, which, unlike agriculture (or mining and manufacturing), derives more benefit from an unpolluted marine environment than from the freedom to contribute to LBMP. ${ }^{3}$ For this reason-and because economic data on the region's fisheries are scant and are believed seriously to underestimate the value of fishing to many WCR cultures and economies (Mahon 1993)-selected data by weight on fish catch, imports, exports, and domestic consumption are presented separately in Table A.4 (Appendix A). Table 10 provides some limited economic data on those WCR countries that rank among the top 50 in the world for the value of their annual fish imports and/or exports, as reported in U.N. trade statistics (UN, n.d.). Nineteen of the WCR countries and territories qualify for inclusion, but only nine of these-the Bahamas, Colombia, Costa Rica, Cuba, French Guiana, Honduras, Mexico, Panama, and Venezuela-are net fish exporters in terms of value of catch.

Tourism, an economic mainstay for many countries of the region, is an activity that can be both vulnerable to and a contributor of LBMP. Tourism receipts as a percentage of GDP are reported in Table A.5 (Appendix A), which also includes a narrative summary highlighting the most prominent economic activities and targeted growth areas for the WCR countries. The countries are grouped in the table according to the six CEPPOL-designated subregions, making it comparatively easy to identify those geographical areas where economic activities and priorities are the most homogeneous (Subregions II and IV), the most vulnerable to LBMP (Subregion IV), or the most likely to create LBMP effects for downstream countries (Subregion V).

\footnotetext{
${ }^{3}$ This statement is particularly true for the smaller island states, where near-shore artisinal fishing accounts for most of the employment in fisheries.
} 
Table 10

Major Net Importers and Net Exporters of Fish and Fish Products in the WCR

\begin{tabular}{||l|r|c||}
\hline \multirow{2}{*}{ State } & \multicolumn{2}{|c|}{1992 Value (\$US 1000) } \\
\cline { 2 - 4 } & Net Imports & Net Exports \\
\hline Bahamas & & 264,033 \\
\hline Barbados & 1,499 & \\
\hline Colombia & & 129,123 \\
\hline Costa Rica & & 26,027 \\
\hline Cuba & & 345,883 \\
\hline Dominican Republic & & \\
\hline French Guiana & & \\
\hline Guadeloupe & 16,457 & \\
\hline Guyana & & \\
\hline Haiti & & \\
\hline Honduras & 14,085 & \\
\hline Jamaica & 1,375 & \\
\hline Martinique & & \\
\hline Mexico & & \\
\hline Netherlands Antilles & & \\
\hline Panama & & \\
\hline Trinidad and Tobago & & \\
\hline United States & & \\
\hline Venezuela & & \\
\hline
\end{tabular}

Source: 1992 International Trade Statistics Yearbook, United Nations. 


\section{Comparative Overview of the CEPPOL-Designated Subregions}

Within four of the six WCR subregions, the amount of divergence in standard of living and the size and composition of economies is nearly as striking at the subregional level as it is throughout the WCR as a whole. The exceptions to the general pattern of diversity are Subregion II, which is typified by agricultural economies with low per capita GDP and fairly low population densities, and Subregion IV, which is typified by tourism-dominated economies with somewhat higher than average GDP and very high population densities.

Fisheries statistics, although very incomplete and often unaccommodating for purposes of direct comparison, provide sketches of the subregions that have similar implications for the emphasis likely to be placed on the quality of the marine environment. For example, the average per capita consumption of fish throughout the WCR is approximately $20 \mathrm{~kg}$, and it ranges from a low of $5.9 \mathrm{~kg}$ in Subregion II (with all 7 states well below the WCR average) to a high of $33.7 \mathrm{~kg}$ in Subregion IV (with 5 states consuming more than twice the WCR average, and another 3 well above average). These patterns, like the larger economic picture, point to strikingly different incentives at work in the two subregions with respect to controlling degradation of marine and coastal resources. Within the other subregions, by contrast, the levels of fish consumption, like the other economic indicators, are much less consistent.

A number of marine pollution and resource degradation problems plague all of the subregions, though in varying degrees. The most widespread problems are direct damage to reefs and mangroves from commercial and recreational activities (e.g., dredging, clearing, dumping, fishing, diving, and boating) and pollution of coastal waters by sewage effluent. Among the problems that reach serious proportions in some subregions while occasioning little distress in others are coastal erosion; deforestation; and pollution from fertilizers and pesticides, bauxite mining, and oil refineries.

\section{Economically heterogeneous subregions}

Subregion III, the most strikingly heterogeneous subregion (in economic terms), includes the Greater Antilles, the Bahamas, and the Cayman and Turks and Caicos Islands. This subregion is home to both the highest and the lowest per capita GDPs throughout the WCR (the Cayman Islands and Haiti, respectively), as well as to the economies that rank highest throughout the WCR in terms of the predominance of agriculture (Haiti, at 34 percent of GDP), versus manufacturing (Cuba and Puerto Rico, both at 39 percent), versus tourism (Cayman Islands at 70 percent, about even with Antigua \& Barbuda and the US Virgin Islands in Subregion IV; and the Bahamas, where tourism has recently declined from about 75 to about 50 percent of GDP). Moreover, among all the economies in the WCR that are heavily oriented toward tourism, those in Subregion III are the most firmly bolstered by a robust financial 
services sector.

Jamaica, at the geographic center of Subregion III, has the most balanced mix of agriculture, manufacturing, tourism, and mining of any country in the WCR (agriculture 5 percent, mining 10 percent, manufacturing 20 percent, tourism 21 percent), and in this sense could perhaps be characterized as the most typical of Caribbean countries, notwithstanding a per capita GDP less than one-third the WCR average.

The Subregion III countries exhibit similar range as well in the extent to which fisheries provide a significant export/import and dietary staple. The value of net fish exports by the Bahamas is the second-highest throughout the entire WCR (after Cuba; Table 10). As can be seen in Figure 12, the Cayman Islands has one of the smallest catches (by weight) and exports the largest share of its catch of any WCR country, relying heavily on imports (Table A.4) to satisfy a roughly average per capita domestic consumption rate among its tiny population of 26,000. Haiti, by contrast, exports less than 10 percent of its catch, which ranks in the middle range (by weight) among all the WCR countries; nonetheless, more than two-thirds of the fish consumed by Haiti's population of 6.5 million must be imported, even though its per capita consumption rate is the fifth lowest in the entire WCR (Table A.4).

Subregions I and V also exhibit considerable divergence in terms of economic size and emphasis, although in neither case is the mix of leading economic sectors for individual countries as pronounced as in Subregion III. ${ }^{4}$

Subregion I. The divergence among Subregion I countries is most striking with respect to per capita GDP (Table A.1, Appendix A). This is the subregion with the highest average per capita GDP by far (1.75 times the WCR average), yet US per capita GDP is 6 times higher than Mexico's and 14 times higher than Cuba's. Similarly, population density is well below the WCR average of $159 / \mathrm{km}^{2}$ in all three countries, but it nonetheless ranges considerably within the subregion, from $27 / \mathrm{km}^{2}$ in the United States ${ }^{5}$ to $96 / \mathrm{km}^{2}$ in Cuba. All three economies are industrialized and diversified, but Cuba's is the most distinctly geared to natural resource exploitation: 20 percent of Cuba's GDP is concentrated in agriculture and mining, as opposed to 11 percent of Mexico's and just 4 percent for the United States-notwithstanding the fact that the United States holds more than 1600 outer continental shelf leases in the Gulf of Mexico and, together with Mexico, accounts for three-quarters of the roughly 100 oil refineries in operation throughout the WCR (Table A.3).

\footnotetext{
${ }^{4}$ This is hardly surprising, given the smaller numbers of countries involved-just 3 in Subregion I and 5 in Subregion V as opposed to 8 in Subregion III-and the higher proportions of large economies, which tend to be more diversified and more balanced than smaller ones. whole.

${ }^{5}$ Population density is roughly the same throughout the five Gulf coastal states as for the United States as a
} 

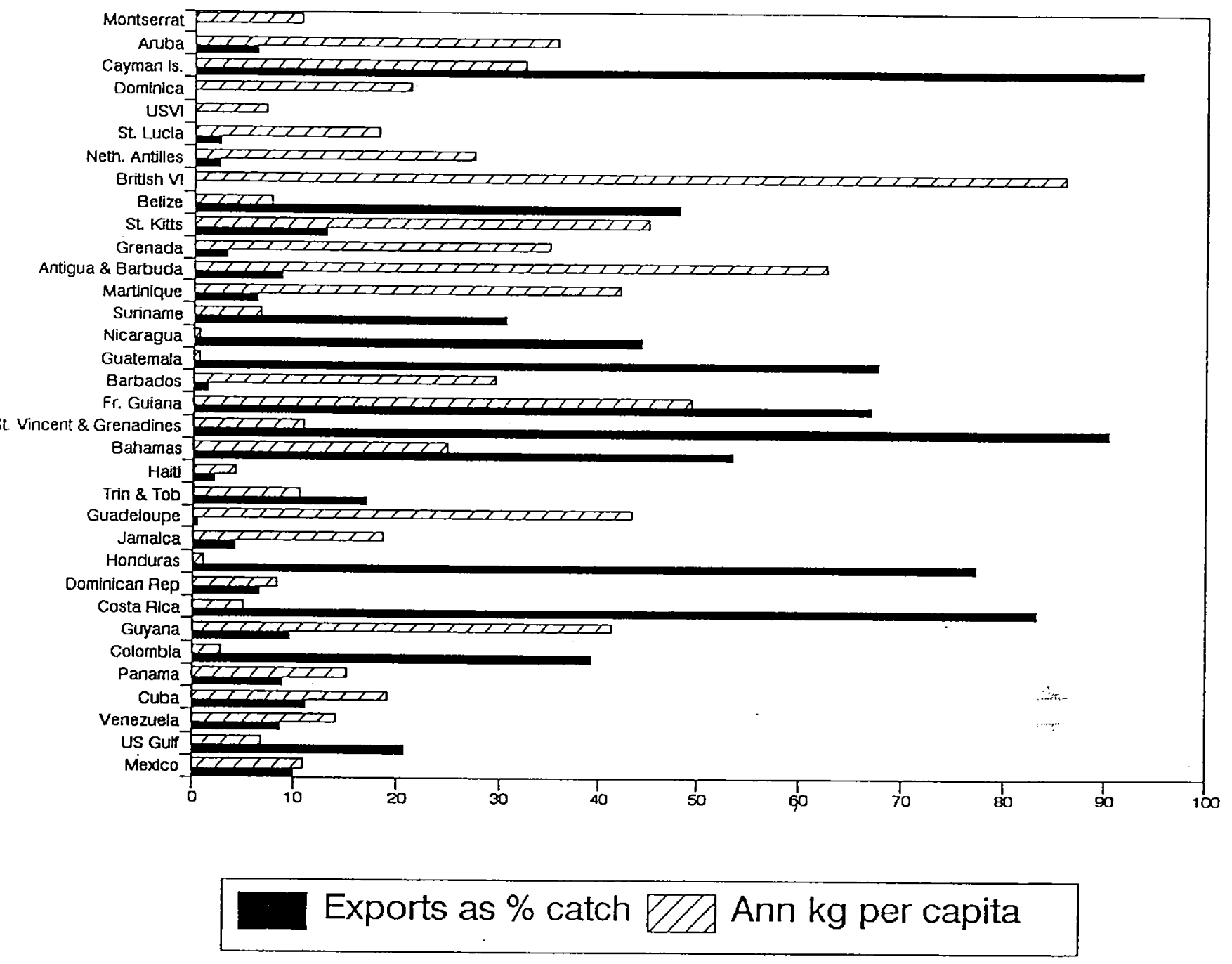

Sources: FAO, 1993a; United Nations, n.d.

Figure 12. WCR fish exports and per capita fish consumption

(Note: States appear in order, bottom to top, from largest to smallest catch by weight.) 
The picture is similar with respect to fish exports: Cuba has the fourth-largest catch by weight in the WCR (after Mexico, the US Gulf Coast states, and Venezuela), and the value of its net fish exports is the highest of any reported for the entire region (Table 10). Only Subregion VI has less economic reliance on tourism, which constitutes less than 2 percent of GDP for each of the three Subregion I countries and about 2.6 percent of GDP for the five US Gulf coastal states.

Subregion $V$. As important as petroleum is in the Gulf of Mexico, it is in Subregion V that its economic dominance is greatest. Each state in the subregion has at least one refinery, and oil accounts for roughly 30 percent of GDP for Trinidad \& Tobago and about 23 percent for Venezuela. Tourism is targeted for development in Venezuela and especially in Trinidad \& Tobago, but in neither country, nor in Colombia, does it yet contribute appreciably to GDP.

The least industrialized state in Subregion $V$ is the Netherlands Antilles, which has the largest commercial drydock in the Western Hemisphere, on Curacao; tourism is the major employer and accounts for more than one-third of GDP, followed in importance by banking/finance and fishing. Although tourism figures even more prominently in Aruba (where it is nearly 50 percent of GDP), Aruba's oil and manufacturing sectors are considerably more robust than in the Netherlands Antilles.

Colombia's mainstays are agriculture and manufacturing (each accounting for 21 percent of GDP), but in no other country of Subregion V does agriculture account for more than 5 percent of GDP.

Fish is an important dietary staple only in the Dutch dependencies, which must import three-quarters or more of their needs to meet domestic demand. The largest fish exporter in the subregion is Colombia (Table 10), which has the sixth largest catch by weight in the WCR, exports 40 percent of its catch, and imports. one-third of its needs to meet the lowest per capita domestic consumption rate outside of Central America. Venezuela, with a catch three times the size of Colombia's, exports very little of its catch (about 10 percent) and imports less than 1 percent of its needs. Trinidad \& Tobago imports just under half of its needs and exports less than one-fifth of its catch.

Subregion VI. Fisheries may well be more important to Guyana and French Guiana in Subregion VI than to any other countries in the WCR. Both have small and quite narrow economies and very high per capita rates of fish consumption. Guyana, with a population of 800,000 , has the distinction of being the only WCR state that is self-sufficient in fish. ${ }^{6}$ French Guiana is one of the major exporters of fish and shrimp in the region, with shrimp accounting

\footnotetext{
${ }^{6}$ According to many sources, including FAO (1993a). UN trade data for 1992 , however, list $\$ 1,375,000$ worth of fresh and frozen shellfish imports by Guyana.
} 
for half of export earnings (and sugar accounting for most of the rest).

Overall, agriculture is the predominant sector in both economies, in terms of share of GDP. In French Guiana, however, the major employers are forestry and construction, although France is both the largest source of income (in the form of subsidies) and the most important source of high-wage and high-skill employment (at the Euro-French space center at Kourou). Guyana, nicknamed the "breadbasket" of the Caribbean, is also known as the world's largest producer of bauxite and has recently become a producer of gold as well.

Agriculture and bauxite mining are less prominent, though not insubstantial, in the economy of Suriname, where the largest share of GDP ( 22 percent) is concentrated in financial and real estate services and the largest segment of the workforce (37 percent) is employed in public administration and defense. Suriname's is decidedly the most precarious economy within the subregion, however, having hovered near the brink of fiscal crisis ever since economic aid from the Netherlands and the United Nations was suspended in 1982 in the wake of a postindependence military coup (U.S. State Department 1994).

Probably the most homogenous aspects of the Subregion VI countries are their remarkably low population density, which averages just 2.6 persons per $\mathrm{km}^{2}$, and the near-total concentration of their populations along the coastline. Per capita GDP is also below the WCR average for all three countries, but it ranges from a very low $\$ 435$ in Guyana to more than ten times that amount in Suriname.

\section{Economically homogeneous subregions}

Subregion II. Average per capita GDP is lowest of all in Subregion II, one of two quite economically homogeneous subregions within the WCR. As noted earlier, agricultural economies with low per capita GDP and low population densities are characteristic of Subregion II. So, too, is a greater economic orientation toward the Pacific than the Caribbean coast for all the Subregion II countries that have two coastlines (i.e., all but Belize). Manufacturing, though generally accounting for a lesser share of GDP than agriculture, is even more ubiquitous throughout the subregion as an important economic sector.

The only two countries that depart appreciably from this description are Mexico (where agriculture is just 9 percent of GDP) and Panama (where agriculture and manufacturing combined are just 20 percent of GDP). Mexico, as noted earlier, is quite highly diversified, and its economy completely dwarfs all others in the subregion (although Mexico's per capita GDP is no more than 50 percent higher than any other in the subregion). Panama alone in Subregion II has an economy dominated by services (26 percent of GDP in transportation/communications, with 32 percent of the workforce employed in government services). 
Only in Belize does tourism represent a substantial proportion of GDP (23 percent) and a priority area for investment and growth.

After Mexico, Panama leads the subregion in fish catch (by weight). Costa Rica, Honduras, Guatemala, and Belize all export substantially greater proportions of their catch than Panama, but within the subregion only Mexico's net fish exports surpass Panama's in value. The average rate of domestic fish consumption in Subregion II is the lowest in the WCR, and only in Mexico and Panama does it surpass $10 \mathrm{~kg}$ per capita per year.

Subregion IV. In striking contrast to this picture is Subregion IV, the only other economically homogeneous subregion, which is typified by tourism-dominated economies, somewhat higher than average per capita GDPs, and very high population densities. Subregion IV contains seven of the bottom eight WCR countries in terms of proportion of GDP accounted for by agriculture, mining, and manufacturing combined.

The homogeneity is particularly noteworthy for the fact that Subregion IV is the one with the greatest number of political units (14) and the broadest array of foreign dependencies (two French overseas departments, the smaller islands of the Netherlands Antilles, three British territories, and the U.S. Virgin Islands). Clearly the commonalities are the small size of the islands and their considerable limitations with respect to natural resources. Only Dominica, Grenada, St. Lucia, and St. Vincent and the Grenadines can support agriculture to any significant extent (i.e., approaching 20 percent of GDP).

Tourism is tremendously important to most of the Subregion IV economies. This is true even of heavily (French) subsidized Guadeloupe and Martinique and those few other states that may be equally well known for other things besides tourism-such as Barbados for its sugar, rum, and banking services, or the US Virgin Islands for its Hess Oil refinery, the largest in the Western Hemisphere.

Fisheries employment and fish consumption also contrast distinctly with the Subregion II pattern. Domestic consumption of fish is very high in nearly all the Subregion IV states, and comparatively little of the fish catch is exported by any state except St. Vincent and the Grenadines.

3. Marine pollution and resource degradation problems within and across subregions

Table 11 displays the observed pollution and resource degradation problems associated with the economic activities and population concentrations within the WCR states and subregions. Nearly every state in the region has suffered direct damage to coral reefs and mangroves from a combination of pollutants and economic and recreational activities (as well as from natural hazards such as hurricanes and coral bleaching). The next most common 

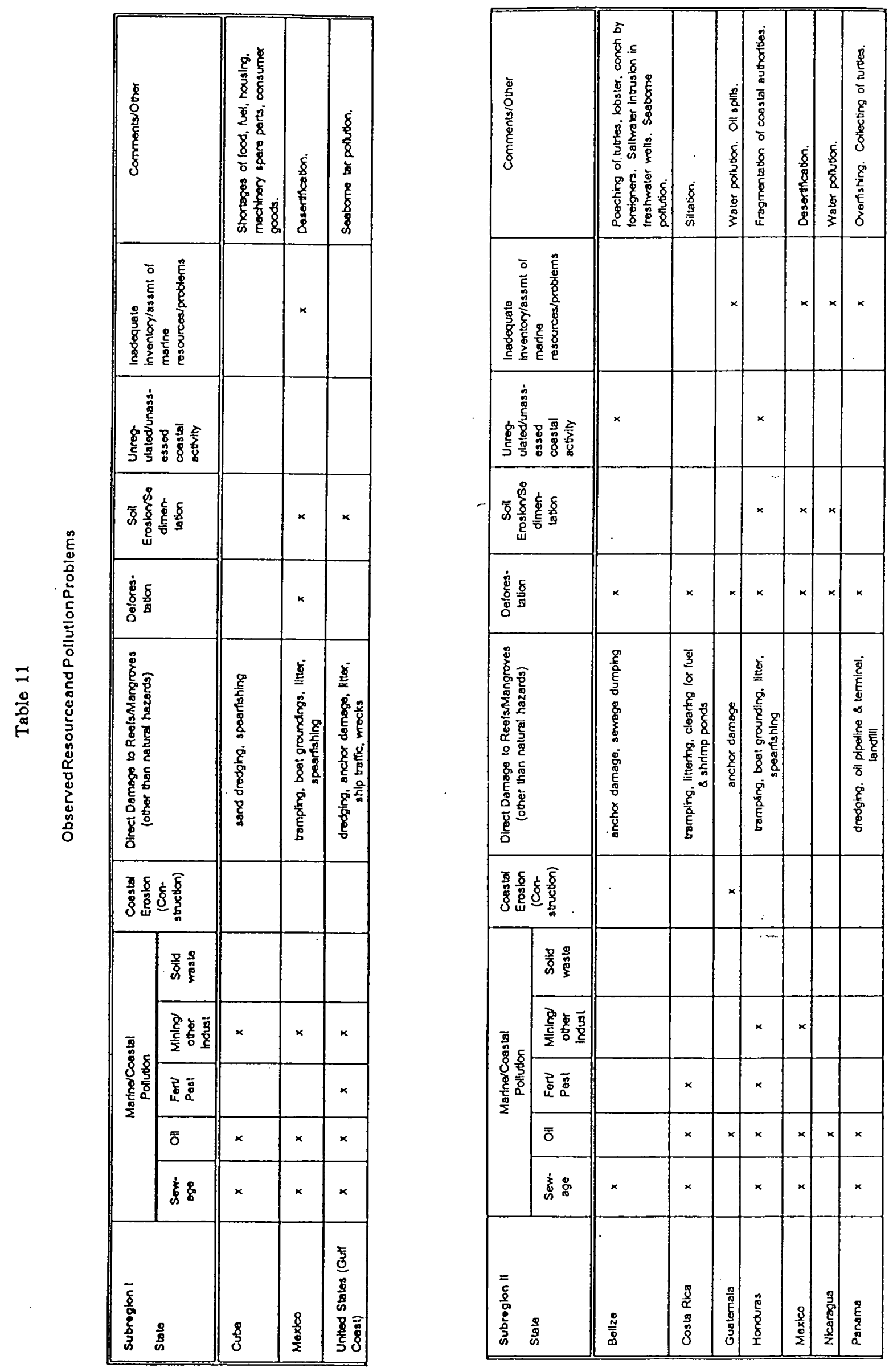


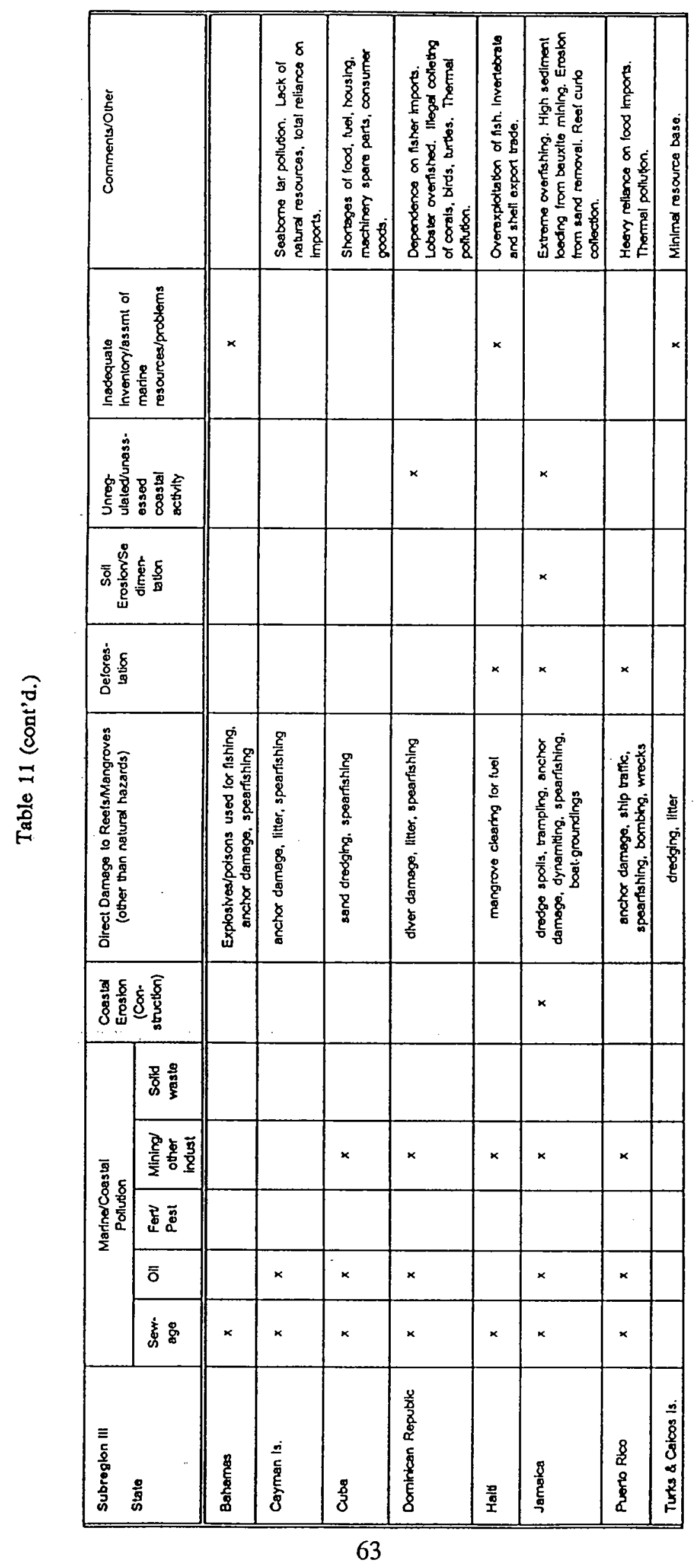




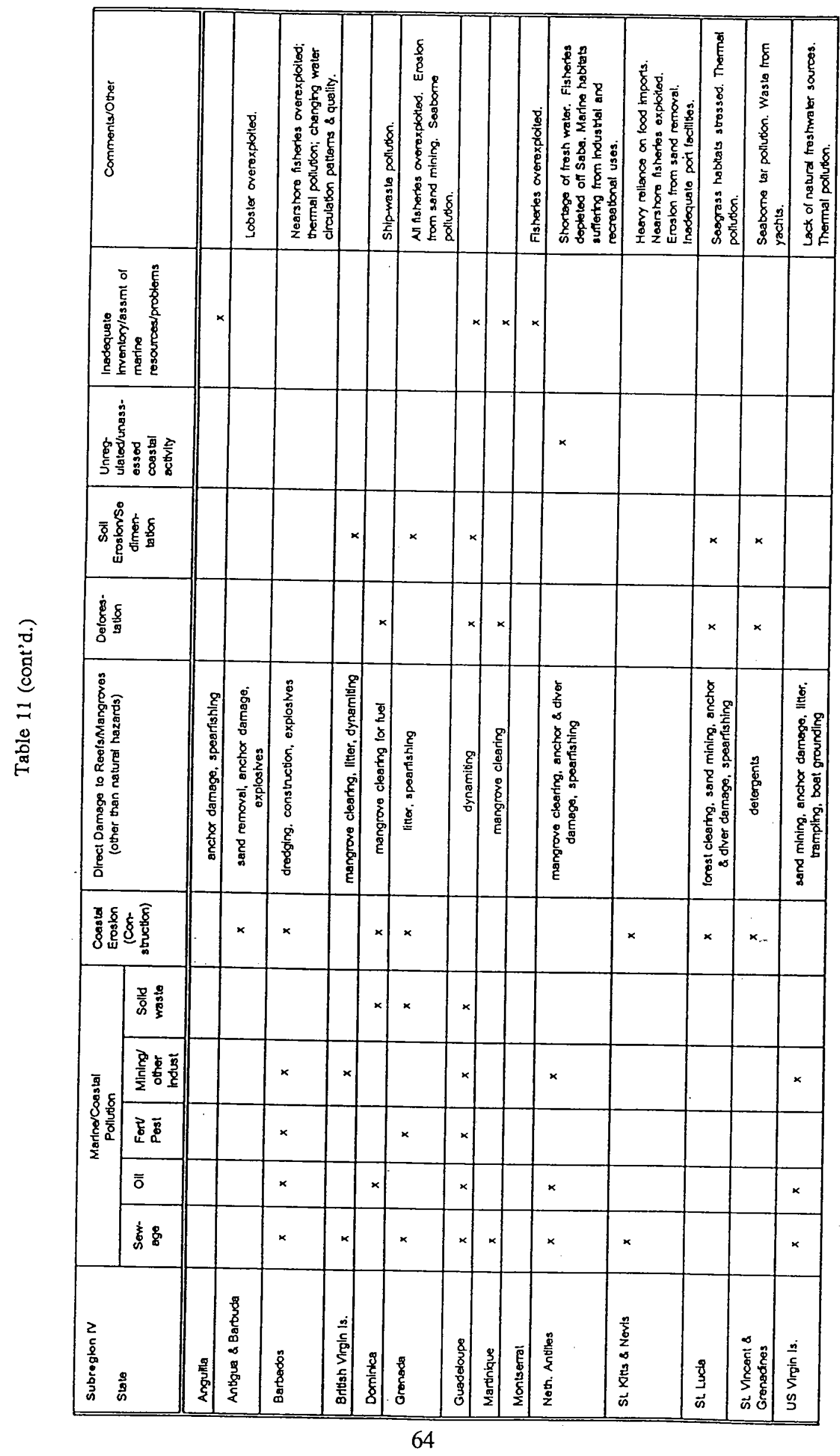



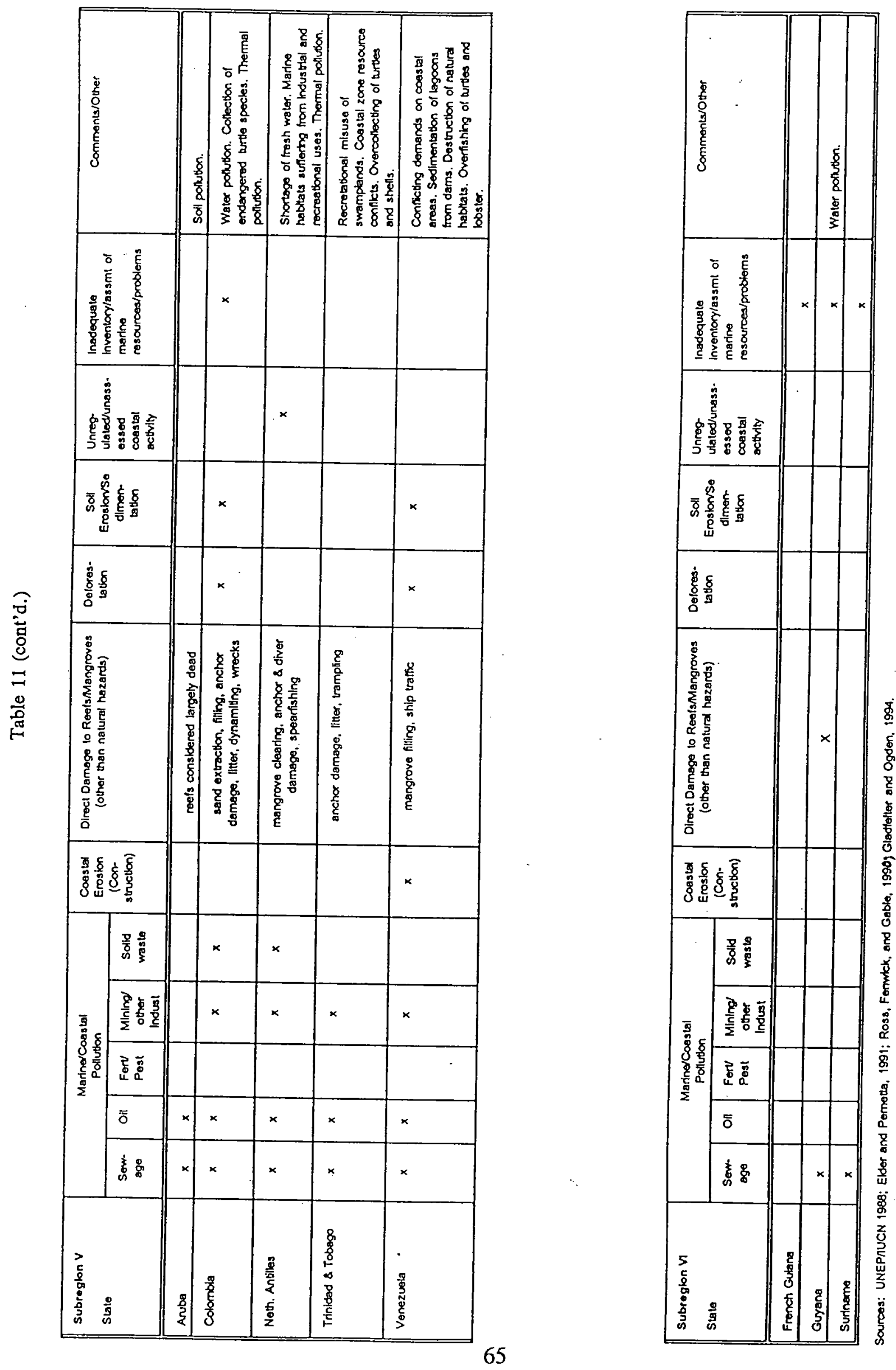
problem throughout the region is pollution of coastal waters by sewage effluent. Oil pollution is another widespread problem, although one that tends to originate primarily from sources and activities that are not based on land.

On average, the states in Subregions I and V do better than those in the other subregions in providing sewerage services (an average of $73 \%$ of citizens in Subregion I have access to services, and an average of $64 \%$ of Subregion $V$ citizens). Being the most heavily industrialized of the subregions, they share other, less desirable, traits as well. Readily apparent in Table 11 (and in the CEPPOL results), for example, are the pollutants associated with the heavy emphasis on oil exploration and refining in both these subregions. Problems of a more localized nature in Subregions I and V include the coastal erosion associated with the high concentration of population in the coastal zone in Venezuela; soil erosion/sedimentation emanating from Mexico, the US Gulf Coast, and Venezuela; deforestation in Mexico, Colombia, and Venezuela; and stress to reefs and mangroves from ship traffic and wrecks off Colombia, the United States, and Venezuela.

The only other area in the WCR where ship traffic and groundings have been cited as a serious problem is the Greater Antilles, especially off Puerto Rico and Jamaica. Far more important and common throughout Subregion III, however, is pollution by oil and grease, mining, and other industrial pollutants, which has left only the Bahamas and the Turks and Caicos Islands relatively untroubled. Jamaica, the most economically broad and balanced state in the subregion, suffers the broadest array of pollution and environmental degradation problems as well, including stress to mangroves from sand removal and bauxite mining, deforestation, and soil erosion. Haiti is noteworthy for its very high rate of mangrove clearing for fuel to sustain a tradition of charcoal-based cooking, and for its very low rate of access to sewerage services. Overall, Subregion III ranks in the middle range for provision of such services, which are available to an average of $62 \%$ of citizens throughout the subregion. The broadest access is provided by the Cayman Islands, where $97 \%$ of the population have access to sewerage services.

The contrasts between Subregions II and IV, and the relative homogeneity within each, are also evident in the environmental problems noted in Table 11. Deforestation is a problem for every Subregion II country, whereas coastal erosion, sewage pollution, and overfishing are the most pervasive natural resource problems in Subregion IV (in addition to the ubiquitous stresses to reefs and mangroves). In both subregions, an average of just $37 \%$ of the population has access to sewage services. ${ }^{7}$ Within Subregion II, the coastal waters of Costa Rica,

\footnotetext{
${ }^{7}$ According to the Britannica Book of the Year 1995. The Pan American Health Organization (PAHO) paints an even more discouraging picture: PAHO estimates that $<10 \%$ of sewerage systems in Latin American countries have adequate treatment plants, and that only $5-10 \%$ of the collected wastewater receives adequate treatment (PAHO/WHO 1992). For the countries of the Caribbean Common Market (CARICOM, including Antigua \& Barbuda, Bahamas, Barbados, Belize, Dominica, Dominican Republic, Grenada, Guyana, Haiti, Jamaica, Mexico, Puerto Rico, St. Kitts \& Nevis, St. Lucia, St. Vincent \& the Grenadines, Suriname, Trinidad \& Tobago, and
} 
Honduras, and Mexico contain substantial amounts of industrial pollutants, which is a problem as well for Barbados, Grenada, Guadeloupe, and the US Virgin Islands in Subregion IV.

The very few indications of pollution and natural resource degradation problems noted for Subregion VI in Table 11 reflects primarily two factors: the relative lack of modern industrialization in the subregion, and a lack of study of its environmental problems. Only the sewage problems associated with the heavily coastal concentration of the population are recorded.

\section{Extra-regional trade as a unifying force}

Having emphasized the economic diversity of the Wider Caribbean Region and the distinct characteristics of its individual states and subregions as crucial considerations in the development of an effective protocol on land-based marine pollution, it is equally important to recognize the degree to which this region has come to be defined and shaped into something of a single, coherent entity by virtue of its trade relations with the rest of the world. The states with important agricultural sectors, for example, are bound by their interest in preferential trade agreements with the United States and the United Kingdom concerning sugar and bananas, and the manufacturing-oriented economies are bound by a similar interest in agreements with the United States concerning garments and other consumer goods.

Currently there is considerable concern that at least some of these sectors are in jeopardy from the trend toward trade liberalization embodied in recent NAFTA and GATT/WTO developments and from changes in UK import policies resulting from the integration of the European market. (In addition, Caribbean shipping services have been predicted to lose market share in the wake of European integration and resulting efforts to strengthen the position of European shipping services.) The fear of falling prices and/or loss of market share has intensified the trend toward investment in tourism throughout virtually the entire region-just as banana production was intensified after a dramatic lowering of US sugar quotas in the 1980s led to a decline in the importance of sugar to many WCR economies.

The increase in banana production has had serious environmental consequences (World Bank 1993), primarily in the forms of soil depletion and erosion and high concentrations of nutrients and pesticides in agricultural run-off. The intensification of tourism-related construction, sewage, transportation, and other activities and services, particularly within the well-established, beach-oriented tourist markets, could eventually prove even more environmentally damaging. As one concerned observer has argued, "Tourism in the Caribbean could cease within ten years if destruction of the environment continues at the present pace"

Venezuela), a recent PAHO survey concluded that only $2 \%$ to $16 \%$ of the population is served by sewage systems (UNEP 1994a). 
(Goodwin 1992).

One encouraging and potentially competing trend, in which Belize, Dominica, and Guyana have been leading the way, is an emphasis on ecotourism and nature activities, which are particularly popular with the Europeans who account for most of the recent growth in tourist arrivals in the region (Goodwin 1992). Another development, embraced by some governments and shunned by others, is the spread of casino gambling, which has proven quite successful in boosting tourism performance in Aruba, for example (Goodwin 1992).

\section{E. Legal and Regulatory Frameworks}

In the context of negotiating an international protocol, a particularly important aspect of regional diversity in the WCR concerns the distinct legal traditions and systems which must be harmonized and upon which a system of effective protocol implementation depends. The majority of states follow one of two primary legal/cultural systems prevailing in the region. The first of these is the Roman civil law tradition of the Spanish-speaking countries, in which patterns of resource use are based upon the principles of private ownership and have been codified over time in a body of civil codes, statutes, and ordinances. The other major tradition in the region is that of Anglo-Saxon common law, which traditionally has emphasized custom, usage, and the decisions and precedents of courts of law, and only comparatively recently has been codified by legislative action.

Characteristic of nearly all the WCR countries, however, irrespective of legal tradition, is an incomplete and somewhat disjointed approach to environmental legislation and management. Two common conclusions noted in studies of the environmental problems of the Wider Caribbean Region are that (1) the laws, regulations, statutes, and ordinances with a bearing on environmental matters typically are too fragmented to deal comprehensively and effectively with the full range of environmental problems in the region; and (2) the legal and/or administrative mechanisms for enforcing environmental rules are too often absent, inappropriate, and/or readily ignored or circumvented.

A 1991 study by the Inter-American Development Bank (IADB), for example, notes that most Bank borrower countries in the $\mathrm{WCR}^{8}$ lack coherent national policies for environmental protection, relying instead on so-called sectoral legislation and ministries, which typically address themselves to three general categories of fundamentally "dissimilar" subjects:

(i) protection of certain natural resources such as water, soil, wildlife, marine and coastal ecosystems, nonrenewable natural resources, etc.;

\footnotetext{
${ }^{8}$ IADB borrower countries in the region include the Bahamas, Barbados, Colombia, Costa Rica, Dominican Republic, Guatemala, Guyana, Haiti, Honduras, Jamaica, Mexico, Nicaragua, Panama, Suriname, Trinidad \& Tobago, and Venezuela.
} 
(ii) management of the urban environment, such as human settlements and industrial sites; and

(iii) protection of human health from environmental impact (Brañes 1991).

The IADB study further notes that this purely administrative approach to environmental legislation is generally accompanied by an approach to enforcement that revolves around the notion of policing and the establishment of penalties. The fines associated with environmental infractions, moreover, are generally too low to constitute a serious deterrent, and in many cases they are easily avoided because of the lack of resources to police effectively.

These points are reinforced in a 1994 World Bank study of the 16 member nations of CARICOM (the Caribbean Common Market). ${ }^{9}$ The World Bank study rates the severity of 11 key environmental issues in each of the 16 countries, using a scale of 1 (least severe) to 5 (most severe). Heading the list, in terms of combined score for all 16 countries, is inadequate "monitoring/enforcement" (54 points). Rated fourth most severe among the 11 issues are the adequacy of the "institutional framework" and "coastal zone degradation" (both at 44 points), after solid waste management (51) and sewage disposal (47).

A third and closely related problem with the institutional framework, according to the IADB study, is the tendency of WCR states to centralize legislative and administrative authority unduly at the national level. Very few of the region's countries-only Cuba, Mexico, St. Kitts \& Nevis, the United States, and Venezuela-have a federalized form of government in which states or provinces are interposed between the national and municipal levels and given extensive authority for establishing or enforcing laws and regulations with environmental relevance. ${ }^{10}$ One important consequence of this approach has been to limit severely the response capability of environmental administrations (Brañes 1991).

As a practical matter, however, the pattern in federalized and non-federalized states alike is for "general issues of the ownership and use of environmental components, damage to the environment, and legal custodianship of the environment" to be governed not by comprehensive legislation but by a patchwork of sectoral legislation and civil codes, under criteria that the IADB study criticizes as "totally inappropriate" (Brañes 1991). At the heart of the problem with the legal and regulatory framework that is characteristic of most WCR countries is legislation that fails to recognize what the World Bank (1994) has termed "the interlocking nature of the economy and the ecology" for most of the Caribbean countries:

${ }^{9}$ The CARICOM members are Antigua \& Barbuda, the Bahamas, Barbados, Belize, Dominica, Dominican Republic, Grenada, Guyana, Haiti, Jamaica, Montserrat, St. Kitts \& Nevis, St. Lucia, St. Vincent \& the Grenadines, Suriname, and Trinidad \& Tobago.

${ }^{10}$ In Venezuela, however, although state governments generally have powers expressly assigned to them as well as residual powers not expressly assigned to the national or municipal governments, authority for environmental matters is reserved for the national government. In Mexico, similarly, the national government has long reserved such powers, although recent reforms allow for a gradual sharing of environmental powers by state and municipal governments (Brañes 1991). 
This legislation ignores the fact that the behavior it attempts to correct through these sanctions does not normally involve individual deviations from an imposed legal order, but generalized social behavior which is deeply rooted in society as a result of the predominant style of development based on production and consumption patterns that often clash with environmental protection. (Brañes 1991)

Nor does the typical pattern of sectoral legislation and civil codes reflect a modern, scientific understanding of the environment as a single, interlocking system.

There are some noteworthy exceptions to this pattern, however, which Brañes argues are contributing to a trend throughout much of the region toward a more comprehensive approach to environmental legislation and management. The IADB study cites national legislation in Colombia, Cuba, Guatemala, and Mexico as instances of "true" environmental legislation-that is, legislation "based on a concept that views the environment as a whole, organized as a system." The specific examples include Colombia's National Code on Renewable Natural Resources and Environmental Protection (1974); Cuba's Act No. 33 on Environmental Protection and the Rational Use of Natural Resources (1981); Guatemala's Environmental Protection and Improvement Act (1986); and Mexico's General Act on Ecological Balance and Environmental Protection (1988), which combines and supersedes two earlier acts of similar character (the 1971 Federal Act on the Prevention and Control of Environmental Pollution, and the 1982 Federal Environmental Protection Act). Although not covered by the IADB studies, both Belize and the United States could be included in this group as well-Belize for its 1992 Environmental Protection Act, and the United States for its 1969 National Environmental Policy Act.

Evidence for the argument that other states in the region are beginning to recognize the integrated nature of the environment and of the causes of its degradation is presented in Table 12 , which indicates the incidence of cabinet-level ministries, national committees, or other national bodies whose charter is to provide comprehensive leadership and coordination on environmental matters. Although comparatively few of the WCR states (Belize, Colombia, Grenada, Mexico, Trinidad \& Tobago, and Venezuela) have yet accorded the environment the importance of a cabinet-level concern, most have at least established a national committee or some other entity that addresses itself more or less exclusively to environmental matters. National committees typically are housed in the office of the president and include in their membership the ministers of relevant sectoral agencies; they may also include representatives of other public or scientific organizations, industry, and NGOs.

Although national committees are generally less influential than groups accorded cabinetlevel status, as permanent bodies they help to ensure that environmental affairs receive continuous, comprehensive, high-level attention. Of the 25 sovereign WCR states ${ }^{11}$ listed in Table 12, only 6 have not established some form of national umbrella organization to provide comprehensive oversight and leadership on environmental matters, and there is no WCR state that does not fill such a gap by vesting at least some measure of national environmental policy

\footnotetext{
"With few exceptions, the Dutch, UK, and US dependencies and the French overseas departments in the region conform to the laws and regulatory structures and procedures of their respective protector states, which are not considered in this discussion.
} 

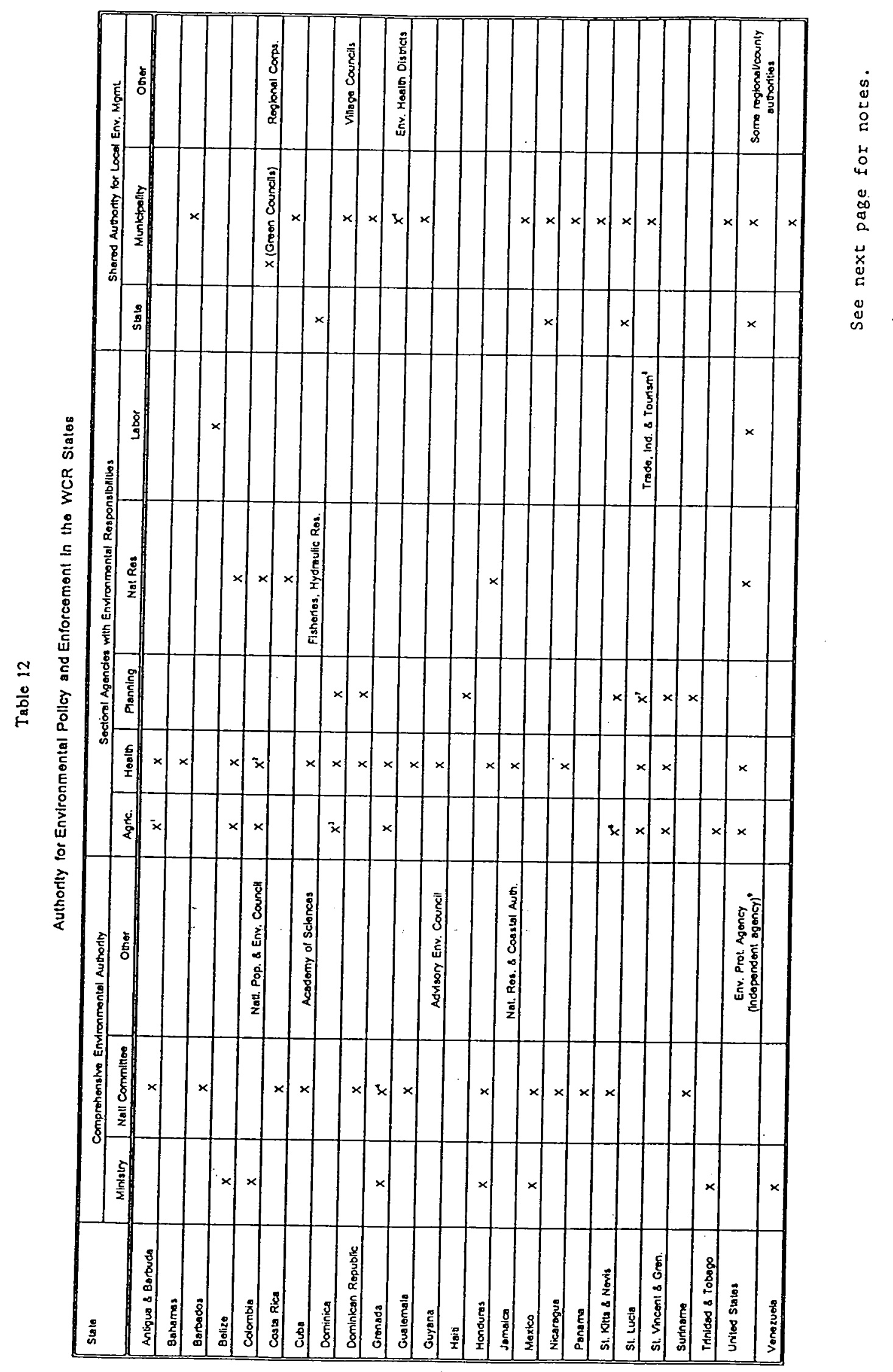


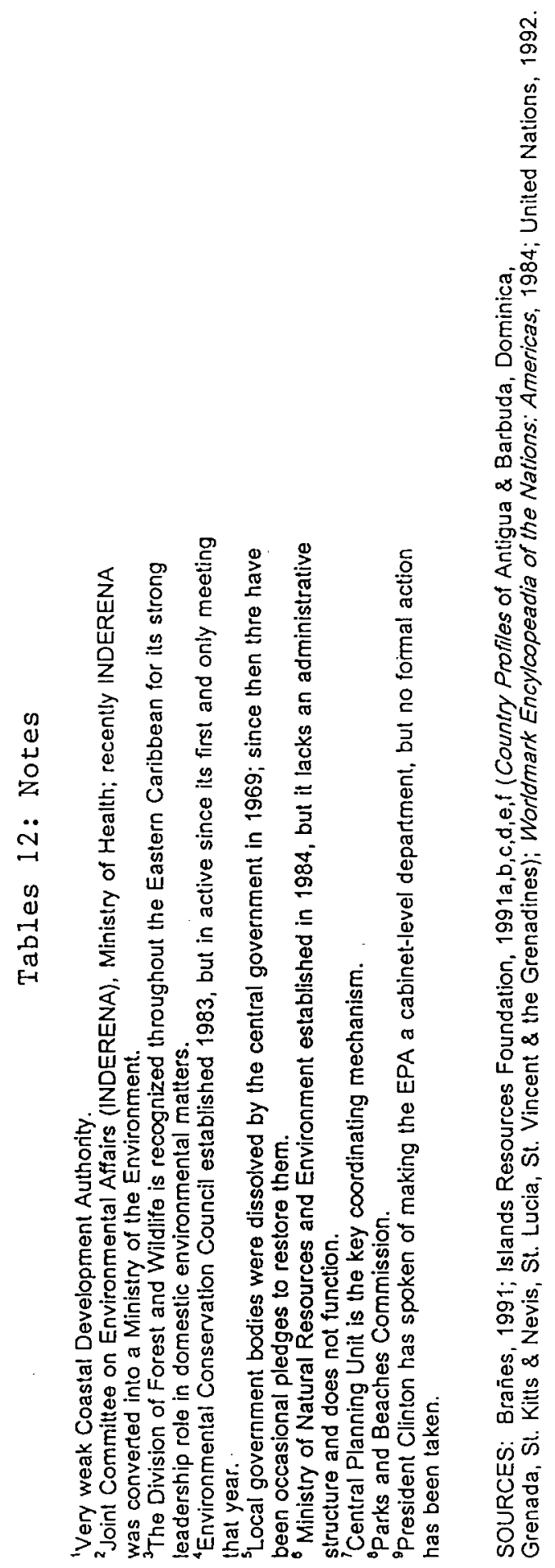


and authority in one or more sectoral ministries. Table 12 also shows that, although intermediate state-level authority for environmental matters is quite rare throughout the WCR, all but 9 national governments share such authority, at least as a practical matter, with municipalities.

Even in those states where a holistic view of the environment has not taken hold, local and national sectoral authorities have in many cases acquired broader responsibility and authority as knowledge of the interactions between environment and economic activity has increased. Ordinances for controlling beach litter, for example, have been expanded to encompass habitat protection and beach stabilization; and port/harbor authorities in some small-island nations have acquired major responsibility for regulation of construction and development activities (UNEP 1994c). As noted in UNEP's 1994 document on Appropriate Approaches to the development of an LBMP protocol for the Wider Caribbean, "[t]he challenge for governments is to determine how to establish a national planning framework that builds on existing power structures and specialized expertise and complements and reinforces local authorities" (UNEP 1994c; emphasis in original). The same document also recommends the designation of a "national focal point" for land-based marine pollution problems and control, which in many instances may well ensure greater and better-integrated attention to LBMP issues than could reasonably be expected of a newly established national ministry with a far more comprehensive environmental charter.

\section{F. Measures of Environmental Infrastructure}

In addition to the environmental laws and regulations described above, we have surveyed the literature for measures of environmental infrastructure. Table 13 compares some useful measures across WCR states. Good summaries of the quality of the local marine environment and the status of institutional and technological capabilities to deal with LBMP problems can be found in the national reports to the UNCED conference (United Nations 1992). Some of the relevant information is listed in the last column of Table 13.

Other useful measures include the number of major submarine outfalls (Salas 1994), the percentage of the state's populations. with access to closed public sewers or septic tanks, and the percentage of the population with access to safe drinking water. Submarine outfalls provide benefits in terms of removing sewage from discharge into immediate coastal environments. Only in the United States and Puerto Rico are discharges subject to primary or secondary treatment. Many states have minor submarine outfalls; for example, in some island states, coastal hotels often discharge in this manner. No statistics have been collected on minor submarine discharges. Where sewage disposal is available, the populations of most small island and developing nations are using septic tanks. Closed public sewers are limited to a few urban environments and to the developed states and associated territories of the WCR. Safe drinking water is readily available to the majority of the region's populations, except in the case of a few very underdeveloped states. Many of the island and coastal populations have encountered problems associated with the draw-down of groundwater supplies, resulting in saline intrusion into aquifers and the contamination of groundwater. In some cases, coastal desalination plants can contribute to excessive salinity levels in wetland or near coastal environments. 


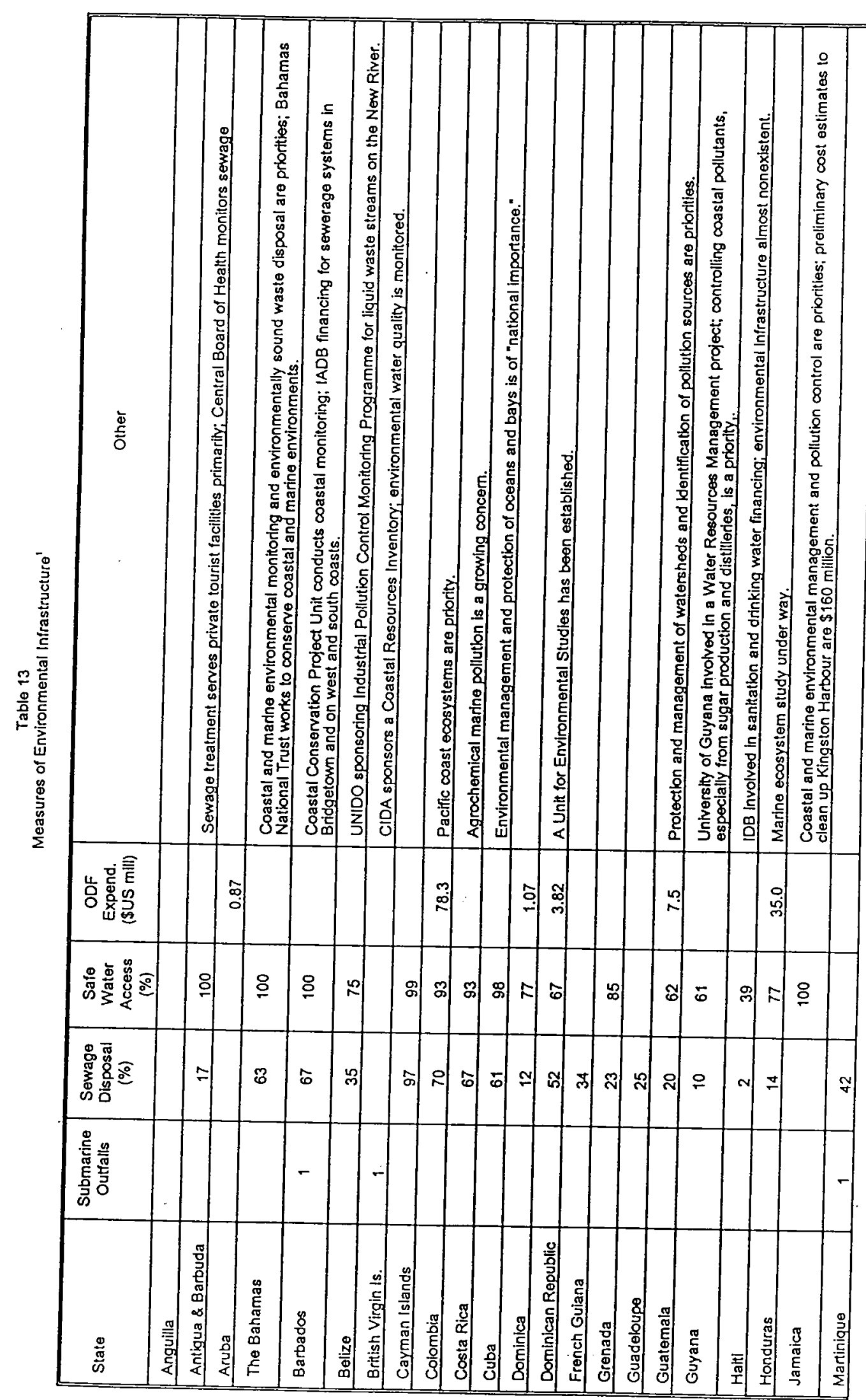




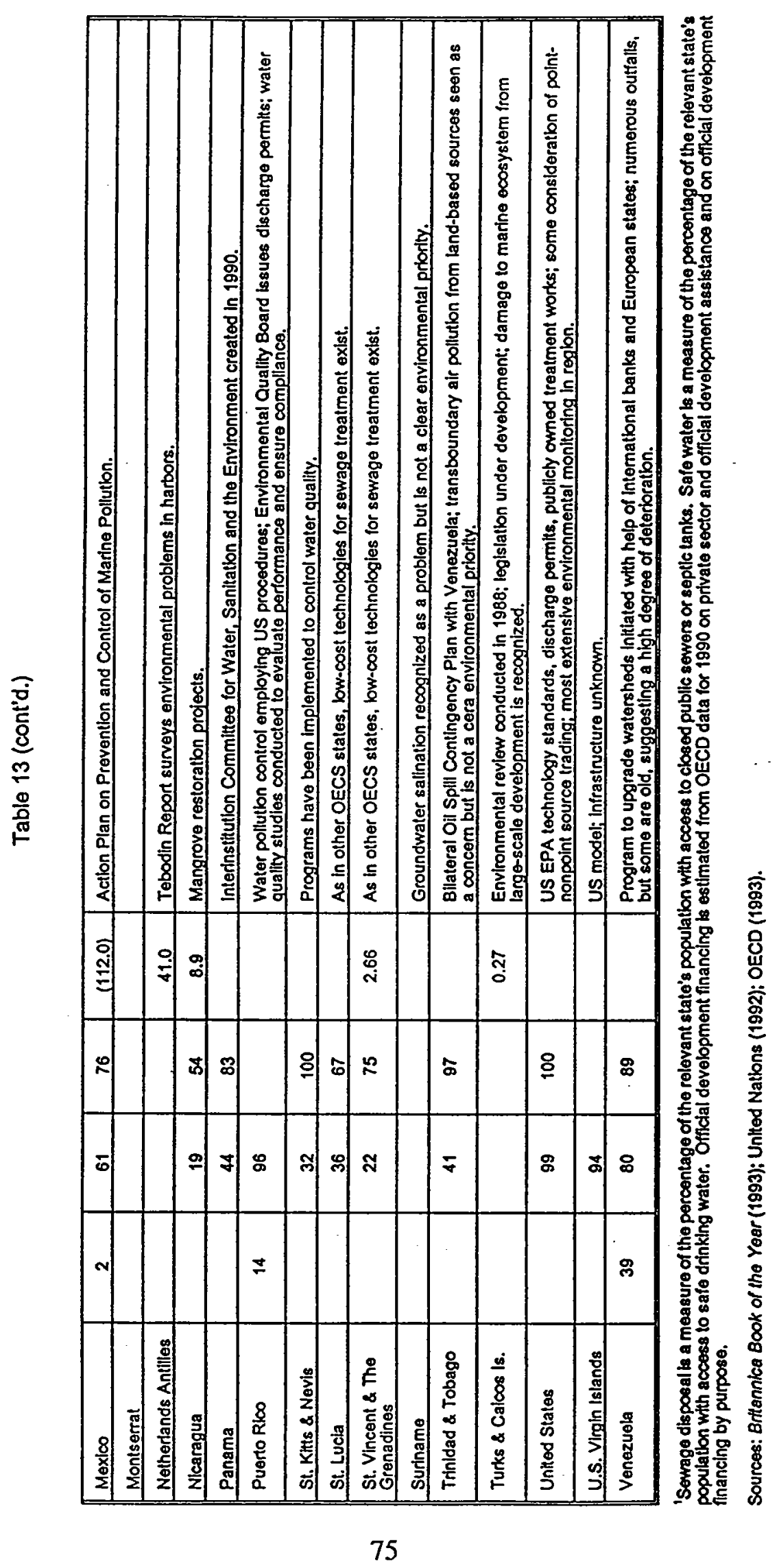


A common plea in the national UNCED reports is for foreign aid and other international financial assistance to help fortify the mostly inadequate capabilities for dealing with LBMP problems in the region.

\section{G. Scientific Capabilities ${ }^{12}$}

Most countries and territories in the WCR support some level of marine scientific research, the most commonly targeted research areas being fisheries, coastal management, and, more recently, the development and maintenance of marine parks and reserves. Much of this research is carried out at regional universities or at small marine laboratories that are owned by a regional or a North American university, supported by competitively awarded government funding. Typically such scientific research programs are seriously constrained by small budgets and associated limitations in staff size and facilities. Formal cooperation among a number of the region's research institutions is well established, however, particularly cooperation toward the goal of promoting general awareness in the region of marine problems and programs to address them. One prominent example is the Association of Marine Laboratories of the Caribbean, which was founded in 1957 (as the Association of Island Marine Laboratories of the Caribbean) and in 1994 included 23 member institutions located in 17 WCR states (see Table A.6, Appendix A).

An important component of the basic ecological research conducted in the Caribbean is research by US university-affiliated scientists working in regional marine laboratories with support from such US government agencies as the National Science Foundation, the National Park Service, and the National Oceanic and Atmospheric Administration. As of the late 1980s, the greater Caribbean accounted for one-fifth of all US marine scientific projects requiring vessel clearances from foreign governments (Negroponte 1987). Included in Table A.6 is a list of member institutions of the Southern Association of Marine Laboratories, a US organization representing government and academic laboratories from the Virginia coast to the tropical southeastern North Atlantic.

In addition to these US research activities, a substantial amount of the marine scientific research conducted in the region is carried out by scientists from Canada, the United Kingdom, the Netherlands, and other European countries with funding provided by their governments.

There are also a good many regionally sponsored cooperative projects or programs that focus on marine resources, pollution, and environmental management. In the mid-1980s such projects numbered about 60 and ranged from small, bilateral efforts to large, long-term multilateral or regionwide efforts (Negroponte 1987) involving UN agencies, environmental nongovernmental organizations (NGOs, discussed separately in the next section), national government agencies, and regional scientific organizations. In the last category is CARICOMP (for Caribbean Coastal Marine Productivity), a research and monitoring network of 24 Caribbean marine program sites (laboratories, parks, and reserves) at which scientists monitor basic

\footnotetext{
${ }^{12}$ Unless otherwise noted, the information in this section is drawn from Gladfelter and Ogden (1994), which was prepared for use in this study.
} 
oceanographic and meteorological variables as well as species type, abundance, and productivity in selected coral reef, seagrass, and mangrove systems. CARICOMP (with member institutions also listed in Table A.6) was established in the mid-1980s with funding assistance from UNESCO and the U.S. National Science Foundation.

Lest the extent of marine scientific activity in the region be overstated, it is important to underscore that national capabilities are in some cases extremely limited, as are the mechanisms and infrastructure to support regional collaboration. According to a 1983 UNESCO survey, for example, fewer than one-half of the marine scientists identified as working in the Caribbean island nations were at work in one of the much more numerous small island states; and only 63 of the 583 scientists working in Latin America were working in the small Central American nations.

\section{H. The Role of NGOs in the WCR ${ }^{13}$}

The extent to which NGOs (and citizens groups) play an important role in bringing popular and official attention to environmental affairs varies considerably across the WCR states, but overall it is markedly on the rise.

In general, NGOs tend to number in the hundreds and to be very well-established, varied, and influential in the larger and more industrialized countries, such as Colombia, Mexico, the United States, and Venezuela. All of these countries afford some legal basis for the establishment of public bodies empowered to represent the public interest, under which NGOs and/or citizen action groups are assured representation.

Throughout most of the WCR, the influence of NGOs is somewhat more limited (though not insubstantial), in part because of the more limited basis for public action, essentially based on the rights of citizen complaint. Although the numbers and the range of interests of NGOs in many WCR countries are considerably more modest, there is nonetheless an unmistakable trend toward their proliferation. In the Bahamas there are fewer than two dozen NGOs, but they have a very long-standing and venerable status dating back to the establishment in 1959, by an act of parliament, of the Bahamas National Trust. The National History Society of Jamaica is even older, but most of Jamaica's 15 or so other active NGOs are less than 20 years old, as is generally true of the growing number of NGOs throughout Central and South America. Even the poorest and least developed of the WCR countries had at least one major environmental NGO by the early 1990s-the Foundation for a Beautiful Suriname, for example, and in Haiti the Friends of Nature Federation and the Association to Combat Erosion and for Full Land Rehabilitation.

An important element in fostering the efforts of NGOs is the emergence of regional NGOs, notably the Regional Network of Nongovernmental Environmental Organizations for Sustained Development in Central America (REDES-CA), established in 1987, and the Caribbean Conservation Association (CCA), established in 1967. The first of these includes

\footnotetext{
${ }^{13}$ Unless otherwise noted, the information in this section is drawn from Brañes (1991).
} 
NGOs from Belize, Costa Rica, Guatemala, Honduras, Nicaragua, and Panama; the latter includes in its membership 17 governments, 65 NGOs, and 120 individuals from among the island and coastal nations of the Gulf of Mexico and the Caribbean Sea, including the Bahamas and Guyana. Headquartered in Barbados, the CCA serves as a clearinghouse for information on the environment and provides technical assistance, environmental education, assistance for parks and protected areas, and regional and national planning services for sustainable development and resource management (Island Resources Foundation 1989).

\section{Other Regional Organizations}

Although the scope of the CCA's membership, interests, and areas of expertise may be unusually broad, the CCA is nonetheless but one of some 100 donor agencies and technical assistance organizations supporting programs for sustainable resource development and environmental management in the Eastern Caribbean alone (Island Resources Foundation 1989). Throughout the entire WCR there are hundreds of such agencies and organizations, including multilateral investment banks, specialized UN agencies, charitable foundations, and NGOs, whose concerns range from disaster preparedness and relief to nutrition and education.

Many of the UN agencies and other intergovernmental organizations focus in one way or another on economic and social development (Table A.7, Appendix A), including public and environmental health concerns. Two of the most prominent agencies active in the region in this latter area are the Pan-American Health Organization (PAHO), part of the World Health Organization (WHO) network; and the Caribbean Environmental Health Institute (CEHI), an arm of CARICOM (see Figure 13).

The Caribbean Environment Programme (CEP), whose legal framework is provided for in the Cartagena Convention, serves as an umbrella organization for collaboration among the many social, economic, scientific, and technical organizations active in the region. The CEP is administered by UNEP, through its Regional Coordinating Unit (RCU) in Kingston, Jamaica. Together with the relevant national and regional environmental institutions (see Table 14), the RCU provides the institutional capabilities necessary for the implementation of a land-based marine pollution protocol. In this context, two of the CEP's most important institutional networks are CEPPOL and a program on Information Systems for the Management of Marine and Coastal Resources (CEPNET), whose role is to ensure that scientific information obtained through CEPPOL is appropriately collated and disseminated through useful databases.

Unlike many of the other organizations whose membership or concerns are limited to either the Caribbean island states or the continental countries of Latin America, the CEP expressly extends its reach to all the WCR coastal and island states. Moreover, it takes a broad, comprehensive view of environmental affairs and of the special link between economic and environmental concerns within the region. Nonetheless, as mentioned in the preceding section, the CEP has had only modest success in this coordinating role. As is true of so many other aspects of the Wider Caribbean Region and its environmental agenda, the rationale for a comprehensive approach may be gaining general acceptance, but many of the mechanisms that allow coherent action are simply not in place. 

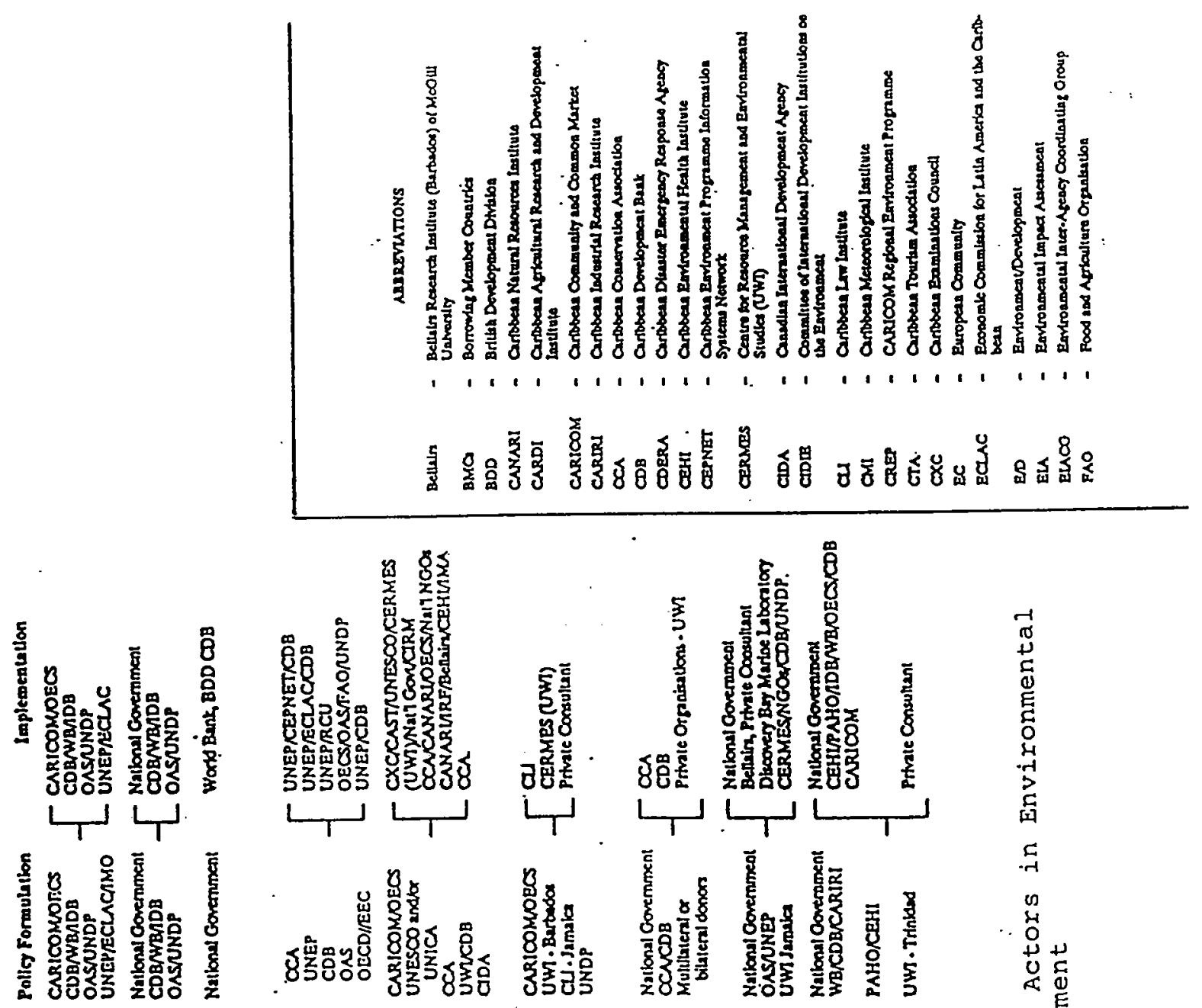

盖

彭.

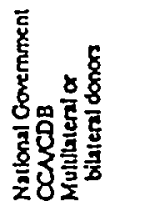

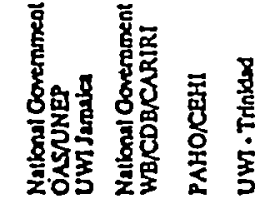
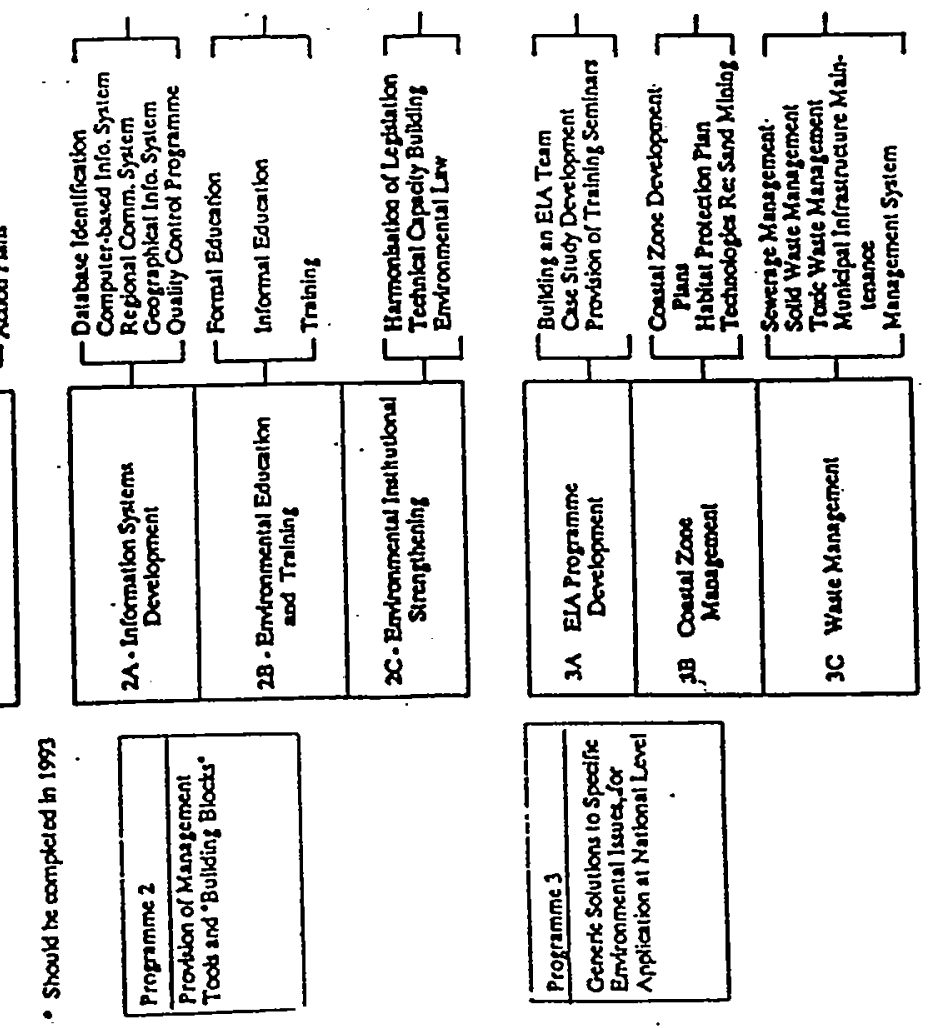

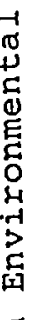
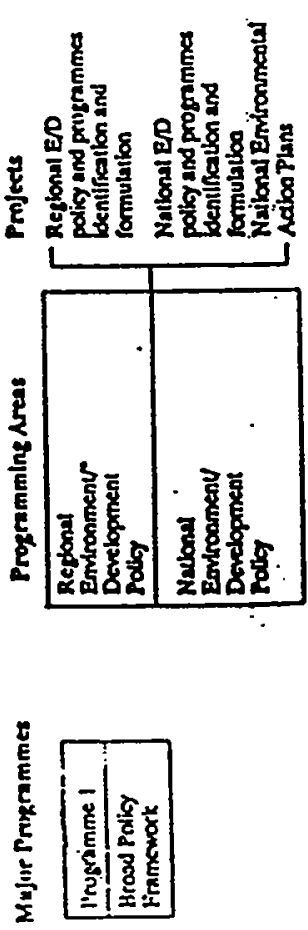

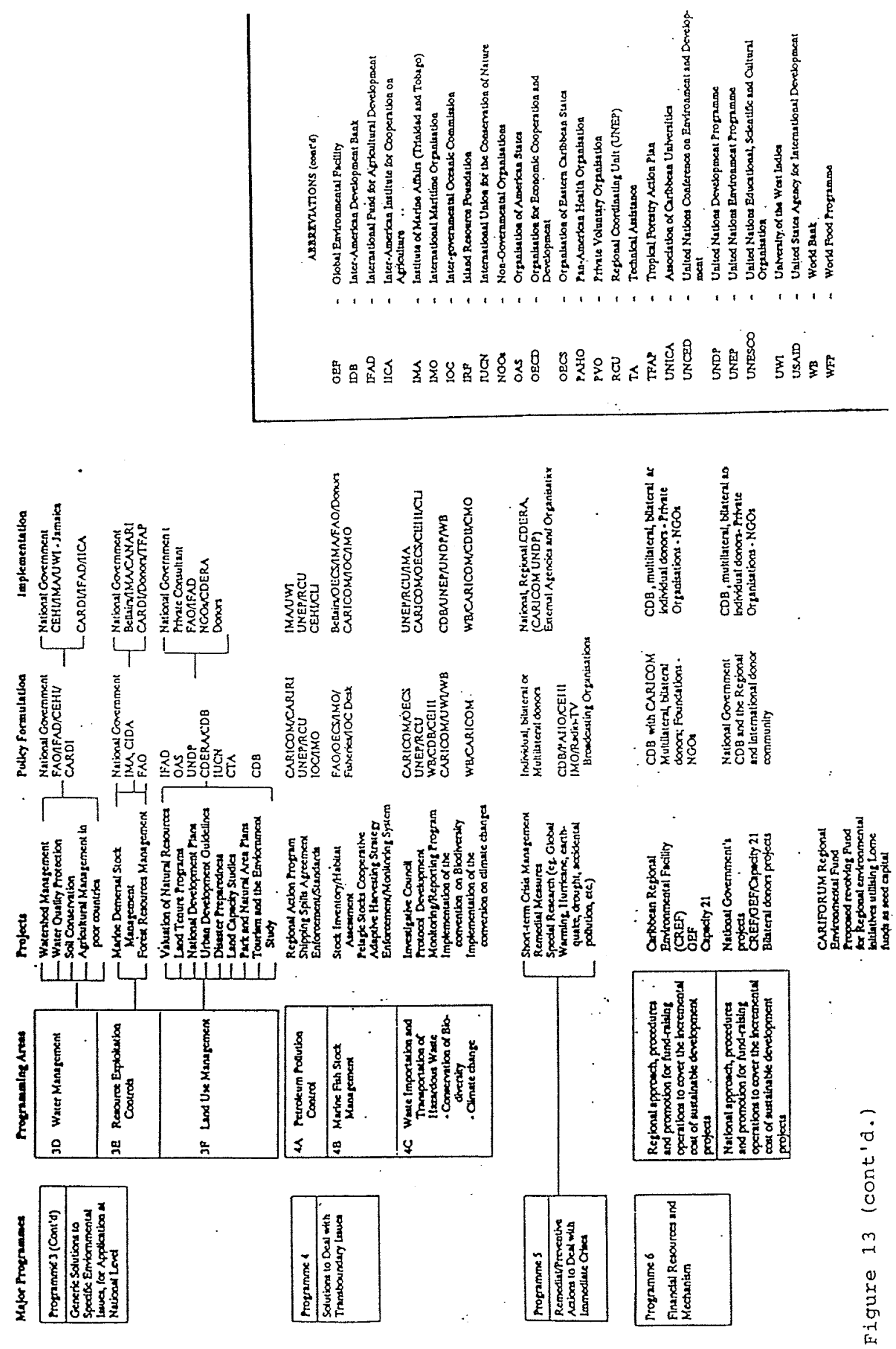
Table 14

Regional Environmental Institutions

\begin{tabular}{|c|c|}
\hline Reglonal Institution & Enviromental Mandate \\
\hline $\begin{array}{l}\text { United Nations Environment Progrumme, } \\
\text { Regional Coardinating Unit foc the Caribbean (UNEP/RCU) }\end{array}$ & $\begin{array}{l}\text { Coordination of UNEP' Regional Seas Programme for } \\
\text { the Caribbean; nupport for Caribbean Environmens } \\
\text { Programme (CRO) }\end{array}$ \\
\hline Uaited Nations Development Programme (UNDP) & Coordination of GEF NGO Small Grants Activity \\
\hline $\begin{array}{l}\text { Univecsity of the Weat Indies: } \\
\text { Department of Biology, Engincering, Geology, end } \\
\text { Zoology } \\
\text { Marine Resources and Environmental Manasemont } \\
\text { Programme (MAREMP) } \\
\text { Caribbean Law Institute (CI) } \\
\text { Centre for Environment and Development (UWICED) }\end{array}$ & $\begin{array}{l}\text { - } \quad \text { Courses in eaviroament-related studies } \\
\text { Research in marino resources conservation and } \\
\text { management } \\
\text { Analysis of environmental laws and regulations } \\
\text { Training, research and information sysiems } \\
\text { development in cavironment and development }\end{array}$ \\
\hline Ceribbeen Environmental theslth Intitute (CEHI) & $\begin{array}{l}\text { Provision of technical and advisory services in } \\
\text { environmental menagement (efr water supply, liquid } \\
\text { and solid waste management, pesticides control); } \\
\text { collection and dissemination of eavironmental dats }\end{array}$ \\
\hline $\begin{array}{l}\text { Ocganization of Eastern Caribbear States (OECS) } \\
\text { Netural Resources management Unit (NRMU) }\end{array}$ & $\begin{array}{l}\text { Coordination of natural resources managerneat } \\
\text { programmes for the OECS }\end{array}$ \\
\hline Institute of Marine Affairs & $\begin{array}{l}\text { Research in marine resources management and } \\
\text { pollution control }\end{array}$ \\
\hline Tropical Forestry Action Programme (TFAP) & $\begin{array}{l}\text { Technical assistance for national forestry resources, } \\
\text { protected areas, and wildlife management programmes }\end{array}$ \\
\hline Curibbean Conservation Areciution (OCA) & $\begin{array}{l}\text { Advocacy, project preparation and implenentation, } \\
\text { instioution building, public awareness, and education }\end{array}$ \\
\hline Curibbeen Netural Resources Institure (CANARD) & $\begin{array}{l}\text { Research, training, and extension in the field of } \\
\text { community participation and co-management of natural } \\
\text { resources }\end{array}$ \\
\hline $\begin{array}{l}\text { Ceribben Agriculural Research and Development Instiute } \\
\text { (CARDI) }\end{array}$ & $\begin{array}{l}\text { Covers eavironmental impacts in the course of its } \\
\text { research on agricultural activities }\end{array}$ \\
\hline $\begin{array}{l}\text { CARICOM Fisheries Resources Assessment and Menagement } \\
\text { Programme (CFRAMP) }\end{array}$ & Studies the marine fisheries resources of the region \\
\hline OECS Fisheries Unit & Sadies OECS sub-regional resources \\
\hline Belleirs Research Institute of MoGill Univecsity & $\begin{array}{l}\text { Covers Marine and Coastal resources - monitoring and } \\
\text { assessment }\end{array}$ \\
\hline Caribbean Centre for Administration Development (CARICAD) & Covers institutional analysis and developneat \\
\hline
\end{tabular}

SOURCE:- WORLD BANK 1994 
Although the impediments to implementation of the CEP are numerous and varied throughout the region, four broad problems have been identified (see Section III and Brewster 1994), including lack of adequate financial support. This point is borne out to some extent in Figure 14, panel a, which displays the levels of contributions and deficits (on pledged amounts) for CEP member states during 1982 through 1992 (in current U.S. dollars). Eight of the 34 member states are in arrears by amounts greater than their cumulative contributions, and it would appear that a disproportionate share of the financial burden has been shouldered by France in particular, and to a lesser extent by Mexico, the United States, Sweden, and Colombia. It is useful, however, to examine different representations of the CEP contributions. ${ }^{14}$ Figure 14, panel $b$, displays each state's CEP contribution (deficit) per coastal inhabitant. On this basis, the British Virgin Islands, France, and the Turks \& Caicos Islands make the leading contributions, and many of the British dependent territories are among some of the leading contributors. In Figure 14, panel c, each state's contribution (deficit) to CEP is shown as a percentage of its "capacity," or an estimate of its coastal GDP (as explained in Section V). In this representation, the self-governing units of the Dutch realm appear to be among the leading contributors, although Nicaragua and France are the lead contributors. France shows up well under any comparison, and, as we will hypothesize in Section V, it may be one of the key states in facilitating WCR trading relationships.

\section{J. Summary}

In this section we have reviewed certain economic, demographic, institutional, and environmental characteristics of the WCR states within the subregional framework established by the CEPPOL program. Our review indicates that only Subregions II and IV have a high degree of homogeneity with respect to economic priorities, and that these priorities, on balance, constitute an incentive for Subregion IV to control LBMP and a disincentive for Subregion II to do so. The other four subregions are all more economically heterogeneous. Although all three Subregion I economies are highly diversified, they represent a tremendous range of living standards, institutional capacities, and pollutant load contributions. Subregion V is apparently the most polarized subregion, with the notable predominance of mining and manufacturing in the economies of Venezuela and Trinidad \& Tobago posing a substantial potential threat to the tourism upon which Aruba and the Netherlands Antilles are heavily dependent.

In Section $V$, we draw upon this review as the basis for identifying alternative subgroupings of WCR states to facilitate control of LBMP.

\footnotetext{
${ }^{14}$ In Figure 15, panels b and c, statistics for Guatemala and Sweden have been left out because of the very small number of individuals in the coastal region (or none in the case of Sweden).
} 


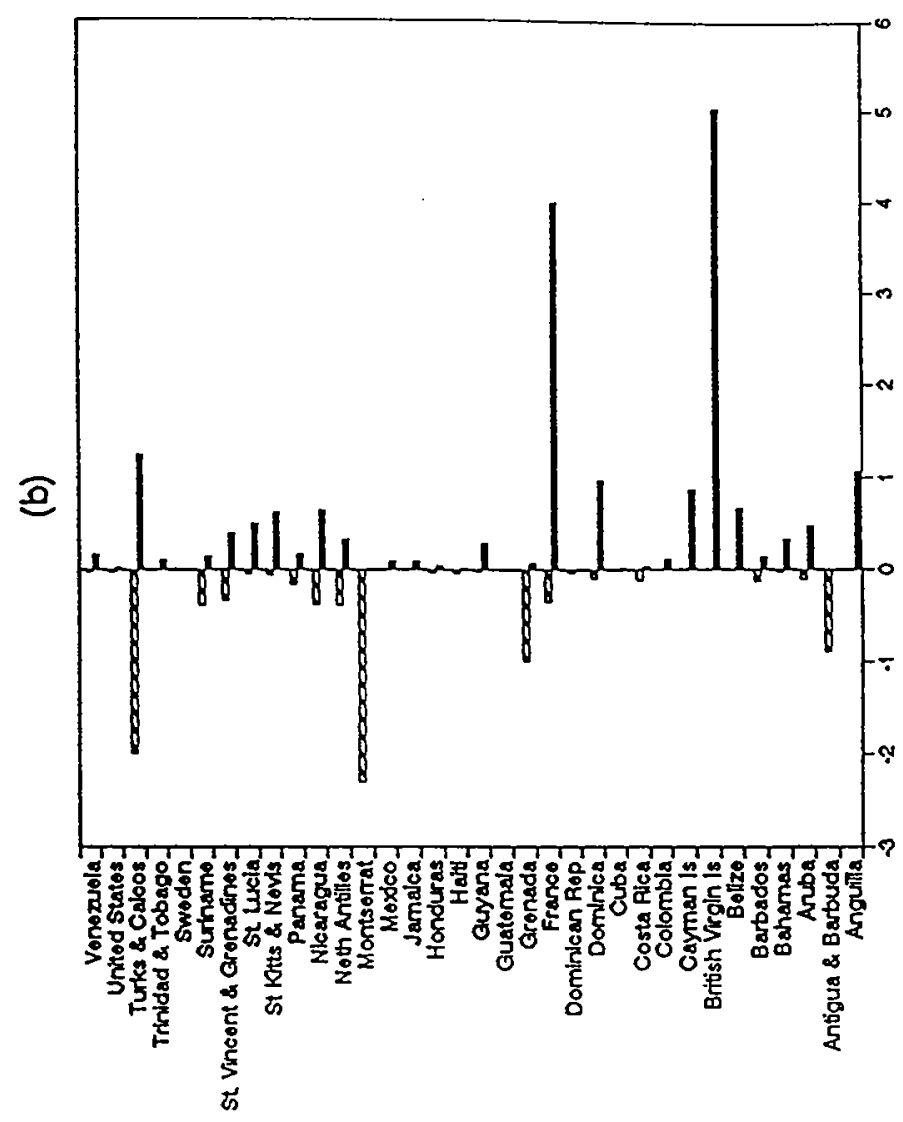

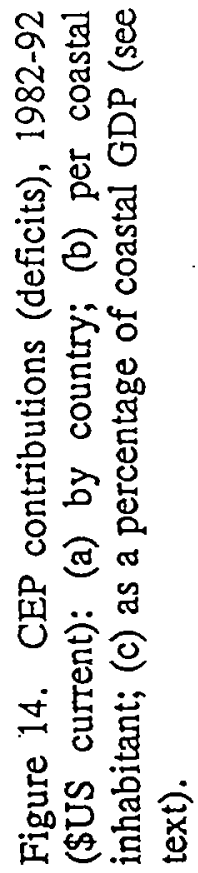
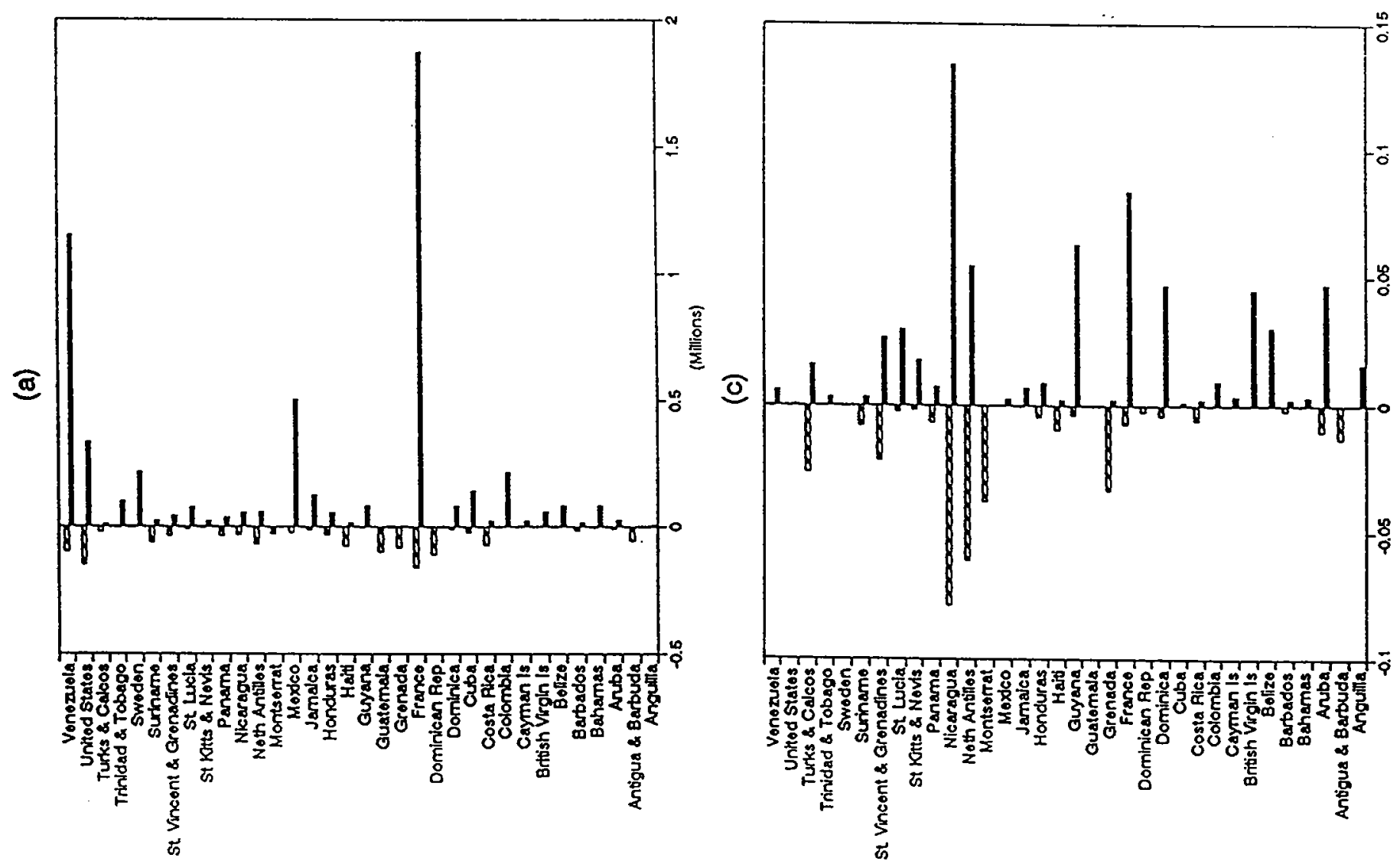


\section{Analysis of the Incentives and Prospects for Collective Action}

\section{A. Analytic Approaches}

In this section, we explore three avenues to identifying promising opportunities for mutually beneficial collaborations and "gains from trade" in pollution control. First, economic commonalities throughout the region are identified, with the states grouped and ranked according to their level of participation in relevant economic sectors. This information is useful, for example, in identifying states engaged in a particular polluting activity on a relatively small scale, who could benefit from pollution control approaches and technologies that have already been adopted by another state engaged in the same activity at a much larger scale. Next we consider the relative identities of WCR states as polluters and pollutees within subregional groupings. Following the approach developed by Broadus et al. (1993), we estimate the extent to which each state is a source of LBMP, the extent to which it has a stake in controlling the problem, and its relative economic capacity to undertake corrective action. Finally, we develop a rating system that attempts to take into account not only the size but also the direction of a state's economic incentive with respect to controlling LBMP, and not only its economic capacity but also its institutional capacity to undertake corrective action.

\section{B. Economic Commonalities}

As a prologue to an analysis of the incentives and prospects for collective action on LBMP problems in the Caribbean, we have organized the states of the region into "economic groups." These groups are rankings of states in terms of size or value of production, or other measures, for specific industries, including hydrocarbon production and refining, farming, marine fishing, and tourism. The states are also ranked in terms of foreign aid receipts and indebtedness.

The purpose of this subsection is to demonstrate similarities and differences among the states of the region with regard to major industries that are known either to affect water quality adversely (hydrocarbon production and refining, industrial chemical production, farming, coastal development) or to be affected by inferior water quality (coastal development, tourism, fisheries). We identify those states in the region that are incumbents in each broadly defined industrial sector. Further, we identify the major, intermediate, and minor producers in each industry. We arrange states into subgroups as an aid in identifying those states with roughly the 
same scale of industrial activity in the relevant industry. ${ }^{1}$

Some observers have hypothesized that, in any particular industry, subgroups of states with the same scale of industrial activity may encounter the same kinds of LBMP problems. If this hypothesis is valid, then it is possible that one state's solutions to these problems may be transferable to others at low cost. Alternatively, subgroups might agree to collaborate on research or technological development to identify or improve LBMP control mechanisms.

A separate hypothesis is that states exhibiting larger scales of activity in any of these industries may have already encountered LBMP problems during their industries' growth and maturation. In this case, states at an earlier stage of industrial development or with a smaller scale of activity might look to states with a more mature industry or a larger scale for solutions to LBMP problems.

Of course, there are many assumptions behind these hypotheses. For example, in order for transfers to occur, we must assume that solutions to LBMP problems exist and that those states that have identified solutions are willing to convey them to other states.

The economic groups described in this subsection are, for the most part, self-explanatory; we describe the groups only briefly here. We expect that the identification of economic groups will be useful as the Contracting Parties to a prospective LBMP protocol begin to consider possibilities for trading relationships in pollution control. We discuss these possibilities at the end of this subsection.

Table 15, panels a and $b$, rank the leading oil and natural gas producers in the Caribbean and the leading oil refiners, respectively. We note that some of the leading hydrocarbon producing states have attempted to control marine pollution problems, some more successfully than others. A group of Latin American national oil companies recently has produced a series of operational practice guidelines for environmental protection (ARPEL 1994). These guidelines are likely to be useful for all of the WCR oil producers and refiners.

Table 15, panel c, ranks, in terms of gross sales revenues, the leading producers of industrial chemicals in the Caribbean.

Table 16, panels $a, b$, and $c$, rank states according to different measures of farming activity. In panel $a$, the states are ranked in terms of the percentage of land area devoted to agriculture. Panels $b$ and $c$ rank the states in sugarcane and banana production. Depending

\footnotetext{
1 We note that this kind of comparison is very general, ignoring economically relevant, but difficult to obtain, information about market structure and firm behavior and performance in these industries. Although industrial organization data would be helpful to this kind of analysis, we expect that its absence will not affect the qualitative points we make here.
} 


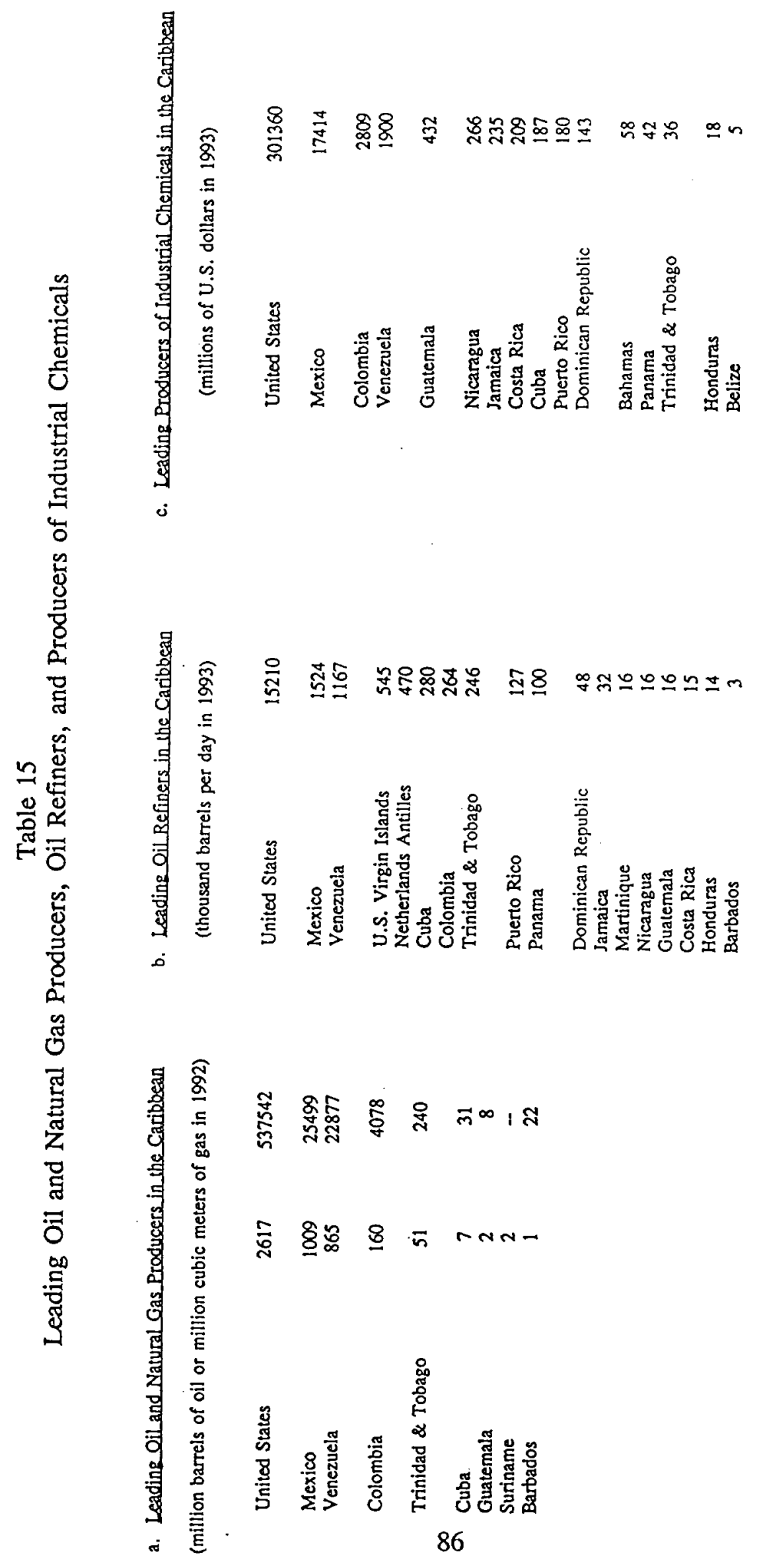




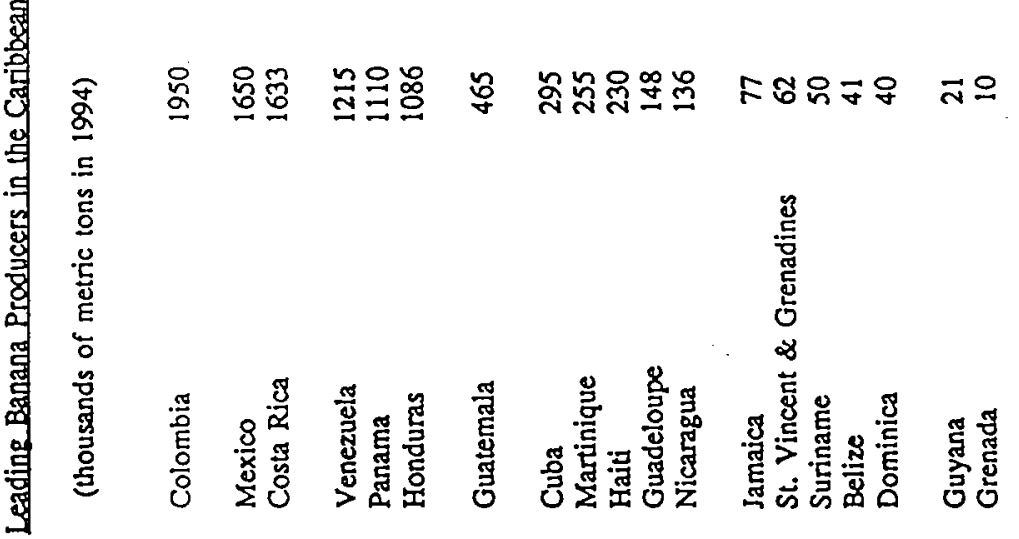

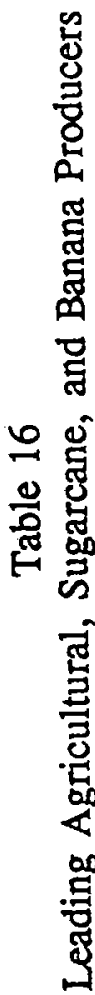

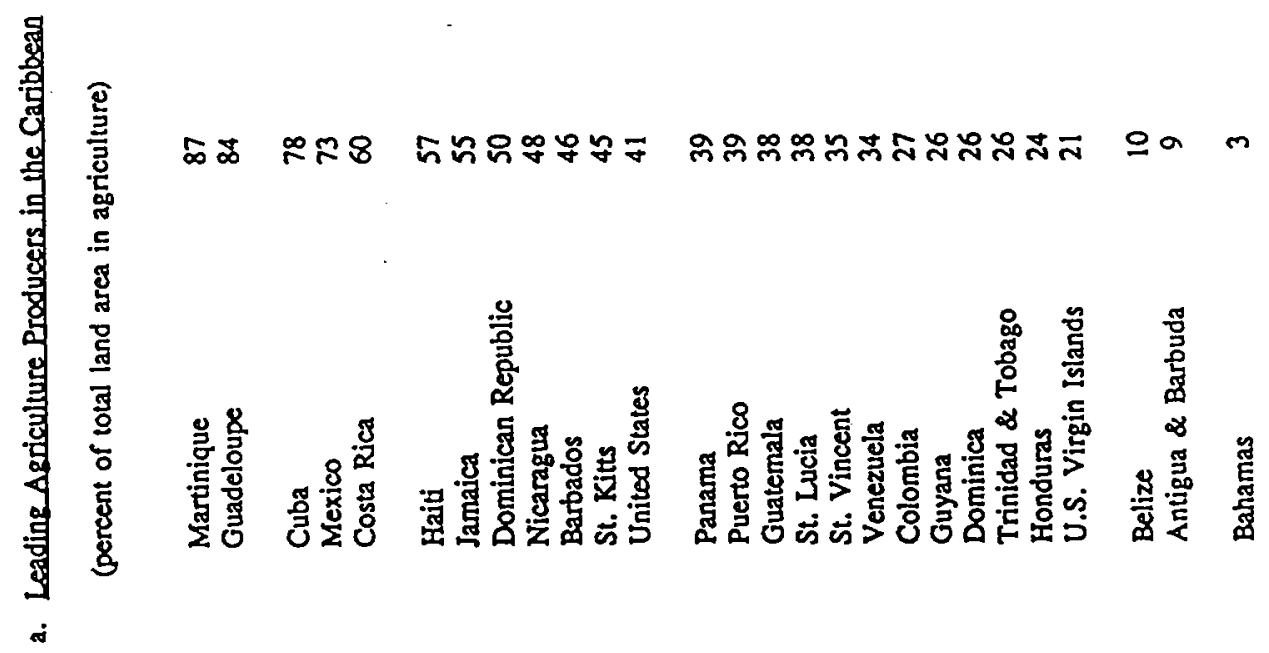


upon the irrigation and erosion-control practices employed, farming can be a major nonpoint source of marine pollution from sediments, fertilizer nutrients, and pesticides.

Table 17, panel a, ranks the states in terms of coastal development, as measured by population density. Note that there may be considerable variation in the concentration of populations within any particular state. This variation may be hidden in the data. Table 17 , panels $b$ and $c$, rank the states in terms of marine fish landings and tourism receipts.

Table 18, panel a, ranks Caribbean states in terms of debt service ratio, which is a measure of each state's ability to repay loans from foreign sources. The debt service ratio gives a sense of the proportion of annual export receipts that could be used to pay interest and principal on international debts. A lower ratio implies that it is relatively easier for a state to repay its foreign debts.

We hypothesize that those states with a history of significant lending or trade relationships may be more likely to cooperate in seeking reductions of LBMP. Table 18, panel $b$, ranks Caribbean states in terms of the cumulative total of official development assistance from OECD countries, including the United States, the United Kingdom, France, the Netherlands, Canada, and Sweden, during the period 1981 to 1991. This assistance includes grants as well as concessional loans that must be repaid. Table 19 describes exporting activity for each of the Caribbean states. For each state, both the leading importing states and the leading export commodities are identified. Table 19 helps to characterize existing trade relationships that may facilitate mutually beneficial relationships in the control of land-based sources of marine pollution.

The development of mutually beneficial relationships in pollution control is sometimes described, in economic parlance, as a type of gain from trade. The possibilities of gains from trade with regard to a pollution problem can be shown clearly using a stylized model, which we describe in detail in Appendix C. In this model, the rights of a state to a clean marine environment are clear ${ }^{2}$, and states have the legal competency to enter into agreements to control pollution. However, states may find other reasons for entering into an agreement to control pollution. Even states that have a legal right to a clean marine environment may be willing to accept some level of pollution in order to benefit in other ways, such as improved international relations or perceived increased benefits to the state of a trading partner's economic development. For example, Mäler (1990) cites studies by John Krutilla and Alan Kneese which demonstrate that:

\section{... at least along the U.S.-Canada and U.S.-Mexico borders, agreements on}

\footnotetext{
${ }^{2}$ In Appendix C, we examine the effects of property right distributions, burden of proof, and lack of clarity in property rights.
} 


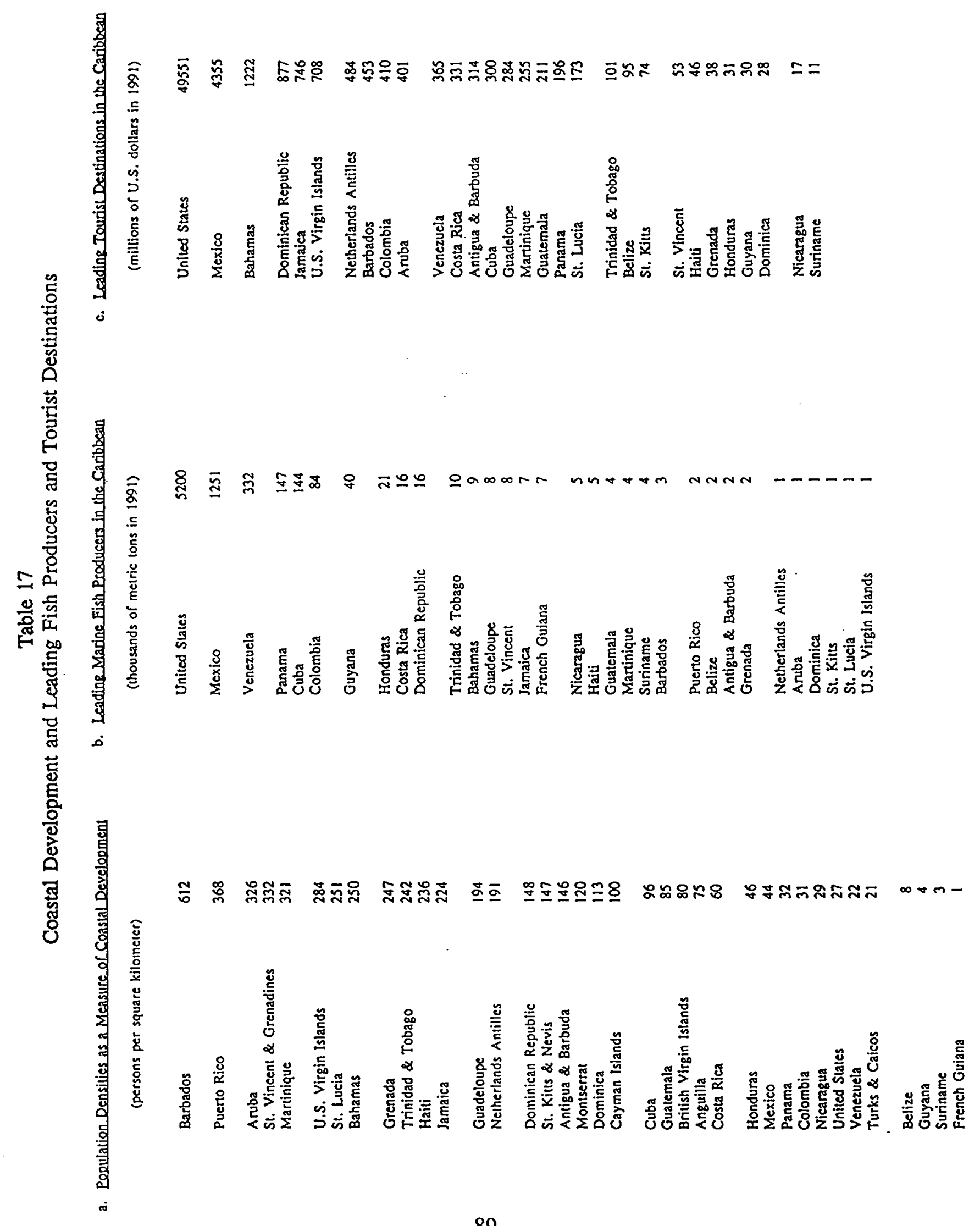




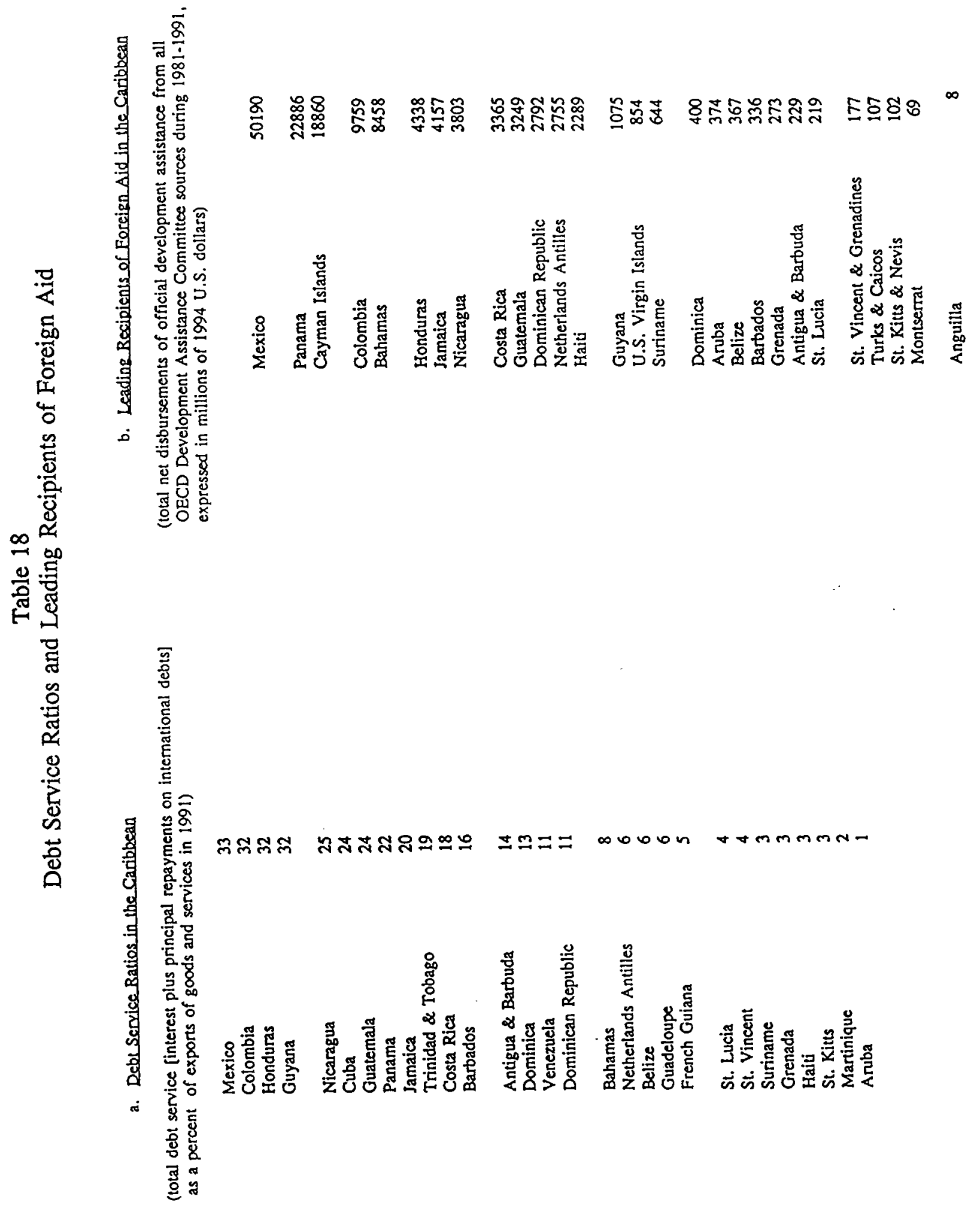


Table 19

Major Exports and Primary Importing States

\begin{tabular}{|c|c|c|}
\hline $\begin{array}{l}\text { EXPORTING } \\
\text { STATE } \\
\end{array}$ & $\begin{array}{l}\text { PRMMARY } \\
\text { OMPORTONC } \\
\text { STATE(S) (> 10X) } \\
\end{array}$ & FRODUCTSS \\
\hline Anguilta & - & - \\
\hline Ancigue \& Barbude & $\begin{array}{l}\text { Unived Saves (41): } \\
\text { Uniled Kingdona (19): } \\
\text { Gerauny (19) }\end{array}$ & roexports of petroleum products \\
\hline Anuba & - & - \\
\hline Bahamas & $\begin{array}{l}\text { Unived Sulas (T): } \\
\text { Pucro Rioo (II) }\end{array}$ & $\begin{array}{l}\text { pharanacarticals: } \\
\text { disiollate fucls }\end{array}$ \\
\hline Bartados & $\begin{array}{l}\text { Unired Kingdom (1): } \\
\text { Unitod States (13) }\end{array}$ & $\begin{array}{l}\text { suev, dhemials; dectrical } \\
\text { somponents }\end{array}$ \\
\hline Belize & $\begin{array}{l}\text { Unived Sures (4): } \\
\text { Unined Kingcom (24): } \\
\text { Mexioo (13) }\end{array}$ & sugar, orange conocherate, permenss \\
\hline $\begin{array}{l}\text { Bridish Virgin } \\
\text { Istands }\end{array}$ & - & - \\
\hline Cayman itlands & - & - \\
\hline Colombia & $\begin{array}{l}\text { Unitod Sales (39): } \\
\text { Germany (9): } \\
\text { Veneavele (9) }\end{array}$ & $\begin{array}{l}\text { fores products: fish; petrokaum } \\
\text { produces: coffoe }\end{array}$ \\
\hline Cosen Ria & $\begin{array}{l}\text { Uniros Sures (S5): } \\
\text { Germany (8) }\end{array}$ & beranas; coflec \\
\hline Cubs & Cas $(60)$ & syegr, mincrils \\
\hline Dominica & Unilod Kingsom (42) & benanas; coconutbased soups \\
\hline Dominican Republic & $\begin{array}{l}\text { Unieod Sales (54): } \\
\text { Netherhands (13) }\end{array}$ & ferronicted; suear \\
\hline French Guyers & $=$ & - \\
\hline Grensadx & $\begin{array}{l}\text { Unired Sules (3S): } \\
\text { United Kingdom (2) }\end{array}$ & baneras: nutrices: cososa banss \\
\hline Guadeloupe & $\begin{array}{l}\text { France (78): } \\
\text { Marinique (14) }\end{array}$ & aericularel produces \\
\hline Guncemala & $\begin{array}{l}\text { Unibod Sule (AS): } \\
\text { EI Salador (14) }\end{array}$ & corfoci supar \\
\hline Guyara & $\begin{array}{l}\text { Unitod Kingdom (33): } \\
\text { Unilod Stala (30) }\end{array}$ & sugar: gots: bauxice \\
\hline Haiti & Unicod Sales (75) & bal manufacturs \\
\hline Hondurss & $\begin{array}{l}\text { Uniced Saves (SA): } \\
\text { Germany (11) }\end{array}$ & basares: coftoc: thrimp and lobseers \\
\hline Jamia & $\begin{array}{l}\text { Unitod Stales (43): } \\
\text { Unitos Kinzdorn (1S): } \\
\text { Cenade (10) }\end{array}$ & Juminz \\
\hline Martinique & $\begin{array}{l}\text { Frnoc (65): } \\
\text { Guadedoupe (B) } \\
\end{array}$ & food products; refinod petrolcum \\
\hline Maios & Unived Sates (81) & $\begin{array}{l}\text { machinery: eloctrical equipment: } \\
\text { crude pesoteum }\end{array}$ \\
\hline Montserrat & - & - \\
\hline Nethariands Antilka & - & - \\
\hline Nicaragus & $\begin{array}{l}\text { Unived Sales (19): } \\
\text { Germany (15) } \\
\end{array}$ & coltex: fresh and frowen meats; 00000 \\
\hline Panems & $\begin{array}{l}\text { Unilod Stules (20): } \\
\text { Germeny (27) }\end{array}$ & banans: strimps \\
\hline Pueno Rioo & Uaived Sales (BT) & $\begin{array}{l}\text { chemicals and chemical products: } \\
\text { food: deocrical mativery }\end{array}$ \\
\hline St Kits a Nevis & $\begin{array}{l}\text { Unitod seces (SS): } \\
\text { Unitod Kinedom (26) } \\
\end{array}$ & nw wes, garments \\
\hline st. Lexil & $\begin{array}{l}\text { Unived Kinedom (SI): } \\
\text { Unived Steves (2I) }\end{array}$ & bunanes; cloctine \\
\hline $\begin{array}{l}\text { St. Vincese \& The } \\
\text { Grandines. }\end{array}$ & 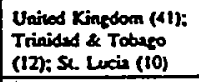 & baranas, flowr \\
\hline Suriname & $\begin{array}{l}\text { Nonway (30): } \\
\text { Netherlends (26): } \\
\text { Unicod Staves (13) }\end{array}$ & dumina \\
\hline Trinidad \& Tobueo & Unired Steves (47) & $\begin{array}{l}\text { mineral-fud lubricants: chemicals and } \\
\text { chemical products }\end{array}$ \\
\hline Turks \& Ciocos & - & .. \\
\hline Unicod Sales & $\begin{array}{l}\text { Canede (22): } \\
\text { Supan (10): } \\
\text { Mexios (9) }\end{array}$ & $\begin{array}{l}\text { molor vetickes and pars: besic and } \\
\text { miscollenoours manufactures }\end{array}$ \\
\hline U.S. Virzia Islands & - & - \\
\hline Veneundr & Uaived Streas (50) & $\begin{array}{l}\text { crude perolourm and petroteun } \\
\text { products }\end{array}$ \\
\hline
\end{tabular}


water and water quality have involved "trades" in areas other than the rather restricted area defined by the environmental resource. The important point here is that there have been trades, although they may not be directly visible.

Table 20, adapted from Kimball (1994), lists some examples of the kinds of trades that might take place with respect to LBMP control in the Caribbean. We note that even when the potential for trade exists outside the realm of pollution control, information about the gains from trade in pollution control per se will be valuable to states negotiating broader agreements.

In the next two subsections, we take a closer look at characteristics of states that might enable mutually beneficial relationships in pollution control to develop. We offer suggestions on opportunities, but we do not identify any immediate solutions. The reduction and control of LBMP in the Caribbean will require much hard work from all of the Contracting Parties to a prospective protocol. As we begin to sketch out some possibilities for mutually beneficial relationships, we have found it helpful to keep in mind the economic groups that have been identified in this subsection.

\section{Sources and Stakes}

In this subsection, we examine the identity of WCR states as polluters or pollutees. We adopt the approach developed by Broadus et al. (1993) to measure "sources," "stakes," and "capacity." "Source" is a measure of a state's relative contribution of land-based marine pollution to a region. "Stake" is a measure of a state's economic interest in reducing marine pollution. "Capacity" is a measure of the economic capabilities that a state has at its disposal to reduce pollution, by cutting its own emissions or by subsidizing the reduction of emissions in another state.

Implicit in this analysis (particularly in the "source" measure) is an assumption of transboundary LBMP effects. Although we have noted in earlier sections that transboundary LBMP, where it occurs in the WCR, is generally limited to border areas shared by two states, we believe that this analytic approach has value as well in a somewhat broader (i.e., subregional) context, primarily because of the potential for larger-scale transboundary effects to develop or be detected in the future. Even if this does not occur, however, and the aim of the protocol remains one of responding collectively to common but nontransboundary LBMP problems, we believe that an understanding of each state's relative standing with respect to source, stake, and capacity should enhance the ability of negotiating parties to concentrate on those specific collaborations and exchanges that are most likely to be successfully implemented.

For our source measure, we would like to have, ideally, data on ambient concentrations of pollutants at any location in the Caribbean, combined with the ability to identify costlessly the exact origin of each pollutant. Such data do not now exist, nor is it likely that they will ever 


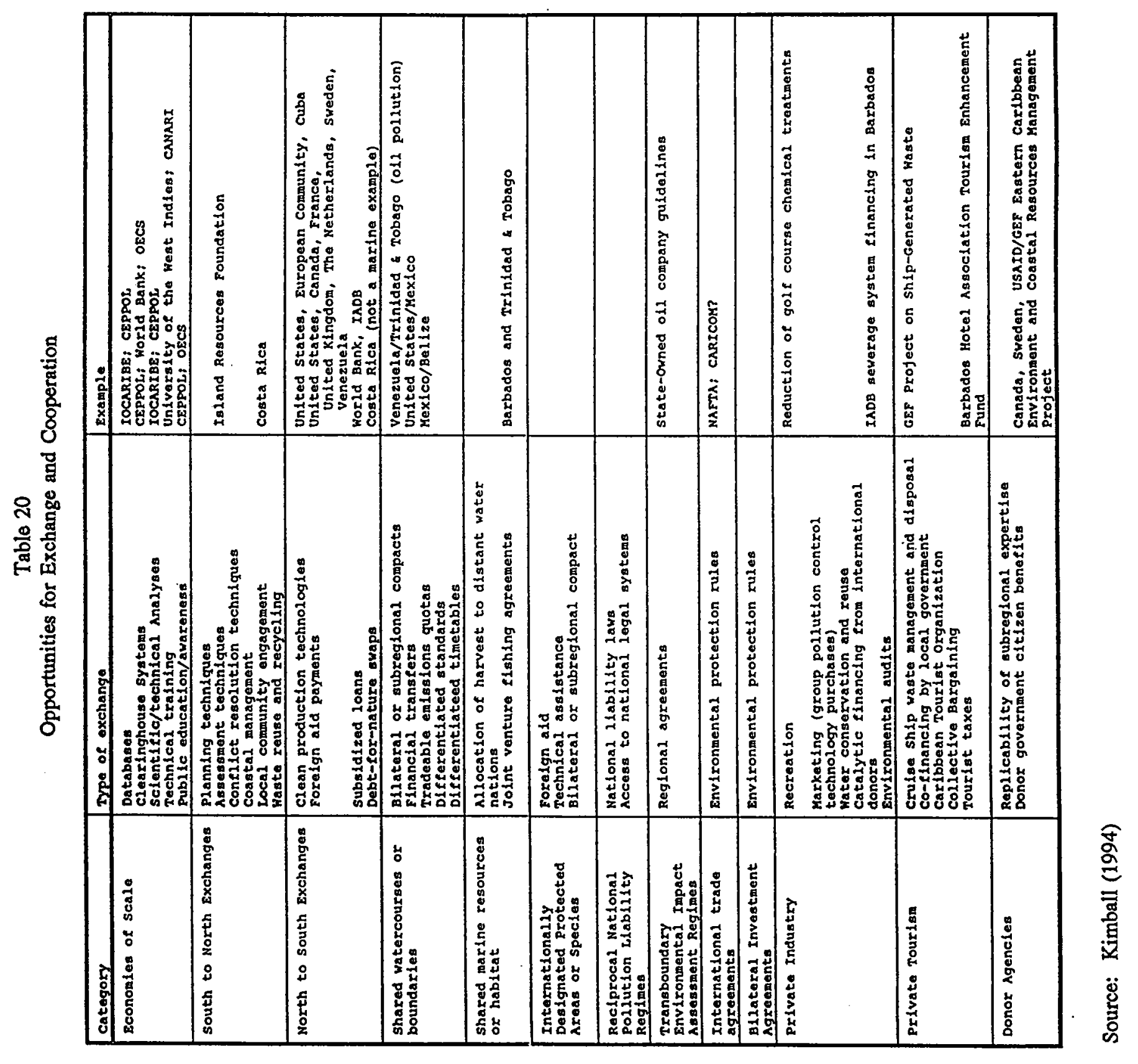


exist. At present, we have incomplete data only on point sources of some pollutants from some of the WCR states and on point and nonpoint sources combined from the U.S. Gulf coast. Even these data may be biased, because data tend not to be collected from states with rudimentary pollution control institutions. Because of these limitations, we employ instead estimates of the populations within the WCR drainage area as a measure of source. (Appendix B contains a description of how these estimates were developed.)

For our stake measure, we would like to have, ideally, data on the value of damages associated with ambient concentrations of pollutants at any location in the Caribbean. As in the case of the ideal source measure, such data on impacts do not now exist. The actual impacts of ambient concentrations of pollutants are further clouded by the issue of "synergistic" effects raised by Gladfelter and Ogden (1994). We employ instead estimates of the proportion of each state's population that is in the Caribbean coastal zone as a measure of stake (Appendix B). ${ }^{3}$

For our capacity measure, we need to know something about the distribution of property rights. If we assume, as in Appendix $\mathrm{C}$, that states have the right to a clean environment, then for source states we would like to have, ideally, an estimate of their ability to offer payments (or in-kind services) to downstream states as compensation for pollution damages. This estimate would be an aggregate of each source state's polluting industries' marginal abatement cost schedules (Figure C.1 in Appendix C). These data do not yet exist. As a proxy for an ideal capacity measure, we employ the stake-weighted gross domestic product for each state. (Note that this capacity statistic might be interpreted as a measure of the economic value of a state's "stake" in controlling or allowing pollution, depending on the nature of its predominant industries.)

Table 21 presents the data on sources, stakes, and capacities for each WCR subregion, as delineated by CEPPOL. A more generalized, geographic depiction of this information is presented separately for each measure in Figure 15, panels a through d. In Figure 15, we have delineated the CEP subregions by following the actual or hypothetical maritime boundaries in the region (panel a). In each of the other panels of Figure 15, states should be compared only within each subregion and not across subregions. Each subregion is associated with a specific color. There are five possible shades for each color; the lighter shades represent lower values of the relevant statistic, and vice versa. The five possible shades represent five possible increments (twenty percent each) of the relevant statistic.

We note that an alternative organization of the WCR into different subregions would result in different measures of source, stake, and capacity for each state. It will be important for the states involved in framing the terms of the protocol to give careful consideration to the

\footnotetext{
${ }^{3}$ Note that this statistic is an improvement on that used by Broadus et al. (1993) because we use only the proportion of a nation's population that is coastal, not the entire drainage basin population.
} 
Table 21

Sources, Stakes, and Capacities within Subregions'

\begin{tabular}{|c|c|c|c|}
\hline State/Subregion & Source Share & Stake & Capacity Sharec \\
\hline \multicolumn{4}{|c|}{ Subregion I } \\
\hline Cubs & 4.0 & 56.8 & 2.7 \\
\hline Mexico & 24.0 & 6.0 & 4.7 \\
\hline United States & 72.0 & 6.0 & 92.6 \\
\hline \multicolumn{4}{|c|}{ Subregion II } \\
\hline Belize & 1.3 & 64.0 & 6.6 \\
\hline Coste Rica & 10.4 & 20.8 & 28.6 \\
\hline Guatemala & 36.8 & - & - \\
\hline Honduras & 32.9 & 22.0 & 16.1 \\
\hline Mexico & 4.1 & 0.5 & 34.9 \\
\hline Nicaragua & 6.5 & 2.4 & 1.0 \\
\hline Panama & 8.0 & 9.5 & 12.8 \\
\hline \multicolumn{4}{|c|}{ Subregion III } \\
\hline Bahamas & 0.1 & 100.0 & 8.3 \\
\hline Coyman Isainds & $=$ & 100.0 & 2.2 \\
\hline Cuba & 19.0 & 16.3 & B.9 \\
\hline Dominican Republic & 30.0 & 58.0 & 13.3 \\
\hline Haiti & 27.0 & 29.2 & 2.5 \\
\hline Jamaica & 10.0 & 55.4 & 6.2 \\
\hline Puerto Rico & 13.6 & 80.0 & 58.5 \\
\hline Turks \& Cajcos & - & 100.0 & 0.2 \\
\hline \multicolumn{4}{|c|}{ Subregion IV } \\
\hline Anguilla & 0.4 & 100.0 & 0.8 \\
\hline Antigua \& Barbuda & 3.9 & 100.0 & 7.4 \\
\hline Barbados & 16.1 & 47.4 & 15.0 \\
\hline British Virgin Islands & 0.7 & 100.0 & 2.3 \\
\hline Dominica & 5.2 & 100.0 & 3.1 \\
\hline Grenada & 5.2 & 100.0 & 4.4 \\
\hline Guadeloupe & 21.0 & 44.2 & 8.5 \\
\hline Martinique & 20.9 & 69.0 & 24.2 \\
\hline Montserrat & 0.7 & 100.0 & 1.3 \\
\hline Netherlands Antilles & 0.9 & 8.0 & 2.0 \\
\hline St. Kitts \& Nevis & 2.5 & 100.0 & 2.5 \\
\hline St. Lucia & 9.4 & 100.0 & 4.4 \\
\hline St. Vincent \& Grenadines & 6.9 & 100.0 & 3.0 \\
\hline US Virgin Islands & 6.1 & 100.0 & 3.0 \\
\hline \multicolumn{4}{|c|}{ Subregion $\mathbf{V}$} \\
\hline Aruba & 0.2 & 100.0 & 0.2 \\
\hline Colombia & 60.4 & 5.4 & 8.4 \\
\hline Netherlands Antilles & 0.3 & 92.0 & 4.8 \\
\hline Trinidad \& Tobago & 2.5 & 69.5 & 12.8 \\
\hline Venezuela & 36.6 & 36.9 & 73.7 \\
\hline \multicolumn{4}{|c|}{ Subregion VI } \\
\hline French Guians & 7.6 & 85.0 & 27.6 \\
\hline Guyane & 61.7 & 38.1 & 10.3 \\
\hline Suriname & 30.7 & 41.5 & 62.1 \\
\hline
\end{tabular}

'See Appendix B for data sources and methodology used to estimate drainage populations (for calculation of source share) and constal zone population (for calculation of stake). 

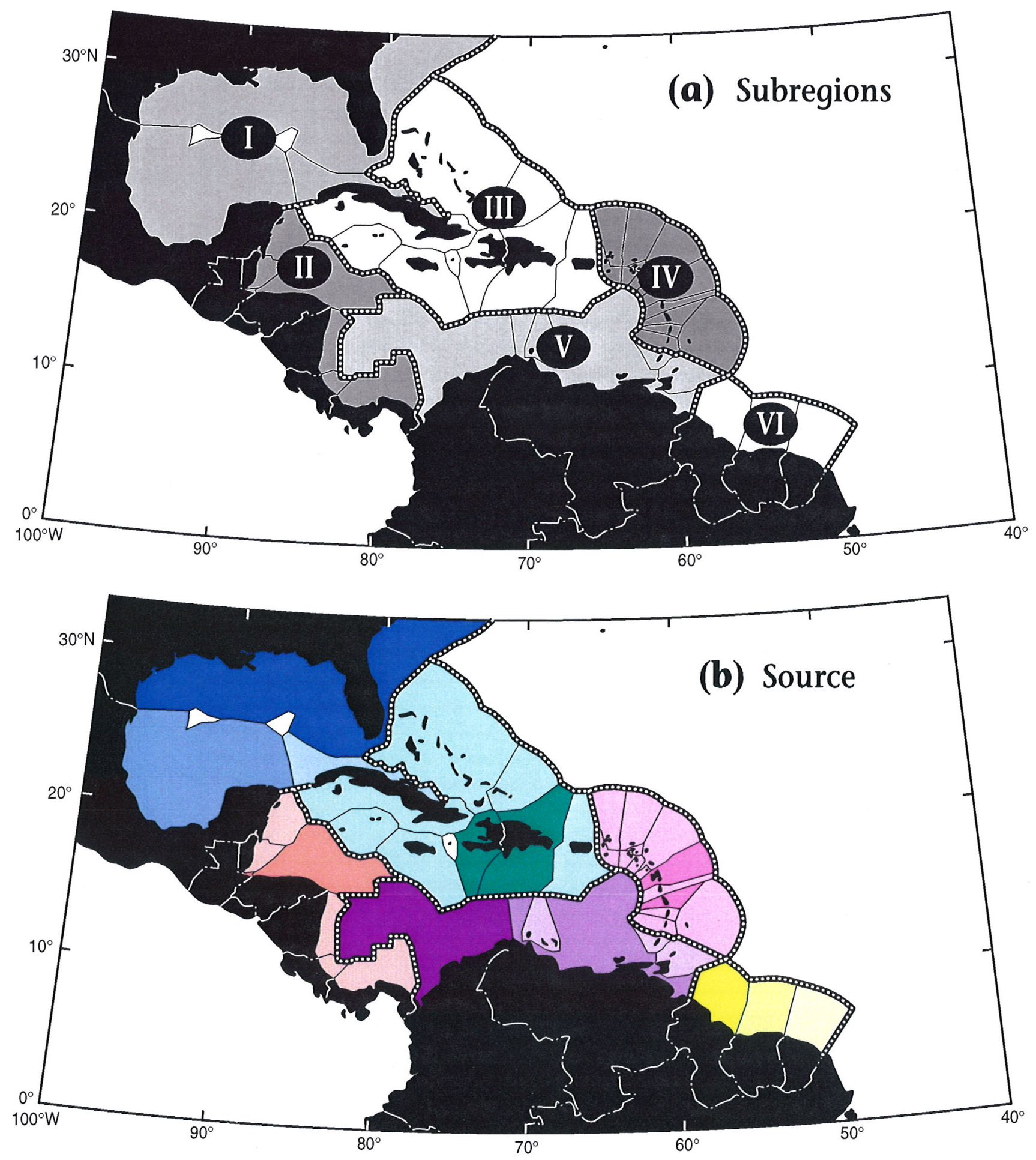

Figure 15. Comparison of Sources, Stakes and Capacities within CEP Subregions. 

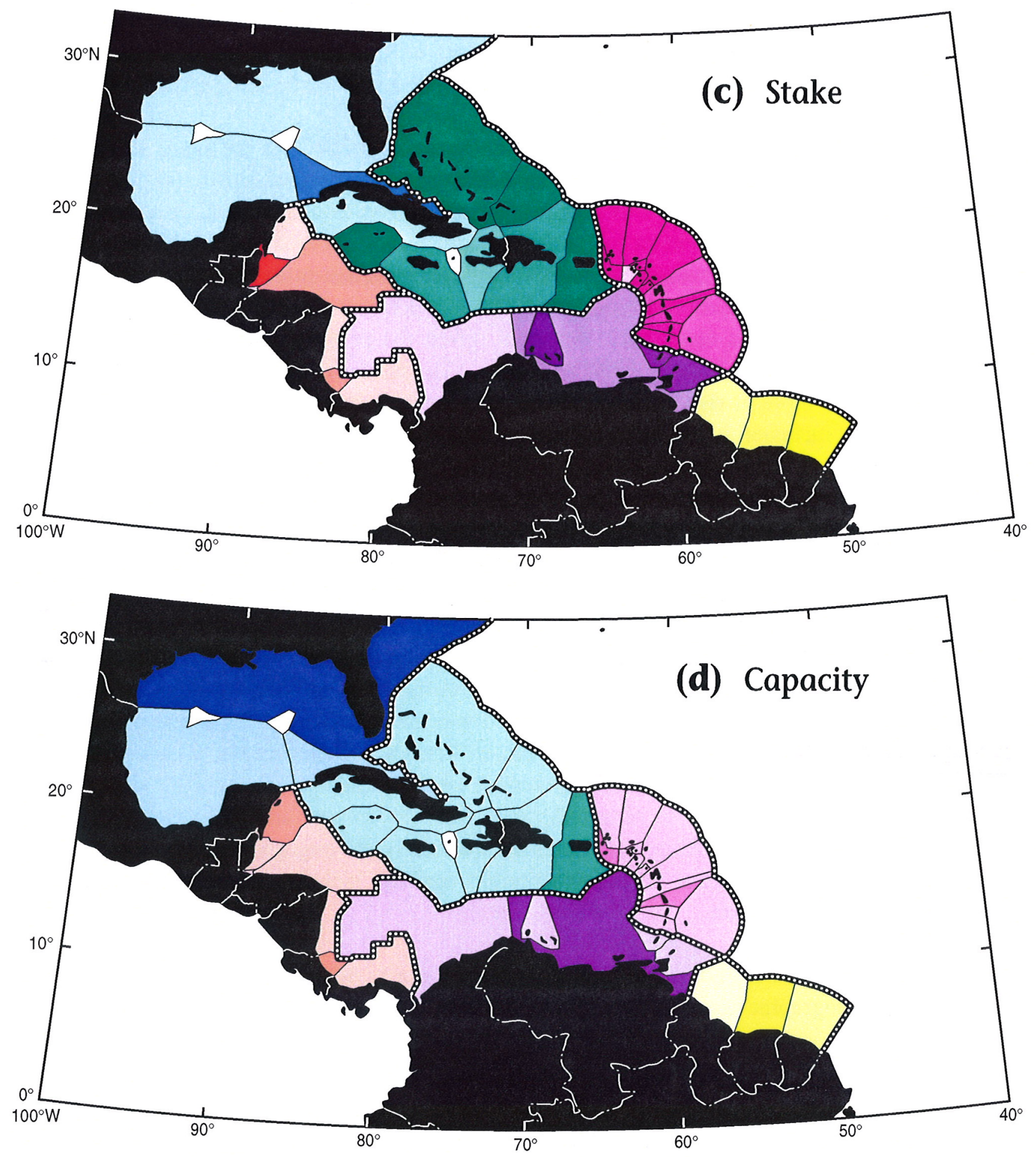

Figure 15 (cont'd). 
delineation of appropriate subregions on the basis of relevant environmental characteristics. In particular, care should be taken to delineate subregions such that they encompass only those states where sources of pollution originate and effects of that same pollution occur. ${ }^{4}$ Our analysis should be interpreted as a first-cut using subregions previously designated by CEP.

In Subregion I, the United States is the major source, and Cuba has the major stake. The United States and Mexico have already concluded a bilateral agreement relating to transboundary marine pollution, the 1983 Mexico-United States Agreement on Cooperation for the Protection and Improvement of the Environment in the Border Area. Reductions of LBM pollutants from U.S. sources through some tightening of its existing water pollution rules might be one element of a larger rapprochement between the United States and Cuba should Cuba begin to move toward democratization and openness. However, given the primary current flows, Cuba is unlikely to be affected much by U.S. LBM pollutants. The northern Bahamas, in Subregion III, would appear to be more at risk from land-based sources in Subregion I, and therefore should be considered for inclusion in the same subregion as the United States.

In Subregion II, Guatemala and Honduras are the main sources and Belize has the largest stake. Encouraging agreement among these states concerning the Gulf of Honduras would appear to be a priority in this subregion. Accentuating Belize's large stake is the fact that it has the most extensive coral reef ecosystem in the Western Hemisphere. However, Belize City is a significant source of pollutants, and Belize is located upstream of the other two states, in terms of the predominant coastal countercurrent. ${ }^{5}$ As alluded to in Section IV, Honduras may begin to shift its banana agriculture to other industries, e.g., ecotourism, as U.K. subsidies are phased out under new European Community rules. This should lower Belize's risks from nutrient and pesticide runoffs. The United States, as a major foreign aid provider to Guatemala and Honduras, might play a role in facilitating agreement by encouraging Honduras and Guatemala to reduce LBM pollutant loads in return for reductions in sewage and industrial pollutants emanating from Belize City. Belize and Guatemala currently are engaged in negotiations over a maritime boundary, and these negotiations might usefully include discussion of potential transboundary pollution flows.

Costa Rica has a significant stake and capacity share in this subregion, but it is located at a substantial geographic distance from the other three major sources and stakeholders. This

\footnotetext{
${ }^{4}$ We note that subregions could overlap. For example, if pollution from state A affects state B, and pollution from $B$ affects state $C$, but pollution from $A$ does not affect $C$, then two overlapping subregions should be established. Furthermore, subregions could be "nested." For example, if pollution from A affects B and C, but pollution from $B$ affects only $C$, then Band $C$ form a subregion that is nested inside the subregion formed by $A$, $\mathrm{B}$, and $\mathrm{C}$.

${ }^{5}$ Note that there may be some cycling of pollutants in the Honduras Gulf, suggesting that these three countries may have a common pool type pollution problem.
} 
point further reinforces the critical need for a careful delineation of subregions: is it reasonable to expect Costa Rica to expend much of its capacity on this problem when it is neither a significant source of LBMP nor noticeably affected by the LBMP contributions of the major source states in the subregion?

In Subregion III, the Dominican Republic and Haiti are the major sources and Puerto Rico has the largest stake and the largest capacity. But the primary current movements suggest that Puerto Rico is upstream of both these states. Transboundary pollution, if it occurs, might follow a path from the Dominican Republic and Haiti to Cuba and from the south coast of Cuba toward Jamaica. The United States, which is closely associated with Puerto Rico and a major foreign aid provider to both the Dominican Republic and Haiti, might play a role in encouraging the latter two states to control LBM pollutants, to reinforce the effects of the existing application of US pollution controls in Puerto Rico.

Subregion III includes three states with economies that are heavily dependent upon tourism: the Bahamas, the Turks \& Caicos Islands, and the Cayman Islands. The southern Bahamas and Turks \& Caicos are relatively protected as upstream states. Reduction of pollution in the southeastern section of Cuba, another significant source in the subregion, could reduce most of the risk faced by these two states. France, which is a major western source of foreign aid to Cuba, might play a role in encouraging Cuba to reduce pollution in this region. The Caymans are protected in a relatively remote area of the Caribbean Sea, but may be at risk, depending upon current flows, to pollution pulses from upstream states in the Caribbean Sea. This risk is likely to be small.

In Subregion IV, Guadeloupe and Martinique are the major sources. Because all of the states in this subregion are islands or island groups, they all have large stakes. Many of the island states in this subregion have undiversified economies, with tourism the overwhelmingly predominant sector. Martinique has the largest capacity to deal with any potential pollution problems, and the U.S. Virgin Islands and Barbados have substantial capacities as well. Although there are some risks of transboundary pollution problems among the states of the subregion, it is likely that actual transboundary effects are small, if they exist at all. Many of the Antilles are islands that have some kind of association with a European state (France, the Netherlands, or the United Kingdom) that can draw upon its experiences in the North Sea LBMP program (and, in the case of France, in the Mediterranean Program as well). It will be important to know whether these European states have already concluded other bilateral or multilateral agreements for control of marine pollution that apply or that can be easily adapted to relations between associated states in the Caribbean. Should transboundary problems develop, or become apparent, states in this region might use OECS resources to assist in the identification of relevant gains from trade (see, e.g., Table 20). Moreover, current OECS member states might benefit from an expansion to include all of the Subregion IV states. 
In Subregion V, Colombia and Venezuela are the primary sources. The island states, again, have major stakes; Aruba and the Netherlands Antilles are comparatively undiversified states, dependent primarily upon their tourism economies. Venezuela and Trinidad \& Tobago already have entered into a bilateral agreement on marine pollution (Goodridge 1994). Although a coastal countercurrent is thought to move from Colombia toward Venezuela, this is not likely to add significantly to the pollutants generated along Venezuela's industrialized coast. In this context, it is interesting to note that Colombia has been working to strengthen its environmental laws, and its efforts have recently drawn praise from Venezuela. ${ }^{6}$ Local pollution control efforts in Venezuela, which has significant source, stake, and capacity statistics, will become increasingly important to the domestic population as Venezuela continues to develop economically.

In Subregion VI, the notions of source and stake are affected strongly by the predominant northwestern current flow. All three states are almost certainly affected by Amazon effluents, which are defined to be outside the Wider Caribbean Region. (Notably, Guyana and Suriname are on the Amazon Cooperation Council with Brazil.) Given the direction of current flows, Suriname is the leading source and Guyana has the largest stake. Suriname also has the largest capacity, suggesting that gains from trade, if transboundary effects are present, might derive from an agreement between Suriname and Guyana. The Netherlands, as a major trading partner with Suriname, might play a critical role in facilitating such a trade.

Table 22 presents an overview of "key" source, stakeholder, and facilitator states in each of the subregions. Key facilitators are those states that provide significant amounts of development assistance to key source states and so might be in a position to encourage a trading relationship to develop. Where the key source state is not receiving development assistance, a major trading partner is identified as the key facilitator. (We reiterate the potential sensitivity of the results to the existing delineation of subregions.)

Matching key facilitator states with key source states may provide clues to important international relationships in the resolution of LBMP problems in the Caribbean. For example, the United States, with assistance from Mexico, might offer the following deal to Belize: in return for the reduction of LBMP emissions in Belize, the United States will put pressure on Honduras (and possibly Guatemala) to reduce its emissions.

Other international trading relationships might cross subregions. For example, the United States, as Venezuela's largest trading partner, might encourage Venezuela to reduce its emissions. The Netherlands would benefit directly from such a move. In return, the

\footnotetext{
${ }^{6}$ At the 25th anniversary of INDERENA, Colombia's environment agency, Arnaldo Jose Gabaldon, Venezuelan Environment Minister, praised the conversion of INDERENA into a Ministry with broader legislative and regulatory powers.
} 


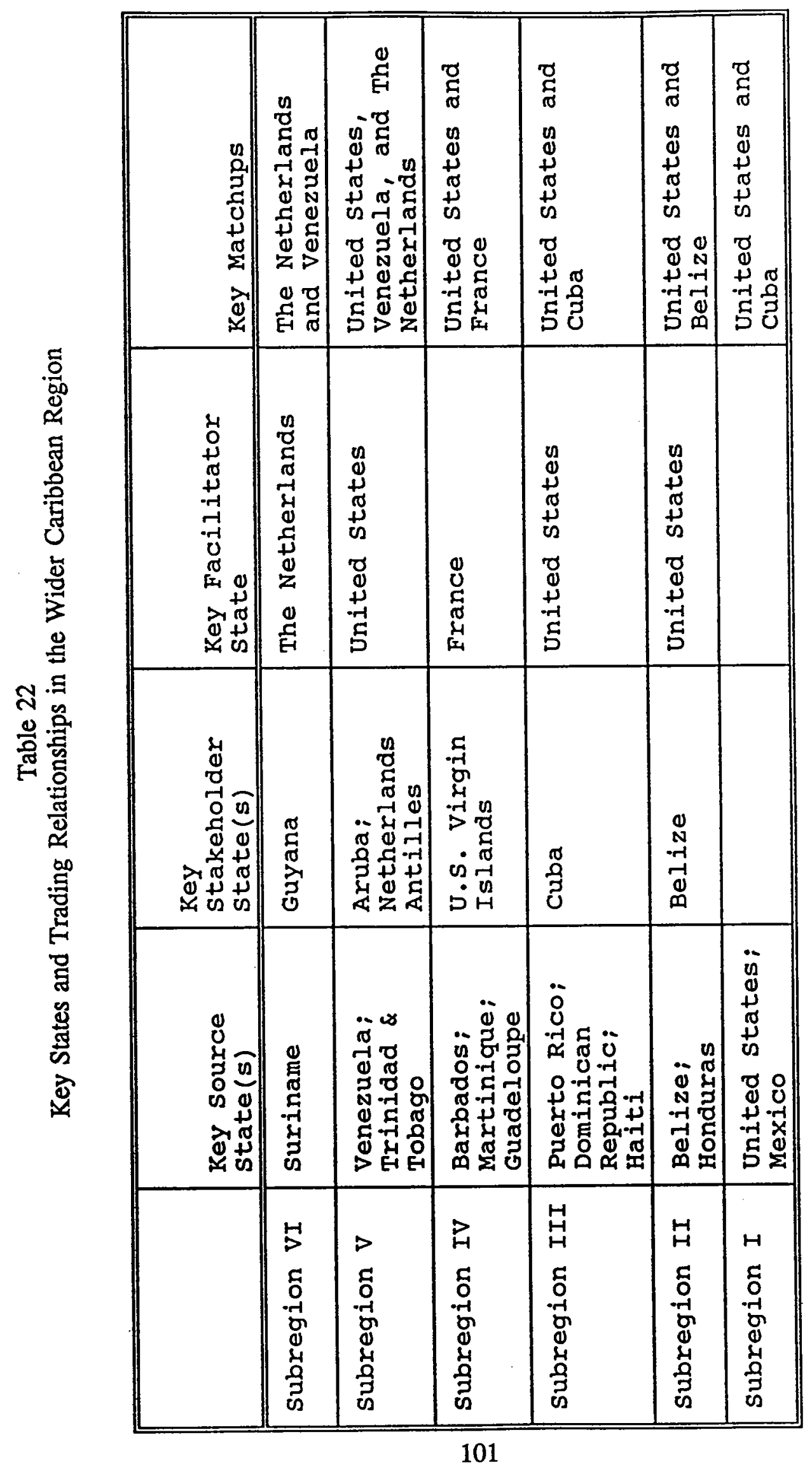


Netherlands might encourage Suriname to reduce its emissions, benefitting Guyana and, potentially, Venezuela. To the extent that the Lesser Antilles are at risk from Venezuelan emissions, France would benefit from Venezuelan cutbacks. In return, France might encourage Martinique and Guadeloupe to control their LBMP emissions, benefitting the U.S. Virgin Islands and thereby completing the link. Although this international negotiation has many links, it involves only four states. In fact, a bargain struck among the United States, Venezuela, and France to reduce LBMP emissions in their respective territories and in the territories of associated states and states to which they give foreign aid might reduce much of the risks associated with transboundary LBM pollution in the WCR.

\section{An Alternative Assessment of Capacities and Incentives to Control LBMP}

As noted in the previous subsection, the analytic approach developed by Broadus et al. (1993) to estimate sources, stakes, and capacities of states proposing to undertake collective action on LBMP has as an underlying assumption the generalized presence of transboundary LBMP effects. This assumption limits the utility of the analysis for a region like the Caribbean, where most LBMP effects have so far been demonstrated to be localized, and where general recognition of this fact has not precluded interest among the Contracting Parties to the Cartagena Convention in negotiating a protocol that addresses common but not necessarily transboundary LBMP problems. The approach has certain other, more general limitations as well. These include the failure of the "stake" measure to distinguish between an economic stake in controlling pollution vs. a stake in continuing to pollute, and the failure of. the "capacity" measure to capture environmental infrastructure as an important component of a state's ability to undertake effective action to control LBMP.

In this section we build on our review of economic, institutional, and environmental characteristics of the WCR states in an attempt to assess the individual and collective prospects for undertaking sustained and effective action to control land-based marine pollution. This assessment is based on the assumption that the factors upon which these prospects mainly depend are a combination of (i) the states' economic and institutional capacity to take corrective action and (ii) the extent to which their economic strengths and priorities represent an incentive to maintain a bealthy coastal environment or, alternatively, to value the surrounding marine environment primarily as a convenient sink for pollutants. Another important difference here is that, unlike the application of the Broadus et al. approach in the preceding section, we do not begin the assessment by assigning states to subregions, but rather by considering all the WCR states together, within a single, uniform context.

Table 23 displays some summary results of this assessment effort, expressed in terms of qualitative ratings for each WCR state in the areas of economic capacity, institutional capacity, and economic incentive. On each of these three measures, a state was assigned a rating on a scale of 1 (weak capacity or incentive) to 4 (strong), based on an admittedly subjective 
Table 23

Qualitative Ratings of Capacity and Incentive to Undertake LBMP Control

\begin{tabular}{|c|c|c|c|c|}
\hline State & $\begin{array}{l}\text { Economic } \\
\text { Capacity }\end{array}$ & $\begin{array}{c}\text { Institutional } \\
\text { Capacity }\end{array}$ & $\begin{array}{l}\text { Economic } \\
\text { Incentive }\end{array}$ & $\begin{array}{l}\text { Combined } \\
\text { "Score" }\end{array}$ \\
\hline Anguilla & 2 & 0 & - & 8 \\
\hline Antigus \& Barbuda & $\otimes$ & 0 & - & 9 \\
\hline Aruba & 9 & 0 & 눈 & 9 \\
\hline Bahamas & $\bullet$ & $\odot$ & - & 10 \\
\hline Barbados & $\theta$ & $\odot$ & $\bullet$ & 9 \\
\hline Belize & 0 & 0 & 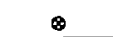 & 5 \\
\hline British Virgin Is. & 9 & o & - & 10 \\
\hline Cayman is. & - & 0 & $\bullet$ & 10 \\
\hline Colombia & 0 & $\odot$ & 0 & 4 \\
\hline Costa Rica & $\mathbf{0}$ & 0 & $\bullet$ & 5 \\
\hline Cuba & $\mathbf{O}$ & $\theta$ & (2) & 7 \\
\hline Dominica & $\mathbf{O}$ & $\boldsymbol{0}$ & $\theta$ & 6 \\
\hline Dominican Republic & $\mathbf{0}$ & 0 & Q & 5 \\
\hline French Guiana & $\odot$ & 0 & 0 & 4 \\
\hline Grenada & $\odot$ & 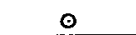 & 0 & 7 \\
\hline Guadeloupe & $\odot$ & 0 & 0 & 6 \\
\hline Guatemala & 0 & 0 & 0 & 3 \\
\hline Guyana & 0 & 0 & $\odot$ & 4 \\
\hline Haiti & 0 & 0 & $\odot$ & 4 \\
\hline Honduras & $\mathrm{O}$ & $\mathbf{O}$ & 0 & 3 \\
\hline Jamaica & 0 & 0 & $\bullet$ & 6 \\
\hline Martinique & 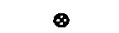 & $\mathbf{O}$ & (2) & 7 \\
\hline Mexico & 0 & $\boldsymbol{\odot}$ & 8 & 7 \\
\hline Montserrat & $\theta$ & $\mathbf{0}$ & - & 9 \\
\hline Netherlands Antilles & 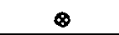 & 0 & $\bullet$ & 8 \\
\hline Nicaragua & 0 & 0 & 0 & 3 \\
\hline Panama & 0 & 0 & $\odot$ & 4 \\
\hline Puerto Rico & 0 & ? & 0 & 10 \\
\hline St. Kitts \& Nevis & $\odot$ & $\boldsymbol{0}$ & - & 8 \\
\hline St. Lucia & 0 & $\odot$ & - & 7 \\
\hline $\begin{array}{l}\text { St. Vincent \& } \\
\text { Grenadines }\end{array}$ & $\mathbf{O}$ & $\mathbf{O}$ & - & 6 \\
\hline Suriname & $\odot$ & 0 & $\mathbf{O}$ & 4 \\
\hline Trinidad \& Tobago & $\odot$ & $\mathbf{0}$ & 0 & 6 \\
\hline Turks \& Caicos Is. & $\theta$ & $\bullet$ & - & 9 \\
\hline United States & 0 & - & $\sigma^{4}$ & 9 \\
\hline US Virgin Is. & 운 & 으 & ㅇ & 12 \\
\hline Veneruela & $\bullet$ & 0 & 0 & 5 \\
\hline
\end{tabular}

\section{0 weak (1)}

O (2)

(3)

- strong (4)

"Based on per capita GDP.

Based on observed resource/pollution problems, provision of sewerage and safe drinking water, and

comprehensiveness of environmental management and enforcement.

Based on relative importance of marine resources and relevant economic activities/priorities.

Gulf Coast states only. 
assessment of one or more relevant factors for which information was available. Specifically:

- economic capacity was rated solely on the basis of per capita GDP;

- institutional capacity was rated on the basis of a state's observed resource/pollution problems, the extent to which it provides sewage services and safe drinking water, and the comprehensiveness of its environmental management and enforcement;

- economic incentive was rated on the basis of the significance of a state's marine resources and the relative importance and direction of pertinent economic activities and priorities.

The assigned ratings for these three factors, and the resulting total "score" for each WCR state, are also displayed in Table 23. Figure 16, panels a through $d$, display the geographic distributions of the WCR states with respect to economic capacity, institutional capacity, economic incentive, and total "score."

Admittedly, the three rating factors constitute a limited and somewhat arbitrary basis for assessing something as complicated as a state's capacity-and especially its motivation or lack of motivation-to devote high-level attention, effort, and other resources to marine environmental concerns. As a practical matter, however, these factors reflect the limits of the relevant information that is available on a more or less uniform and comprehensive basis for all the WCR states. At least equally important, they constitute what we believe to be the most reliable indicators of the WCR states' long-term capabilities, intentions, and priorities (in contrast to, for example, the charter or early statement of objectives of a fledgling environmental ministry).

Table 24 arrays the WCR states according to their total "scores" for the three qualitative rating measures, which range from 3 to 12 . As indicated by the title of the table, we consider these results to provide a qualitative idea of each state's overall prospect or likelihood of engaging in sustained and effective action to control LBMP, based on its economic and institutional capacity and its economic incentive to do so. Another way of describing the information in Table 24 is to consider the states in the far-right columns (i.e., US Virgin Islands, British Virgin Islands, Cayman Islands, and United States) as those most likely to bring to the effort the strongest mix of know-how, financial commitment, and political determination, whereas those listed at the far left (i.e., Guatemala, Honduras, Nicaragua, Colombia, French Guiana, Guyana, Haiti, Panama, and Suriname) are the states least likely to participate in any meaningful way without substantial financial and technical assistance and other, special inducements.

Clearly, the majority of WCR states fall somewhere between these two extremes (i.e., 

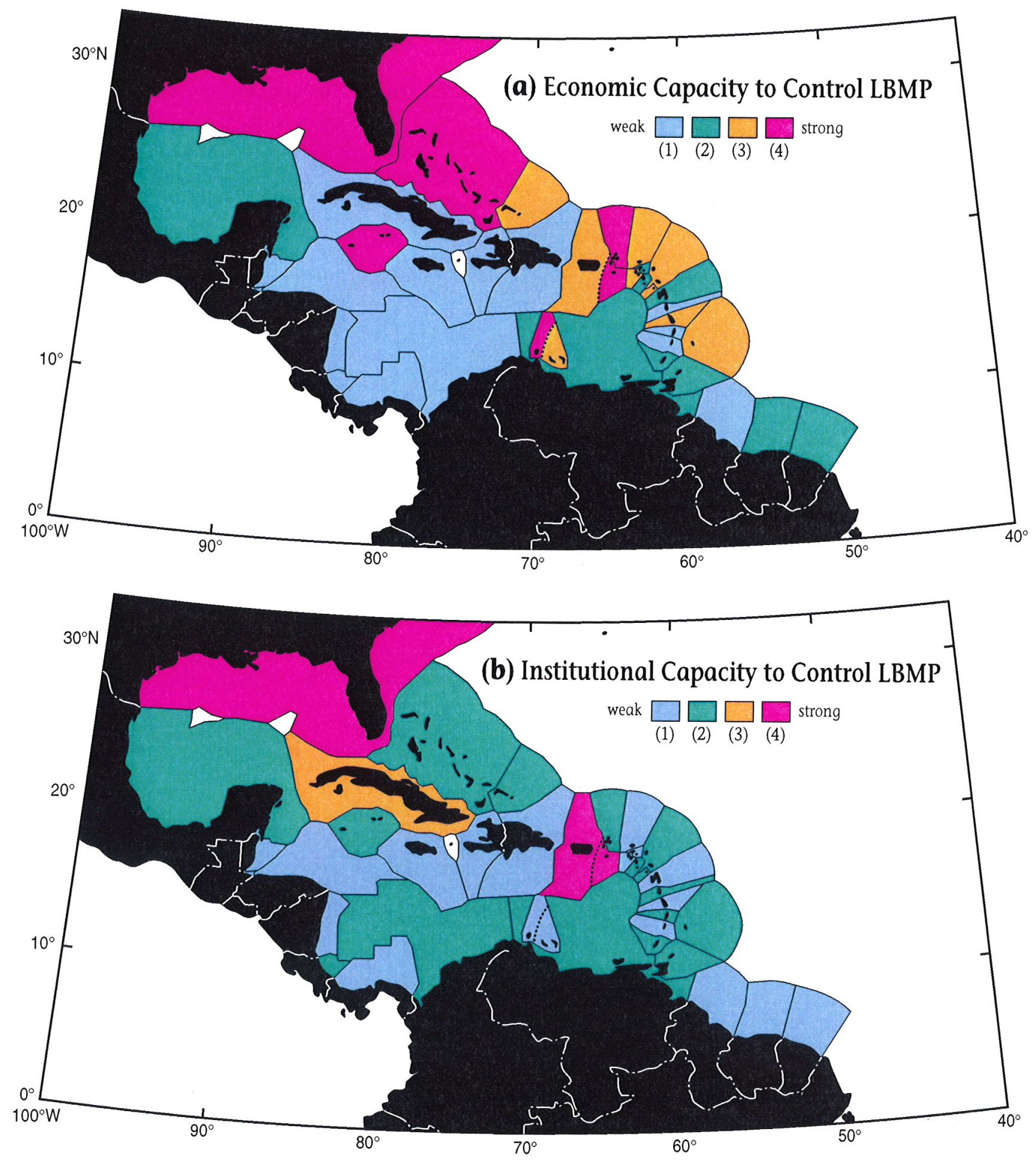

Figure 16. Relative Capacities and Incentives to Control LBMP Throughout the WCR 

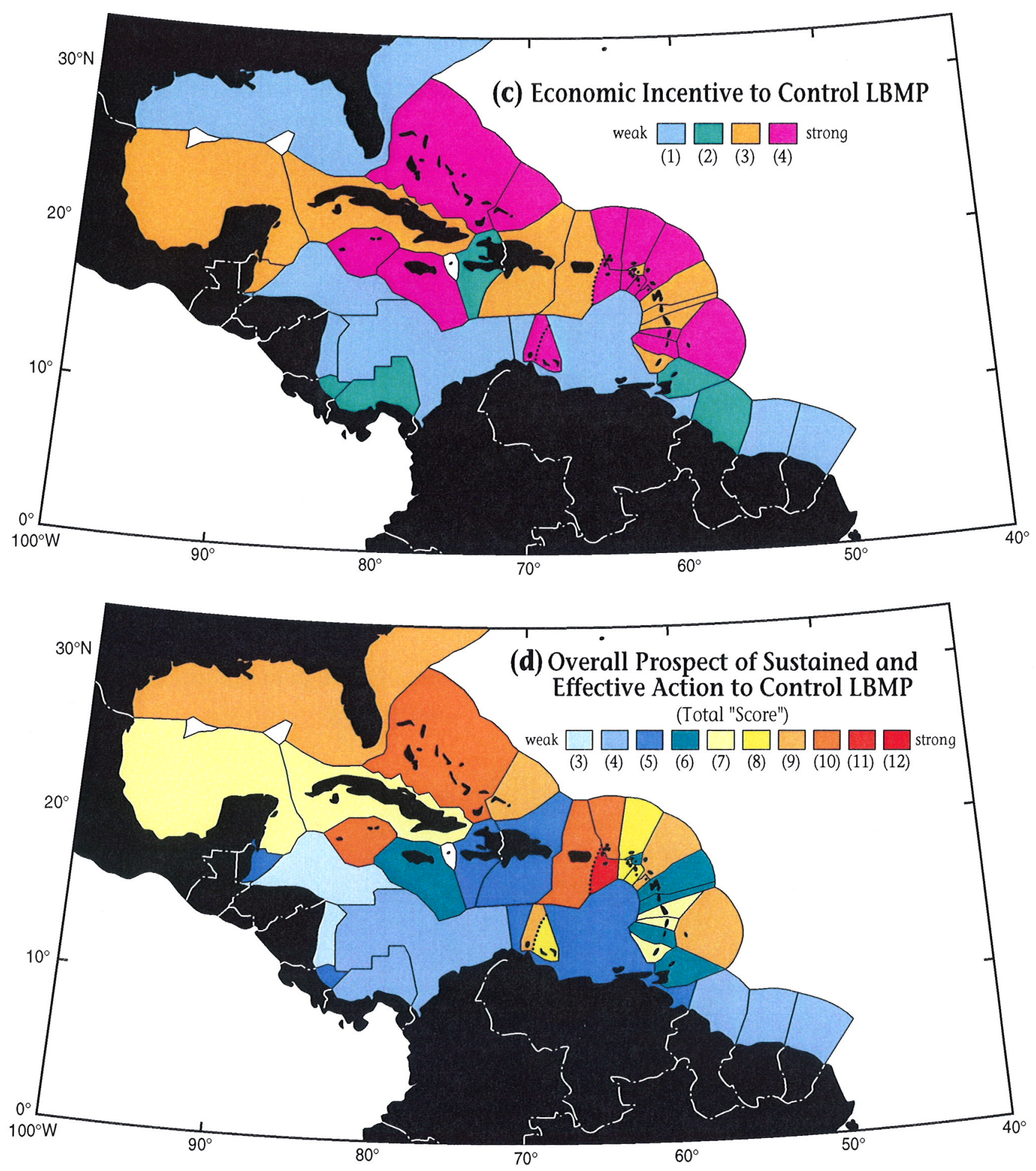

Figure 16 (cont'd). 


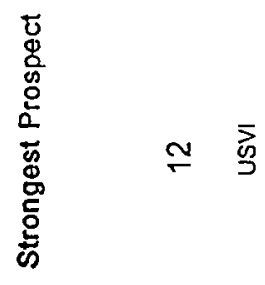

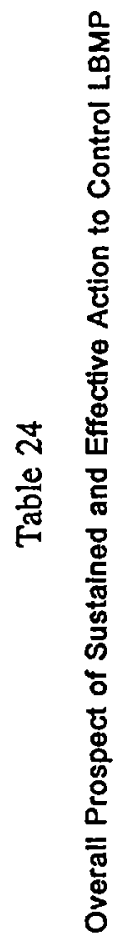

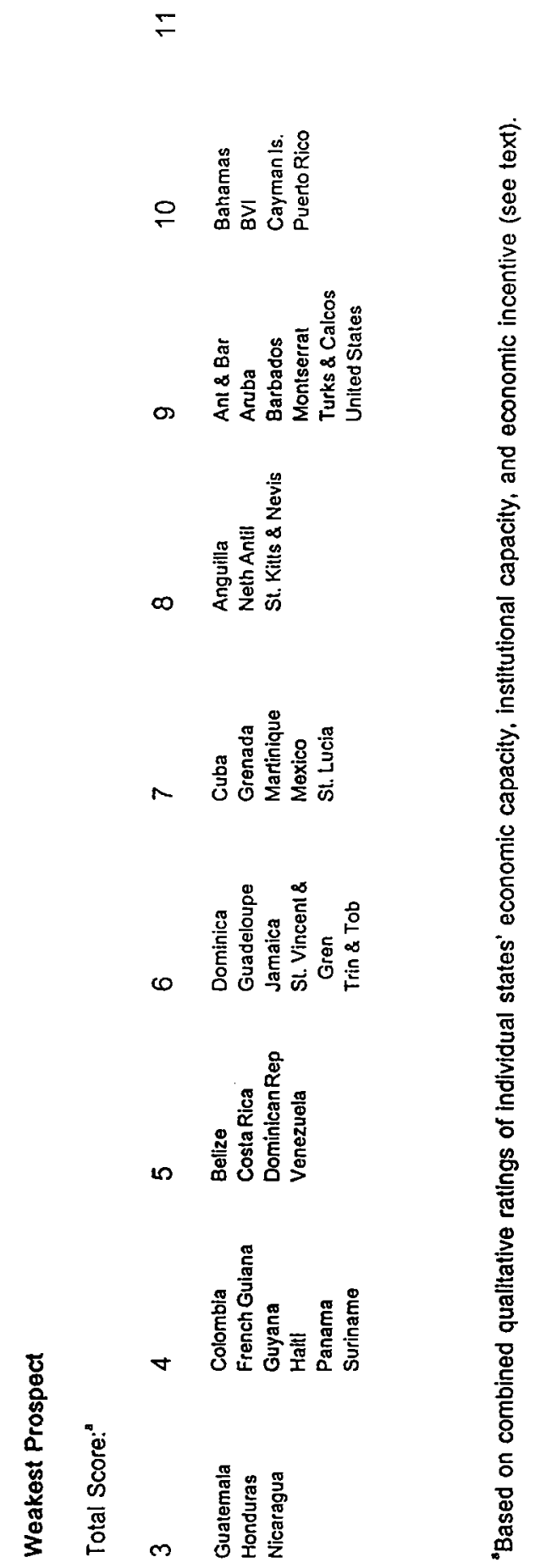

107 
in groups with total "scores" ranging from 5 to 9), and the specifics of their circumstances warrant closer scrutiny. Fifteen of the WCR states-all of them island nations or dependencies-have very strong economic incentives to control LBMP (see Table 22 and Figure 16, panel c). This group includes: Anguilla, Antigua \& Barbuda, the Bahamas, Barbados, the British Virgin Islands, the Cayman Islands, Jamaica, Montserrat, the Netherlands Antilles, St. Kitts \& Nevis, St. Lucia, St. Vincent \& the Grenadines, the Turks \& Caicos Islands, and the US Virgin Islands.

Of these 15, all but the US Virgin Islands have a substantial to very serious need for technical assistance to overcome weak institutional capacity, and 4 of them (Jamaica, St. Kitts \& Nevis, St. Lucia, and St. Vincent \& the Grenadines) have a substantial to very serious need for financial assistance as well (Figure 16, panel a). In contrast to this latter subgroup is another subgroup of 3 (Aruba, the Bahamas, and the British Virgin Islands) that is in a comparatively strong position to pay for the technical assistance or institutional strengthening they would need to control LBMP to a level that is consonant with their economic incentive to do so.

Other than stress to coastal ecosystems, which is a ubiquitous problem throughout the WCR, pollution from sewage is the most widespread of the serious LBMP problems confronting this group of 15 states with especially strong economic incentives (affecting 9 of the 15). Sewage is followed by coastal erosion (affecting 7 of the 15 states). Other LBMP and related resource degradation problems that affect at least one-third of this group are pollution of coastal waters by oil, mining, and other industrial effluents; deforestation; and overfishing. In addition, 5 of the states in this group have been cited in various studies for failure to undertake an assessment of their marine resources and problems, and an additional 2 (Jamaica and the Netherlands Antilles) have been criticized for their general failure to regulate development and other activity in the coastal zone (refer again to Table 11 in Section IV).

The most obvious sources of both financial strength and technical assistance within the WCR are the United States and the US Virgin Islands (although the latter has its own difficulties with sewage management). Puerto Rico is another comparatively strong prospect for technical assistance-perhaps particularly to those neighboring countries that have yet to inventory their coastal assets and problems or to develop and enforce effective regulations concerning coastal zone activity. Although not in the top tier in terms of overall institutional capacity, Cuba rates well above average for the region, and it should be considered as a potential source of technical assistance, especially on the use of "clean" technologies to reduce pollution by industrial effluents.

Cuba is one of 9 WCR states whose economic incentives to control LBMP may be described as important but not compelling, in that industries such as tourism and fishing are together substantially less important than manufacturing and/or agriculture. Cuba is noteworthy among this group for having developed its quite strong institutional capacities despite a very low 
standard of living, ${ }^{7}$ whereas something like the reverse is true of Martinique, whose relatively high standard of living has not translated into much progress in the area of environmental infrastructure. For the rest of this group, there tends to be a much closer correspondence between standard of living and institutional capacity to control LBMP and other environmental problems, with the need for both financial and technical assistance being most serious for Belize, Dominica, Haiti, and the Dominican Republic.

Other than Belize and perhaps Costa Rica (as discussed further below), the Central American countries should not be expected to participate in a sustained and meaningful way without special inducements. ${ }^{8}$ All of these states have little in the way of economic capacity, institutional capacity, or economic incentive to participate. In Central America, two main reasons for the low incentive are the predominance of the agriculture and manufacturing sectors, and the far greater orientation of population centers and economic activities toward the Pacific coast and watershed.

For several of the WCR states, factors other than economic self-interest should not be overlooked as major motivations to participate in a regional protocol on LBMP. For the United States, for example, the apparent motive is a sense of responsibility, as the dominant economic power in the region, to share its strong institutional and technical expertise with its neighbors (and to improve the well-being of its own citizens and resources in the Mexican border area as well). Venezuela is likely to be motivated by similar sentiments, including a desire (or perhaps a political necessity) to improve the environmental quality of life for the very high proportion of its population that is concentrated along the Caribbean coast. Perhaps most important for Venezuela, however-and for Puerto Rico and Trinidad \& Tobago as well-is an awareness that these states account for most of the industrial point-source pollution entering the Caribbean proper (i.e., not including the Gulf of Mexico). Finally, Colombia and Costa Rica have both taken various steps which indicate that environmental concerns are a much higher priority than their actual institutional capacities would suggest, and it is likely that both these states see the completion of a regional protocol on LBMP as improving the chances that greater attention and resources will be made available to improve their domestic capabilities in this area.

\section{E. Concluding Remarks}

The analytic approaches and examples described in this section, together with the

\footnotetext{
${ }^{7}$ As noted by Broadus (pers. comm., 1994), one explanation that readily comes to mind is the low opportunity cost within a command economy, particularly one that until recently enjoyed tremendous foreign subsidies.

${ }^{8}$ The same is probably true for the three South American states to the east of Venezuela, although Guyana and Suriname do participate in the Amazon Cooperation Treaty, which may well be more relevant to their environmental concerns than LBMP in the Caribbean.
} 
information compiled in the previous section and in the Appendix A data tables, are intended to serve as a basis for explicitly recognizing common and complementary self-interests, strengths, and weaknesses in the design of protocol mechanisms to facilitate mutually beneficial collaborations and exchanges.

No attempt has been made to integrate these analytic approaches into a single "formula" for determining the "best" organization of states into subregions. Nonetheless, the present study has given attention to concerns that were expressed by some reviewers of the earlier, comparative study (i.e., Broadus et al. 1993) as to the desirability of relying on a single indicator-population-to represent a state's stake in controlling LBMP. Specifically, Broadus et al. (1993:48) used the percentage of a state's population in the relevant drainage area as a proxy for "political and economic interest in reducing marine pollution"-a measure for which few other reliable data are uniformly available.

In this study, the approach of Broadus et al. has been refined by using an estimate of coastal population rather than drainage area population to represent a state's "stake" in controlling LBMP.9 In addition, an attempt was made to test the validity of the abovementioned criticism. The coastal population estimate was weighted by our composite indicator of "economic incentive to control LBMP" (see Section V.D), which represents the significance of a state's marine resources and the relative importance and direction of pertinent economic activities and priorities.

Reviewers of the earlier study may be surprised to learn that this weighting exercise resulted in only minor deviations from the results reported in Section V.D. For example, Costa Rica and Honduras exchanged places but remained fairly close in the middle range of stakes within Subregion II; and in Subregion III, there was a similar reversal of position for the Dominican Republic and Jamaica, with both remaining in the middle range.

Curious readers can easily perform this exercise and consider the results for themselves. The results are not reported here because we remain skeptical about the utility and validity of weighting factors that provide only a narrow sense of a large and complicated economic picture (e.g., agriculture as \% of GDP) or cannot be reliably quantified for such use (e.g., targeting of industries for concerted development efforts). ${ }^{10}$

\footnotetext{
${ }^{9}$ The preferability of coastal population is obvious if one considers that residents of the US states of Montana and Pennsylvania, for example, although part of the WCR drainage basin population, are unlikely to see themselves as having an economic stake in the quality of the Gulf of Mexico or WCR marine environment.

${ }^{10}$ Similarly, we have rejected a suggestion that land-use data be used to weight population for a better indicator of "stake." Land-use data are quite difficult to obtain, especially for the small island states. Far more important is the fact that, even where available, they are by their nature destined to capture only the relative importance of polluting and "pollution-neutral" industries, while failing to capture the importance of industries that are vulnerable to LBMP, such as tourism and fisheries. As such, land-use data, were they more uniformly available, might more
} 
A case in point is the evolving economic reality of Cuba, which was singled out by one reviewer as a state for which population alone suggests a far greater stake in controlling LBMP than its overall economic make-up would suggest (Wood-Thomas, pers. comm., 1995). While it is true that Cuba has an unusually high proportion of GDP accounted for by manufacturing (39\%), there are other important (but difficult to quantify) factors that account for Cuba's having been assigned a rating of "3" for economic incentive to control LBMP. The most important of these factors are the following:

Tourism has been targeted as the number one growth area by the government, and foreign investment in tourism development has been very strong.

Cuba is the largest net exporter of fish in the WCR; the reported value of its net exports exceeds that of the second-largest net exporter (Bahamas) by more than 30 percent.

Manufacturing is heavily concentrated in paper products and has been targeted by the government for strategic diversification. An emerging industry that could well benefit from this move, and in which Cuba is a leader in the WCR, is the development and application of so-called clean technologies.

Such factors, we believe, constitute a sound basis for characterizing Cuba as having a much stronger economic incentive to control LBMP than its historical emphasis on manufacturing (and, to a lesser extent, agriculture) would indicate. At the same time, however, such information-being difficult to quantify and not uniformly available or relevant across the region-does not lend itself to use as a weighting factor.

The development of one or more weighting factors for use in analyzing states' relative stake in controlling LBMP remains an intriguing area for further effort, but one in which success will depend heavily on substantial improvement in the collection and availability of relevant demographic and socioeconomic data. For the present, we offer the information and analyses reported here as a framework for assessing which states are the most likely to engage in sustained and successful action to control LBMP, and the general categories of assistance or special inducements that the other states are likely to need in order to participate successfully.

appropriately be used as a weighting factor for "source" if one were needed (which, to our knowledge, has not been suuggested). 


\section{Lessons Learned ${ }^{1}$}

A review of experience with regional programs to control land-based marine pollution in the Baltic, North Sea, and Mediterranean has revealed a number of factors that can contribute to program effectiveness (Broadus et al. 1993). We compare these factors with expectations about a protocol for the Caribbean region, based upon regional characteristics and the current state of policy debate over the establishment of an LBMP protocol. ${ }^{2}$

We present here and apply a checklist to help summarize effectiveness factors across the four regions (Table 25). In general, factors for success can be classified into three categories. The first is a set of regional background characteristics associated with effective cooperation. The second is a set of program design elements, which are explicitly subject to the control of program planners. The third is a set of indicators of program effectiveness. (Success breeds further success, and evidence that a program is in fact doing what it set out to do serves to reinforce or provide momentum for further program effectiveness.)

In the case of the Caribbean, our checklist is necessarily incomplete because there is no practice under an LBMP protocol to be observed and evaluated. Nevertheless, we feel that this checklist provides a useful comparison across the four regional international programs.

\section{A. Regional Background Characteristics}

\section{Delineation of Subregions}

The appropriate region must be defined in terms of the actual environmental relationship between states. If pollutants do not circulate widely, then the inclusion of unaffected states in a regional program will only complicate cooperative efforts.

In the Baltic and North Sea regions, marine pollution is truly a transboundary problem. The Baltic is shallow and stagnant and thus tends to trap discharged pollutants, affecting all states bordering it. The counter-clockwise currents of the North Sea provide a better flushing mechanism for that regional sea, but a general transboundary problem remains in that the discharges of some states are exported to other states.

\footnotetext{
${ }^{1}$ Much of this section has been adapted from Broadus et al. (1993) in order to facilitate the application of "lessons learned" from regional international programs to control land-based marine pollution in the Mediterranean, Baltic, and North Sea regions to the Wider Caribbean.

${ }^{2}$ This comparison was initiated through discussions at a workshop conducted as part of this study, which was held 4-6 December 1994, at the University of the West Indies in Bridgetown, Barbados.
} 
Table 25

Checklist: Factors for Regional Program Success

\begin{tabular}{|c|c|c|c|c|}
\hline $\begin{array}{l}\text { Regional Background Characteristics for } \\
\text { Effective Cooperation }\end{array}$ & Baltic & $\begin{array}{l}\text { North } \\
\text { Sea }\end{array}$ & Med & Caribbean \\
\hline $\begin{array}{l}\text { Is the region defined in terms of the pollution } \\
\text { problem? Do the pollutants affect all of the states } \\
\text { entering into the agreement? }\end{array}$ & Yes & Yes & Doubtful & $\begin{array}{l}\text { No. focus should be on delineation } \\
\text { of subregions }\end{array}$ \\
\hline $\begin{array}{l}\text { Is there coherence among member states? Are they } \\
\text { at similar levels economic and scientific } \\
\text { development. and do they have similar resources at } \\
\text { stake? }\end{array}$ & $\begin{array}{l}\text { Largely, } \\
\text { but some } \\
\text { disparity }\end{array}$ & Yes & No & $\begin{array}{l}\text { No, but possibly yes at an } \\
\text { appropriately delineated } \\
\text { subregional level }\end{array}$ \\
\hline $\begin{array}{l}\text { Are the member states politically committed to the } \\
\text { program? Is the condition of the regional sea a } \\
\text { priority issue. and are high level political officials } \\
\text { involved in overseeing the program? }\end{array}$ & Yes & Yes & No & $\begin{array}{l}\text { Doubeful. although issue is } \\
\text { recognized }\end{array}$ \\
\hline $\begin{array}{l}\text { Was there general knowledge of the baseline } \\
\text { environmental conditions in the sea at the time of the } \\
\text { program's inception? Where the basic sources and } \\
\text { shares of pollutant inputs known? }\end{array}$ & Yes, fair & No, poor & $\begin{array}{l}\text { Some. } \\
\text { partial }\end{array}$ & $\begin{array}{l}\text { IOCARBE and CEPPOL have } \\
\text { made a good start: focus should be } \\
\text { on priority problem areas }\end{array}$ \\
\hline \multicolumn{5}{|l|}{ Elements of Efrective Program Design } \\
\hline $\begin{array}{l}\text { Is the goal of the regional agreement clearly stated, } \\
\text { and are the program objectives designed to meet this } \\
\text { goat? }\end{array}$ & Yes & Yes & Yes & Should receive priority \\
\hline $\begin{array}{l}\text { Does the agreement oblige contracting parties to } \\
\text { adopt measures to meet program objectives? }\end{array}$ & Yes & Yes & Yes & $\begin{array}{l}\text { Focus on encouragements: } \\
\text { transactions cost reductions }\end{array}$ \\
\hline $\begin{array}{l}\text { Do measures specify reduction argets and deadlines } \\
\text { for their achievement? }\end{array}$ & Yes & Yes & Few & $\begin{array}{c}\text { Encourage flexibility at subregional } \\
\text { level }\end{array}$ \\
\hline $\begin{array}{l}\text { Are program measures designed efficiently? Do they } \\
\text { target pollution sources for which the greacest } \\
\text { reductions can be achieved at the lowest marginal } \\
\text { cost? }\end{array}$ & $\begin{array}{l}\text { No, but } \\
\text { improving }\end{array}$ & No & No & $\begin{array}{l}\text { Design protocol institutions to } \\
\text { encourage efficient subregional } \\
\text { gains from trade }\end{array}$ \\
\hline $\begin{array}{l}\text { Does the agreement provide a mechanism to } \\
\text { determine whether or not contracting parties comply } \\
\text { with adopted measures? Is there an obligation to } \\
\text { report on program implementation? }\end{array}$ & $\begin{array}{l}\text { Yes, but } \\
\text { not in the } \\
\text { past }\end{array}$ & Yes & Yes & $\begin{array}{l}\text { Environmental monitoring and } \\
\text { enforcement are roles for protocot } \\
\text { instirutions }\end{array}$ \\
\hline $\begin{array}{l}\text { Does the program incorporate mechanisms for trade } \\
\text { to increase program efficiency? }\end{array}$ & Limited & No & Some & $\begin{array}{c}\text { Encourage bilateral or small group } \\
\text { agreements }\end{array}$ \\
\hline Adequale financing feaures? & Yes & Yes & Problems & Build on CEPPOL foundation \\
\hline $\begin{array}{l}\text { Is the program's declisionmaking process effective? } \\
\text { Are measures adopted so as to keep their content } \\
\text { meaningful without alienating reluctant participants? }\end{array}$ & Fair & Yes & Fair & $\begin{array}{l}\text { Focus should be on procedures that } \\
\text { aim to reduce transactions costs } \\
\text { and define rights to a clean marine } \\
\text { environment }\end{array}$ \\
\hline $\begin{array}{l}\text { Is the program adaptable? Can it be adjusted to } \\
\text { reflect changed circumstances and improved } \\
\text { knowledge? }\end{array}$ & Yes & Yes & Somewhat & Design into protocol \\
\hline \multicolumn{5}{|l|}{ Dynamle Measures of Erfectiveness } \\
\hline $\begin{array}{l}\text { Is there compliance with the program? Do } \\
\text { contracting parties implement program } \\
\text { recommendations? }\end{array}$ & $\begin{array}{l}\text { Yes, but } \\
\text { limited }\end{array}$ & $?$ & $\begin{array}{l}\text { Sorne or } \\
\text { minimal }\end{array}$ & $\begin{array}{l}\text { Design into protocol using } \\
\text { environmental monitoring support }\end{array}$ \\
\hline $\begin{array}{l}\text { Is the goal being achieved? Has the regional } \\
\text { environment improved relative to the hypothetical } \\
\text { situation that would have occurred without the } \\
\text { regional program? }\end{array}$ & Yes & Yes & Perhaps & - \\
\hline $\begin{array}{l}\text { Have national abatement efforts been greater than } \\
\text { they would have been without regional cooperation? }\end{array}$ & Yes & Yes & Doubrful & $\begin{array}{l}\text { Aim should be to hamess explicitly } \\
\text { national abatement efforts through } \\
\text { the facilitation of subregional } \\
\text { arrangements }\end{array}$ \\
\hline
\end{tabular}

Adapted from Broadus et al. (1993). 
The weak currents and small tides of the Mediterranean Sea leave pollutants mostly in the areas where they are discharged. Although some of the current flows in the Caribbean are strong, most effects of LBM pollutant emissions are felt locally or subregionally. Pollution problems that are local or subregional imply that subregional efforts will be more effective. Effective reduction of pollutant discharges at the subregional level can reduce the risks of regionwide effects.

Broadus et al. (1993) found that cooperative efforts to control land-based sources of marine pollution are most appropriately based in regions defined in terms of the pollution problem itself. In regions where measures to control land-based sources are only one component of a larger umbrella agreement, it may be useful to focus on environmentally defined subregions when addressing land-based sources, rather than unnecessarily including unaffected states.

In the WCR, CEPPOL has identified 6 subregions of contiguous states for purposes of analyzing the distribution of pollutant loads (UNEP 1994a). This delineation is a useful initial attempt, but we note that the occurrence of localized LBMP problems does not follow this pattern in most cases. For example, some of the most common and pressing problems and their distribution across WCR states (based on information summarized in Table 11) are as follows:

Sewage management: Aruba, Bahamas, Barbados, Belize, British Virgin Islands, Cayman Islands, Colombia, Costa Rica, Cuba, Dominican Republic, Grenada, Guadeloupe, Guyana, Haiti, Honduras, Jamaica, Martinique, Mexico, Netherlands Antilles, Panama, Puerto Rico, St. Kitts \& Nevis, Suriname, Trinidad \& Tobago, United States, US Virgin Islands, Venezuela

Industrial pollutants: Barbados, British Virgin Islands, Colombia, Cuba, Dominican Republic, Grenada, Guadeloupe Jamaica, Martinique, Mexico, Netherlands Antilles, St. Kitts \& Nevis, Puerto Rico, Trinidad \& Tobago, United States, US Virgin Islands, Venezuela

Need for better resource assessment/coastal use regulation: Anguilla, Bahamas, Belize, Colombia, French Guiana, Guadeloupe, Guatemala, Guyana, Haiti, Jamaica, Honduras, Martinique, Mexico, Montserrat, Nicaragua, Panama, Suriname, Turks \& Caicos Islands

Deforestation: Belize, Colombia, Costa Rica, Dominica, Grenada, Guatemala, Haiti, Honduras, Jamaica, Martinique, Mexico, Nicaragua, Panama, St. Lucia, St. Vincent \& Grenadines, Venezuela

Coastal erosion: Antigua \& Barbuda, Barbados, Dominica, Grenada, Guatemala, Jamaica, St. Kitts \& Nevis, St. Lucia, St. Vincent \& Grenadines, Venezuela 
Solid waste management: Colombia, Dominica, Grenada, Guadeloupe, Netherlands Antilles

Delineation of subregions is one of the most important tasks that must be undertaken under the auspices of a protocol. Clearly some of the above problems are more common than others, suggesting that a system of overlapping subregions, defined by the presence of targeted LBMP problems (as arrayed in Table 26) might be appropriate. As scientific information is developed, revision of existing subregions may be required.

\section{Coherence Among Member States}

The success of cooperative efforts depends upon "coherence:" shared cultural values, public preferences that coincide, similar stages of economic development, and compatible political organizations. Regions with states at similar stages of economic development, such as the Baltic and North Sea states, are able to contribute on a relatively equal basis to a marine pollution control program, in terms of the scientific, technical, and financial resources they have at their disposal. Conversely, regions comprising states at varying stages of economic development, such as the Mediterranean and Caribbean, may need specialized technology transfer and financial assistance mechanisms if their programs are to function on a fully regional scale.

In the cases studied, the regions with the best coherence have the most effective regional cooperation and are least complicated by a number of transfer issues. Furthermore, cooperative efforts are most effective when member states are similarly affected by a degraded marine environment and have similar resources at stake. If they are not similarly affected by pollutant discharges or do not perceive the condition of the marine environment as a priority issue, it is more difficult to design a program in which participation is beneficial to all members.

The effectiveness of the Baltic and North Sea regional programs, relative to the Mediterranean and, potentially, to the Caribbean, can be explained by the nature of each region's member states and the degree of coherence among them. The North Sea region consists of a small number of relatively homogeneous states, sharing similar stakes in the condition of their regional sea. Most of the Baltic states similarly share a stake in and commitment to their regional sea's environment, though some disparity is evident between the traditional democracies and the formerly communist states. Cooperative efforts in these regions have been able to function on a more uniform basis, with a higher level of political commitment and few transfer issues.

The disparity in levels of economic development in the Mediterranean, in particular, has made uniform action virtually impossible and has complicated relations by virtue of the need for transfer mechanisms. We expect that the existence of similar types of disparities among 
Table 26

Commonality of Specific LBMP Problems as Basis for Subregional Groupings

\begin{tabular}{|c|c|c|c|c|c|c|}
\hline $\begin{array}{l}\text { State } \\
\text { (economic capacity- } \\
\text { institutional capacity- } \\
\text { economic incentive) }\end{array}$ & $\begin{array}{c}\text { Defor- } \\
\text { estation }\end{array}$ & $\begin{array}{l}\text { Solid } \\
\text { waste }\end{array}$ & $\begin{array}{l}\text { Coasal } \\
\text { erosion }\end{array}$ & $\begin{array}{l}\text { Industrial } \\
\text { pollutants }\end{array}$ & $\begin{array}{c}\text { Resource } \\
\text { inventory/ } \\
\text { mgmt }\end{array}$ & $\begin{array}{c}\text { Sewage } \\
\text { mgmt }\end{array}$ \\
\hline Anguilla (3-1-4) & & & & & - & \\
\hline Antigua \& Barbuda (3-2-4) & & & - & & & \\
\hline Aruba $(4-1-4)$ & & & & & & - \\
\hline Bahamas (4-2-4) & & & & & - & - \\
\hline Barbados (3-2-4) & & & - & - & & - \\
\hline Belize (1-1-3) & - & & & & - & - \\
\hline British Virgin Is (4-2-4) & & & & - & & $\bullet$ \\
\hline Cayman Is (4-2-4) & & & & & & - \\
\hline 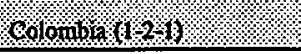 & 8 & 8 & 4 & 80 & 8 & 2 \\
\hline Costa Rica (1-2-2) & - & & & & & $\bullet$ \\
\hline Cuba $(1-3-3)$ & & & & - & & $\bullet$ \\
\hline Dominica (1-2-3) & - & - & - & & & \\
\hline Dominican Rep (1-1-3) & & & & 울 & & 울 \\
\hline French Guiana (2-1-1) & & & & & - & \\
\hline (Grond, $(2,23)$, & $\Leftrightarrow$ & 8 & 8 & 2 & \% & 8 \\
\hline Guadelouper 139$)$ & & 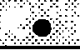 & ?ै & 20 & 8 & 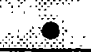 \\
\hline Guatemala $(1-1-1)$ & $\bullet$ & & - & & $\bullet$ & \\
\hline Guyana (1-1-2) & & & & & - & 은 \\
\hline Haiti (1-1-2) & $\bullet$ & & & & 9 & $\dot{0}$ \\
\hline Honduras (1-1-1) & - & & & & - & - \\
\hline Tamiancis: $(1,144)$ & 8 & ? & 8 & 8 & 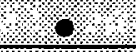 & 8 \\
\hline Xringug 8.13 & 8 & ?. & & 2.8 & 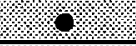 & 8 \\
\hline 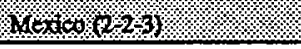 & 8 & & & 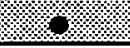 & 8 & 8 \\
\hline Montserrat (3-2-4) & & & & & 은 & \\
\hline Neth. Antilles (3-1-4) & & 울 & & 은 & & 는 \\
\hline Nicaragua $(1-1-1)$ & - & & & & - & \\
\hline Panama (1-1-2) & - & & & & - & - \\
\hline Puerto Rico (3-4-3) & & & & 은 & & - \\
\hline St. Kitts \& Nevis (2-2-4) & & & - & - & & 는 \\
\hline St. Lucia (1-2-4) & - & & - & & & \\
\hline St. Vincent \& Gren $(1-1-4)$ & - & & 운 & & & \\
\hline Suriname (2-1-1) & & & & & 는 & - \\
\hline Trinidad \& Tobago (2-2-2) & & & & 은 & & - \\
\hline Turks \& Caicos (3-2-4) & & & & & - & \\
\hline United States (4-4-1) & & & & - & & 눈 \\
\hline US Virgin Is (4-4-4) & & & & - & & - \\
\hline 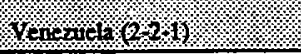 & 2 & & 2 & 8 & & 8 \\
\hline
\end{tabular}

See Section V.C, especially Table 23.

Shading indicates those states suffering from at least 4 of the 6 problems listed. 
Caribbean states implies a high potential for lack of coherence there. A careful delineation of subregions would enhance the potential for coherence among states within each subregion.

Building upon the example introduced in the preceding subsection, we note that Table 26 presents the qualitative ratings (from Section V) of individual states' economic capacity, institutional capacity, and economic incentive to control LBMP. Of the 37 political units in the region, there are only 7, or fewer than one-fifth, for which at least 4 of the 6 selected LBMP problems are significant: Colombia, Grenada, Guadeloupe, Jamaica, Martinique, Mexico, and Venezuela (the shaded rows in Table 26). Five of these seven have strong to very strong economic incentives to participate in an LBMP protocol, but none has an institutional capacity rating higher than 2 , and the average economic capacity rating for the group is just 1.85 . The addition of the United States (including Puerto Rico and the US Virgin Islands) and Cuba to this group, however, could make for a kind of "super" subregion that is truly representative of the full range of problems, incentives, and capacities throughout the region. Within a framework of overlapping subregions, a "super" subregion constituted on such a basis could be explicitly chartered to play a coordinative role among all the other subregions; to ensure equal access to the protocol's clearinghouse products; and to promote fairness in the internal allocation of financial and technical assistance to all participating states and subregions.

\section{High-Level Political Commitment and Oversight}

The success of a regional program inevitably depends on the political commitment of its member states. Unless members accept the condition of their regional sea as a domestic priority issue, it will be difficult to get them to take costly effective action. One indicator of likely political commitment is whether the program grew out of internal or external motivations. A program that develops out of mutual concern for a shared resource is likely to enjoy a greater level of commitment than a program initiated by external players, whose concerns and motivations differ from those of the regional states. The frequency of ministerial-level meetings may also indicate continued interest and commitment to a regional program. High-level political involvement in setting program objectives and reporting on program implementation also adds some accountability to the program framework.

Both the Baltic and North Sea programs were internally motivated, growing out of a shared perception among regional states that the degradation of the marine environment was an issue of great importance. Ministerial conferences have contributed to the success of these programs by producing specific commitments with meaningful timetables and by encouraging Contracting Parties to take actions with greater scope.

Both the Mediterranean and Caribbean programs, on the other hand, have resulted primarily from external UNEP initiatives. As in the other regions, ministerial-level meetings 
have contributed to the effectiveness of the Mediterranean program by expediting the adoption of common measures.

A sense of urgency and concern for the condition of a regional sea, essential to the success of a pollution control program, cannot be introduced into regional states by external organizations. Many WCR states already consider the risks of transboundary LBMP to be a pressing problem, especially because of threats to tourism economies. Even nontransboundary pollution problems may harm other tourist economies, especially those linked by cruise ship business, in that visitors may form a general impression of the Caribbean as polluted on the basis of localized problems. Institutions organized through a Caribbean regional protocol may have an important role to play in encouraging subregional agreements to reduce pollution by lowering transactions costs, channeling foreign assistance efforts, and serving as a clearinghouse.

\section{Knowledge of Baseline Conditions}

All four regions suffer from a lack of adequate baseline data. Without such information it is difficult to establish effective program priorities, to gauge program effect, or to adjust effort in response to changing conditions.

Thanks to the long tradition of environmental monitoring in the Baltic Sea, the nature of the region's pollution problem was relatively well understood at the time of the Helsinki Convention's inception. This knowledge of baseline environmental conditions has increased the effectiveness of cooperative efforts in the region.

The baseline conditions of the North Sea were not very well understood when cooperative efforts were first undertaken. As of 1988, estimates have been developed for the inputs of nutrients, heavy metals, and halogenated substances, with resulting improvements in effectiveness.

Baseline pollution sources in the Mediterranean were loosely identified in 1972 by the FAO's General Fishery Council. Therefore, some information on the pollutants discharged into the Mediterranean and their sources was available in 1975 when the Med Plan was developed. However, the degree of pollutant transport was overestimated.

CEPPOL has begun to assemble data from each state on its point source contributions to the Caribbean Sea and connected waters. Further research efforts are needed to develop a better understanding of current flows and the associated distribution of pollutants. A regional monitoring system would improve the quality of scientific data and deepen our understanding of pollutant dispersal and the potential for damages. This task is one of the most important to be undertaken by the WCR states. In combination with IOCARIBE, the CEP program has taken valuable first steps in characterizing baseline conditions. 
Further improvements could be made by encouraging the scientific community involved in local monitoring of Caribbean waters to make coarse approximations and estimates of environmental conditions, suitable for management guidance, rather than waiting for more thorough and exact research results. The World Bank has already taken steps in this direction (Elvis and Colbert 1994). These estimates should be employed in identifying priority bilateral relationships, delineating subregions, and assisting states in the identification of potential gains from trade.

\section{B. Elements of Effective Program Design}

\section{Clear Goals and Objectives}

Effectiveness will hinge on the aptness of program objectives in light of the overall goal. When a regional program is established to improve the quality of the marine environment, objectives should be realistically designed to reduce emission of pollutants into the marine environment. A program is ineffective if the successful attainment of objectives does not result in the achievement of the goal. For example, objectives that call for "confidence-building" exercises do not, in themselves, result in improved marine environmental quality.

All of the cooperative agreements operating in the North Sea region clearly state their goals. In the case of the Interministerial North Sea Conferences (INSC) and the Paris Convention, objectives have been designed to meet the goal. The Paris Convention calls for the elimination of blacklisted substances, the strict limitation or elimination of greylisted substances, and the prevention of pollution from radioactive substances in order to attain the goal of reducing pollution of the Convention area from emissions of land-based sources. The Declarations of the INSC call for the development of timetables for the various actions aiming to achieve the goal of protecting the North Sea environment.

The goal of the Helsinki Convention is clearly stated in the Convention text. Annexes to the Convention identify substances that Baltic member states should endeavor to prohibit or minimize in order to attain the Convention's goal.

The Barcelona Convention is not very specific in outlining its goals and the means to achieving them. However, the Athens Protocol states its goal as taking "all appropriate measures to prevent, abate, combat, and control pollution from land-based sources." Program objectives are outlined in Articles 5,6, and 7 and call on Contracting Parties to eliminate (Article 5) or strictly limit (Article 6) pollution by substances listed in Annexes 1 and 2, respectively. Article 7, however, limits this obligation by conditioning the adoption of programs and measures under Articles 5 and 6 on the "capacity to adapt and reconvert existing installations, the economic capacity of the Parties and their need for development." 
A clear goal for the reduction and control of LBMP has not yet been articulated by the parties to the Cartagena Convention. In articulating such a goal, states should take advantage of existing institutions, including bilateral agreements to control pollution, and international organizations, such as the CEP and the World Bank. We have argued in this report that an explicitly subregional focus should be incorporated into an LBMP protocol for the WCR. Gains from trade are more readily apparent at the subregional, especially bilateral, level. By encouraging states to control the actual incidence of pollution at the subregional level, the risks of potentially widespread regional pollution can be lowered dramatically. By taking "small" initial steps requiring relatively few but more easily accessible resources, an effective approach to the reduction and control of LBMP in the Caribbean can be built. A careful examination of existing institutions and programs shows that some small steps in this direction have already been taken, providing a firm basis for the subregional approach we recommend.

Clarification of the term "appropriate measures" for LBMP reduction or control, as in the Barcelona Convention, will be another important focus of discussions leading toward a protocol for the Wider Caribbean Region. It is more likely that effective pollution control measures will be adopted if states are permitted to choose the most cost-effective approach for any given level of water quality. At the subregional level, WCR states should be given flexibility in the adoption of appropriate pollution control measures. Flexibility will permit control measures to be one term of negotiation in a trading arrangement.

\section{Obligation to Adopt Measures: Targets and Deadlines}

Effectiveness depends on the degree to which a program's objectives, however aptly designed, have been met by its Contracting Parties. Specific targets and timetables for emission reductions are necessary first steps towards ensuring that program objectives result in real action. The practice of including dates and procedures for reporting on implementation in issued recommendations is also useful in this regard.

PARCOM issues recommendations to its Contracting Parties and calls upon them to implement the recommended programs and measures in order to attain adopted objectives. The effectiveness of these measures improved with the 1987 and 1990 North Sea Conferences, when an emissions reduction program with specified targets and time limits was adopted (Wettestad 1992). Prior to the 1987 Conference, the reduction programs adopted were vague and reflected the position of the most reluctant participants.

HELCOM issues recommendations to its Contracting Parties on the adoption of measures necessary to fulfill the program objectives. These measures usually contain specific targets and deadlines for their accomplishment.

Recommended common measures have been adopted in conjunction with the Athens 
Protocol, addressing 12 of the 28 substances covered in Annexes I and II. However, the content of the adopted measures is general, with few fixed time limits related to concrete reduction goals. Only four of these measures include target dates, or periods, for their achievement. Thus the recommendations effectively do not demand that practical action be taken by the Contracting Parties. In such a diverse region, however, there may be so many local variables that common action becomes virtually impossible. In these situations it may be more effective to adopt variable standards or differential timetables than to adopt uniform measures that result in little or no practical action.

A useful method of accommodating a region's developing states, or states otherwise subject to drastically different conditions or incentives, is to employ differential timetables for complying with objectives, accompanied by mandatory reporting requirements on progress made toward implementation. In this way, Contracting Parties are encouraged to take some sort of action toward meeting program objectives, at least in the form of enabling steps, and some record of their progress can be observed.

The differential timetable method can be applied to subregions in the Caribbean. With guidance from protocol institutions, subregional groupings of WCR states should be encouraged to set standards, identify appropriate pollution control mechanisms, and determine appropriate timetables for control. Regional institutions, such as the CEP or the World Bank, might be called upon for general advice in selecting these parameters of a program.

\section{Efficiently Designed Program Measures}

Program measures are most effective when they target effluents and locations for which the greatest damage reduction can be achieved for the least cost. Reductions across the board, such as those required by uniform standards, tend to be more costly and less efficient than a strategy that bases reductions on the marginal damage done and the marginal cost of abatement for each substance.

The measures adopted for the protection of the North Sea Convention area were not designed efficiently. Improvements in the marine environment will be made at a higher economic cost than necessary (Wettestad 1992). This is evident in the apparent preference for uniform emission reduction standards over environmental quality standards, and in the fact that the major problems in the region are confined to several coastal hot spots while the measures adopted address the entire North Sea area.

Past HELCOM recommendations have not been designed efficiently. As with the 50 percent reduction target, past measures have been taken across the board. However, the Baltic program seems to be moving away from across-the-board reduction strategies. The prefeasibility studies of the Baltic Joint Comprehensive Programme focus on the most serious point 
sources of pollution in an attempt to provide a basis for cost-effective action. Thus, if HELCOM follows the lead of the Baltic Task Force, measures adopted for the protection of the Baltic Sea should become more effective and efficient.

The measures adopted for the protection of the Mediterranean region are ineffectively designed and often do not result in practical action.

In the WCR case, arguments are now being made for regionwide uniform water quality standards and technology-based emission controls. These approaches are inflexible and potentially quite costly. Further, they are warranted only in special cases, where threshold effects are strongly suspected or actually evident. As in the case of the Mediterranean, it seems unlikely that an "effective" protocol will result from agreement on regionwide standards of these types. WCR states should be encouraged to focus on relevant marginal abatement benefits and costs. Where water quality standards are determined to be a more practical approach than the determination of economic damages, states should be encouraged to adopt instruments of control that allow the standards to be met in the most cost-effective manner. Although there may be an important role for technology-based controls on certain discharges or for certain industries, in the interest of effectiveness, they should not be imposed arbitrarily as the only feasible pollution control measure.

\section{Compliance Mechanisms}

Reporting on measures taken toward implementation is a critical element of any subregional pollution control agreement. This is particularly true in a common-pool environment, because many states may be reluctant to take action without the knowledge that other states are doing the same or at least not subverting their efforts. In a unidirectional pollution case, such as for many Caribbean pollutants, downstream state(s) have a strong incentive to monitor changes in environmental quality to ensure compliance by the upstream state(s).

In the absence of physical evidence to determine compliance, parties should be called upon to report on their level of compliance, in terms of legal, regulatory, or other measures taken toward implementing program objectives. However, it is essential that reporting be made convenient and easy, to ensure that failures to report are not mistakenly interpreted as failures to comply.

Although there are no physical mechanisms to monitor the compliance of Contracting Parties in the North Sea region, the recommendations issued by the INSC and the Paris Commission include a date and procedure for reporting on measures taken. Member states report on the implementation of recommendations at the meetings of the Contracting Parties. 
HELCOM is becoming increasingly effective at ensuring the compliance of its Contracting Parties. Until recently, reporting on compliance was voluntary. The 1992 Helsinki Convention has expanded the requirement to report on domestic implementation, as well as the obligation to provide information on discharge permits, emissions, and environmental quality. This information is now to be provided upon the request of a Contracting Party or the Commission, thus improving the Commission's effectiveness in determining compliance.

The Mediterranean regional program is relatively ineffective in monitoring compliance. Although the Barcelona Convention contains an article on "compliance control," it has never been implemented. Thus, there is no effective, binding mechanism to assure the reporting or verification of actions taken.

In the WCR, a regional protocol might contain reporting mechanisms as one way in which to reduce the costs to individual parties of gaining information, negotiation, and enforcement ("transactions costs"). A regional verification authority, deploying environmental monitoring technologies, could be empowered to determine compliance in the event of a dispute over whether or not a state has made good faith efforts to comply.

\section{Mechanisms for Trade}

Trading mechanisms can facilitate the accomplishment of mutual goals in regions where members' abilities and preferences vary. Where there are substantial differences in levels of economic development, the transfer of financial resources, technology, and information to developing states may allow the region to achieve improvements in the marine environment that would otherwise be impossible. Such transfers may also serve as inducements for states to adopt goals and actions more in line with those of their partners. Trading can also improve the efficiency of a regional program, if member states are allowed to exchange pollution reduction responsibilities. None of the programs studied, however, has utilized mechanisms such as tradeable emissions quotas to increase program efficiency.

The Baltic regional program has been successful in utilizing the differing expertise of its member states. The "lead state" principle has called upon states with a comparative advantage in dealing with particular substances, sectors, or processes to be responsible for directing related program initiatives. This innovation has provided Baltic states with access to expertise relevant to the state-of-the-art technologies for particular industrial sectors. The 1992 Helsinki Convention reinforces the importance of information exchange by expanding the duties of the Commission to include promoting relevant research and receiving, processing, and disseminating relevant scientific and technical information.

The Mediterranean program, with its diverse participants, presents many opportunities for trade. The Mediterranean program has done the most of the four to transfer financial 
assistance and encourage capacity building among its members. Most information and technology transfers in the Mediterranean region have focused on environmental monitoring programs, treatment plant design, and training for economic policy personnel in the region's developing states. The potential benefits of trade in the Mediterranean program have not been fully realized, and other agencies have intervened to encourage and execute transfers.

Trading among member states improves a program's ability to achieve the mutual goals of its members. Trading mechanisms become increasingly important in regions with diverse member states. A successful program explicitly recognizes the differences in the endowment of its members, and facilitates trading that allows each state to do what it does relatively best.

In this report, we have developed a stylized model of bilateral trade in pollution control to clarify the opportunities for gains in the Caribbean (Appendix C). These opportunities are diminished to the extent that property rights in a clean marine environment are obfuscated; scientific, technical, and economic information useful for characterizing marginal abatement schedules remains undeveloped or is kept proprietary; barriers to negotiation among polluter and pollutee remain in place; and trading relationships are weakened by inadequate enforcement. All of these hindrances to gains from trade are appropriate focuses for LBMP protocol institutions.

\section{Adequate Financing Features}

The efforts involved in reaching, maintaining, and evolving regional agreement are costly in themselves, and the measures required to implement program recommendations are much more so. The inclusion of adequate financing mechanisms is therefore indispensable for program success.

Financing of program organization and secretariat costs on the basis of equal contributions or on shares pro-rated by economic capability (or with supplemental contributions from host members) is simple and expedient as long as these costs are relatively modest. This formula, however, does not take account of the relative stakes, responsibilities, and capabilities of the members with respect to the specific problem at hand. For example, both the percentage of France's population in the Mediterranean coastal region and its share of economic capacity in that region are less than one-third of its required share of payments to support the program's operating costs. This can lead to problems if, as in the Mediterranean, secretariat and administrative costs grow large. These problems may be exacerbated where financial transfers between states are involved and when the mechanisms for these transfers lack transparency.

Implementation of measures agreed to by the program, such as installation of sewage treatment facilities and introduction of modernized industrial production or control technologies, is a different problem. These measures will cost orders of magnitude more than cooperative 
program expenses. Reliance on domestic financial resolve for compliance seems unavoidable, although measures for international financial assistance will be needed where intra-regional economic discrepancies are large. We have begun to see already an interest by the World Bank, GEF, IADB, and UNDP in assisting in the financing of marine pollution control facilities in the Caribbean.

The Baltic's Joint Comprehensive Programme (JCP) appears to offer a good example of both flexible targeting of regional priorities and realistic consolidation of financial resources to address those priorities. How successful it will be in practice remains to be seen, and this will depend significantly on success in mobilizing and managing financial resources. The use of existing multilateral financial institutions in the region as executing agencies promises smooth and competent financial management through well-understood mechanisms. Greater transfers (from west to east) will be required in the Baltic, but the regional program can also help guide the allocation of assistance from outside the region through external institutions such as the World Bank, GEF, and EIB.

The Mediterranean program also has shown some success in shaping the funding priorities of external donor organizations, though to some degree this has been in reaction to initiatives outside the program arising in part because of dissatisfaction with the program's effectiveness and lack of financial transparency. The Mediterranean Trust Fund mechanism has not been notably effective in achieving regional program goals, though it should be acknowledged that it was not intended to finance domestic implementation and capital investment projects.

Based upon our analysis of the Baltic, North Sea, and Mediterranean cases, it has become apparent that a key to effective financing is to sustain the program's credibility by keeping its goals and recommended measures in line with the true priorities of its members and by not allowing its recommended measures to outstrip realistic financial means.

In the Caribbean, program funding might build upon the foundation already established through the CEP. We recommend that small steps be taken, starting with a focus on the region's existing priority transboundary marine pollution problems. If warranted, the program and its resources can be expanded as experience in catalyzing subregional agreements is gained. This kind of "ramping up" approach is more likely to elucidate relevant protocol "scale economies" and to build confidence among Contracting Parties than a more grandiose effort from the outset.

\section{Effective Decisionmaking Process}

The means by which measures are adopted is likely to influence the effectiveness of the program. Seeking consensus ensures broad-based support for adopted measures but tends to 
drive the content down to a level that is palatable to the most reluctant parties (Sand 1991). Although the compromises necessary to reach a consensus may demonstrate a high capacity for political problem solving, they often result in ineffective pollution control measures. Strict insistence on a unanimous choice can be an obstacle to progress.

Conversely, measures adopted without consensus tend to be more substantive, but may also discourage a high level of consistent participation. Without consensus, and with no supranational authority to enforce adopted measures, such an approach is likely to introduce problems of non-compliance.

The approach adopted by the Paris Convention represents a feasible compromise. Consensus is sought, thus building support for adopted measures. However, if the Contracting Parties cannot reach a consensus, measures are adopted by a three-quarters majority vote. Thus, Contracting Parties are not confined to the preferences of the least enthusiastic participants, and an "opt-out" opportunity is available.

In the Caribbean, the trade-off between the level of participation in the program and the level of action called for in adopted measures should be explicitly recognized and addressed in light of a clearly articulated overall goal. Instead of focusing on consensus or majority agreement over uniform standards, the Contracting Parties might usefully decide on procedures for clarifying the legal rights to a clean environment and reducing states' costs of information gathering, negotiation, and enforcement. These procedures can then be applied in any particular subregional case.

\section{Adaptability Over Time}

The ability to adjust the program to changed circumstances and improved knowledge is vital to its effectiveness over time. The method of keeping the framework convention quite spare and leaving program elaboration to subsequent protocols and recommendations is useful in this regard. So, too, is the periodic oversight and intervention of high-level political authority from among the parties.

All four programs exhibit relatively spare framework conventions, leaving program elaboration to protocols and recommendations. The Baltic program introduces further adaptability by devising specific priority projects and tasks without the need to adopt formal recommendations. Both the informal and formal interplay between the INSC and the Commission in the North-East Atlantic region help the North Sea program adapt to changing circumstances and knowledge.

To a large extent, adaptability is related to decisionmaking rules. Reliance on consensus hinders innovation and adaptability. Decision mechanisms that permit or specify variable 
timetables or the ability to opt-out or opt-in on particular measures, as in the North Sea region, also enhance adaptability. So do mechanisms that encourage the formation of subregional compacts and projects, again as in the Paris Convention.

The constant public and political pressure assured through high-level political oversight and involvement, as with the INSC and Baltic Ministerial meetings, encourages program adaptability. So does pressure from NGOs and public interest groups that is facilitated by program transparency and accessibility.

Both the Baltic and North Sea programs have demonstrated adaptability with adoption of revised 1992 conventions, but even greater adaptability would not require so fundamental a change at the framework level. There is some evidence that the adaptability of the Mediterranean program, and, by implication, that of the Caribbean program, may be hindered by their being embedded in the United Nations system. In the Med Program, for example, the ability to generate baseline data was hindered to some extent by the inclusion of all parties in the study effort, rather than relying on research institutions that were already functioning effectively in the region (Broadus et al. 1993; Skjaerseth 1992). There is already some indication that the CEPPOL program is following a similar approach and suffering similar consequences (see Section II, especially footnote 6). Another institutional problem encountered by the Med Plan was a disagreement over funding between UNEP and UNDP, which caused a three-year delay in the implementation of a Priority Action Program (Broadus et al. 1993); in this respect, the negotiating parties would be well advised to learn what they can about the experience to date of the GEF project on ship-generated waste in the WCR, which is a joint effort of UNEP, UNDP, and the World Bank.

None of the three earlier programs exhibits adaptive features that specify uncertainties or changed conditions whose resolution would lead to specific adaptation in the program. These, too, would be useful features.

\section{Dynamic Measures of Effectiveness}

\section{Level of Compliance}

Program effectiveness is in part reflected in the proportion of issued recommendations that are actually implemented by the Contracting Parties. If the program merely issues recommendations that none of the parties adopts in practice, then the program may be deemed ineffective.

Although North Sea states report on the measures taken toward program implementation at the meetings of Contracting Parties, no coherent record of their comments is compiled by the INSC or PARCOM, making it is impossible to monitor the effectiveness of the program in this 
respect.

Mechanisms to monitor the compliance of Baltic Sea states have been put into place, but it is still difficult to draw any concrete conclusions on the present degree of compliance. The available information indicates that only 12 of the 47 LBS recommendations issued between 1980 and 1991 have been implemented by Contracting Parties, implying that the regional program still cannot be considered completely effective in this respect.

It is very difficult to determine the degree of compliance with the Mediterranean cooperative program. Despite the obligation to report on measures taken and results achieved, Contracting Parties show a great reluctance to provide such information (Skjaerseth 1992). Requests for information on land-based sources and domestic legislation have received little or no response. Furthermore, there is evidence that most Contracting Parties have failed to adopt domestic laws and legislation reflecting the provisions of the Athens Protocol and its Annexes (UNEP 1991b). The available information suggests that the level of compliance is quite low.

We are greatly concerned that if an LBMP protocol for the Caribbean follows along the lines of the development of the Mediterranean program, that compliance will be predictably low. This lesson provides one of the strongest arguments for a subregional approach in which downstream WCR states have immediate incentives to seek pollution reduction from upstream WCR states and a forum to which they can turn, at low cost, to see that such reductions can be implemented.

\section{Achievement of the Program Goal}

A regional program can be considered effective if the regional environment has improved relative to the hypothetical situation that would have occurred without the regional program. Knowing the initial environmental conditions that the pollution control program is designed to alleviate is essential in this respect.

Following the agreement by states of the North Sea region to reduce pollutant emissions by 50 to 70 percent by 1995 , it appears that the goal of reducing pollution from land-based sources is progressing toward being achieved. Although the physical evidence to support this conclusion is scant, there is a general sense among experts that there has been some improvement in the North Sea environment. In fact, the Quality Status Report produced in conjunction with the 1987 North Sea Conference noted that "the few sufficiently long time series available indicate that with a few exceptions, contamination has been reduced or at least has not increased over the last decade" (as reported in Wettestad 1992).

There is some evidence that HELCOM has been effective in achieving its goal and improving the condition of the Baltic Sea. According to HELCOM experts, the Baltic 
environment would have been much worse off in the absence of the Commission's activities (Rodionov 1992). This view is corroborated by the official statement of the Finnish Delegation, which concluded that "the state of the Baltic Sea today is definitely better than it would have been without the many efforts and concrete . . . measures of the Baltic Sea states" (Delegation of Finland 1990).

There are no reliable time series data that would indicate changes in marine environmental quality resulting from Med Plan activities. The best available information is provided by UNEP's 1989 "State of the Mediterranean Marine Environment" report (UNEP 1989b), which gives a fragmented and uncertain account of the condition of the Mediterranean environment. There is some evidence of localized improvements, but how these were influenced by the Med Plan is unclear. Interviews with regional scientists indicate that they feel that the level of pollution has remained roughly constant over the last decade, while coastal population and industry have grown steadily (Skjaerseth 1992). Thus it appears that the effects of increases in population and industry may have been offset by the actions taken from 1976 to 1990 . There may thus be some basis for believing that the Mediterranean marine environment would have been worse off without regional cooperation.

Progress has been made on characterizing baseline environmental conditions in the Caribbean. Further research will be necessary, and this research should focus on marine areas that are seen to be priorities in terms of the incidence of actual transboundary pollution effects or acute localized problems.

\section{Increased Domestic Abatement Efforts}

If a regional program is operating effectively, one would expect member states to engage in greater pollution abatement efforts than they would without regional cooperation.

The pollution abatement efforts of the North Sea and Baltic states are probably at a higher level than would have occurred in the absence of regional cooperation, especially with respect to the adoption of the 50 percent emissions reduction target for the North Sea region. It is reasonable to assume that no single state would adopt so stringent a measure without reciprocal action from other discharging states.

Domestic abatement efforts in the Mediterranean region are not obviously greater than they would have been without the Barcelona Convention and its Protocols. It can be argued that the efforts of several states (specifically Greece, Albania, and Egypt) were affected by the regional program, because they embarked on vigorous new public administrative campaigns to integrate environmental considerations into traditional coastal zone development and economic planning. However, many polluting states had established domestic environmental authorities and legislation prior to the Med Plan's inception in 1976. Many actions taken during Med Plan 
years were taken at the domestic level and likely would have been taken anyway. Although the Mediterranean would have been worse off without regulation, the Med Plan probably only accounts for a minor part of the achievement witnessed (Skjaerseth 1992).

WCR states already recognize the existence of LBMP problems, and many have begun already to develop the infrastructure, including the legal institutions and technological controls, to begin to deal with these problems. An effective LBMP protocol would build upon these nascent efforts, taking small but certain steps to move in the direction of pollution prevention, reduction, and control.

\section{Summary}

At this juncture, it is not yet possible to evaluate the effectiveness of a protocol on LBMP control for the Caribbean. We can, however, say something about the general features and elements of a protocol that might be incorporated to improve its potential for effectiveness (Table 25). The WCR resembles the Mediterranean as a regional sea, suggesting that many lessons can be drawn from the Mediterranean experience. Experience with the control of LBMP in other regional seas can provide useful lessons as well, particularly in the areas of program financing (Baltic), political commitment, (Baltic, North Sea), statements of goals (Baltic, North Sea), targets and deadlines (Baltic, North Sea), and compliance (North Sea).

We argue, in this section, for a careful consideration and delineation of subregions, based on shared LBMP problems of a localized nature, and, where relevant, transboundary pollution effects. In the latter case, protocol mechanisms should build upon existing bilateral arrangements, if these are seen to be effective in themselves. A WCR protocol can also utilize and build upon the resources and capabilities of existing institutions for scientific research, monitoring, and clearinghouse functions. These institutions should be expanded, or contracted, incrementally to determine their most appropriate and efficient scales of operation.

The rights of a state to a clean marine environment should be clarified within the protocol, enabling stakeholder states to seek beneficial reductions in actual or expected LBMP from source states. The Contracting Parties should employ the protocol and its institutions as a forum within which the agreements to reduce LBMP, based upon transboundary effects or common needs, are facilitated, thereby reducing transactions costs (see especially Appendix C). The protocol should encourage states to adopt cost-effective instruments for pollution control, including tradeable pollution permits, emission charges, or technology-based controls, where threshold effects are apparent. 
APPENDIX A

\author{
Data Tables
}


Table A.1

Economic and Population Data for WCR States

\begin{tabular}{|c|c|c|c|c|c|c|}
\hline \multirow[b]{2}{*}{ State } & \multicolumn{3}{|c|}{ Gross Domestic Product (GDP) } & \multicolumn{3}{|c|}{ Population" } \\
\hline & $\begin{array}{c}\text { Total 1991 } \\
\text { (SUS millions) }\end{array}$ & $\begin{array}{l}\text { Per capita } 1991 \\
\text { (SUS) }\end{array}$ & $\begin{array}{l}\text { Avg. ann. } \\
\text { growth rate } \\
\text { (\%) 1980-91 }\end{array}$ & Total $1990^{\circ}$ & $\begin{array}{l}\text { Ann. } \\
\text { Growth } \\
\text { (\%) } 1990 \text {. } \\
95^{4}\end{array}$ & $\begin{array}{c}\text { Density } \\
\text { (persogns } \\
\mathrm{km}^{4}\end{array}$ \\
\hline Anguilla" & 47.4 & 6,800 & 6.5 & 6,800 & 0.6 & 75 \\
\hline Antigua-Bartuda" & 424 & 6,000 & 1.4 & 64,000 & 0.3 & 146 \\
\hline Aruba" & 854 & 13,600 & $10.0^{2}$ & 63,000 & 0.2 & 326 \\
\hline Bahamas' & 2,600 & 10,200 & 3.0 & 247,000 & 1.2 & $250^{\circ}$ \\
\hline Barbados" & 1,800 & 7,000 & $(4.0)$ & 263,000 & 0.6 & 612 \\
\hline Belize & 420 & 2,165 & $9.0^{\circ}$ & 190,000 & 2.03 & 8.3 \\
\hline British Virgin Is." & 133 & 10,600 & 2.0 & 12,000 & 1.1 & 80 \\
\hline Cayman Is. & 670 & 23,000 & 4.4 & 26,000 & $4.3^{2}$ & 100 \\
\hline Colombia & 41,700 & 1,269 & 3.7 & $32,300,000$ & 1.66 & 31 \\
\hline Costa Rica & 5,635 & 1,810 & 3.1 & $3,040,000$ & 2.41 & 60 \\
\hline Cuba" & $17,000^{\circ}$ & $1,580^{\circ}$ & $(20.0)^{1}$ & $10,610,000$ & 0.89 & 96 \\
\hline Dominica & 174 & 2,100 & 2.1 & 85,000 & 1.7 & 113 \\
\hline Dominican Rep. & 7,148 & 976 & 1.7 & $7,170,000$ & 1.98 & 148 \\
\hline Fr. Guiana" & $421^{\circ}$ & $4,390^{\circ}$ & - & 98,000 & 3.4 & 1.1 \\
\hline Grenada" & 250 & 3,000 & $(0.4)^{\circ}$ & 84,000 & (0.4) & 247 \\
\hline Guadeloupe" & $1,100^{\circ}$ & $3,300^{4}$ & - & 342,000 & 0.8 & 194 \\
\hline Guatemala & 9,353 & 988 & 1.1 & $9,200,000$ & 2.88 & $B 5$ \\
\hline Guyana & 349 & 435 & $7.0^{\circ}$ & 800,000 & 0.94 & 4.1 \\
\hline Haiti & 2,641 & 399 & $(0.7)$ & $6,490,000$ & 2.03 & 236 \\
\hline Honduras & 3,004 & 567 & 2.7 & $5,140,000$ & 3.00 & 46 \\
\hline jamaica & 3,497 & 1,431 & 1.6 & $2,420,000$ & 1.02 & 224 \\
\hline Martinique" & $2,000^{\circ}$ & $6,000^{4}$ & - & 340,000 & 0.9 & 321 \\
\hline Mexico & 286,628 & 3,321 & 1.2 & $84,490,000$ & 2.06 & 44 \\
\hline Montserrat & 73 & 5,800 & $13.5^{\circ}$ & 12,000 & 0.3 & 120 \\
\hline $\begin{array}{l}\text { Netherlannds } \\
\text { Antilles }\end{array}$ & 1.400 & 7,600 & $1.5^{4}$ & 183,000 & 0.2 & 191 \\
\hline Nicaragua & 1,736 & 456 & (1.9) & $3,680,000$ & 3.74 & 29 \\
\hline Panama & 5,544 & 2,248 & 0.5 & $2,420,000$ & 1.90 & 32 \\
\hline Puerto Rico" & 22,800 & 6,200 & $2.22^{\circ}$ & $3,300,000$ & $0.1^{\prime \prime}$ & 368 \\
\hline St. Kitts \& Nevis" & 142 & 3,500 & 6.8 & 40,000 & 0.3 & 147 \\
\hline SLL Lucia" & 250 & 1,650 & 2.5 & 153,000 & 26 & 251 \\
\hline $\begin{array}{l}\text { St. Vincent \& } \\
\text { Grenadines }\end{array}$ & 171 & 1,500 & $3.0^{\circ}$ & 113,000 & 1.4 & 332 \\
\hline Suriname & 1,941 & 4,513 & (2.5) & 420,000 & 1.86 & 2.6 \\
\hline Trinidad \& Tobago & 4,939 & 3,948 & (4.4) & $1,240,000$ & 1.08 & 242 \\
\hline Turks \& Caicos" & 68.5 & 5,000 & - & 9,000 & $2.3^{4}$ & 21 \\
\hline United States & $5,610,802$ & 22,219 & 2.6 & $249,980,000$ & 1.03 & 27 \\
\hline U.S. Virgin 1s." & 1,200 & 11,000 & - & 99,000 & $(0.3)$ & 284 \\
\hline Venezuela & 53,441 & 2,705 & 1.5 & $19,320,000$ & 2.12 & 22 \\
\hline WCR & & $\begin{array}{l}\text { Avg.: } \\
5,132\end{array}$ & & $\begin{array}{r}\text { Total: } \\
444,450,000\end{array}$ & & $\begin{array}{l}\text { Avg:: } \\
149\end{array}$ \\
\hline
\end{tabular}

"Sounce: WRI 1994 except fox countries where nole " $b$ " applies.

"Sources: CIA 1990 for population, CIA 1992 for GDP.

GNP.

“1987.

Table indicales density over 22 inhabited islands of a blal of about 700 islands; however, population is heavily concentrated on New Providence, where density approaches 700 persors: $/ \mathrm{km}^{2}$. 
Table A.2

Land Areas, Coastlines, and EEZs

\begin{tabular}{|c|c|c|c|c|c|}
\hline \multirow[b]{2}{*}{ State } & \multirow{2}{*}{$\begin{array}{c}\text { Land Area } \\
\left(\mathrm{km}^{2}\right)^{4}\end{array}$} & \multicolumn{2}{|c|}{ WCR Coastline" } & \multicolumn{2}{|c|}{ EEE ${ }^{6}$} \\
\hline & & Km & $\begin{array}{l}\text { As \% of } \\
\text { total (if } \\
\text { not } 100 \text { ) }\end{array}$ & $\mathbf{n m}$ & $\begin{array}{c}\text { Year } \\
\text { declared }\end{array}$ \\
\hline Anguilla & 91 & 61 & & ND & \\
\hline Antiqua \& Barbuda & 440 & 153 & & 200 & 1982 \\
\hline Aruba & 193 & 68.5 & & ND & \\
\hline Bahamas & 10,070 & 3.542 & & ND & \\
\hline Barbados & 430 & 97 & & 200 & .1979 \\
\hline Belize & 22,960 & 386 & & 200 & 1992 \\
\hline British Virgin Is. & 150 & 80 & & NO & \\
\hline Cayman Is. & 260 & 160 & & ND & \\
\hline Colombia & $1,038,700$ & 1,760 & 55 & 200 & 1978 \\
\hline Costa Rica & 50,660 & $212^{b}$ & 16 & 200 & 1975 \\
\hline Cuba & 110,860 & 3,735 & & 200 & 1977 \\
\hline Dominica & 750 & 148 & & 200 & 1981 \\
\hline Dominican Rep. & 48,380 & 1,288 & & 200 & 1977 \\
\hline Fr. Guiana & 89,150 & 378 & & 200 & 1978 \\
\hline Grenada & 340 & 121 & & 200 & 1978 \\
\hline Guadeloupe & 1,760 & 306 & & 200 & 1978 \\
\hline Guatemala & 108,430 & $85^{b}$ & 22 & 200 & 1976 \\
\hline Guyana & 196,850 & 459 & & 200 & 1977 \\
\hline Haiti & 27,560 & 1,771 & & 200 & 1977 \\
\hline Honduras & 111,890 & $591^{\circ}$ & 72 & 200 & 1980 \\
\hline Jamaica & 10,830 & 1,022 & & 200 & 1991 \\
\hline Martinique & 1,060 & 290 & & 200 & 1978 \\
\hline Mexico & $1,923,040$ & $2,070^{\circ}$ & 21 & 200 & 1976 \\
\hline Montserrat & 100 & 40 & & ND & \\
\hline Netherlands Antilles & 960 & 364 & & ND & \\
\hline Nicaraqua & 129,240 & $478^{\circ}$ & 53 & ND & \\
\hline Panama & 75,990 & $624^{\circ}$ & 25 & ND & \\
\hline Puerto Rico & 8,959 & 501 & & 200 & 1983 \\
\hline St. Kitts \& Nevis & 269 & 135 & & 200 & 1984 \\
\hline St. Lucia & 610 & 158 & & 200 & 1984 \\
\hline SI. Vincent \& Grenadines & 340 & 84 & & 200 & 1983 \\
\hline Suriname & 161,470 & 386 & & 200 & 1978 \\
\hline Trinidad \& Tobago & 5,130 & 362 & & 200 & 1983 \\
\hline Turks \& Caicos & 430 & 389 & & ND & \\
\hline United States & $9,166,600$ & $2,625^{b}$ & 13 & 200 & 1983 \\
\hline U.S. Virgin Is. & 349 & 188 & & 200 & 1983 \\
\hline Venezuela & 882,050 & 2,800 & & 200 & 1978 \\
\hline
\end{tabular}

ND not declared

'Source: CIA, 1994.

Source: Worldmark Encyclopedia of the Nations: Americas. 1984.

'Source: Fenwick, 1992. 


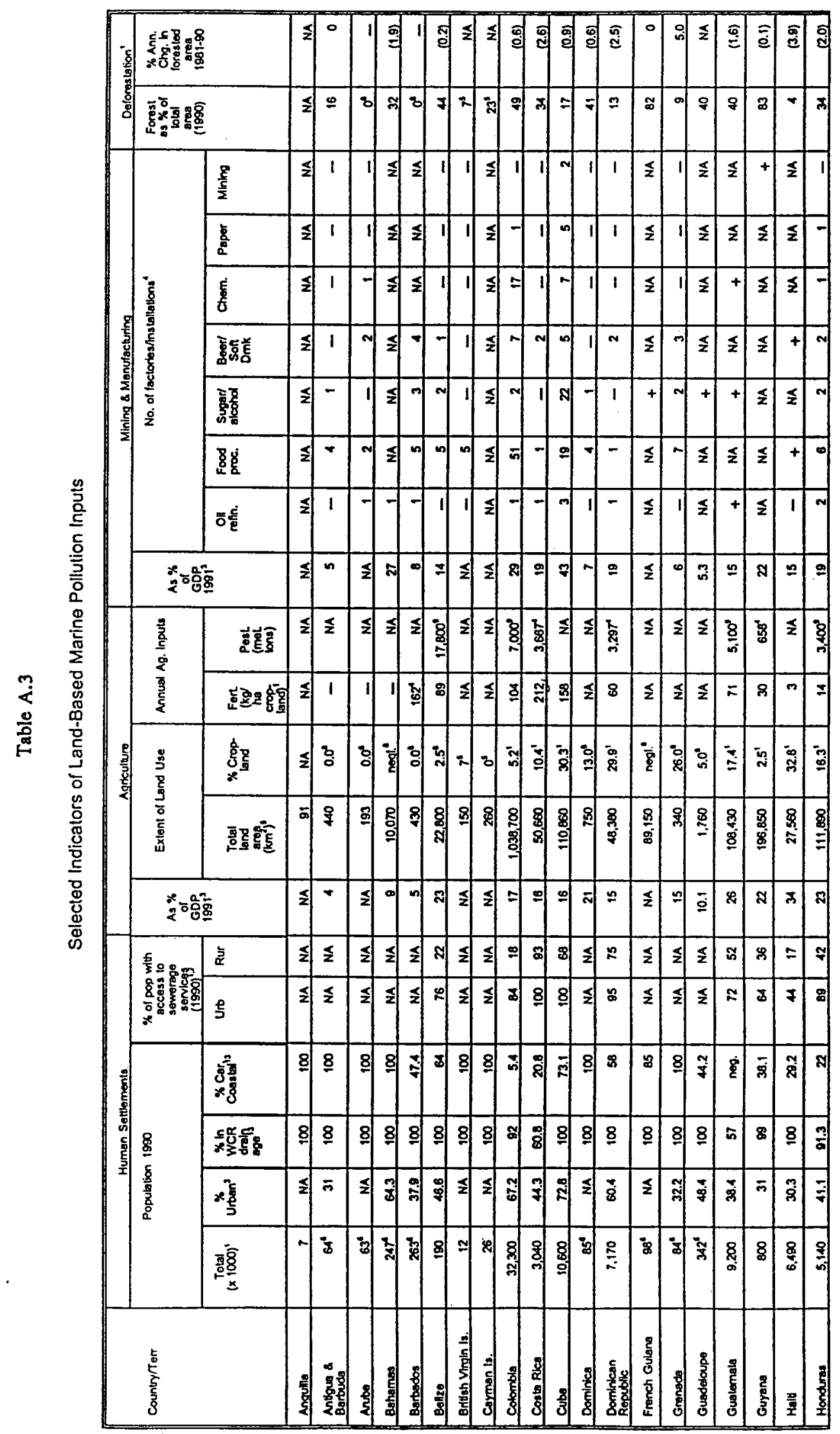




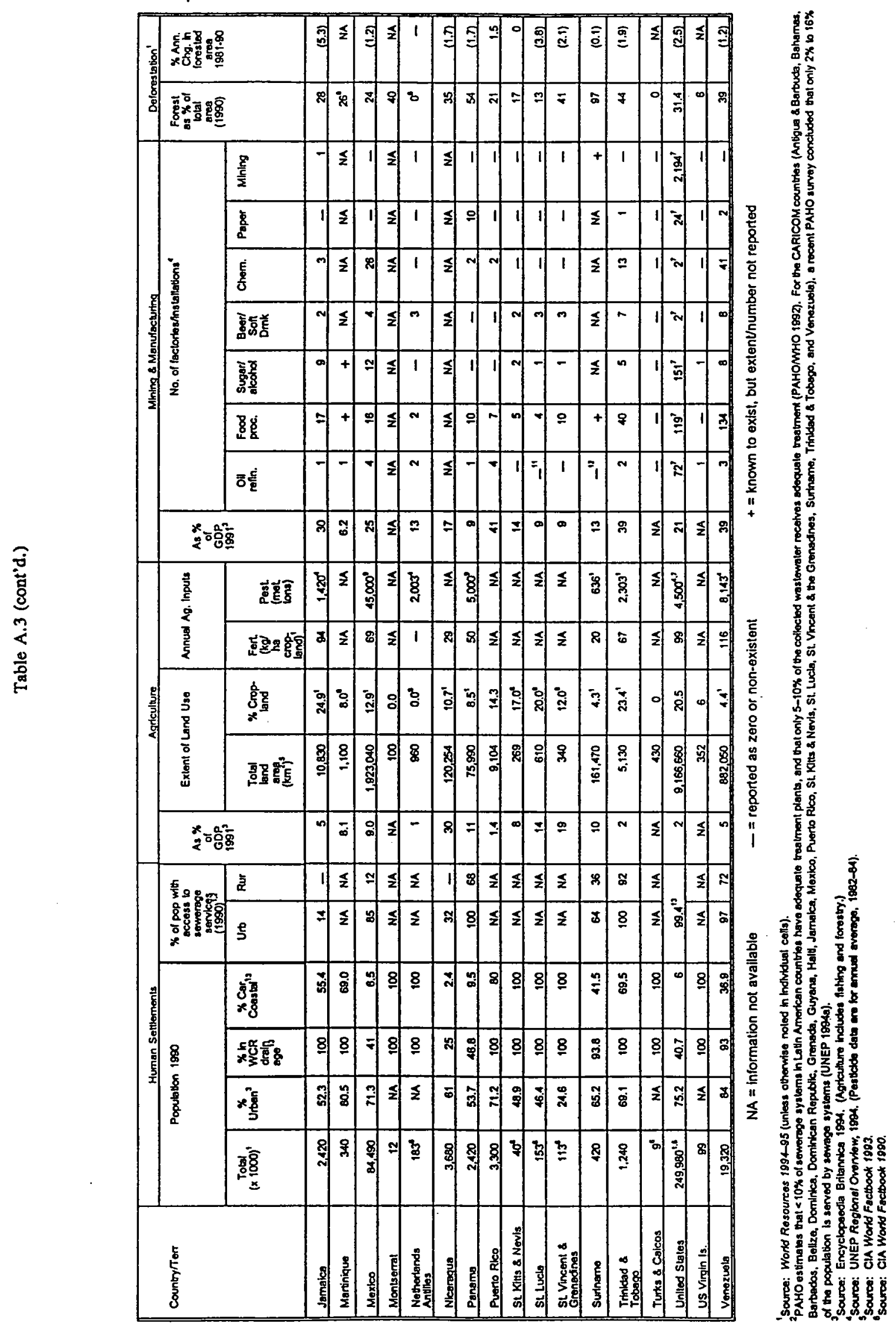


Table A.4

Selected Fisheries Data, 1990

\begin{tabular}{|c|c|c|c|c|c|c|c|c|c|c|}
\hline \multirow[t]{2}{*}{ State } & \multirow{2}{*}{$\begin{array}{c}\text { Fish } \\
\text { Catch } \\
\text { (metric } \\
\text { tons) }\end{array}$} & \multicolumn{2}{|c|}{ Non-Food Uses } & \multicolumn{3}{|c|}{ Fish Exports } & \multicolumn{2}{|c|}{ Fish Imports } & \multicolumn{2}{|c|}{ Food supply from fish } \\
\hline & & $\begin{array}{l}\text { Metric } \\
\text { Tons }\end{array}$ & $\begin{array}{c}\text { As } \% \\
\text { of } \\
\text { Calch }\end{array}$ & $\begin{array}{c}\text { Metric } \\
\text { Tons }\end{array}$ & $\begin{array}{l}\text { As } \% \\
\text { of } \\
\text { Calch }\end{array}$ & $\begin{array}{l}\text { As } \% \text { of } \\
\text { Total } \\
\text { Food } \\
\text { Suppty } \\
\text { from } \\
\text { Fish }\end{array}$ & $\begin{array}{l}\text { Melsk } \\
\text { Tons }\end{array}$ & $\begin{array}{l}\text { As } \% \\
\text { of Tolat } \\
\text { Food } \\
\text { Supply } \\
\text { from } \\
\text { Fish }\end{array}$ & $\begin{array}{l}\text { Por } \\
\text { capita } \\
(\mathrm{kg} / \mathrm{yr})\end{array}$ & $\begin{array}{l}\text { Total } \\
\text { (motric } \\
\text { cons) }\end{array}$ \\
\hline Anguita & NA & NA & NA & NA & NA & NA & NA & NA & NA & NA \\
\hline Antigua \& Barbuda & 2333 & 0 & 0 & 201 & 6.6 & 5.0 & 1.908 & 47.2 & 62.6 & 4.040 \\
\hline Aruba & 483 & 0 & 0 & 30 & 6.2 & 1.4 & 1.713 & 79.1 & 35.5 & 2,167 \\
\hline Bahamas & 7644 & 18 & $<1$ & 4.082 & 53.4 & 65.8 & 2,330 & 37.5 & 24.8 & 6,208 \\
\hline Barbados & 4870 & 1,336 & 17.5 & 105 & 1.4 & 1.4 & 4.151 & 54.7 & 29.5 & 7.582 \\
\hline Belize & 1595 & 0 & 0 & 766 & 48.0 & 54.5 & 575 & 40.9 & 7.6 & 1.405 \\
\hline British Virgin is. & 1339 & 0 & 0 & NA & NA & NA & NA & NA & 86.0 & 1,339 \\
\hline Cayman is. & 613 & $\mathbf{0}$ & 0 & 574 & 93.6 & 72 & 757 & 95.0 & 324 & 796 \\
\hline Colombla & 95,897 & 2 & $<1$ & 37,591 & 39.2 & 42.3 & 30,567 & 34.4 & 28 & 88.871 \\
\hline Costa Rica & 20,644 & 0 & 0 & 17.191 & 83.3 & 113.3 & 11.720 & 77.3 & 5.1 & 15.172 \\
\hline Cerba & 203.853 & 37,389 & 18.3 & 22,795 & 11.2 & 11.4 & 56,571 & 28.3 & 19.1 & 200.240 \\
\hline Domirica & 667 & 0 & 0 & 0 & 0 & 0 & 859 & 56.3 & 21.9 & 1.525 \\
\hline Dominican Reputric & 18.268 & 0 & 0 & 1.182 & 6.5 & 20 & 41,502 & 70.8 & 8.4 & 58,588 \\
\hline French Gulana & 6.280 & 0 & 0 & 4.206 & 67.0 & 90.0 & 2,352 & 50.2 & 49.3 & 4,676 \\
\hline Grenada & 1.832 & 5 & $<1$ & 59 & 3.2 & 1.9 & 1,388 & 44.0 & 34.8 & 3.155 \\
\hline Guadeloupe & 8.373 & 0 & 0 & 42 & 0.5 & $<1$ & 8,279 & 49.8 & 43.4 & 16.610 \\
\hline Guaternala & 4.600 & 0 & 0 & 3.112 & 67.7 & 57.0 & 4.183 & 76.7 & 0.6 & 5.456 \\
\hline Guyana & 36.242 & 0 & 0 & 3.471 & 9.6 & 10.6 & 0 & 0 & $41.3^{\circ}$ & 32,771 \\
\hline Matti & 7.867 & 0 & 0 & 166 & 2.1 & $<1$ & 19,148 & 71.3 & 4.2 & 26.848 \\
\hline Honduras & 17.519 & 1 & $<1$ & 13,538 & 77.3 & 264.0 & 2,033 & 40.0 & 1.0 & 5.123 \\
\hline Jamaica & 10.334 & 0 & 0 & 432 & 4.2 & 1.0 & 34,652 & 77.8 & 18.7 & 44.560 \\
\hline Martinique & 3.251 & 2 & $<1$ & 206 & 6.3 & 1.4 & 11,964 & 79.7 & 42.1 & 15,006 \\
\hline Mexico & 1.414 .332 & 402,813 & 28.5 & 141,090 & 10.0 & 15.5 & 19.274 & 2.1 & 11.0 & 911,911 \\
\hline Montserrat & 115 & 0 & 0 & NA & NA & NA & NA & NA & 10.5 & 115 \\
\hline Neth Antites & 1,200 & 0 & 0 & 29 & 24 & $<1$ & 3,604 & 75.5 & 27.3 & 4.775 \\
\hline Nicaragua & 4,108 & 0 & 0 & 1,824 & 44.4 & 80.0 & 0 & 0 & 0.6 & 2.284 \\
\hline Panama & 157.633 & 116.631 & 74 & 13.933 & 8.9 & 38.7 & 9,157 & 25.3 & 15.3 & 36,167 \\
\hline Puerto Rico & NA & NA & NA & NA & NA & NA & NA & NA & NA & NA \\
\hline St. Kitts \& Nevis & 1.700 & 0 & 0 & 221 & 13.0 & 11.6 & 424 & 22.3 & 45.1 & 1.903 \\
\hline St Lucia & 825 & 0 & 0 & 21 & 2.5 & $<1$ & 1.587 & 66.4 & 18.2 & 2.390 \\
\hline $\begin{array}{l}\text { St Vincent \& } \\
\text { Grenadines }\end{array}$ & 6.302 & 0 & 0 & 5.700 & 90.4 & 496.0 & 546 & 47.5 & 10.8 & 1.149 \\
\hline Suriname & 3.795 & 0 & 0 & 1,158 & 30.5 & 42.2 & 105 & 3.8 & 6.6 & 2,741 \\
\hline Triridad \& Tobago & 7.967 & 2 & $<1$ & 1,351 & 17.0 & 10.5 & 6.266 & 48.6 & 10.6 & 12,900 \\
\hline Turks \& Caicos & NA & NA & NA & NA & NA & NA & NA & NA & NA & NA \\
\hline United States" & $4,269,416$ & 1.072802 & 25 & 884,070 & 20.7 & 27.7 & $1,309,606$ & 41.0 & 6.8 & $3,196,614$ \\
\hline Gutf Coast & 737.582 & NA & NA & NA & NA & NA & NA & NA & NA & NA \\
\hline US Virgin is. & 763 & 0 & 0 & NA & NA & NA & NA & NA & 7.1 & 763 \\
\hline Venezuola & 315,690 & 21.950 & 7 & 27,236 & 8.6 & 10.2 & 337 & $<1$ & 14.1 & 266,823 \\
\hline
\end{tabular}

Source (except for US data): FAO Yeartrook: Fishery Slatistics 1992 (FAO 1993a).

'Source: Fisheries of the Unied States, 1992 (NOANNMFS May 1993). 


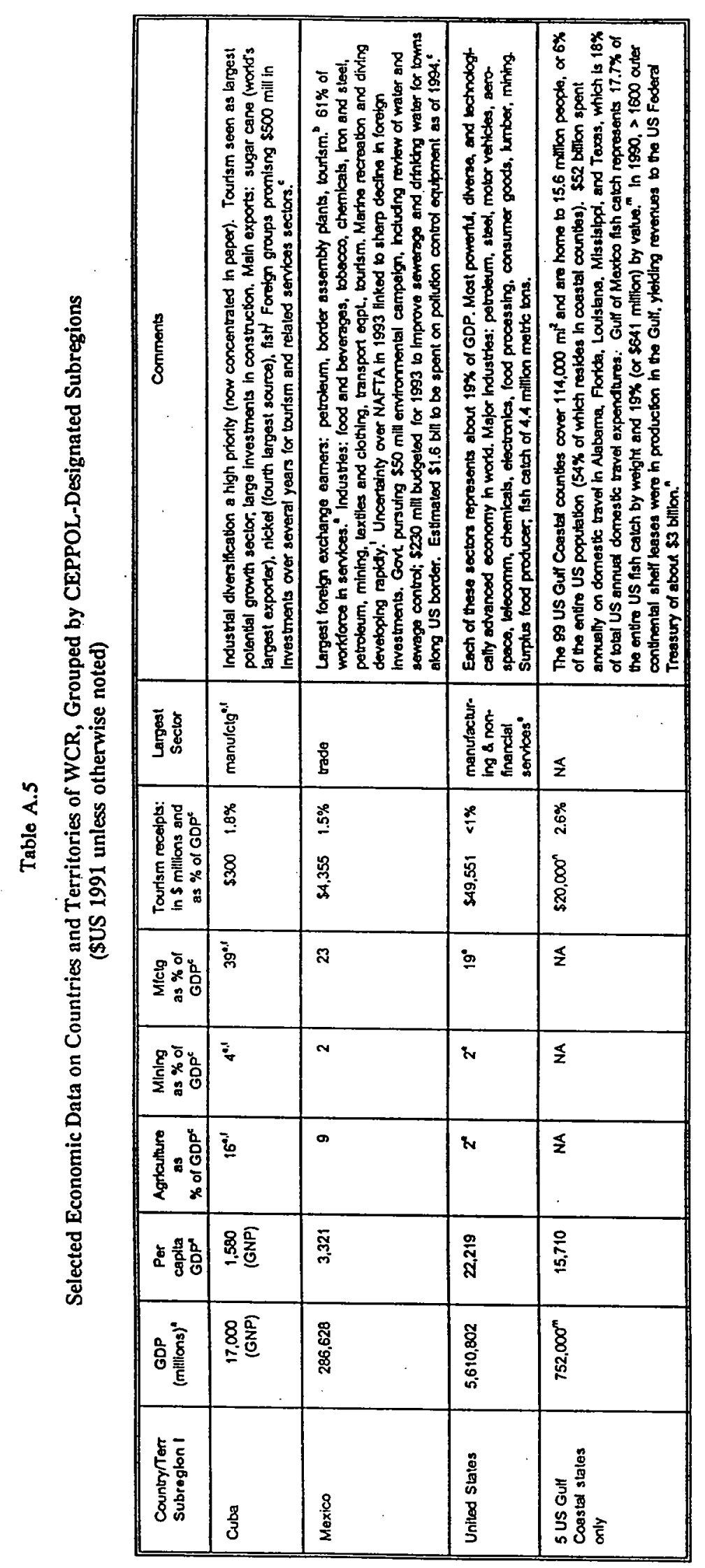




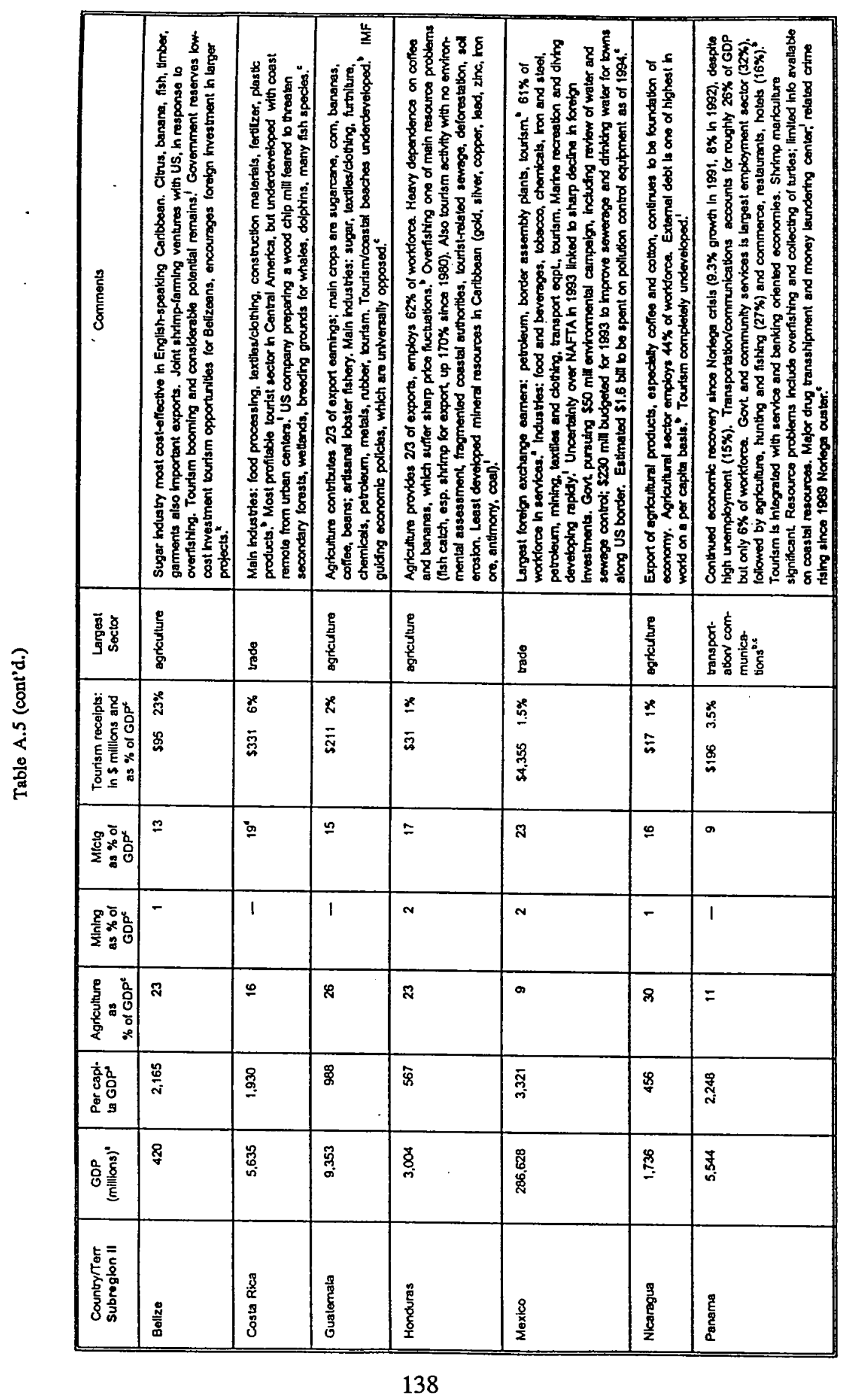




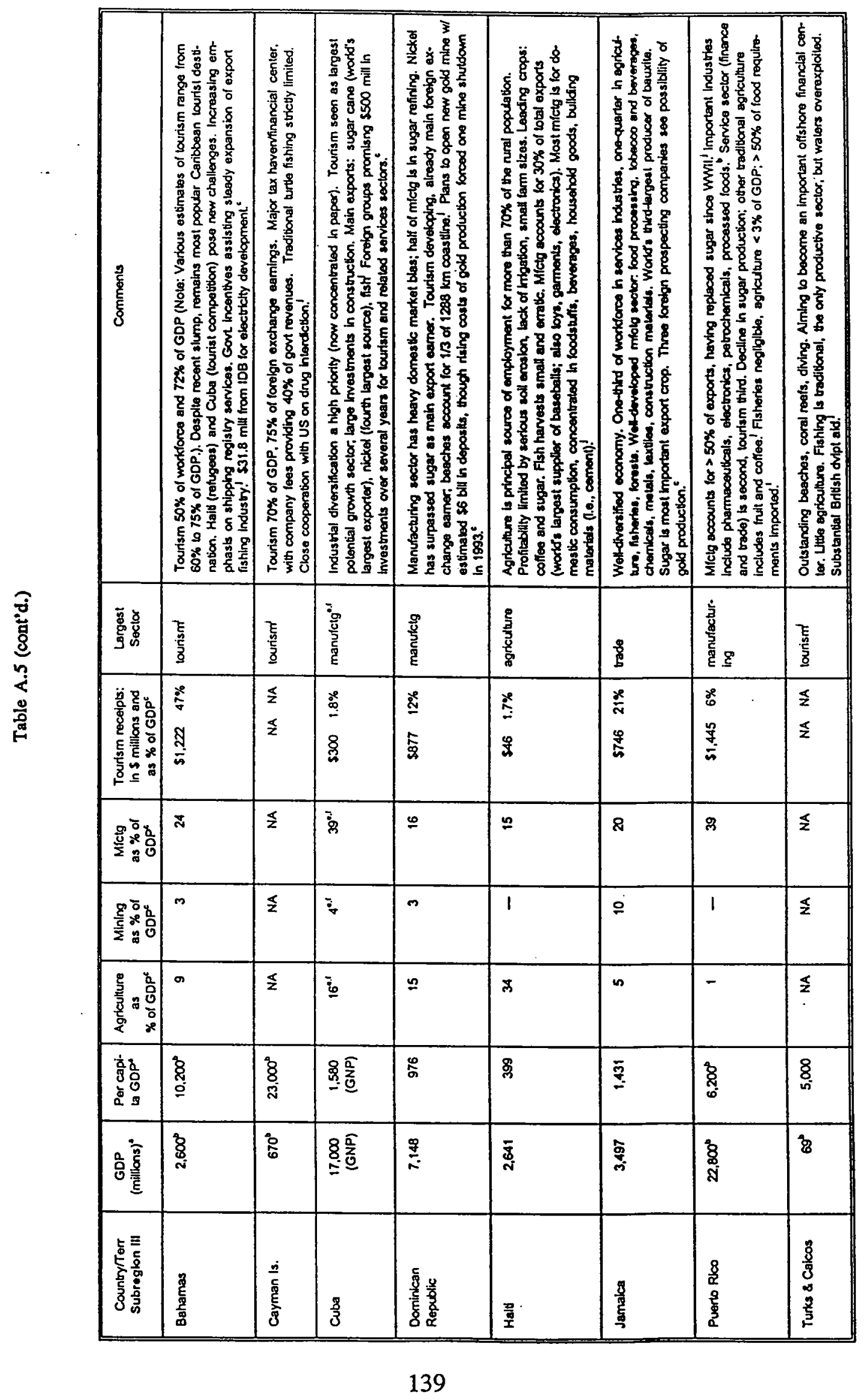




\begin{tabular}{|c|c|c|c|c|c|c|c|c|c|c|c|c|c|c|}
\hline & 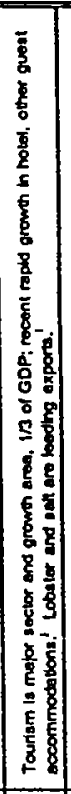 & 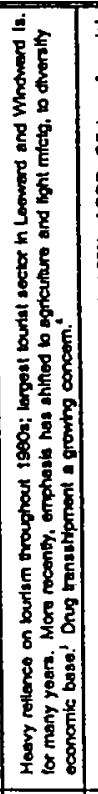 & 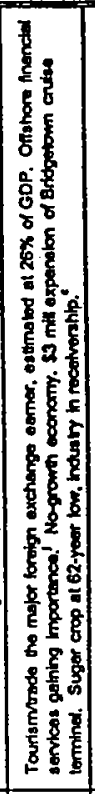 & 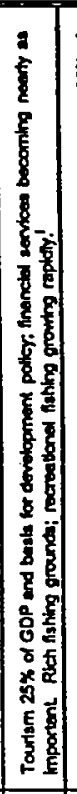 & 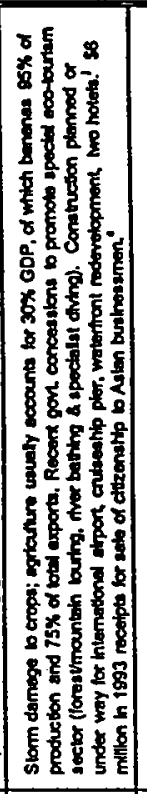 & 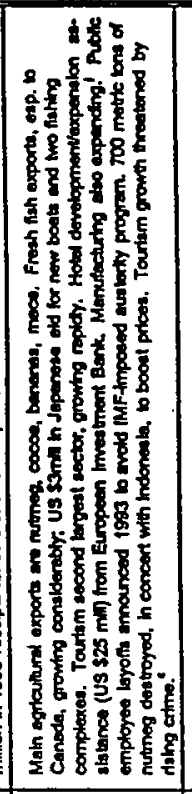 & 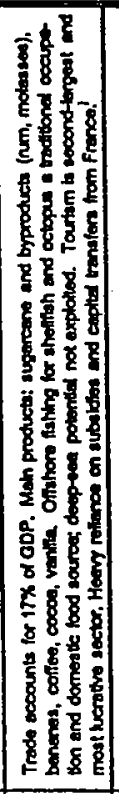 & 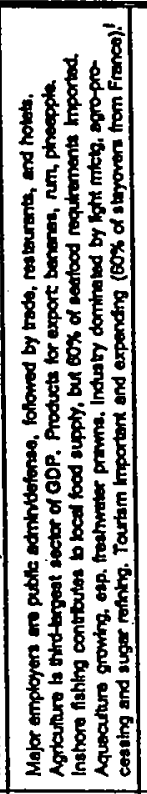 & 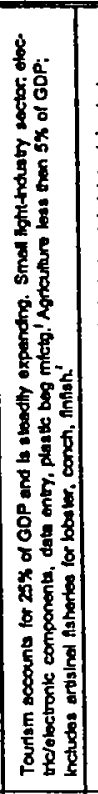 & 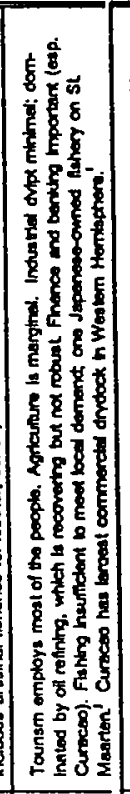 & 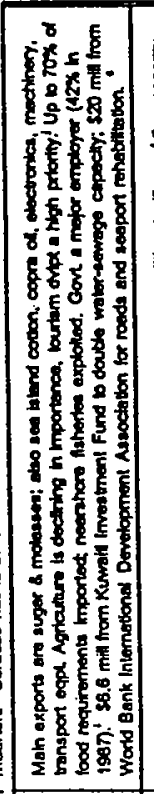 & 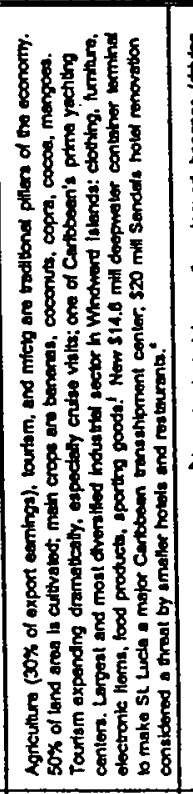 & 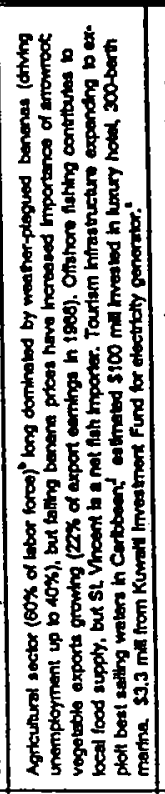 & 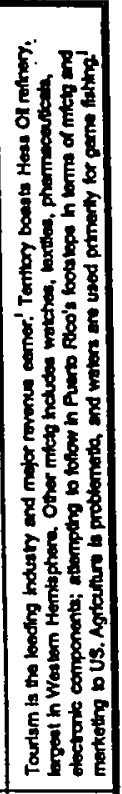 \\
\hline 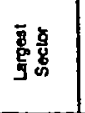 & $\begin{array}{l}\underline{\underline{n}} \\
\underline{z} \\
\underline{z}\end{array}$ & \begin{tabular}{|l|}
$\underline{E}$ \\
$\underline{\underline{z}}$ \\
$\underline{\underline{z}}$
\end{tabular} & 鹿兽 & $\begin{array}{l}E \\
\frac{5}{5} \\
3\end{array}$ & $\begin{array}{l}5 \\
\frac{5}{8} \\
8\end{array}$ & $\frac{7}{5}$ & 点 & 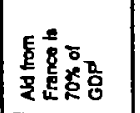 & \begin{tabular}{|l}
$\underline{\underline{E}}$ \\
$\underline{\underline{z}}$ \\
$\underline{\underline{z}}$
\end{tabular} & \begin{tabular}{|l}
$\underline{E}$ \\
$\underline{\underline{g}}$ \\
$\underline{\underline{z}}$
\end{tabular} & 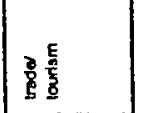 & 离 & 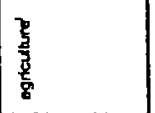 & \begin{tabular}{|l}
$\underline{\underline{5}}$ \\
$\underline{\underline{z}}$ \\
$\underline{\underline{z}}$
\end{tabular} \\
\hline 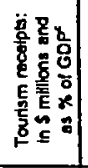 & $\begin{array}{l}\frac{1}{z} \\
\frac{1}{z}\end{array}$ & $\begin{array}{l}\frac{z}{2} \\
\frac{z}{z} \\
\frac{z}{2}\end{array}$ & $\begin{array}{l}x \\
a \\
a \\
3\end{array}$ & 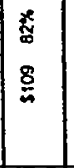 & $\frac{2}{6}$ & $\begin{array}{l}\not{x} \\
\stackrel{x}{a} \\
g\end{array}$ & $\begin{array}{l}\text { 炎 } \\
\text { 总 }\end{array}$ & $\begin{array}{l}x \\
y \\
z \\
z\end{array}$ & $\begin{array}{l}\frac{x}{z} \\
\frac{x}{2}\end{array}$ & $\begin{array}{l}x \\
a \\
z \\
z\end{array}$ & : & $\begin{array}{l}x \\
0 \\
0 \\
0\end{array}$ & $\begin{array}{l}\frac{x}{n} \\
a\end{array}$ & $\begin{array}{l}\text { 卷 } \\
\text { s } \\
8\end{array}$ \\
\hline 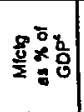 & $\frac{1}{z}$ & $m$ & $n$ & $\underline{z}$ & $\infty$ & $\infty$ & 氨 & $\overline{\overline{8}}$ & $\frac{\pi}{2}$ & 的 & $=$ & $\infty$ & $\infty$ & $\underline{\Sigma}$ \\
\hline 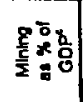 & $\frac{1}{z}$ & $N$ & - & $\underline{z}$ & - & 1 & $\frac{8}{8}$ & $\frac{8}{8}$ & $\frac{\mathbf{s}}{\mathrm{z}}$ & & 1 & - & 1 & $\overline{\underline{x}}$ \\
\hline 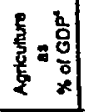 & $\frac{1}{z}$ & ${ }^{\circ}$ & n & $\frac{1}{2}$ & $\bar{\alpha}$ & 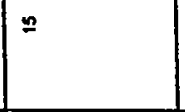 & : & $\overline{0}$ & $\mathfrak{z}$ & $=$ & $\infty$ & \pm & Q & $\mathfrak{z}$ \\
\hline 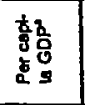 & 8 & 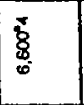 & 8 & 8 & $\frac{8}{10}$ & $\underset{8}{8}$ & 务 & 8 & $\underset{8}{8}$ & 8 & $\underset{\mathrm{f}}{\mathrm{z}}$ & 密 & 8 & 8 \\
\hline 总 & 12 & $\dot{z}$ & 8 & 2 & $\$$ & 3 & 8 & 安 & 2 & $\$$ & $\stackrel{N}{\Sigma}$ & 多 & $\vdots$ & \&్త్ \\
\hline 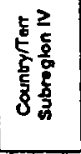 & 妾 & 焉 & $\begin{array}{l}8 \\
8 \\
\dot{8} \\
\mathbf{a} \\
\end{array}$ & 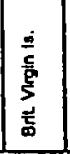 & $\frac{8}{8}$ & $\begin{array}{l}8 \\
\text { है } \\
\end{array}$ & & 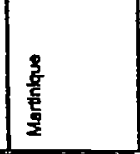 & \begin{tabular}{|l} 
\\
5 \\
5 \\
$\Sigma$ \\
$\Sigma$ \\
\end{tabular} & 童高 & 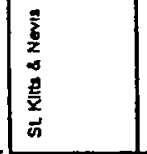 & $\frac{d}{3}$ & 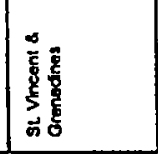 & 窟 \\
\hline
\end{tabular}




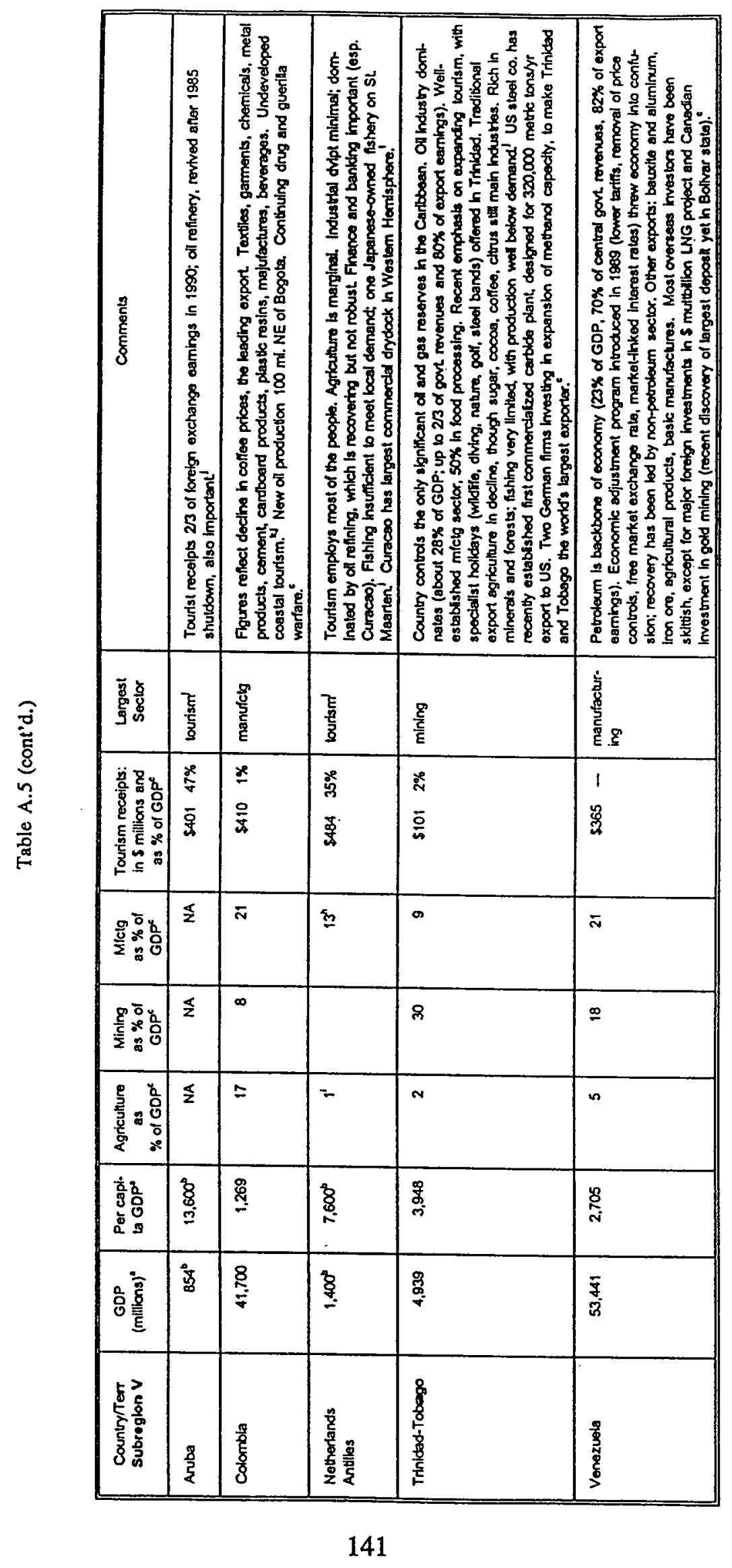




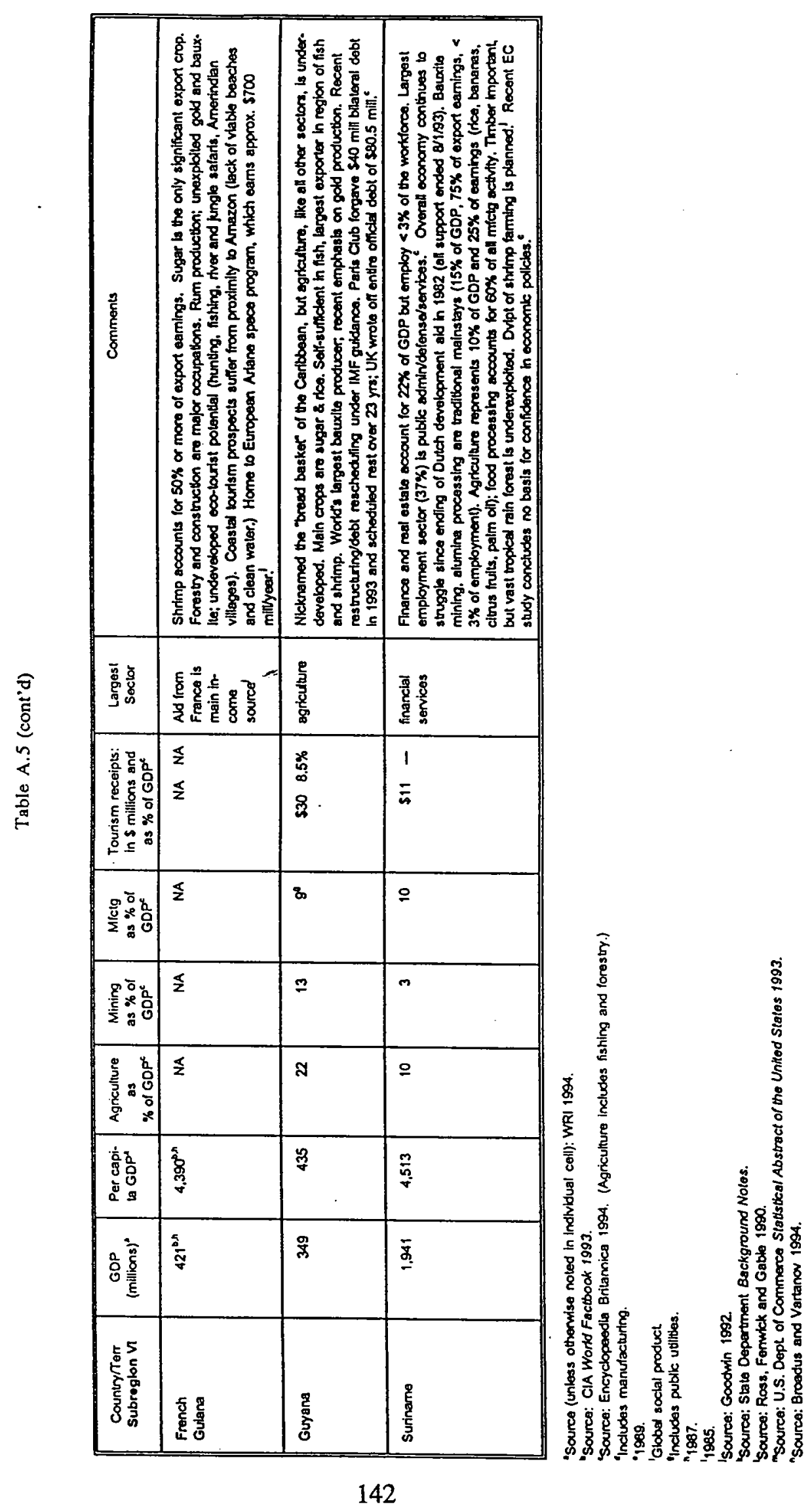


Table A.6

Scientific Associations and Member Institutions in the WCR

Association of Marine Laboratories of the Caribtrean (AMLC)

Bellairs Research Institule of McGill University. Barbados

Bermuda Biological Station

Bitter End Field Sution. BVI

Carribisch Marien Biologisch Instituut. Curzcao. NA

Caribbean Marine Research Leboratory. Bahames

Center for Energy and Environmental Research. Puerto Rico

Ceatro de Investigaciones de Biologin Marina. Republica Dominicana

Centro de Investigacion y de Estudios Avanzados del IPN-Unidad Merida, Mexico

Centre Universitaire Antilles-Guyane, Guadeloupe

CCFL Bahamien Field Station. Florida

Department of Marine Sciences, UPR, Puerto Rico

Discovery Bay Marine Laboratory. Jamaica

Estacion de Investigaciones Marinas de Magarita. Vecoezula

Leboratorio Investigaciones Pesquerzs. Puerto Rico

Fundacion Cientifica Los Roques. Venezuala

Lnstitute of Marine Affairs. Trinidad and Tobago

Instituto de Investigaciones Marinas de Punto de Betin. Colombia

Instituto Oceanographico. Venezuela

Marine Science Center, UVI, USVI

Mole Maribe Laboratory. Florida

Port Royal Marine Laboratory. Jamaica

Rosenstiel School of Marine and Almospheric Sciences, U. Miami. Florida

Smithsonian Tropical Research Institute, Panama
Caribbean Coastal Marine Productirity (CARICOMP)

Fundacion La Salle De Ciencias Naturales, Venezuela Universidad Simon Bolivar. Venezucla

Foundation CARMABI. Curacao

Bonnire Marine Park

Universidad de Panama, Pansma

INVEMNR. Sente Marte, Colombir

University of Costa Rica

Instituto de Recursos Naturales (IRENA), Nicaragua

Smithsonien Institution, Carrie Bow Cay, Belize

Hol Chan Marine Reserve, Belize

CINVESTAV. Merida, Mexico

Univ. Nac. Auto. de Mexico, Puerto Morelos, Mexico

EPOMEX, Campeche, Mexico

Instituto de Oceanologia. Cubz

University of the West Indies, Jamzica

Natural Resources Unit, Cayman Islands

Universidad Autonoma de Santo Domingo, Dominican Republic

Saba Merine Park, Netheriands Antilles

Babemian Field Station, San Salvador

Bermude Biological Station, Bermuda

Ceribbean Environmental Health Institute, St. Lucia

Institute of Marine Affairs. Trinidad and Tobago

Beflairs Research Institute. Berbados

Southern Association of Marine Laboratories (SAML)

Regular Menbers

Benedia Esturine Research Laboratory, MD

Bermuda Biological Station for Research. Inc.

Chesaperke Biological Laboratory. MD

College of Charleston. SC

Dauphin Island Sea Leb, AL

Duke University Marine Laboratory. NC

Florida Department of Natural Resources. FL

Florida institute of Tochnology. FL

Florida State University, FL

Gulf Coest Research Laboratory. MS

Hempron University, VA

Hartor Braseb Ocennographic Institution, FL

Horne Poiot Environmental Leboratory. MD

Lamar University. TX

Louisiana Universities Marine Consortium. LA

Mote Merioe Laboratory. FL

Old Dominion University, $V A$

Sevannab State College, GA

Skidrway Institule of Ocanography, GA

Smithsonise Environmental Research Center. MD

South Carolina Wildlife and Marine Resources

$$
\text { Department, SC }
$$

Texes A\&M University-Corpus Christi, TX

Texas A\&M University at Galveston. TX

Texas Parks and Wildlife Department. TX

University of Florida (Marine Laboratory). FL

University of Florida (Whitney Laboratory). FL

Univeristy of Georgin Marine Institute. GA

University of Mismi (RSMAS). FL

University of North Crolina-Chapel Hill, NC

Uitiversity of North CArolina-Wilmington. NC

Universily of Puerto Rico. PR

University of South Carolina, SC

University of South Florida, FL

University of Southern Mississigpi, MS

University of Texas (Marine Biomedical Institute). TX

Universily of Texas-Austin (Marine Science Institute). TX

University of Texas-Pan American (Coastal Studies Leboratory).TX

Virginia Institute of Marine Science, VA
Associale Members

Florida Institute of Oceanography. FL

National Marine Fisheries Service (NMFS). Southeas Fisheries Center. Miami, FL

NMFS-Benufort Laboratory, NC

NMFS-Charleston Laboratory, SC

NMFS-Galveston, TX

NMFS-Miami. FL

NMFS-Penema City Leboratory. FL

NMFS-Pescagoula Leboritory. MS

North Carolinz Sute University. NC

US Environmental Protoction Agency-Eoviroamental Research Leboratory. FL 
Table A.7

Participation in Global and Regional Organizations

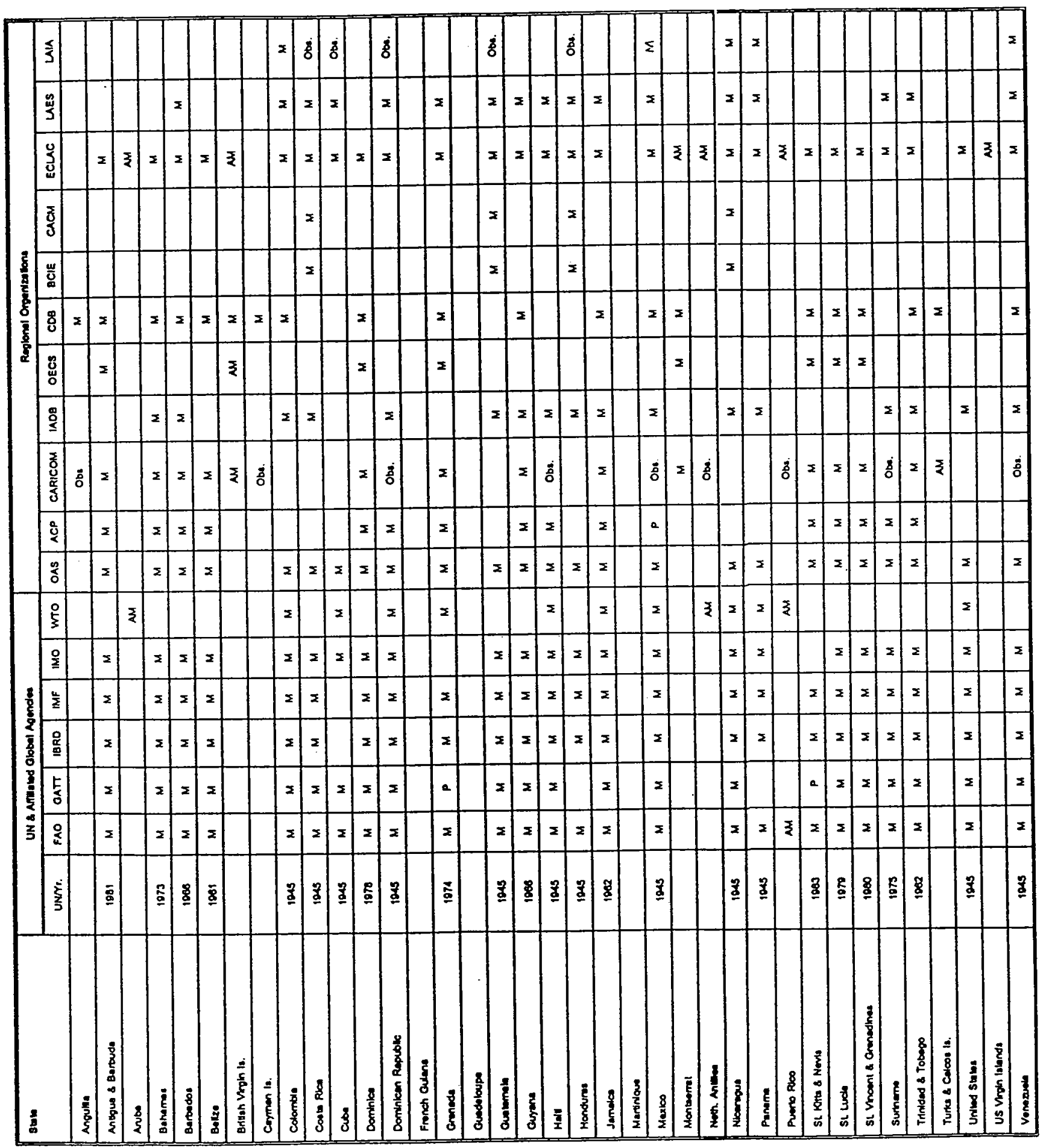




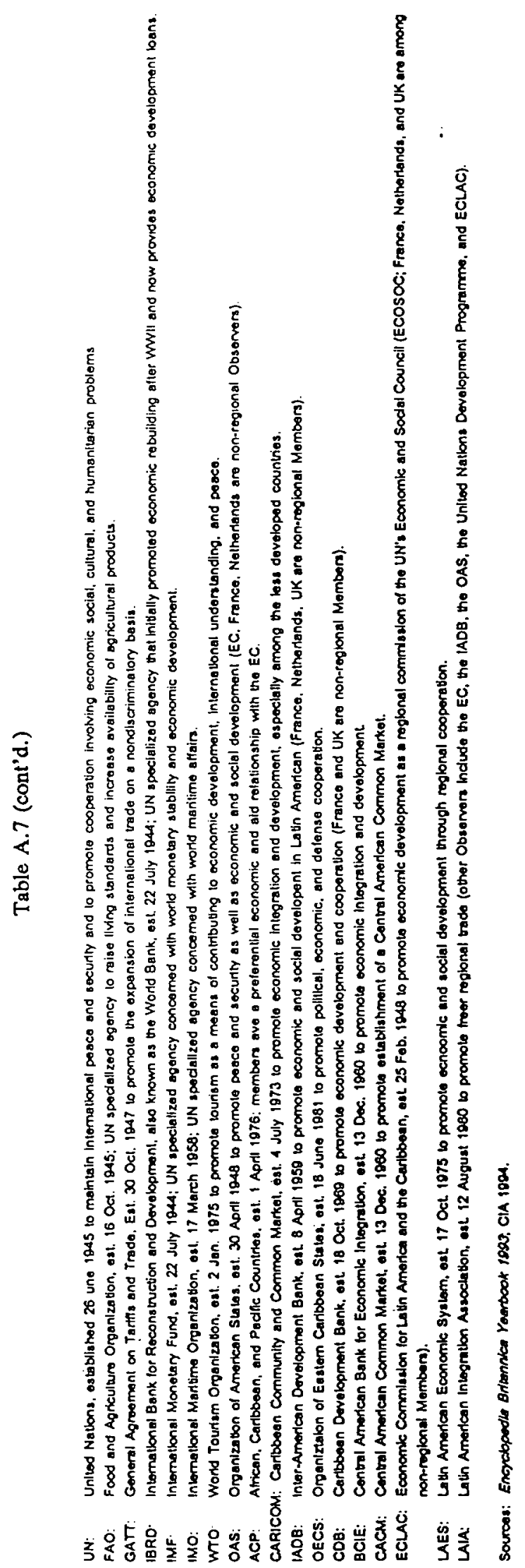




\section{APPENDIX B}

\section{Estimation of Drainage Basin and Coastal Populations}




\section{Appendix B: Estimation of Drainage Basin and Coastal Populations}

\section{A. Drainage Basin Populations}

Estimation of drainage basin populations began with development of a drainage map for the Wider Caribbean Region by cartographer Tamara Oshychny, based on existing drainage basin maps for the Caribbean Sea and Atlantic Ocean (Oxford Atlas of the World 1992) and the Orinoco and Amazon Rivers (The Times Atlas of the World 1985). The results were translated to the UNEP map depicting the six CEPPOL-designated subregions of the Wider Caribbean Region (UNEP 1994a) and are included here as Figure B.1.

For countries that lie only partially within the drainage basin, the drainage map was superimposed on country maps showing state/administrative divisions, and appropriate proportions of division-level populations were totaled for each country. For each country, the sum was then calculated as a proportion of the total population reported for the same year by the same source, and the proportion was applied to the 1990 population totals used throughout this report.

A comparable process was used in the cases of Mexico, Cuba, and the Netherlands Antilles to determine the distribution of drainage basin population across the two CEPPOL subregions in which each is designated as lying. In the case of Cuba, however, which drains virtually entirely toward the south, an adjustment was made to capture the heavy concentration of population in the northwest Havana area and the related discharge into Gulf of Mexico waters.

The resulting drainage area estimates are reported in Table B.1.

\section{Data sources: State/administrative division maps and population data}

Twelve countries and one overseas department of France lie only partially within the Wider Caribbean drainage basin. These are listed on the next page with the sources that were consulted for state/administrative division maps and population counts. Also listed are Cuba and the Netherlands Antilles, for which drainage basin population counts were assigned to two separate CEPPOL-designated subregions (as was also done for Mexico). 

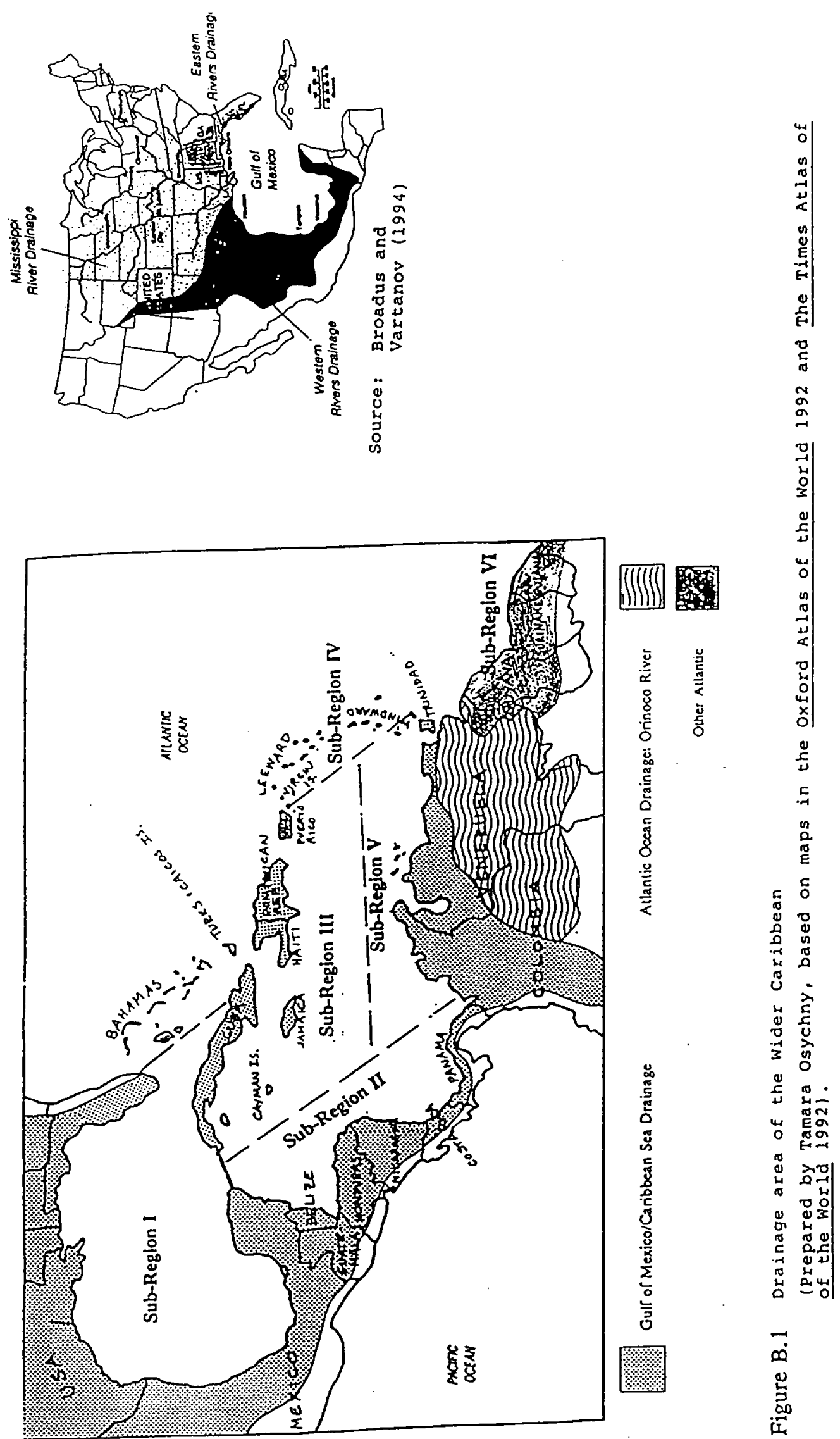
Table B.1

Estimated Drainage Basin and Coastal Populations of the WCR States'

\begin{tabular}{|c|c|c|}
\hline Subregion/State & $\begin{array}{c}\text { Estimated Drainatye Busin } \\
\text { Population 1990 } \\
(\times 1000)\end{array}$ & $\begin{array}{c}\text { Estimuted Coastal Population } \\
1990 \\
(\times 1000) \\
\end{array}$ \\
\hline Subregion I & 141,836 & 26,210 \\
\hline Cuba & 6.026 & 5.941 \\
\hline Mexico & 34,050 & 5.069 \\
\hline United States & 101.760 & 15,200 \\
\hline Subregion II & 14,259 & 2,625 \\
\hline Belize & 190 & 122 \\
\hline Costa Rica & 1.488 & 632 \\
\hline Guatemala & 5.244 & - \\
\hline Honduras & 4.693 & 1,131 \\
\hline Mexico & 591 & 422 \\
\hline Nicaraguz & 920 & 88 \\
\hline Panama & 1,133 & 230 \\
\hline Subregion III & 24,246 & 12,046 \\
\hline Bahamas & 247 & 247 \\
\hline Cayman Islands & 26 & 26 \\
\hline Cuba & 4.584 & 1.729 \\
\hline Dominican Republic & 7.170 & 4.159 \\
\hline Haiti & 6.490 & 1,895 \\
\hline Jamaica & 2,420 & 1,341 \\
\hline Puerto Rico & 3,300 & 2.640 \\
\hline Turks \& Caicos Islands & 9 & 9 \\
\hline Subregion IV & 1,629 & 1,188 \\
\hline Anguilla & 7 & 7 \\
\hline Antigua \& Barbuda & 64 & 64 \\
\hline Barbados & 263 & 125 \\
\hline British Virgin Islands & 12 & 12 \\
\hline Dominica & 85 & 85 \\
\hline Grenada & 84 & 84 \\
\hline Guadeloupe & 342 & 151 \\
\hline Martinique & 340 & 235 \\
\hline Netherlands Antilles & 15 & 15 \\
\hline St. Kitts \& Nevis & 40 & 40 \\
\hline St. Vincent \& Grenadines & 113 & 113 \\
\hline US Virgin Islands & 99 & 99 \\
\hline Suhregion V & 49,171 & 9,825 \\
\hline Anuba & 63 & 63 \\
\hline Colombia & 29.700 & 1.603 \\
\hline Netherlands Antilles & 168 & 168 \\
\hline Trinidad \& Tobago & 1.240 & 862 \\
\hline Venezuela & 18.000 & 7.129 \\
\hline Subregion VI & 1,284 & 562 \\
\hline French Guiana & 98 & 83 \\
\hline Guyana & 792 & 305 \\
\hline Suriname & 394 & 174 \\
\hline WCR TOTAL & 232,425 & 52,456 \\
\hline
\end{tabular}




\begin{tabular}{|c|c|c|}
\hline Country & Administrative map & Population data \\
\hline United States & Broadus and Vartanov 1994 & $\begin{array}{l}\text { Statistical Abstract of the United } \\
\text { States } 1993\end{array}$ \\
\hline Mexico & James and Minkel $1986^{\mathrm{b}}$ & $\begin{array}{l}\text { Britannica Book of the Year } \\
1994\end{array}$ \\
\hline Guatemala & James and Minkel 1986 & Britannica 1994 \\
\hline Honduras & James and Minkel 1986 & Britannica 1994 \\
\hline Nicaragua & James and Minkel 1986 & Britannica 1994 \\
\hline Costa Rica & Worldmark Encylcopedia $1984^{\circ}$ & Britannica 1994 \\
\hline Panama & U.S. State Dept. $1992^{\mathrm{d}}$ & Britannica 1994 \\
\hline Colombia & James and Minkel 1986 & Britannica 1994 \\
\hline Venezuela & James and Minkel 1986 & Britannica 1994 \\
\hline Guyana & James and Minkel 1986 & Britannica 1994 \\
\hline Suriname & James and Minkel 1986 & Britannica 1994 \\
\hline French Guiana & James and Minkel 1986 & James and Minkel 1986 \\
\hline Cuba & James and Minkel 1986 & Britannica 1994 \\
\hline $\begin{array}{l}\text { Netherlands } \\
\text { Antilles }\end{array}$ & Worldmark Encylcopedia 1984 & Worldmark Encylcopedia 1984 \\
\hline
\end{tabular}

${ }^{a} T h e$ Oceans and Environmental Security: Shared U.S. and Russian Perspectives, James M. Broadus and Raphael V. Vartanov, eds. (Washington, DC: Island Press, 1994). This source includes a map showing U.S. state boundaries and the drainage basin of the Gulf of Mexico.

${ }^{\circ}$ Latin America, Preston E. James and C. W. Minkel, with Eileen W. James. (New York: John Wiley \& Sons, 5th edition, 1986). This source also includes population distribution maps for individual countries, which were used as an informal check on the methodology described above.

'Worldmark Encyclopedia of the Nations: Americas (New York: Worldmark Press and John Wiley \& Sons, Inc., 1984).

¿Background Notes: Panama (Washington, DC, U.S. Department of State, March 1992). 


\section{B. Coastal Populations}

Where necessary, coastal populations were estimated using several methodologies, depending on the form and availability of data.

\section{Populations entirely within the coastal zone}

The populations of the following island countries were deemed to be entirely coastal: Anguilla, Antigua \& Barbuda, Aruba, Bahamas, British Virgin Islands, Cayman Islands, Dominica, Grenada, Montserrat, Netherlands Antilles, St. Kitts \& Nevis, St. Lucia, St. Vincent \& the Grenadines, U.S. Virgin Islands.

\section{Countries for which relevant coastal population data were directly available}

For the United States, 1990 Gulf of Mexico coastal population was directly available (as number of persons and as a percentage of U.S. total population) from the Statistical Abstract of the United States 1993.

For 17 countries-Barbados, Colombia, Costa Rica, Cuba, Dominican Republic, Guadeloupe, Guatemala, Guyana, Haiti, Honduras, Jamaica, Mexico, Nicaragua, Panama, Suriname, Trinidad \& Tobago, Venezuela-data were available from the World Resources 1992-93 Data Base Diskette. The data used for the coastal population estimation included 1980 coastal and total population and projected 2000 coastal and total population. For each country, the proportion of coastal to total population was calculated for 1980 and 2000 , the results were averaged, and the average proportion (\% coastal population) was applied to the 1990 total population data used throughout this report.

Countries for which Caribbean coastal population was calculated from available data on total coastal population

For countries that also have coastlines outside the Wider Caribbean Region (i.e., Colombia, Costa Rica, Honduras, Mexico, Nicaragua, Panama), data on the populations of major cities (from Britannica Book of the Year 1994) were used to approximate the proportion of a country's total coastal population (as reported in World Resources 1992-93 Data Base Diskette) that is concentrated on the Caribbean coast. (Here, too, the relevant percentage was then applied to 1990 population data for use in the study analyses.) For countries with no major urban concentrations on the Caribbean coast (e.g., Guatemala, Nicaragua), state/administrative division-level population data (also from Britannica 1994) were used instead of urban population data. 


\section{Countries/territories not included in the World Resources Data Base, and countries spanning two CEPPOL-designated subregions}

The coastal populations of Puerto Rico and Guyana were estimated from urban population data (Britannica 1994) using a methodology comparable to the one described above for countries with coastal populations along more than one coast. This method was also used to estimate, in the case of Mexico, Cuba, and the Netherlands Antilles, the proportions of the total coastal population residing in each of two CEPPOL subregions spanned by these countries.

Finally, no urban or administrative-level population data could be found for French Guiana. For purposes of this study, $85 \%$ of the population was deemed to be in the coastal zone, based on statements in various sources (e.g., James and Minkel 1986, U.S. State Dept. Background Notes 1989, Worldmark Encyclopedia 1984) indicating that somewhat more than four-fifths of the population of French Guiana resides in the coastal lowlands.

The resulting coastal population estimates are reported in Table B.1. 


\section{APPENDIX C}

Opportunities for Gains from Trade: A Stylized Model 


\section{Appendix C: Opportunities for Gains from Trade: A Stylized Model}

\section{Introduction}

The possibilities of gains from trade with regard to a pollution problem can be shown clearly using a stylized model (Mäler 1990; Dasgupta 1982). We will focus on the problem of transboundary pollution effects between two states.' In this model, states have the legal competency to enter into agreements to control pollution, and we assume that subnational agents, such as industries or consumers, are not involved directly in the negotiations. ${ }^{2}$ Note, however, that a negotiated outcome might involve the participation of subnational agents. For example, two states might decide that the best way in which to resolve a transboundary pollution problem is to create a market in pollution rights open to subnational agents from both states.

In order to illustrate opportunities for gains from trade, we abstract from the real world in another important way. We assume that the two states are striking a bargain over pollution control. After all, pollution control is the main focus of the proposed protocol. However, states may find other reasons for entering into an agreement to control pollution. Even states that have a legal right to a clean marine environment may be willing to accept some level of pollution in order to benefit in other ways, such as improved international relations or perceived increased benefits to the state of a trading partner's economic development. For example, Mäler (1990) cites studies by John Krutilla and Alan Kneese which demonstrate that:

. . . at least along the U.S.-Canada and U.S.-Mexico borders, agreements on water and water quality have involved 'trades' in areas other than the rather restricted area defined by the environmental resource. The important point here is that there have been trades, although they may not be directly visible.

We assume as well that, because of the strong directional nature of WCR current flows (Gladfelter and Ogden 1994), there exists an "upstream" polluter and a "downstream" pollutee. We believe that these assumptions characterize many of the potential transboundary pollution problems in the WCR. Some localized "commons-type" pollution problems (where each state is both a polluter and a pollutee) may exist in the Caribbean, particularly in shared rivers, estuaries, or embayments. Gains from trade are possible in the commons context as well,

${ }^{1}$ This is known as the "producer-producer" externality problem of Coase (1960). Note, however, that where small countries are involved, income effects not unlike those in a "producer-consumer" externality problem may arise. See Baumol and Oates (1988) for details.

${ }^{2}$ In reality, subnational agents could influence the negotiating position of the relevant states either by exerting influence on their national government or by opportunities provided through developing principles of transnational law. Putnam (1988) develops a political model of "two-level games in which a national government negotiates at both the international and domestic levels. Sand (1991) advocates "opening local remedies to foreign parties" as one means for de-escalating transboundary environmental disputes. 
although, for heuristic reasons, we will not use the commons example here. ${ }^{3}$

Although we employ an economic model, and we identify an economically "efficient" level of pollution in the context of the model, we will not be overly concerned with calculating "optimal" levels of pollution here. We are interested in characterizing the conditions under which economic incentives exist for states to reallocate their resources in a manner that improves the welfare of both states and, by definition, that of the relevant society as well. In this sense, "gains from trade" harness the economic self-interest of individual states to achieve a collective end (cf., Ridley and Low 1993). We identify the potential roles of WCR states in Section V.

In Figure C.1, we represent the hypothetical benefits and costs of a problem of pollution control involving two hypothetical states, $\mathrm{X}$ and $\mathrm{Y}$, at any point in time. ${ }^{4}$ Our analysis is static, although it is possible to interpret the representation in Figure C.1 as the present values of a flow of benefits or costs. State $X$ is emitting a pollutant that has an impact on the waters of state $Y{ }^{5}$ State $\mathrm{Y}$ would benefit from a reduction in X's emissions according to the total benefits curve displayed in panel a. In a typical case, total benefits of pollution control rise quickly at first and then begin to diminish as more and more emissions are controlled. Reduction of emissions is costly for state $X$, and its total costs of reductions increase slowly at first and rise more rapidly with increasing reductions. ${ }^{6}$

Panel $b$ displays the slopes (marginal abatement schedules) of the total benefit and cost curves in panel a. According to coasean logic, if we assume either that the legal rights to be free of pollution have been assigned to $\mathrm{Y}$ or that rights to pollute have been assigned to $\mathrm{X}$, then the two states can realize gains from trade by bargaining to level $\mathrm{p}^{*}$. To see this point, consider a case where $X$ has the legal right to emit pollutants into the Caribbean Sea from land-based

\footnotetext{
${ }^{3}$ Several analysts have examined the problem of international pollution control in the case of a commons. See Braden and Bromley (1980) and Hoel (1991) for static analyses. Dockner and Long (1993) show in a theoretical dynamic model that nations may approach an economically efficient level of environmental quality even when they have not committed themselves to control pollution through an international agreement. What is required is that the countries communicate before choosing levels of economic output and associated levels of pollution (i.e., they engage in "cheap talk"). Chander and Tulkens (1992) develop a sharing rule that allows states to divvy up the "ecological surplus" (gains from trade) and to allocate total abatement costs. Dockner and Long (1993) are skeptical about the likelihood of approaching efficient outcomes where information is incomplete or nations are dissimilar in economic characteristics.

${ }^{4}$ Note that the information required to construct these relationships can, in some cases, be difficult to acquire (see Section IV).

${ }^{5}$ Dasgupta (1982) refers to this example as a "unidirectional externality." Unidirectional externalities are distinguished from "reciprocal externalities," which could occur when nations pollute each other. We believe that the case of transboundary land-based marine pollution in the WCR is best characterized as one in which there exists some risk of unidirectional pollution impacts.

${ }^{6}$ Note that this curve also represents the polluter's "demand" for pollution as an input into its production processes (Baumol and Oates 1988; Seibert 1987). As such, it can be interpreted as a measure of the polluters willingness to pay compensation to a pollutee under a regime in which the pollutee has the right to a clean environment. We discuss this in more detail below.
} 
(a)

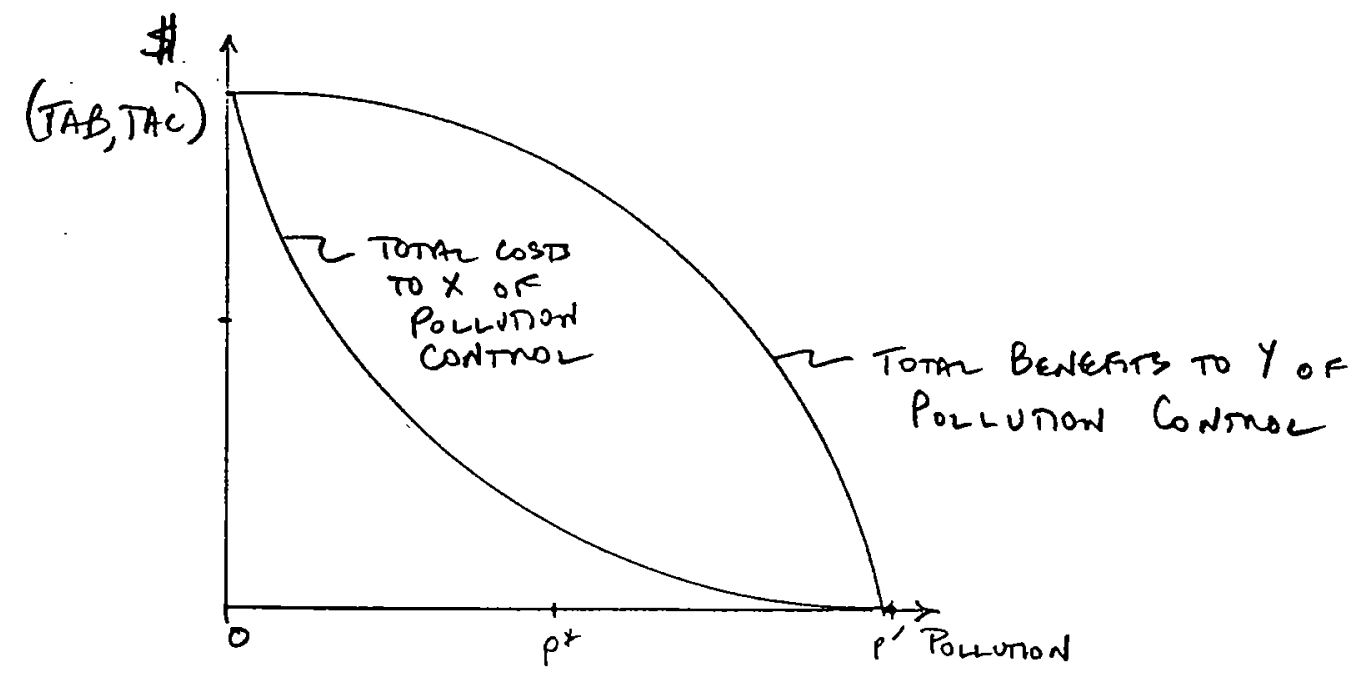

(b)

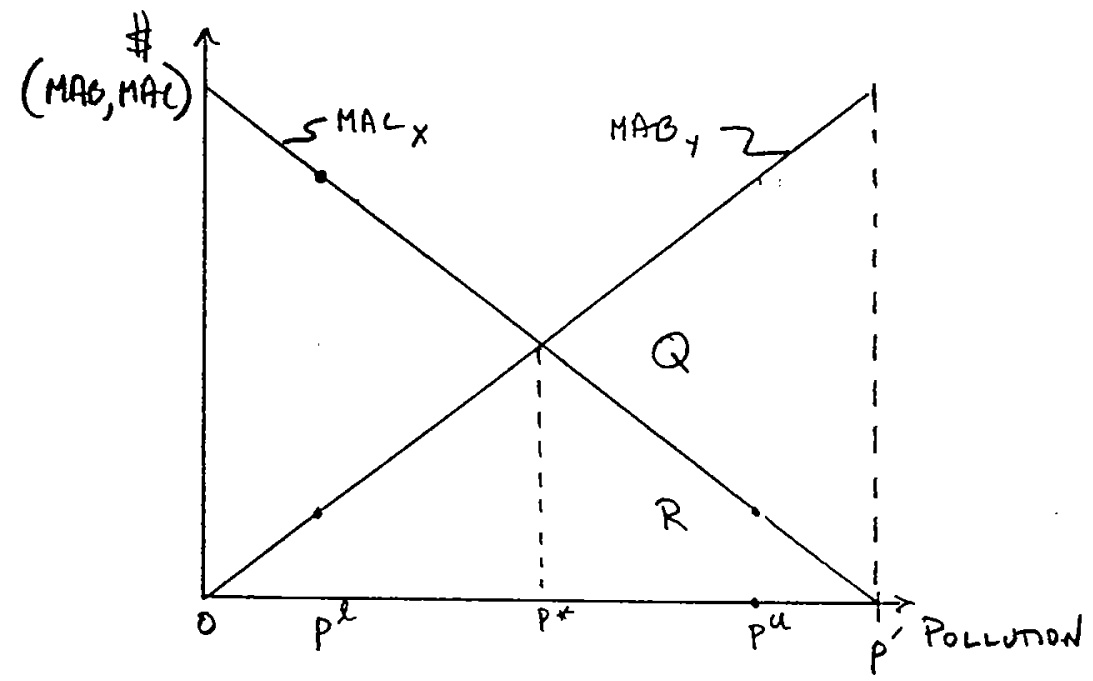

(c)

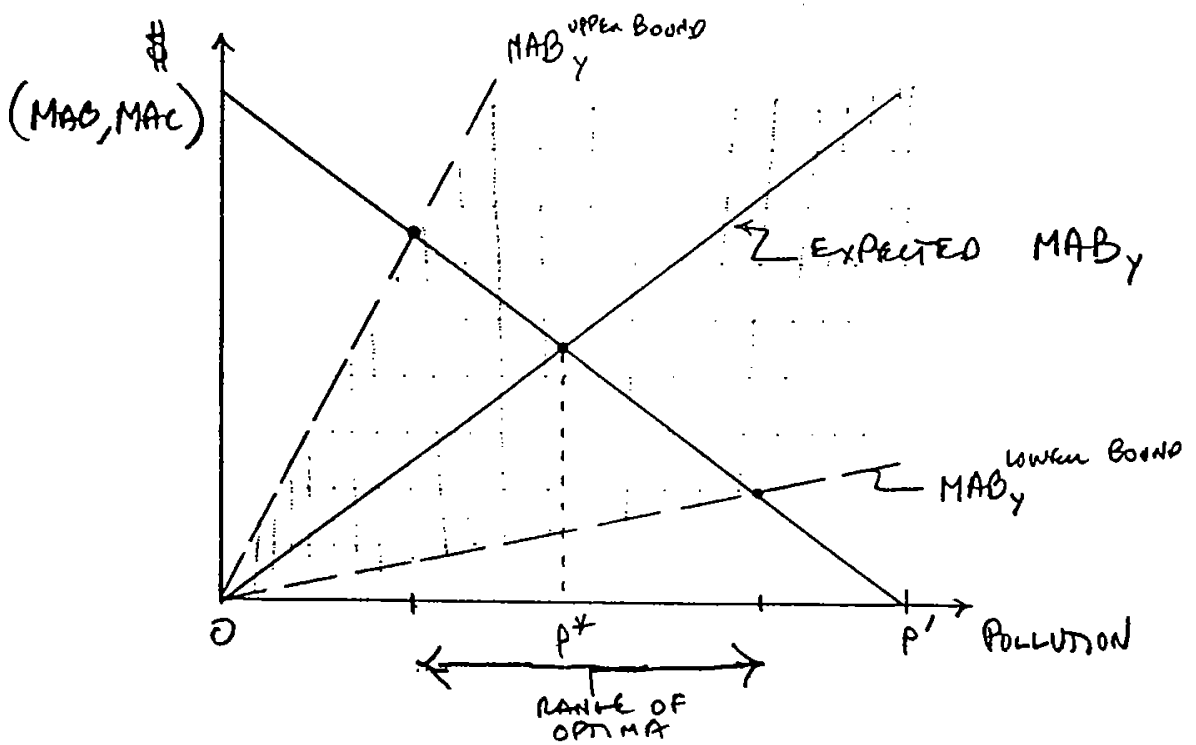

Figure C.1. A Model of Transboundary Pollution Control 
(d)

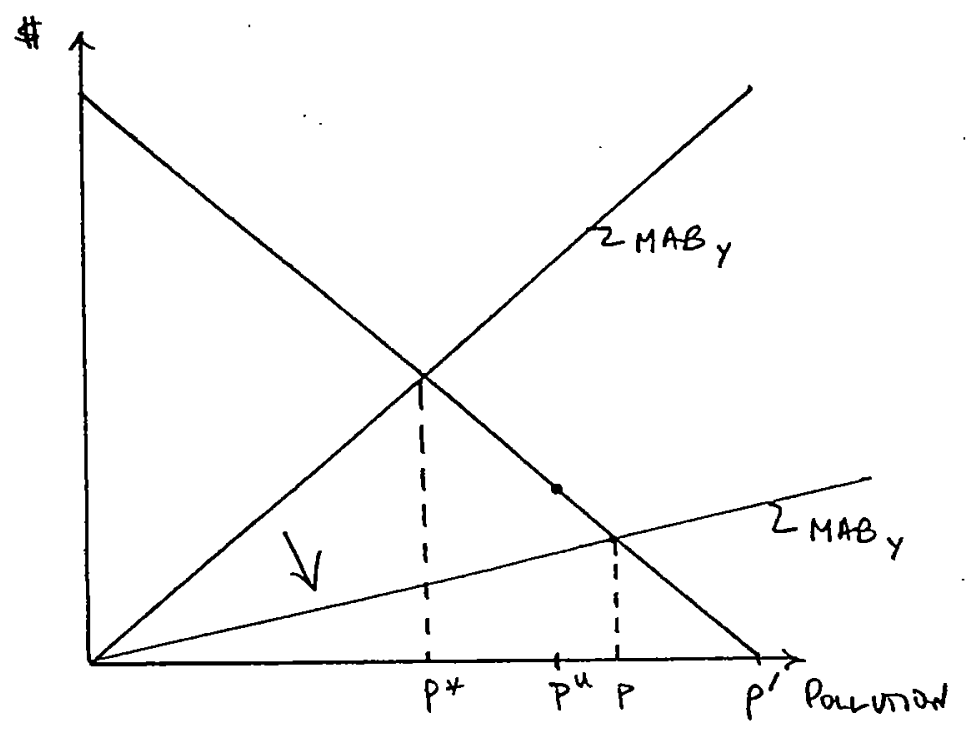

(e)

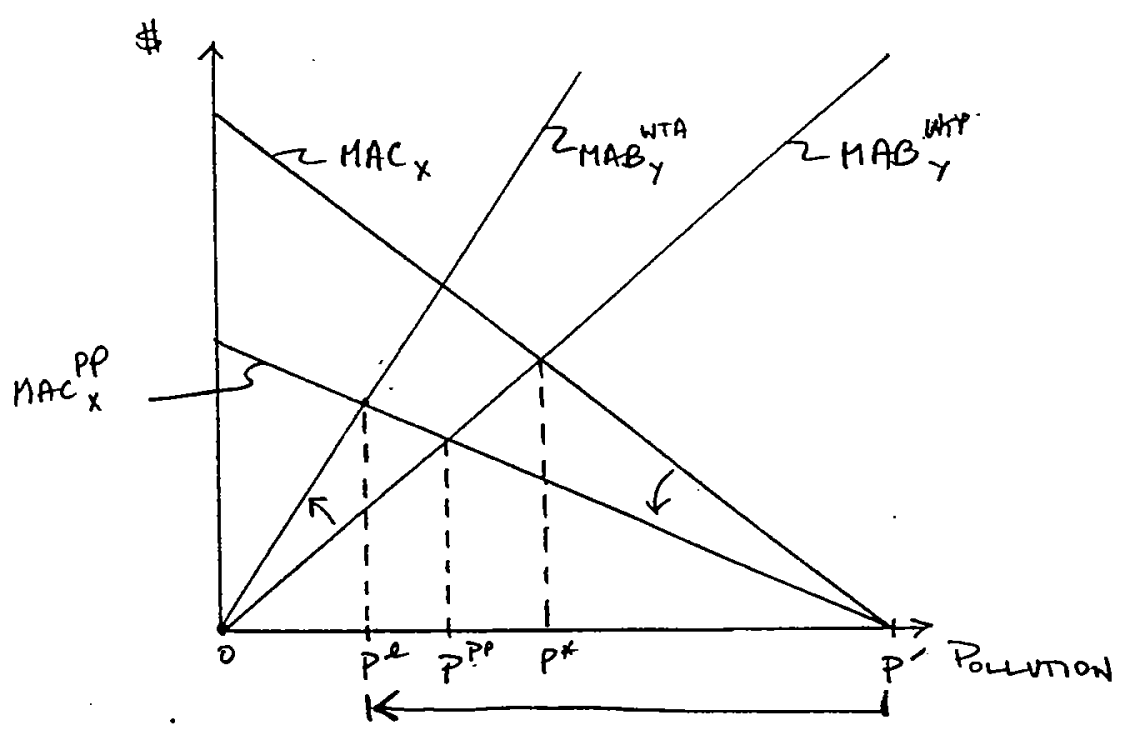

Figure C.1 (continued) 
sources. We start at point p'. $Y$ would benefit by the amount $Q+R$ from a reduction in pollution from $\mathrm{p}^{\prime}$ to $\mathrm{p}^{*}$. $\mathrm{X}$ would reduce pollution over this range at a cost $\mathrm{R}$. Y could afford to pay $X$ an amount equal to $R^{7}$ plus some part of $Q$, and both states would have gained from the bargain. Although there still exists a measurable level of "pollution" at point $\mathrm{p}^{*}$, there is no economic reason to reduce pollution to a lower level.

This stylized scenario requires two further assumptions. First, transactions costs, including costs associated with each state's gathering information about the benefits and costs of pollution control, striking a bargain, and enforcing it, must be zero. The effect of positive transactions costs would be to shift the marginal abatement schedules for each state in the relevant direction and by an amount proportional to the transactions costs each must bear (Seibert 1987; Bromley 1986). We discuss this in more detail below. Second, the effects of compensation payments on the wealth of the states involved must be negligible. ${ }^{8}$ If these socalled "income effects" are significant, the position of the marginal abatement schedules will be affected, perhaps in ambiguous ways, as trading takes place. ${ }^{9}$

\section{Distribution of Property Rights}

Ignore for the moment the effect of transactions costs and income effects, and consider the possibility of gains from trade from pollution control in the Caribbean. The first thing one must know is the nature and distribution of legal rights regarding pollution control. ${ }^{10}$ If there is no clear assignment of rights, then we can probably expect continuous disagreement over who is responsible for pollution control.

Rules of customary international law, such as the "no-harm principle," assert that polluting states have an obligation not to cause serious or significant harm to other states (HLR 1991). Such rules imply that states have a right to be free of marine pollution from others. However, Boyle (1992) believes that such rules are "too general to afford useful guidance to States in the control of land-based sources of pollution" (see also Churchill and Lowe 1985).

\footnotetext{
${ }^{7}$ Note that, at the international level, this payment could take many forms: direct cash payments, subsidized foreign loans, tied foreign aid payments, transfer of pollution control technology, preferential access to fishing grounds, among others. See Kimball (1994) for a list of additional suggestions.

${ }^{8}$ We might expect that "income effects" are likely to occur. The reason is that if the pollution problem is so small that its resolution will have a negligible effect on the wealth of the parties, then it seems unlikely that the parties will be motivated to resolve it.

${ }^{9}$ For example, the extent to which a country may be willing to pay for environmental protection may depend upon its level of development. Moreover, the distribution of property rights may affect the position of marginal abatement schedules. The latter issue relates to whether or not the relevant party is income constrained. See Mishan (1982) for an exposition of this issue.

${ }^{10}$ The Coase Theorem does not apply unless property rights are assigned to one of the parties.
} 
Another principle, that of "polluter pays," appears, superficially, to say that polluters have the responsibility to reduce emissions (or possibly to compensate others for adverse impacts). In Appropriate Approaches, UNEP (1994c) has recommended that the polluter pays principle be "phased-in" for the control of WCR land-based marine pollution, at least at the domestic level. (However, this principle was not incorporated explicitly into either UNCLOS III or the Cartagena Convention. ") In general, the polluter pays principle refers to the distribution of rights at the domestic level (Hunter, Sommer, and Vaughan 1994). It is not clear that the principle could be applied between states, although Boyle (1992) suggests that transnational institutions, such as civil liability treaties or international supervisory mechanisms, might permit application of the principle.

Article 194(2) of UNCLOS III obliges states to ". . . take all measures necessary to ensure that activities under their jurisdiction or control are so conducted as not to cause damage to other states or their environment. . . ."12 Ostensibly, this duty is clear in its requirement that pollutee states have the right to a clean marine environment. However, Stevenson and Oxman (1994) explain that provisions found in UNCLOS III with respect to the enforcement of international standards on LBMP are weaker than many participants had hoped for. The reason for this weakness is a familiar one:

One difficulty was that delegates to a conference on the law of the sea had doubts about their competence to deal with activities on land that might cause marine pollution. Delegates to the 1992 Rio Conference, who suffered from no such disability, witnessed the difficulty of getting states to agree to binding rules affecting significant activities on land.

We note further that the Law of the Sea Convention has not yet entered into force for some Caribbean states that are major sources of LBMP, including the United States and Venezuela.

The "Montreal Guidelines"13 refer to obligations that states have with respect to transboundary pollution flows (Meng 1987). Guideline 3 reads:

States have the duty to ensure that discharges from land-based sources within their territories do not cause pollution to the marine environment of other States or of areas beyond the limits of national jurisdiction.

Note that these "obligations" do not have the status or legal force of an international agreement or treaty. Even so, this guideline, in combination with the customary "no-harm" principle and the language in UNCLOS III, suggests that states have the right to a clean environment.

${ }^{11}$ This principle has been incorporated into the 1986 Single European Act, implying that territories governed by the Netherlands, France, and the United Kingdom must abide by it.

${ }^{12}$ Article 207 contains specific language referring to the obligation of states to prevent, reduce, or control pollution from land based sources. This obligation extends to the marine environment within national jurisdictions (Charney, 1994).

${ }^{13}$ Montreal Guidelines for the Protection of the Marine Environment against Pollution from Land-Based Sources, UNEP/WG. 120/3 (1985). 
Here we will assume that the international distribution of property rights is such that "downstream" states have the right to a clean environment. ${ }^{14}$ Under this scenario, the extent to which gains from trade exist may depend upon the existing level of pollution. Return to Figure C.1, panel b. If the current level of pollution is $\mathrm{p}^{u}$, then state $\mathrm{X}$ would be forced by law-costlessly under our assumptions, but probably not in reality-to reduce pollution at least to $\mathrm{p}^{*}$. At any level below $\mathrm{p}^{*}, \mathrm{X}$ would be willing to compensate $\mathrm{Y}$ to move back up to $\mathrm{p}^{*}$, if this is permitted by law. Note that $\mathrm{p}^{*}$ is efficient from the standpoint of society (both states in our example). Society gains when $\mathrm{X}$ reduces pollution from $\mathrm{p}^{u}$ to $\mathrm{p}^{*}$, but the distribution of benefits from such a move accrue completely to $\mathrm{Y}$ ( $\mathrm{Y}$ is not required to compensate $\mathrm{X}$ ). Thus there is no explicit "trade" or, therefore, "gains from trade" in the legally required move from $\mathrm{p}^{\mathrm{u}}$ to $\mathrm{p}^{*}$. However, if the current level of pollution is $\mathrm{p}^{1}$, then gains from trade are possible when $\mathrm{X}$ compensates $\mathrm{Y}$ to move to $\mathrm{p} *$.

As suggested by the quotation from Stevenson and Oxman above, we may be dealing with a difficult issue concerning the redistribution of assumed pollution rights. States have traditionally benefited from using the ocean as a sink for the disposal of wastes from land-based sources. Until relatively recently, this practice has been tolerated for the pragmatic reason that it may have been much too costly to attempt to enforce nebulous customary rights to a clean marine environment. In special cases, such as the Trail Smelter litigation, ${ }^{15}$ principles of customary international law, such as "no harm," have been invoked to curb serious transboundary pollution (Churchill and Lowe 1985). More recently, international conventions such as UNCLOS III, and soft law, such as the Montreal Guidelines, have strengthened the legal rights of downstream states. In the classic coasean model, when downstream states have clear property rights, the scenario involves a move from zero pollution to an efficient level. The situation is different for what amounts to a switch in the distribution of property rights from polluter to pollutee: in this kind of a situation, the polluter is required to shoulder the burden of emission cuts to levels below its full emissions.

Another factor hindering the realization of gains from trade in this kind of model is a complete understanding of state Y's marginal abatement benefits. In the absence of any actual transboundary impacts, there are no benefits from pollution abatement, and, therefore, no opportunities for gains from trade. On the other hand, risks of pollution effects may be based upon complicated dose-response relationships or cumulative effects about which little is known. If there is uncertainty about effects, then the marginal benefits of abatement may be more accurately represented as a range instead of a line (Figure C.1, panel c). Negotiations over pollution compensation might still take place using expected marginal benefits, but it is likely that agreement will be more difficult to reach than in the absence of uncertainty. This suggests that there exist benefits to scientific research that help to elucidate the nature of the schedule of

\footnotetext{
${ }^{14}$ We assume as well that we have a full understanding of the movement of pollution flows, the costs of emission reductions, and the benefits of reduced damages on the downstream nations from such reductions.

${ }^{15}$ United States v. Canada, III R.I.A.A. 1911 (16 April 1936).
} 
abatement benefits. ${ }^{16}$

Also of importance are the international legal definitions of "pollution" and "pollution control". ${ }^{17}$ Without a clear definition of pollution and an understanding of the legal basis for its control, it is likely to be difficult for trading opportunities to arise. Extant definitions of pollution and its control appear broad enough to incorporate interpretations ranging from UNCLOS III's restrictive definition (possibly requiring increasingly stringent pollution control as the "best practical means" at a state's disposal change over time) to the Cartegena Convention's looser definition (calling merely for "appropriate measures"). Boyle (1992) explains that "[o]ne of the objects of regional treaties is to identify what substances will be treated as causing 'pollution,' and in what circumstances." One benefit of a protocol would be to give precise definitions to terms such as "pollution," as is commonly done through Annexes listing "black" and "grey" substances, and to clarify opportunities for trade in pollution rights as one "appropriate means" for pollution control.

\section{Transactions Costs}

After clarifying property rights, the potential for lowering transactions costs is likely to be one of the most important justifications for a protocol on land-based marine pollution in the WCR. In general, it is possible to identify three broad types of transactions costs. The first type is that associated with information about the marginal costs and benefits of pollution abatement. If such information is either highly uncertain or unequally distributed between the states (or believed to be so by one or both states), then the potential for gains from trade is less than otherwise. ${ }^{18}$ For example, in a survey of theories of bargaining delays, Kennan and Wilson (1990) explain that "uncertainty about whether the gain from trade is positive requires some inefficiency, either as delay or as a breakdown of negotiations." The clearinghouse role of a protocol in providing scientific and technical information and in channeling assistance to develop such information can help to reduce the transactions costs associated with information about marginal costs and benefits.

A second type of transactions costs concerns negotiations (or "contracting") between states over pollution abatement. Model agreements, facilitation and arbitration services,

\footnotetext{
${ }^{16}$ Note that Broadus et al. (1993) make the important point that there exists an optimal level of "ignorance." In other words, there may be decreasing returns to the supply, through scientific research, of information about marginal abatement benefits.

${ }^{17}$ Meng (1987) traces the evolution of the definition from the Group of Experts on the Scientific Aspects of Marine Pollution (GESAMP) in the late 1960s to the Stockholm Report and from there to UNCLOS III and regional agreements such as the Cartegena Convention. See also Kimball (1995).

${ }^{18}$ Baumol and Oates (1988: 10) note that "[i]f both sides to such a negotiation try to outsmart one another by devious strategies, an optimal outcome is by no means certain." Mäler (1990) explains a result from game theory which states that if both states know the parameters of probability distributions that describe the position of their respective schedules, then neither state has an incentive to outsmart the other. This result was developed in an international pollution context by Smets (1973).
} 
brokerage services, dispute resolution mechanisms, and other means of reducing negotiation costs can enhance opportunities for gains from trade. These functions are among those that a protocol might usefully incorporate or develop in order to increase effectiveness.

A third broad type of transactions costs are those associated with enforcement of a negotiated "trade." These can include costs associated with environmental monitoring, submitting to adjudication a complaint of a purported infraction, and imposing a penalty on the state that deviates from an agreement. In their study of international compliance, Chayes and Chayes (1993) argue for improvement of dispute resolution procedures, technical and financial assistance to developing states to enhance their capacities to enter into and comply with agreements, and increased transparency of domestic policy actions.

The existence of transactions costs, which may be closely associated with the incidence of "burden of proof," is an important consideration. Historically, the burden of proof may have rested with the downstream state. Examine Figure C.1, panel d. Consider the case in which $\mathrm{X}$ has already controlled pollution to some level, perhaps for its own internal reasons. We start at point $\mathrm{p}^{\mathrm{u}}$. If the burden of proof rests with $\mathrm{Y}, \mathrm{Y}$ 's marginal abatement benefits schedule could shift downward, reflecting a decreased ability to offer compensation to Y (Seibert 1987; Bromley 1986). The shift may be so large as to cause the "optimal" level of pollution, as perceived by $\mathrm{Y}$, to be greater than $\mathrm{p}^{\mathrm{u}}$. This kind of scenario might occur in cases where enforcement is problematic $^{19}$ and upstream states have been allowed historically to emit pollutants into the marine environment.

An application of the "precautionary principle" implies that polluters must shoulder responsibility for demonstrating that discharges will not harm the marine environment (Hunter, Sommer and Vaughan 1994). If the burden of transactions costs fall on X, its marginal cost of abatement will shift downward (Bromley 1986). We show this in Figure C.1, panel e. In panel e, we show also the effect of the "polluter pays principle" as an upward shift in the marginal abatement benefits schedule for Y (Mishan 1982). Such a shift might occur when Y's willingness to accept compensation, unconstrained by its wealth or "capacity" (see section V.D.), exceeds its willingness to pay compensation if property rights had been reversed. ${ }^{20}$ The net effect of these two principles is to shift the optimum from $\mathrm{p}^{*}$, in the absence of uncertainty, transactions costs, and property assignment effects, to $\mathrm{p}^{\prime}$. As described above, this may imply a movement, which does not involve any trades, from the unenforced outcome of $\mathrm{p}^{\prime}$ to $\mathrm{p}^{\prime}$. To the extent that burden of proof involves transactions costs, the opportunities for gains from trade will be enhanced through the reduction of these costs.

\footnotetext{
${ }^{19}$ For example, Churchill and Lowe (1985: 248) explain that ". . there are no international agreements to facilitate the bringing of claims for compensation by a national of one State who has suffered damage from pollution emanating from another State."

${ }^{20}$ In theory, willingness to accept compensation should be the same as willingness to pay compensation. However, where unique marine resources, such as coral reef ecosystems, are at stake and where substantial uncertainty surrounds the potential damages caused by LBMP discharges, willingness to accept might well differ from willingness to pay. See Freeman (1992) for a general discussion of the issues.
} 
The extent to which transactions costs affect the marginal benefit curve will depend upon the nature of transactions costs as either fixed or varying with the level of pollution or pollution abatement (Tietenberg, pers. comm., 1995). If transactions costs are mostly fixed, e.g., costs associated with a one-time negotiation, then the position of the relevant marginal schedules will be unaffected. If negotiation costs are large enough, however, then they may still preclude the desirability of pollution control. Further work is required to examine the nature of transactions costs in the context of transboundary pollution in the WCR. 


\section{References}

ARPEL (Asistencia Reciproca Petrolera Empresarial Latinoamericana). 1994. ARPEL Environmental Guidelines. Montevideo, Uruguay: ARPEL.

Atwood, D.K., F.J. Burton, J.E. Corredor, G.R. Harvey, A.J. Mata-Jimenez, A. VasqueBotello, and B.A. Wade, 1987. Petroleum pollution in the Caribbean. Oceanus 30(4):225-32.

Baumol, W.J., and W.E. Oates. 1988. The Theory of Environmental Policy. Second Edition. Cambridge: Cambridge University Press.

Bernauer, T. 1995. The effect of international environmental institutions: how we might learn more. International Organization 49(2):351-377.

BNA (Bureau of National Affairs). 1992. Venezuelan minister calls for strong, centralized state environmental agencies. International Environment Reporter Current Report 16(23):872.

Borgese, E.M., and N. Ginsburg. 1982. Ocean Yearbook 3. Chicago: University of Chicago Press.

Boyle, A.E. 1992. Land-based sources of marine pollution. Marine Policy 16(1):20-35.

Braden, J.B. and D. Bromley. 1981. The economics of cooperation over collective bads. Journal of Environmental Economics and Management 8:134-150.

Brañes, R. 1991. Institutional and Legal Aspects of the Environment in Latin America, Including the Participation of Nongovernmental Organizations in Environmental Management. Washington, DC: Inter-American Development Bank.

Brewster, L. 1994. Comments at the Workshop on Regional Control of Land-Based Marine Pollution: Lessons from Other Regions for the Wider Caribbean. December 1-3 at the University of the West Indies, Bridgetown, Barbados. Sponsored by the Marine Policy Center of the Woods Hole Oceanographic Institution, with support from the U.S. Environmental Protection Agency.

Britannica Book of the Year 1995. Chicago: Encylcopaedia Britannica, Inc.

Britannica Book of the Year 1994. Chicago: Encylcopaedia Britannica, Inc.

Britannica Book of the Year 1993. Chicago: Encylcopaedia Britannica, Inc.

Broadus, J.M. 1992. Creature feature too: principium precautionarium. Oceanus 35(1): 6-7. 
Broadus, J.M., S. Demisch, K. Gjerde, P. Haas, Y. Kaoru, G. Peet, S. Repetto, and A. Roginko. 1993. Comparative Assessment of Regional International Programs to Control Land-Based Marine Pollution: The Baltic, North Sea, and Mediterranean. Woods Hole, MA: Marine Policy Center, Woods Hole Oceanographic Institution.

Broadus, J.M., and R. V. Vartanov (Eds.). 1994. The Oceans and Environmental Security: Shared U.S. and Russian Perspectives. Washington, DC: Island Press.

Bromley, D.W. 1986. Markets and externalities. Natural Resource Economics 37-88.

Brongersma-Sanders, M., 1957. Mass mortality in the sea. Chapter 29 [In] J.W. Hedgpeth (ed.), Treatise on Marine Ecology and Paleoecology, Volume 1. Geol. Soc. America Memoir 67.

C/CAA (Caribbean/Central American Action). 1986. C/CAA's 1987 Caribbean and Central American Databook. Washington, DC: Caribbean/Central American Action.

CIA (Central Intelligence Agency). 1990, 1992, 1993, 1994. The World Factbook. Washington, DC: Central Intelligence Agency.

Chander, P. and H. Tulkens. 1992. Theoretical foundations of negotiations and cost sharing in transfrontier pollution problems. European Economic Review 36:388-398.

Charney, J.I. 1994. The marine environment and the 1982 United Nations Convention on the Law of the Sea. The International Lawyer 28(4):879-901.

Chayes, A., and A.H. Chayes. 1993. On compliance. International Organization 47(2):175205.

Churchill, R.R. and A.V. Lowe. 1985. The Law of the Sea. Manchester, England: Manchester University Press.

Coase, R.H. 1960. The problem of social cost. Journal of Law and Economics 3:1-44.

Cortés, J., and M. J. Risk. 1985. A reef under siltation stress: Cahuita, Costa Rica. Bulletin of Marine Science 36(2):339-356.

Cropper, M.L., and W.E. Oates. 1992. Environmental economics: a survey. Journal of Economic Literature 30:675-740.

Cumberland, J. 1981. Efficiency and equity in interregional environmental management. The Review of Regional Studies 10(2):1-9.

Curtis, C. 1993. The London Convention and radioactive waste dumping at sea: a global treaty regime in transition. Paper presented at the Conference on Radioactivity and 
Environmental Security in the Oceans: New Research and Policy Priorities in the Arctic and North Atlantic, 7-9 June, Woods Hole Oceanographic Institution, Woods Hole, MA.

Dasgupta, P. 1982. The Control of Resources. Cambridge, Mass.: Harvard University Press.

Delegation of Finland. 1990. Protection of the marine environment of the Baltic Sea. Document submitted to the CSCE Meeting on Environmental Protection in the Mediterranena, Palma de Mallorca, October.

Dewees, D.N. 1983. Instrument choice in environmental policy. Economic Inquiry 21:53-71.

Diagram Group. 1985. The Atlas of Central America and the Caribbean. New York and London: Collier Macmillan.

Dockner, E.J., and N.V. Long. 1993. International pollution control: cooperative versus noncooperative strategies. Journal of Environmental Economics and Management 24:1329.

ECLAC (UN Economic Commission for Latin America and the Caribbean). 1990. The Water Resources of Latin America and the Caribbean-Planning, Hazards and Pollution. Santiago, Chile: United Nations Economic Commission for Latin America and the Caribbean.

1993. Population, Social Equity and Changing Production Patterns. Santiago, Chile: Latin American Demographic Centre, United Nations Commission for Latin America and the Caribbean.

Elder, D., and J. Pernetta, Oceans: A Mitchell Beazley World Conservation Atlas. Mitchell Beazley in association with IUCN: The World Conservation Union, London, 1991.

Elvis, D., and D. Colbert. 1994. Initiatives for regional action on Caribbean environmental issues. Washington: Country Department III, Caribbean Division, World Bank.

Espenshade, E. G., Jr., and J. L. Morrison. 1986. Goode's World Atlas. Chicago, New York, San Francisco: Rand McNally.

Famighetti, R. [ed], 1995. The World Almanac and Book of Facts. Mahwah, NJ: Funk \& Wagnalls.

FAO (Food and Agriculture Organization). 1993a. FAO Yearbook: Fishery Statistics 1992. Rome: United Nations Food and Agriculture Organization.

1993b. Marine fishery resources of the Antilles. FAO Fisheries Technical Paper 326. Rome: Food and Agriculture Organization of the United Nations. 
Fenwick, J. 1992. International Profiles on Marine Scientific Research: National Maritime Claims, MSR Jurisdiction, and U.S. Research Clearance Histories for the World's Coastal States. Woods Hole, MA: WHOI Sea Grant Program, Woods Hole Oceanographic Institution.

1995. (Department of Marine Chemistry, Woods Hole Oceanographic Institution). Personal communication.

Fisher, A.C., and F.M. Peterson. 1973. The environment in economics: a survey. Journal of Economic Literature 13:1-33.

Freeman, A.M. 1992. The Measurement of Environmental and Resource Values: Theory and Methods. Washington: Resources for the Future.

Froelich, P. N., Jr., D. K. Atwood, and G. S. Giese. 1978. Influence of Amazon River discharge on surface salinity and dissolved silicate concentration in the Caribbean Sea. Deep-Sea Research 25:735-744.

GESAMP (Joint Group of Experts on the Scientific Aspects of Marine Pollution). 1990. The state of the marine environment. UNEP Regional Seas Reports and Studies No. 115.

Gladfelter, E. H., and J. C. Ogden. 1994. The status of relevant scientific capabilities and knowledge of land-based marine pollution problems in the Caribbean. Consultant discussion paper prepared for "Regional Control of Land-Based Marine Pollution: Lessons from Other Regions for the Wider Caribbean, " an EPA-supported project of the Marine Policy Center, Woods Hole Oceanographic Institution, Woods Hole, MA.

Goodridge, J.A. 1994. Comments at the Workshop on Regional Control of Land-Based Marine Pollution: Lessons from Other Regions for the Wider Caribbean. December 1-3 at the University of the West Indies, Bridgetown, Barbados. Sponsored by the Marine Policy Center of the Woods Hole Oceanographic Institution, with support from the U.S. Environmental Protection Agency.

Goodwin, C. (Ed.). 1992. The Caribbean Handbook 1992/93. St. John's, Antigua: FT Caribbean.

Gray, C.R. 1992. History of tropical cyclones in the Carbbean: 1886-1986. Pp. 677-690 (in) J. O'Callahan (Ed.). Global Climate Change and the Rising Challenge of the Sea. Proceedings of the IPCC workshop held at Margarita Island, Venezuela, March 1992. Silver Spring, MD: U.S. National Oceanic and Atmospheric Administration.

Hammond Atlas of the World. 1993. Maplewood, NJ: Hammond Inc.

Harvey, G.R. 1987. A personal overview of oil in the marine environment. Caribbean Journal of Science 23(1):5-10. 
Helfand, G.E. 1991. Standards versus standards: the effects of different pollution restrictions. The American Economic Review 81(3):622-634.

Henao, S., J. Finkelman, L. Albert, and H. W. de Koning. 1993. Pesticides and Health in the Americas. Washington, DC: Division of Health and Environment, Pan America Health Organization/World Health Organization (February).

Herbich, J.B. (ed.). 1992. Handbook of Coastal and Ocean Engineering. Volume 3. Harbors, Navigational Channels, Estuaries, Environmental Effects. Houston, TX: Gulf Publishing Co.

HLR (Harvard Law Review). 1991. Developments - International environmental law 104(7) Cambridge, MA: Harvard Law Review Association, Inc.

Hoel, M. 1991. Global environmental problems: the effects of unilateral actions taken by one country. Journal of Environmental Economics and Management 20:55-70.

Hunte, W. 1994. Comments at the Workshop on Regional Control of Land-Based Marine Pollution: Lessons from Other Regions for the Wider Caribbean. December 1-3 at the University of the West Indies, Bridgetown, Barbados. Sponsored by the Marine Policy Center of the Woods Hole Oceanographic Institution, with support from the U.S. Environmental Protection Agency.

Hunter, D., J. Sommer, and S. Vaughan. 1994. Concepts and principles of international environmental law: an introduction. UNEP Environment and Trade.

IMO (International Maritime Organization). 1991. The London Dumping Convention: The First Decade and Beyond. London: IMO, Office for the London Dumping Convention.

Island Resources Foundation. 1989. Organizational profiles of who is doing what in support of programs for sustainable resource development and environmental management in the eastern Caribbean: a guide to donor organizations and technical assistance agencies. St. Thomas, U.S. Virgin Islands: Island Resources Foundation (February).

1991 a,b,c,d,e,f. Environmental Profiles of Antigua \& Barbuda, Dominica, Grenada, St. Kitts \& Nevis, St. Lucia, St. Vincent and the Grenadines. St. Thomas, U.S. Virgin Islands: Island Resources Foundation

IUCN (International Union for Conservation of Nature and Natural Resources). n.d. Data Atlas: Planning a Marine Conservation Strategy for the Caribbean Region. Gland, Switzerland: IUCN.

Jacobsen, M. 1995. The United Nations Regional Seas Programme: How does it measure up? Coastal Management 23:19-39. 
Jaffe, A.B., S.R. Peterson, P.R. Portney, and R. N. Stavins. 1995. Environmental regulation and the competitiveness of U.S. manufacturing: What does the evidence tell us? Journal of Economic Literature 33:132-163.

James, P.E., and C. W. Minkel. 1986. Latin America. Fifth edition. New York: John Wiley $\&$ Sons.

Kasten, T.J. 1994. Pollution control strategies to be consider [sic] for application and use in the wider Caribbean-a conceptual document. UNEP Second meeting of experts on landbased sources of pollution in the wider Caribbean region, San Juan, Puerto Rico, 21-25 March. UNEP(OCA)/CAR WG.14/INF.12.

Kennan, J., and R. Wilson. 1990. Theories of bargaining delays. Science 249:1124-1128.

Kimball, L. A. 1994. Land-based source marine pollution: institutions and exchanges. A discussion paper on regional control of land-based marine pollution: lessons from other regions for the wider Caribbean. Prepared under Cooperative Agreement No. CX821540-01-0 with the Environmental Protection Agency/Office of International Affairs. 30pp.

1995. The United Nations Convention on the Law of the Sea: A Framework for Marine Conservation. Part I in: The Law of the Sea: Priorities and Responsibilities in Implementing the Convention. Gland, Switzerland: IUCN.

Lynne, G.D., P. Conroy, and F.J. Prochaska. 1981. Economic valuation of marsh areas for marine production processes. Journal of Environmental Economics and Management 8:175-186.

Lyon, F. M., and S. Farrow. 1995. An economic analysis of Clean Water Act issues. Water Resources Research 30(1):213-223.

Mahon, R. 1993. "Lesser Antilles." Pp. 5-98 in Marine fishery resources of the Antilles. FAO Fisheries Technical Paper 326. Rome: Food and Agriculture Organization of the United Nations.

Mäler, K.-G. 1990. International environmental problems. Oxford Review of Economic Policy 6(1):80-108.

Mandelli, E. F. 1994. Land-based sources of marine pollution, legal instruments and institutional capabilities in the Spanish-speaking countries of the Wider Caribbean Region. Consultant discussion paper prepared for "Regional Control of Land-Based Marine Pollution: Lessons from Other Regions for the Wider Caribbean," an EPAsupported project of the Marine Policy Center, Woods Hole Oceanographic Institution, Woods Hole, MA. 
Mangone, G.S. 1990. Mangone's Concise Marine Almanac. New York: Taylor \& Francis.

Maul, G.A. (Ed.). 1993. Climatic Change in the Intra-Americas Sea. London: Edward Arnold.

1995. (University of Miami.) Personal communication.

Meng, Q-n. 1987. Land-based Marine Pollution: International Law Development. London: Graham and Trotman.

Mishan, E.J. 1982. What Political Economy is All About: An Exposition and Critique. New York: Cambridge University Press.

MPC (Marine Policy Center). 1993. Proposal for Study Grant Assistance. Regional Control of Land-Based Marine Pollution: Lessons from Other Regions for the Wider Caribbean. Submitted to the U.S. Environmental Protection Agency. Woods Hole, MA: Marine Policy Center, Woods Hole Oceanographic Institution (March).

Müller-Karger, F.E. 1993. River discharge variability including satellite-observed plume dispersal patterns. Chapter 8 (in) G.A. Maul (ed.). Climatic Change in the IntraAmericas Sea. London: Edward Arnold.

Negroponte, J. D. 1987. Caribbean marine science. Oceanus 30(4):3-8.

New Oxford Atlas. 1975. Great Britain: Oxford University Press.

Nollkaemper, A. 1992. Laws of the sea. Marine pollution from land-based sources: towards a global approach. Marine Pollution Bulletin 24(1):8-12.

NOAA/NMFS (National Oceanic and Atmospheric Administration/National Marine Fisheries Service). 1993. Fisheries of the United States 1992. Washington, DC: NOAA/NMFS.

Oates, W.E. and R. Schwab. 1988. Economic competition among jurisdictions: efficiency enhancing or distortion inducing? Mimeo. College Park, Md.: Department of Economics, University of Maryland.

OECD (Organisation for Economic Co-operation and Development). 1993. Geographical Distribution of Financial Flows to Developing Countries, 1988/91. Paris: OECD. 1994. Managing the Environment: The Role of Economic Instruments. Paris: OECD.

Oxford Atlas of the World. 1992. London: George Philip Ltd.

PAHO/WHO (Pan American Health Organization/World Health Organization). 1992. Consultative Meeting on Excreta and Wastewater Disposal in Latin America and the 
Caribbean. Washington, DC: PAHO Environmental Health Program.

Pendleton, L.H. 1994. Environmental quality and recreation demand in a Caribbean coral reef. Coastal Management 22:399-404.

Putnam, R.D. 1988. Diplomacy and domestic politics: the logic of two-level games. International Organization 42:427-460.

Rand McNally Atlas of the Oceans. 1977. Chicago, New York, San Francisco: Rand McNally.

Rand McNally Universal World Atlas: Census Edition. (n.d.; includes 1980 census data). Chicago, New York, San Francisco: Rand McNally.

Ray, C. n.d. Data Atlas: Planning a Marine Conservation Strategy for the Caribbean Region. Gland, Switzerland: IUCN.

Richardson, P. 1994. (Department of Physical Oceanography, Woods Hole Oceanographic Institution). Personal communication.

Ridley, M., and B.S. Low. 1993. Can selfishness save the environment? The Atlantic Monthly 76-86.

Rodionov, V. 1992. Perdonal communication with A. Roginko. A meeting at the Baltic Marine Environment Protection Commission, 14 January.

Ross, D.A., J. Fenwick, and F. Gable. 1990. Study on the viability of establishing a Caribbean regional center for marine industrial technology. Woods Hole, MA.

Salas, H.J. 1994. Sewage Disposal for Coastal Cities in Latian America and the Caribbean. Report prepared for the Experts Meeting on Land Based Sources of Pollution, San Juan, Puerto Rico, 1-5 November 1993.

Sand, P.H. 1991. Lessons learned in global environmental governance. Environmental Affairs 18(213):213-277.

Seibert, H. 1987. Economics of the Environment: Theory and Policy. New York: SpringerVerlag.

Skjaerseth, J.B. 1992. The "effectiveness" of the Mediterranean Action Plan. International Environmental Affairs 4:313-334.

Smets, H. 1973. The mutual compensation principle. Paris: OECD.

Spurgeon, J. P. G. 1992. The economic valuation of coral reefs. Marine Pollution Bulletin 
24(11):529-536.

Stevenson, J.R., and B.H. Oxman. 1994. The future of the United Nations Convention on the Law of the Sea. American Journal of International Law 88(3):488-499.

Tietenberg, T.H. 1985. Emissions trading: an exercise in reforming pollution policy. Washington, DC: Resources for the Future, Inc.

1988. Chapter Fourteen. Economics of pollution control: an overview. Library of Congress Cataloging-in-Publication Data, Environmental and natural resource economics, Harper-Collins, 306-332.

Times Atlas of the World. 1985. New York: Times Books.

Underdal, A., S. Andresen, J.B. Skjaerseth, and J. Wettestad. 1992. The effectiveness of international resource cooperation. Draft paper prepared for the Inaugural Pan-European Conference in International Relations in Heidelberg, 16-20 September.

UNEP (United Nations Environment Programme). 1983. Convention for the Protection and Development of the Marine Environment of the Wider Caribbean Region [and] Protocol concerning Co-operation in Combating Oil Spills in the Wider Caribbean Region. UNEP, Nairobi and UN, New York.

1989a. Regional Overview of Environmental Problems and Priorities Affecting the Coastal and Marine Resources of the Wider Caribbean. CEP Technical Report No. 2. UNEP, Kingston, Jamaica.

$1989 \mathrm{~b}$. State of the Mediterranean marine environment. MAP Technical Report Series No. 28. UNEP, Athens.

1991a. Background Document for the Development of a Protocol Concerning LandBased Sources of Marine Pollution to the Cartagena Convention for the Protection and Development of the Marine Environment of the Wider Caribbean Region. Kingston, Jamaica: UNEP-CAR/RCU.

1991b. Report on the CEPPOL Seminar in Monitoring and Control of Sanitary Quality of Bathing and Shellfish-Growing Marine Waters in the Wider Caribbean. Kingston, Jamaica: CEP Technical Report No. 9.

1992. Report of the Executive Director of UNEP on the Status of Implementation of the Caribbean Environment Programme (1990-1992). Sixth Intergovernmental Meeting on the Action Plan for the Caribbean Environment Programme and Third Meeting of the Contracting Parties to the Convention for the Protection and Development of the Marine Environment of the Wider Caribbean Region. Kingston, Jamaica, 16-18 November, UNEP (OC)/CAR IG.10/4. 
1994a. Regional Overview of Land-Based Sources of Pollution in the Wider Caribbean Region. Second Meeting of Experts on Land-Based Sources of Pollution in the Wider Caribbean Region. San Juan, Puerto Rico, 21-25 March.

1994b. Submarine Outfalls-A Viable Alternative for Sewage Discharge of Coastal Cities in Latin America and the Caribbean. Second Meeting of Experts on Land-Based Sources of Pollution in the Wider Caribbean Region. San Juan, Puerto Rico, 21-25 March.

1994c. Appropriate Approaches to the Development of a Protocol on Land-Based Sources of Marine Pollution for the Wider Caribbean Region. Second Meeting of Experts on Land-Based Sources of Pollution in the Wider Caribbean Region. San Juan, Puerto Rico, 21-25 March.

UNEP/IUCN (UNEP and International Union for the Conservation of Nature and Natural Resources). 1988. Coral Reefs of the World. Volume 1: Atlantic and Eastern Pacific. UNEP Regional Seas Directories and Bibliographies. Gland, Switzerland and Cambridge, UK/UNEP, Nairobi, Kenya.

United Nations. n.d. 1992 International Trade Statistics Yearbook.

1992. Nations of the Earth Report, Vols. 1-3. United Nations Conference on Environment and Development National Reports Summaries. Geneva: United Nations.

U.S. Department of Commerce. 1994. Statistical Abstract of the United States 1993. Washington, DC: U.S. Dept. of Commerce.

U.S. Department of State. 1992. Background Notes: Panama. Washington, DC: U.S. Dept. of State.

1994. Background Notes: Suriname. Washington, DC: U.S. Dept. of State.

van't Hof, T. 1986. The Economic Benefits of Marine Parks and Protected Areas in the Caribbean Region. Washington, DC: Sanctuary Programs Division, National Oceanic and Atmospheric Administration, U.S. Dept. of Commerce.

Wettestad, J. 1992. The "effectiveness" of the Paris Convention on Marine Pollution from Land-based Sources. International Environmental Affairs 4(20):101-121.

Wood-Thomas, B. 1995. (US Environmental Protection Agency, Office of International Activities.) Personal communication.

World Bank. 1993. Caribbean Region: Current Economic Situation, Regional Issues, and Capital Flows, 1992. Washington, DC: World Bank. 
1994. Initiatives for Regional Action on Caribbean Environmental Issues. Washington, DC: World Bank Caribbean Division, Country Department III, Latin America and the Caribbean.

World Resources 1992-93 Data Base Diskette. Washington, DC: World Resources Institute.

Worldmark Encyclopedia of the Nations: Americas. 1984. New York: Worldmark Press.

WRI (World Resources Institute), in collaboration with UNEP and UNDP. 1994. World Resources 1994-95. New York and Oxford: Oxford University Press.

WTO (World Tourism Organization). 1986. Country Tourism Profiles.

WWF and ESI (World Wildlife Fund and Environmental Solutions International). 1994. "Policy Principles Concerning Caribbean Land-Based Sources of Marine Pollution." Discussion Paper. Washington, DC and London: World Wildlife Fund and Environmental Solutions International (November). 


\section{DOCUMENT LIBRARY}

Distribution List for Technical Report Exchange - May 1995

University of California, San Diego

SIO Library $0175 \mathrm{C}$

9500 Gilman Drive

La Jolla, CA 92093-0175

Hancock Library of Biology \& Oceanography

Alan Hancock Laboratory

University of Southern California

University Park

Los Angeles, CA 90089-0371

Gifts \& Exchanges

Library

Bedford Institute of Oceanography

P.O. Box 1006

Dartmouth, NS, B2Y 4A2, CANADA

Commander

International Ice Patrol

1082 Shennecossett Road

Groton, CT 06340-6095

NOAA/EDIS Miami Library Center

4301 Rickenbacker Causeway

Miami, FL 33149

Research Library

U.S. Army Corps of Engineers

Waterways Experiment Station

3909 Halls Ferry Road

Vicksburg, MS 39180-6199

Institute of Geophysics

University of Hawaii

Library Room 252

2525 Correa Road

Honolulu, HI 96822

Marine Resources Information Center

Building E38-320

MIT

Cambridge, MA 02139

Library

Lamont-Doherty Geological Observatory

Columbia University

Palisades, NY z10964

Library

Serials Department

Oregon State University

Corvallis, OR 97331

Pell Marine Science Library

University of Rhode Island

Narragansett Bay Campus

Narragansett, RI 02882
Working Collection

Texas A\&M University

Dept. of Oceanography

College Station, TX 77843

Fisheries-Oceanography Library

151 Oceanography Teaching Bldg.

University of Washington

Seattle, WA 98195

Library

R.S.M.A.S.

University of Miami

4600 Rickenbacker Causeway

Miami, FL 33149

Maury Oceanographic Library

Naval Oceanographic Office

Building 1003 South

1002 Balch Blvd.

Stennis Space Center, MS, 39522-5001

Library

Institute of Ocean Sciences

P.O. Box 6000

Sidney, B.C. V8L 4B2

CANADA

Library

Institute of Oceanographic Sciences

Deacon Laboratory

Wormley, Godalming

Surrey GU8 5UB

UNITED KINGDOM

The Librarian

CSIRO Marine Laboratories

G.P.O. Box 1538

Hobart, Tasmania

AUSTRALIA 7001

Library

Proudman Oceanographic Laboratory

Bidston Observatory

Birkenhead

Merseyside L43 7 RA

UNITED KINGDOM

IFREMER

Centre de Brest

Service Documentation - Publications

BP 7029280 PLOUZANE

FRANCE 


\begin{tabular}{|c|c|c|c|}
\hline $\begin{array}{l}\text { REPORT DOCUMENTATION } \\
\text { PAGE }\end{array}$ & $\begin{array}{l}\text { 1. REPORT NO. } \\
\text { WHOI-95-10 }\end{array}$ & 2. & 3. Recipient's Accession No. \\
\hline \multirow{2}{*}{\multicolumn{3}{|c|}{$\begin{array}{l}\text { 4. Title and Subtitle } \\
\text { Toward an Effective Protocol on Land-Based Marine Pollution in the Wider Caribbean } \\
\text { Region }\end{array}$}} & $\begin{array}{l}\text { 5. Report Date } \\
\text { July } 1995\end{array}$ \\
\hline & & & 6. \\
\hline \multicolumn{3}{|c|}{$\begin{array}{l}\text { 7. Author(s) } \\
\text { Porter Hoagland, Mary E. Schumacher, Arthur G. Gaines, Jr. }\end{array}$} & $\begin{array}{l}\text { 8. Performing Organization Rept. No. } \\
\text { WHOI } 93-54\end{array}$ \\
\hline \multirow{2}{*}{\multicolumn{3}{|c|}{$\begin{array}{l}\text { 9. Performing Organization Name and Address } \\
\text { The Woods Hole Oceanographic Institution } \\
\text { Woods Hole, Massachusetts } 02543\end{array}$}} & 10. Project/Task/Work Unit No. \\
\hline & & & $\begin{array}{l}\text { 11. Contract(C) or Grant(G) No. } \\
\text { (C) } \mathrm{CX} 821540-01-0 \\
\text { (G) }\end{array}$ \\
\hline \multirow{3}{*}{\multicolumn{3}{|c|}{$\begin{array}{l}\text { 12. Sponsoring Organization Name and Address } \\
\text { Funding was provided by the United States Environmental Protection Agency, Office of } \\
\text { International Activities under Co-operative Agreement No. CX821540-01-0. }\end{array}$}} & 13. Type of Report \& Period Covered \\
\hline & & & Technical Report \\
\hline & & & 14. \\
\hline
\end{tabular}

\section{Supplementary Notes}

This report should be cited as: Woods Hole Oceanog. Inst. Tech. Rept., WHOI-95-10.

\section{Abstract (Limit: 200 words)}

This study was undertaken to advance the basis for discussions among Contracting Parties to the Cartagena Convention concerning a protocol on land-based marine pollution (LBMP) in the Wider Caribbean Region (WCR). The study has four principal objectives: (1) a review and summary of LBMP problems to determine common problems and priority areas; (2) a survey of broadly defined environmental infrastructure to help identify national commitments and national capacities to prevent, reduce, or control LBMP; (3) a survey and analysis of subregional differences in commitment or interest in regional control of LBMP; and (4) a comparison of program approaches from other regions, providing lessons from which an effective program for the Caribbean might be designed. The study argues that the environmental, economic, and institutional diversity of the region as a whole suggests (1) an incremental approach to international resolution of LBMP problems, one that builds upon successful arrangements among states that have appropriate incentives for solving real transboundary pollution problems; and (2) a subregional approach to the control of localized but widely occurring pollution problems, in which the "umbrella" function of a regional protocol would concentrate on the need to ensure uniform access to all clearinghouse products and on the internal allocation of financial and technical assistance to individual states and subregions.

\section{Document Analysis a. Descriptors}

1. marine pollution

2. international protocols

3. UNEP Regional Seas Programme

b. Identifiers/Open-Ended Terms

c. COSATI Field/Group

18. Availability Statement

Approved for publication; distribution unlimited.

\begin{tabular}{|l|l|}
\hline $\begin{array}{c}\text { 19. Security Class (This Report) } \\
\text { UNCLASSIFIED }\end{array}$ & $\begin{array}{c}\text { 21. No. of Pages } \\
192\end{array}$ \\
\hline 20. Security Class (This Page) & 22. Price \\
\hline
\end{tabular}

